\title{
Henk Borgdorff
}

\section{The Conflict of the Faculties \\ Perspectives on \\ Artistic Research \\ and Academia}

Leiden University Press 
The Conflict of the Faculties 


\section{Henk Borgdorff}

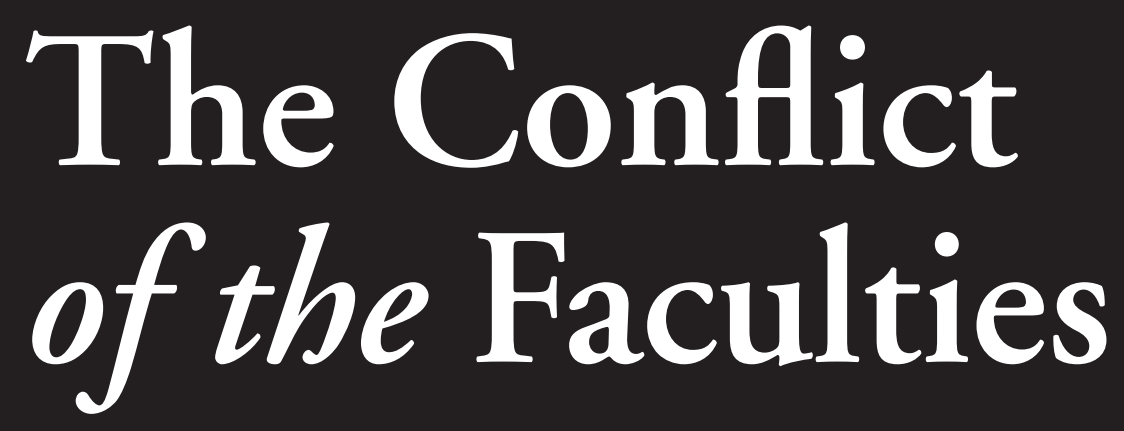

Perspectives on Artistic Research and Academia 
The conflict of disciplines is not a brake on the development of science, but one of its motors.

Bruno Latour

Leiden University Press 
The publication of this book is made possible by a grant from University of the Arts, The Hague

Academy of Creative and Performing Arts, Leiden University Faculty of Fine, Applied and Performing Arts, University of Gothenburg

Cover design and layout: Mulder van Meurs, Amsterdam

$\begin{array}{ll}\text { ISBN } & 978908728 \text { I67 O } \\ \text { e-ISBN } & 9789400600997 \text { (pdf) } \\ \text { NUR } & 640 / 65 \mathrm{I}\end{array}$

(C) H. Borgdorff / Leiden University Press, 2012

All rights reserved. Without limiting the rights under copyright reserved above, no part of this book may be reproduced, stored in or introduced into a retrieval system, or transmitted, in any form or by any means (electronic, mechanical, photocopying, recording or otherwise) without the written permission of both the copyright owner and the author of the book. 
To Barbara and Hans 
Contents 
Acknowledgements and Provenance of the Chapters viII

Introduction

I The Conflict of the Faculties I4

2 The Debate on Research in the Arts 28

3 Artistic Research and Academia: An Uneasy Relationship 56

4 Artistic Research within the Fields of Science $\quad 74$

5 Where Are We Today? The State of the Art in

$\begin{array}{ll}\text { Artistic Research } & \text { IO4 }\end{array}$

6 Artistic Research as Boundary Work I28

7 The Production of Knowledge in Artistic Research I4O

8 Boundary Work: An Interview $\quad$ I74

9 Artistic Practices and Epistemic Things $\quad$ I84

IO Ingredients for the Assessment of Artistic Research 200

II The Case of the Journal for Artistic Research 2 I4

Bibliography $\quad 242$

Index $\quad 260$ 
Acknowledgements and

Provenance of the Chapters 

My earliest thoughts about research in the arts began to take on more tangible form ten years ago when I was involved in developing the masters programme in music at the Conservatorium van Amsterdam and in setting up the practice-based doctorate programme docARTES. This book can be read as a written account of an expedition that has occupied a good deal of my working life ever since - the exploratory and preparatory work for the artistic research agenda, and its eventual realisation. During my expedition, I have known and met many people who were working along with me towards those goals or who have supported, encouraged, or redirected my efforts. My heartfelt thanks is due to all of them.

Starting in 2002, the Amsterdam School of the Arts (AHK) gave me the opportunity to put research on the agenda in terms of both content and infrastructure, in an environment that was not yet fully equipped for that purpose. It was a pleasure to lead the Art Research, Theory and Interpretation (ARTI) research group, where staff and graduates from several AHK faculties and different artistic disciplines worked together in a broad array of research projects, both practice-based and more theoretical and conceptual. I have particularly good memories of those times, which were an inspiration to me and to many others along with me. Carel Alons and Marianne Gerner were the people in the AHK administration who supported my efforts. ARTI members Scott deLahunta and Sher Doruff were more than just discussion partners over the years. On the theoretical and political rationale of research in an arts education framework, I had many enlightening exchanges with my immediate colleagues Folkert Haanstra, Marijke Hoogenboom, and Peter van Mensch, and also with Michiel Schuijer in an intellectual dialogue that has continued ever since the founding of the Dutch Journal of Music Theory (DJMT) in 1996.

Such exchanges also took place within the Forum of Professors at Arts Schools (LOK), in which I participated from its founding in 2002. Early discussion partners were Joost Smiers (Utrecht School of the Arts, HKU) and Joep Bor (Codarts, Rotterdam), about a national school for practice-based research in the arts (which has still not materialised). Later productive dialogues were with Jeroen Boomgaard (Gerrit Rietveld Academie and University of Amsterdam, UvA) regarding the Artis- 
tic Research masters programme at the UvA; with Geert Lovink (UvA and Amsterdam University of Applied Sciences, HvA) on art in a contemporary culture that is networked through new and social media; Bart van Rosmalen (Royal Conservatoire, The Hague) on the conferences we organised together; Henk Slager (Utrecht School of the Arts), whom I regularly meet at conferences everywhere in Europe, but never in the city we both live in; Peter Peters (Zuyd University), who recently, given our shared backgrounds, inspired me to explore the field of science and technology studies; and Peter Sonderen (ArtEZ Institute of the Arts), with whom I recently edited a volume of essays entitled Denken in kunst: Theorie en reflectie in het kunstonderwijs. Like my ARTI research group, the LOK also provided an environment where I could regularly 'try out' my papers and presentations.

My involvement in docARTES was vital to my explorations in the field of artistic research. Together with Peter Dejans, Johan Huys (Orpheus Institute, Ghent) and Frans de Ruiter (Academy of Creative and Performing Arts, Leiden University; then also of the University of the Arts The Hague), I worked on the development of the docARTES programme. Their leadership and unflagging energy ultimately resulted in the creation of an international doctorate programme for musicians that is now regarded as exemplary far beyond the Low Countries. The exchanges of ideas I had with the doctoral students, and with Peter, Johan, and Frans, during the monthly two-day sessions were for me a hands-on learning experience in practice-based research in music. It was my privilege to moderate the student discussions and conduct seminars on the theory of science. I also better got to know Marcel Cobussen (Leiden University), who teaches aesthetics and philosophy at docARTES. For quite some time, we facilitated the collegia, where doctoral candidates reported on and discussed their ongoing research projects. Marcel and I spoke continuously about the rationale of artistic research. Although I was not always persuaded by his poststructuralist take on the subject, the exchanges heightened my need to eventually come to terms with that strand of philosophy. Marcel and I collaborated in 2007 as editors of a special issue of DJMT on practice-based research in music, to which he contributed a fine essay explaining his perspective on artistic research and academia. 
Working from the Orpheus Institute in Ghent, the site of docARTES, Peter Dejans has built a strong international network that facilitates the exchange of knowledge and experiences relating to practicebased doctoral programmes. I learned a great deal from the critical dialogues in MIDAS (Musical Institutions with Doctoral Arts Studies) and the think-tank EMPaR (Enquiry into Musical Practice as Research), and later I also profited from Peter's efforts for the third-cycle working group within the Polifonia project of the European Association of Conservatoires (AEC). I also hope to benefit from his current work for the Polifonia working group on artistic research and for the European Platform for Artistic Research in Music (EPARM), both under AEC auspices. This international network enabled me to meet Darla Crispin and Jeremy Cox (London/Ghent), Brinley Yare (London), Henry Stobart (London), Jonathan Cross (Oxford), Celia Duffy and Stephen Broad (Glasgow), Harold Jörgenson (Oslo), Magnus Eldenius and Eva Nässen (Gothenburg), Johannes Johansson (Stockholm), Håkan Lundström (Malmö), Kari Kurkela (Helsinki), Urve Lippus (Tallinn), Yves Knockaert (Leuven), Héctor Perez (Valencia), as well as other people, all of whom helped me develop my thinking about research.

After a presentation I made in Berlin in October 2005 at the 'RE:SEARCH in and through the Arts' conference, convened by the European League of Institutes of the Arts (ELIA), I came into contact with many people who, in conversations and correspondence, were to support and critically accompany my expedition in the years to follow: Efva Lilja (University College of Dance and Circus, Stockholm), Søren Kjørup and Nina Malterud (Bergen National Academy of the Arts), Ólöf Gerður Sigfúsdóttir (Iceland Academy of the Arts), Christoph Schenker, Corina Caduff, and Anton Rey (Zurich University of the Arts), Christopher Bannerman (Middlesex University), Martin Tröndle (Zeppelin University, Friedrichshafen), Michael Biggs (University of Hertfordshire), Henrik Karlsson (Riksbankens Jubileumsfond, Stockholm), Janet Ritterman (Royal College of Music, London, and Austrian Science Board), and many more. With Johan Haarberg (Norwegian Artistic Research Fellowship Programme), an intellectual exchange about the agenda of artistic research began which has developed into a friendship. 
Since 2009, my post at the University of the Arts The Hague has allowed me to devote myself to the further exploration and realisation of the programme of artistic research. The appointment has brought me back to a familiar environment in the Royal Conservatoire (KC) and Leiden University. I had taught music theory and musical aesthetics at the KC from 1990 to 1994, and earlier I had studied in both institutions. In The Hague I met my colleague Janneke Wesseling, who had just launched PhDArts, a new doctorate programme for visual artists and designers; and in Leiden I got to know Kitty Zijlmans, who, with Frans de Ruiter, has supported me in completing this book project. I hope to be able to continue my expedition with Janneke, Frans, and Kitty in The Hague and Leiden for many years to come. I am also grateful to Henk van der Meulen and Martin Prchal (Royal Conservatoire) for the latitude they have permitted me to finish the book project, as well as to the members of the research focus group at the KC for the critical dialogue about the hows and whats of research in music education settings.

My work since 2009 with Michael Schwab (Royal College of Art, London) and Florian Dombois (then of the Bern, now of the Zurich University of the Arts) has been of tremendous influence on the final leg of my expedition that I report on in this book. We have collaborated in planning and establishing the Journal for Artistic Research and the Society for Artistic Research, as well as on the Artistic Research Catalogue (ARC) project. Altogether, these have generated an active discursive field in which the programme of artistic research is being explored and brought to fruition, in both theory and practice. The concluding chapter of my book is a written account of that effort. My almost daily contacts with Michael about the conceptual and material aspects of those undertakings have helped to sustain me in my expedition. Michael has not only become a partner in crime; he is also one of those people with whom one connects strongly at an intellectual level. Innumerable conversations in the Editorial Board of the Journal (with Annette Arlander, Barnaby Drabble, Mika Elo, Nicola Foster, Julian Klein, and Michael Schwab) and in the Executive Board of the Society (with Barbara Bolt, Darla Crispin, Florian Dombois, Gerhard Eckel, Kim Gorus, Rolf Hughes, Anna Lindal, George Petelin, and 
Stephen Scrivener) have deepened my understanding of the dynamics of the new field of research. At the University of Gothenburg, where I have been spending part of my time since 20I0, I have enjoyed support and critical guidance from Anna Lindal, Johan Öberg, Sverker Jullander, Anna Frisk, the members of the research council of the Academy of Music and Drama, and many others.

The voices of philosophers who held the Spinoza chair at the University of Amsterdam in the late twentieth and early twenty-first centuries can be discerned now and then throughout the book. Seminars and staff colloquia conducted by Richard Rorty, Stanley Cavell, Hilary Putnam, and Hubert Dreyfus made a lasting impression on me and have had some ramifications for my explorations. In some chapters, the voices of Theodor W. Adorno and Ludwig Wittgenstein can also be heard. At the UvA I had a far too brief encounter with Ruth Sonderegger that enabled me to exchange some thoughts with her about the promise of the artistic research programme. Her move to Vienna has occasioned a pause in our dialogue, but hopefully not an end to it.

This book is about transformations - the transformation of artistic practices to artistic research, and the transformation of academia to a domain that also provides a place for non-discursive forms of knowledge, unconventional research methods and enhanced modes of presentation and publication. Yet the book could never have been written without the transformations made by my translator, Michael Dallas. His translations, often accompanied by intensive consultations, helped me better understand what I did and did not mean to say. If the published articles have had a certain impact, then that owes in large part to their articulate English. I thank Michael for his devoted, conscientious work.

Chapter I, 'The Conflict of the Faculties', has not been published before in its present form. Parts of it appeared as 'On Theory, Practice and Research in Professional Art Academies' in The Reflexive Zone: Research into Theory in Practice, edited by Anke Coumans and Helen Westgeest (Utrecht: Utrecht School of the Arts), 2004, pp. II7-24; and in Dutch as 'De strijd der faculteiten: Over zin en onzin van onderzoek in de kunsten' [The Conflict of the Faculties: On Sense and Nonsense of Re- 
search in the Arts] in Boekman (special issue, Kunst en Wetenschap), 58/59 (Spring 2004), pp. I9I-96. The final part of the chapter was published in the Dutch newspaper NRC Handelsblad as 'Emancipatie "faculteit der kunsten" nodig' [Emancipation of 'Arts Faculties' Needed], 29 September 2005, Opiniepagina section, p. 9.

Chapter 2, 'The Debate on Research in the Arts', was published in 2006 in the Sensuous Knowledge series, 02 (Bergen: Bergen National Academy of the Arts), and reprinted in 2007 in the Dutch Journal for Music Theory, I2.I, pp. I-I7. It was published in Dutch as 'Het debat over onderzoek in de kunsten' in De theatermaker als onderzoeker, edited by Maaike Bleeker and others (Amsterdam: Amsterdam University Press), 2006, pp. 2I-39. It was published in German as 'Die Debatte über Forschung in der Kunst' in Künstlerische Forschung: Positionen und Perspektiven, edited by Anton Rey and Stefan Schöbi (Zurich: Institute for the Performing Arts and Film, Zurich University of the Arts), 2009, pp. 23-51. A Spanish translation 'El debate sobre la investigación en las artes' appeared in CAIRON: Revista de estudios de danza [Journal of Dance Studies] (Madrid: Universidad de Alcalá), I3 (2010), pp. 25-46.

Chapter 3, 'Artistic Research and Academia: An Uneasy Relationship', was published in Autonomi och egenart: Konstnärligforskning söker identitet [Autonomy and Individuality: Artistic Research Seeks an Identity], Årsbok KFoU 2008 [Yearbook for Artistic Research and Development] (Stockholm: Swedish Research Council), pp. 82-97.

Chapter 4, 'Artistic Research within the Fields of Science', was published in its present form in 2009 in the Sensuous Knowledge series, 06 (Bergen: Bergen National Academy of the Arts). Parts of the article were published earlier in German as 'Der Modus der Wissensproduktion in der künstlerischen Forschung' in Wissen in Bewegung, edited by Sabine Gehm, Pirkko Husemann, and Katharina von Wilcke (Bielefeld: Transcript), 2007, pp. 73-80; and in English as 'Artistic Research and Pasteur's Quadrant' in GRAY Magazine, 3 (special issue, Artistic Research) (Amsterdam: Gerrit Rietveld Academy), 2007, pp. I2-I7; as well as in Close Encounters: Artists on Artistic Research, edited by Erna Grönlund and others, Rapportserien Dans: Forskning och utveckling [Dance: Research and Development Series], 
2 (Stockholm: University College of Dance), 2007, pp. I2-I7. The entire chapter was published in Dutch as 'Artistiek onderzoek in het geheel der wetenschappen' in Krisis: Tijdschrift voor actuele filosofie, I (2009), pp. 65-70.

Chapter 5, 'Where Are We Today: The State of the Art in Artistic Research' was first published in Forskning och kritik: Granskning och recension av konstnärlig forskning [Research and Criticism: Reviewing Artistic Research], Årsbok KFoU 2010 [Yearbook for Artistic Research and Development] (Stockholm: Swedish Research Council), pp. I7-3I. A slightly altered version was published in Kunst und Forschung: Können Künstler Forscher sein?, edited by Janet Ritterman, Gerald Bast, and Jürgen Mittelstraß (Vienna: Springer), 20II, pp. 57-79. A German translation, 'Wo stehen wir in der künstlerischen Forschung?', was provided in the same volume, pp. 29-55.

Chapter 6, 'Artistic Research as Boundary Work', was published in Art and Artistic Research, edited by Corina Caduff, Fiona Siegenthaler, and Tan Wälchli, Zurich Yearbook of the Arts 2009 (Zurich: Scheidegger und Spiess), pp. 72-79. It was published in German in the same yearbook as 'Künstlerische Forschung als Grenzarbeit', pp. 78-87.

Chapter 7, 'The Production of Knowledge in Artistic Research', was published in The Routledge Companion to Research in the Arts, edited by Michael Biggs and Henrik Karlsson (London: Routledge), 20II, pp. 44-63. Parts of the chapter were published in German as 'Künstlerische Forschung und akademische Forschung' in Kunstforschung als ästhetische Wissenschaft: Beiträge zur transdisziplinären Hybridisierung von Wissenschaft und Kunst, edited by Martin Tröndle and Julia Warmers (Bielefeld: Transcript), 20I2, pp. 69-90.

Chapter 8, 'Boundary Work: An Interview', was published as 'Boundary Work: Henk Borgdorff interviewed by Michael Schwab' in Intellectual Birdhouse: Art Practice as Research, edited by Florian Dombois, Ute Meta Bauer, Claudia Mareis, and Michael Schwab (London: Koenig Books), 20I2, pp. II7-23.

Chapter 9, 'Artistic Practices and Epistemic Things', will be part of a volume entitled Experimental Systems: Future Knowledge in Artistic Research, edited by Michael Schwab, Orpheus Research Centre in Music Series (Leuven: Leuven University Press), forthcoming in 2013. 
Chapter Io, 'Ingredients for the Assessment of Artistic Research', was written for the present volume and is not to be published elsewhere.

Chapter II, 'The Case of the Journal for Artistic Research', forms the basis for a chapter in The Exposition of Artistic Research: Publishing Art in Academia, edited by Michael Schwab and Henk Borgdorff (Leiden: Leiden University Press), forthcoming in 2012.

Amsterdam, January 2012 
Introduction 
You won't, for example, tell us, nor could you possibly tell us, what the criteria are by which we know which uses of 'know' in the future will be legitimate or rational .... Hilary Putnam

The content of a science [is] the reconfiguration of the world ... through practical engagement with things, people, and prior patterns of talk.

Joseph Rouse*

* Hilary Putnam, Pragmatism (Oxford: Blackwell, I995), p. 32. Joseph Rouse, 'Vampires: Social Constructivism, Realism, and Other Philosophical Undead', History and Theory, 4I (2002), 60-78 (p. 73). 
This book is about artistic research - what it is, or what it could be. And it is about the place that artistic research could have in academia, within the whole of academic research. It is also about the ways we speak about such issues, and about how the things we say (in this book and elsewhere) cause the practices involved to manifest themselves in specific ways, while also setting them into motion. In this sense, the book not only explores the phenomenon of artistic research in relation to academia, but it also engages with that relationship. This performative dimension of the book is interwoven with its constative and interpretive dimensions. If the book succeeds in its aims, it will not only advance knowledge and understanding of artistic research, but it will further the development of this emerging field. Such an articulation of artistic research, in which thinking and doing are enmeshed, implies a certain engagement. Though that might seem to stand in the way of an objective assessment, there are good reasons to defend the intertwinement of theoretical and practical agency, as I shall make clear below. 
The field of endeavour that I articulate and analyse here is, as mentioned, artistic research in its relationship to academia. It is a field of research under study, and my investigation can therefore be regarded (to use an old expression) as metatheoretical, as metascientific, as foundational research. It thereby situates itself in the domains of philosophy of science and science policy, in a field currently known as science and technology studies (STS). I would not go so far as to claim that the research I present here forms a significant contribution to various STS standpoints, nor that it adopts a stance in the STS debate. It can, however, be regarded as an extensive case study in which I sometimes partake of insights developed in the STS context. A thoroughgoing study from an STS perspective has yet to be undertaken; a whole territory awaits exploration.

The area covered by this book is limited. The focus is on artistic research - that is, on an endeavour in which the artistic and the academic are united. The field of artistic research thereby sets itself apart from other encounters between the arts and academia. It is important to draw a clear distinction between artistic research and other forms of art-science collaboration, where artists are outsiders, visitors, or participants in scientific practice (cf. Zijlmans, Zwijnenberg, and Clevis 2007: 3334). Such relations between artists and scientists remain outside the scope of this book, though I do refer to them in several chapters. My present study focuses on an undertaking in which artistic practices contribute as research to what we know and understand, and in which academia opens its mind to forms of knowledge and understanding that are entwined with artistic practices.

A further delimitation concerns the book's orientation. As the subtitle announces, it is about artistic research and academia. Although artistic research is positioned at the interface of art and academia - at the place where the art world and the world of academic research meet - the book concentrates not primarily on the art world, on issues in the domain of the arts, but on the relationship artistic research might have to academic research. Obviously such topics cannot be viewed in isolation from one another, and developments and critical issues arising in the art world will certainly come under discussion in various chapters. But the relationship between artistic research and the art 
world still needs to be explicitly investigated by other studies. A historical study of artistic research, which is likewise yet to be written, will not only have to uncover what factors - or better still, actors - have contributed to the rise of this research field, but it will also need to show what developments immanent in art practice have fuelled its emergence.

The fact that I am confining myself to artistic research and academia may perhaps justify my slightly undifferentiated, or sometimes ostensibly uncritical, use of the term 'art' in various chapters. Though I do distinguish here and there between different art practices and disciplines where relevant, and though I do realise that, since the historical avant garde, 'nothing concerning art goes without saying' (Adorno 1997 [1970]: I2), I do not pretend to make a sophisticated contribution to the history, theory, or criticism of art. At the same time, I am also aware that the advent of artistic research does potentially influence how we think about 'art' (as well as about 'academia').

Besides being a field that is strongly proliferating, artistic research is also a controversial matter. It is important to underline its disputed status from the start, even before I discuss this with varying degrees of emphasis in later chapters. Whether in the art world, in the arts education sector, or in the world of academic research, there are always people who react to artistic research with reserve, if not with scepticism or outright rejection. As we shall see, their motives and arguments for so doing differ greatly. I will highlight one such viewpoint straightaway, since it could recently be heard once again in distinguished art circles. ${ }^{\mathrm{I}}$ It involves the presumed disciplining effect of 'academic' artistic research. In contrast to disciplined academic research, it was argued, the unregulated field of research in the arts exempts itself, as a matter of principle, from standards, restrictions, and criteria - which naturally could never arise out of the autonomous work of artists. The artistic

I. Kathrin Busch, 'Generating Knowledge in the Arts: A Philosophical Daydream', Texte zur Kunst (special issue, Artistic Research), 20.82 (20II), 70-79. Cf. Michael Schwab's commentary in Schwab 2orrb. See also Peter Geimer, 'Das große Recherche-Getue in der Kunst. Sollen Hochschulen "Master of Arts"-Titel und Doktorhüte für Malerei verleihen?', Frankfurter Allgemeine Zeitung, 20 April 20II, Forschung und Lehre section, p. N5. <http://www.hkb.bfh.ch/uploads/media/Das_grosse_Recherche-Getue_in_der_ Kunst.pdf>. Cf. Elke Bippus's commentary in Bippus $201 \mathrm{I}$. 
production of knowledge was seen to have potentially more in common with speculative philosophy and the knowledge criticism it practises than with scientific knowledge production. The institutionalised field of artistic research was also accused of leaning strongly on an obsolete concept of science or scientific rigour and of failing to take into account recent insights from the sociology of science. It was warned, moreover, with recourse to Heidegger, Foucault, Derrida, Deleuze, and Levinas, that true artistic research should resist, as an independent form of knowledge production, any kind of academisation. Through its focus on the singular, the aesthetic-affective, the transgressive, the unforeseen, artistic research should exemplify an alternative culture of knowledge.

The problem with this type of criticism is that it fabricates its own object of criticism. It begins by constructing a caricature of artistic research in academia - it is disciplining, homogenising, restrictive, conformist, naive. After that, it is no longer difficult to field a whole line-up of post-Nietzschean witnesses to lambast those pernicious practices, which are inimical to art and which, under pressure from an equally maleficent education policy, are seen to have infected the art world under the label 'academisation' in order to subject art practices to their disciplining forces. Such argumentation often follows the same pattern: first you create an antithesis between (inadequate) academic research and the liberating cognitive practices of artists, and then you go on to defend the latter from unwarranted institutionalisation and normalisation.

This pattern is the mirror image of another sort of reasoning that likewise posits an antithesis between artistic research and academic research. It is deployed to protect the realm of the sciences against an invasion by unfounded ideas and strategies that cannot withstand systematic scrutiny, even if they might be of value in the enigmatic practices of artists. These defenders of science insist that the arts and sciences, though perhaps close together at some points in history, still remain two fundamentally different domains and practices, and that it would be highly inappropriate to lump them together in a single higher education and research framework.

It is one of my objectives in this book to counter some of these, in my eyes, needless oppositions between artistic and academic research, 
between art and academia. Clearly, these represent, at first sight, two domains and traditions of human activity that are institutionally and theoretically (and to some extent historically) segregated; no extensive research is necessary to confirm that. Nor are there many people who would claim that every expression of artistry is a form of scholarly research; those who do so tend not to be taken seriously in the discourse. All this notwithstanding, it is in this emergent field of artistic research that the domains of art and academia meet and intersect. At that very junction, something significant happens that could influence how we think, or might begin to think, about both domains.

At the same time, the warnings made by these critics ought to be taken seriously. If we near the point where institutionalisation of artistic research leads to curtailment or dilution of artistic practice, or to an erosion of academic values and conventions, it is time to step on the brake. And, now already, the way that institutionalisation has actually occurred in some places gives reason to watchfully monitor and criticise how the field is developing. At present, that development is characterised by a diversity of initiatives, models, and practices, not all of which will prove equally fruitful. Yet such heterogeneity is inherent in a field that is still in development and has not yet fully crystallised. Establishing a new research field simply takes time - as well as sparking a lot of conflict. My motivation in writing The Conflict of the Faculties is to contribute to that struggle. It is not helpful when people give up the struggle beforehand by ossifying the antithesis between artistic and academic research. The challenge lies in exploring whether and how artistic research could cohere with academic research.

So what is the current state of affairs in this research field, and how do I position my contribution? In chapters 2 and 5 , I attempt to document the state of the art, but I can already disclose for now that there actually is no 'state of the art'. Any effort to provide a current overview is undermined by the heterogeneity and dynamism of the research field. Owing to the stream of new developments, my own texts, as compiled here, were in danger of being obsolete at publication. To paraphrase Bruno Latour, it is a field in action. Viewed in a particular, mainly institutional light, the research field has already been established in some countries since the early I990s. From a more theoretical per- 
spective, however, the field is still in a continuous state of flux and some turmoil. The foundational debate has not yet led to a status quo. It may indeed be inherent to the field of artistic research that such a status quo cannot ultimately be achieved. I shall defend that possibility below.

A growing number of publications relating to the new field of research - journal articles, books, conference proceedings, policy papers - are now seeing the light. But the number of studies that explicitly examine the relationship between artistic research and academia is still scant. The voluminous 'companion' by Biggs and Karlsson (20II) therefore represents a milestone, though it still covers a limited number of viewpoints. If something can presently be said about a state of affairs, it is that there is a particular need for studies to illuminate the new research field from the perspectives of sociology of science and history of science. I would definitely endorse Helga Nowotny's appeal (made in Biggs and Karlsson, p. xxii) to science and technology researchers to engage with the new field. I hope that my present volume will also contribute towards this.

My own contribution to the field of artistic research and the associated debate may be roughly described using the terms clarification, justification, and positioning. Particularly in the early chapters of the book, I try to create some terminological and conceptual clarity regarding the phenomenon of artistic research. The theoretical and political rationale of this type of research is a theme that pervades all chapters, and I also attempt to situate artistic research within the academic realm. The earlier publication of the articles incorporated here was also part of an effort to promote the concrete establishment of the new research domain (more on this below).

The principal theme addressed by this book is: What are the characteristics of artistic research? This general question breaks down into a series of more specific questions, explored in different chapters.

a. How can we differentiate artistic research practices from artistic practices?

b. What are the ontological, epistemological, and methodological attributes of artistic research?

c. How can the relationship between artistic research and academia be characterised? 
d. What position does the artistic research programme occupy in science and technology policy and classification?

e. Under what terms does artistic research qualify as academic research?

f. What are the similarities and differences between artistic research and other academic research fields and how does artistic research relate to other life domains?

g. What criteria may we employ in assessing artistic research?

h. How is such an assessment framework rendered into concrete practice in a peer-reviewed journal?

The focus in the later chapters turns increasingly to the epistemology of artistic research and the criteria for research assessment. Throughout the work, I urge the acceptance of artistic research as a fully fledged research form, including institutional recognition.

My exploration of the theoretical and political rationale of artistic research is based in part on the study of texts, complemented by a case study to test the artistic research assessment framework. Concrete artistic research itself is not a focus of my study. The book is about artistic research - I do not discuss (analyse, interpret, criticise) specific research projects, though these do receive some attention in the literature I treat. In the emergent field of artistic research, there is a significant need to bring together exemplary research, to create a canon of projects that can serve as examples or mirrors for comparison or can qualify as paradigmatic. A new field of research usually evolves against the backdrop of uncontroversial work to which one can have recourse which represents the research domain, as it were. The fact that no such corpus of exemplifying research now exists gives pause for thought. Does the establishment of artistic research as a new domain perhaps follow a different logic? Whatever the case, my present study should not be seen as a contribution to that facet of the artistic research domain. Although I am aware that a study on and about artistic research which does not draw on concrete research is at risk of remaining an abstract exercise, I believe my study helps to clarify, justify, and position artistic research within academia.

The sources I have consulted deal roughly with four domains: artistic research, theory of science, philosophy, and research policy. 
(Policy documents and online resources are listed in a separate section of the bibliography.) In studying the texts and other sources, I focus not only on the theoretical and political rationale of artistic research, but also (albeit less explicitly) on what academia is, on how we can think about academic research against the background of the discourse on artistic research. One aim of the book is therefore to make a contribution of my own to the current discourse about academia and the future of academic research. In doing so, I do not position myself on the outside, either by branding academic research beforehand as flawed or by presupposing an opposition between artistic and academic research, but I contribute from within - by showing that there are good reasons to champion and bolster within academia the alternative culture of knowledge to which the cited critics refer. Here, too, there is considerable work to be done. The challenge is to find and mobilise allies at all levels within the world of academic research and the science system - in theory and in practice, conceptually and strategically, for the debate on values and criteria and for the material and procedural infrastructures. Natural allies can be expected in the humanities and social sciences, for instance in cultural studies and anthropology. But beyond that, exchanges of ideas and research strategies with people from areas like physics or engineering could also help strengthen the enhanced and expanded culture of knowledge. As I shall discuss below, the emergence of newer forms of transdisciplinary and Mode 2 research may also be relevant. And clearly the new artistic research domain can and should be further sustained by insights emanating from science and technology studies.

The study presented here consists mostly of chapters that have been published earlier as articles in their own right. Only the final two were written specifically for this book. The first two chapters explore the territory covered by the study and provide a tentative characterisation of the emerging field of research. Chapters 3,4 , and 6 focus on various aspects of artistic research: the often uneasy relationship with academia, the place of artistic research in the wider realm of science and technology, and its status on the borderlines between art and other life domains, including science. Chapter 5 may be seen as a sort of intermediate tally on the state of the art in the emergent domain. In chap- 
ter 7 , I attempt to position artistic research within academic research and as academic research. Under the notions of non-conceptualism, realism, and contingency, I also discuss in relation to artistic research a number of more speculative viewpoints that have been mentioned in passing in previous chapters. Such views invite additional brainwork. In the interview in chapter 8 , amongst other subjects I anticipate the central theme of chapter 9: the status of artworks and art practices as 'epistemic things'. In chapter Io, I draw together the insights gained so far and mould them into a framework for assessing artistic research. This framework is tested and put into operation in chapter II, the case study on the creation and functioning of the peer-reviewed Journal for Artistic Research.

As noted, most chapters have been published before. Those publications have meanwhile had some effect on the international discourse about the artistic research programme. One reason why I wrote them was to promote the establishment of that programme in concrete initiatives. That might explain the slightly combative and occasionally categorical tone of some passages. Matters of fact and matters of concern are intermingled. That obliges me now to engage in some reflection about how theoretical analysis relates to practical agency. Such reflection is not a secondary consideration; it goes to the very heart of the matter.

In addition to being an essay on artistic research (in relation to academia), this book is also a project and a proposition. It is a project in the literal sense of 'that which is thrown forth', and this is done with a specific purpose: to achieve something in practice, to make a difference there. This performative dimension of the book, as I have pointed out in the beginning, is interwoven with the discursive dimension. Theories are not disinterested attempts to approach an ever-receding practice, nor are they imperfect representations of a constant reality. Theories, including ones about artistic research, co-constitute the practices they address - just as there are no practices that are not permeated by theories and beliefs. This intertwinement between theory and practice - acknowledged both in hermeneutics and in constructivism - is the departure point of my analysis in the first chapter. But this relationship between theory and practice also figures in the entire project of which this book forms a written account. No one, of course, is the sole owner of the viewpoints advanced here, as any certificate of 
ownership bears traces of things that others have left behind in intertextual space. These shared viewpoints exert their performative force on the practices they become involved with. This can be illustrated by the interplay between the framework for assessing artistic research, as developed in this book, and the peer review criteria employed in practice by the Journal for Artistic Research. The unmistakable reality of those criteria (sedimented in the peer review form that guides reviewers through the assessment process) cannot be seen in isolation from the discursive practice articulated in the criteria. That discursive practice has both unfolded within the assessment framework proposed here and transformed itself into the peer review form. That double transformation may serve to exemplify the paradox that this book, this project, indeed this whole endeavour demonstrates. Theories exercise their performative power on the very practices that are described by those theories. Bruno Latour has shown how we can escape from this paradox - or rather, from what perspective the paradox no longer manifests itself as a paradox. For indeed, the opposition between theory and practice dissipates as soon as we learn to understand the dynamic of the emergent field as a chain of transformations - in which something that belongs at one moment to the 'logical space of reasons' (to use Wilfrid Sellars's term) is set into operation at the next moment and becomes reality. Latour referred to this double 'articulation'z of the field as 'constructivist realism' (Latour 1999: 135). Reality becomes more real through our interpretations of reality. And if only because of that, the present project is not a relativist undertaking. At first glance we seem to be dealing with a double circle: that which is to be proved is already assumed, and we test our assumptions in implementing them. In actual fact, however, this is not self-referential at all; it is a dynamic chain of interactions, transformations, and articulations that may ultimately produce more reality.

This book is also a proposition, in the literal sense of 'a proposal to do something'. It might go too far to designate what I have under-

2. Latour 1999: 303. 'This term [articulation] occupies the position left empty by the dichotomy between the object and the subject or the external world and the mind. Articulation is not a property of human speech but an ontological property of the universe. The question is no longer whether or not statements refer to a state of affairs, but only whether or not propositions are well articulated.' 
taken in this book as action research, although the chain of reflection and intervention might certainly tempt one to do so. It is better to describe my work as a proposition ${ }^{3}$ to view reality differently, to offer an alternative for what now exists, by connecting and mobilising ideas, people, institutions, and material things. This makes my project resemble art practice itself (if indeed I may say so), since art practice likewise offers another perspective, or a perspective on the other. Such a perspective is fundamentally contingent. Things could be different, but whether we succeed in fulfilling the proposition depends on how powerfully it is articulated. The artistic research programme is not a given; it is itself a project and a proposition. It provides the opportunity, 'through practical engagement with things, people, and prior patterns of talk' (Rouse 2002: 73), to look at artistic practices differently and to articulate their epistemic potential. And precisely because we cannot say "what the criteria are by which we know which uses of "know" in the future will be legitimate or rational' (Putnam 1995: 32), there is room here to propose an enriched and expanded epistemic culture. Articulating artistic research in academia therefore also amounts to a proposition to speak differently about academia, to reconfigure academia.

The earlier published texts that comprise most of this book came about in a variety of circumstances. That explains differences in style, tone, length, and structure. I have decided to include them here in their original form, save some minor adaptations, in order to allow the context to resonate in the narrative, as it were. Occasionally, but not too often, that context is specifically Dutch; if so I point that out.

The various texts do not follow on one another precisely, but they overlap as tiles on a roof. Repetitions or paraphrasings may occur here and there, for which I hope the reader will forgive me. Each chapter is preceded by a small preface that briefly explains the context of its in-

3. Latour 1999: 309. 'I do not use this term [proposition] in the epistemological sense of a sentence that is judged to be true or false [...], but in the ontological sense of what an actor offers to other actors. The claim is that the price of gaining analytical clarity - words severed from world and then reconnected by reference and judgment - is greater and produces, in the end, more obscurity than granting entities the capacity to connect to one another through events.' 
ception and may link it to preceding or subsequent texts. This might seem to divorce the context from the content; but, as I have pointed out, the context also resonates through the text. And, just as theory and practice, the discursive and the performative, are interwoven, so should the distinction between content and context be de-emphasised here.

The texts were written between 2004 and 20II. Not only did the field of artistic research expand decisively during that time, but the terminology used to describe it also shifted. Although this is explained in subsequent chapters, I should point out here, to avoid misunderstandings, that the expression 'artistic research' is used here synonymously with 'research in the arts' (as contrasted with 'research on the arts'). Some shifts have occurred, too, in my own thinking about artistic research as well as in my perspective on artistic research and academia. For that reason, I provide annotations alongside the texts of all chapters but the last two; these contain either my own comments and elaborations on the adjacent passages or a kind of stage directions to aid in following the book's line of reasoning. Together with the short prefaces explaining the context, the annotations may be regarded as a sort of metatext that further articulates my perspective on artistic research and academia. 
Chapter I

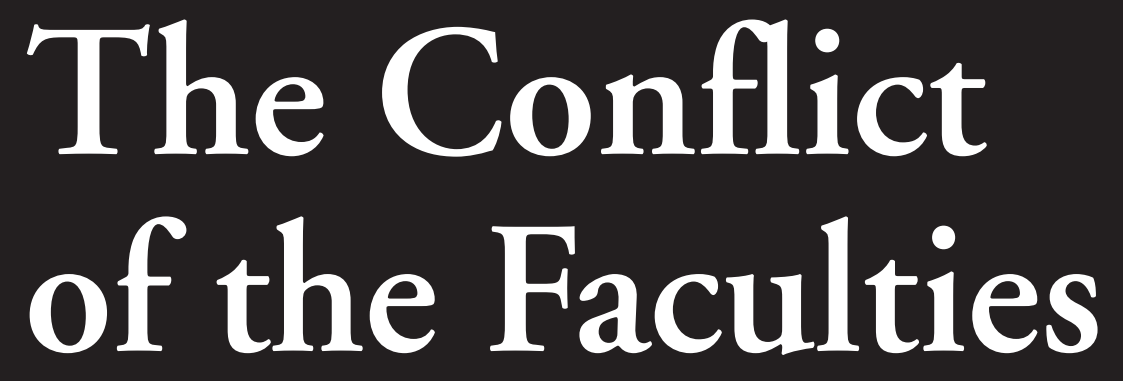

On theory, practice and research in professional arts academies 



\section{Context}

This opening chapter signals the beginning (in the

Netherlands at least) of the debate on research in the arts. It contains the text of a lecture I delivered at the expert meeting 'Kunst als Onderzoek' (Art as Research), held at Amsterdam's Felix Meritis centre on 6 February 2004. It also marks the creation of a new type of professorial chair known as lectoraat at the Dutch universities of the arts. In my research group Art Research, Theory and Interpretation (ARTI) at the Amsterdam School of the Arts, the rationale of artistic research - and in particular the relationship between theory and practice in the arts and in arts education - was a subject of lively debate. The third part of the chapter, which urges institutional recognition for artistic research, was published in abridged form on 29 September 2005 in the Dutch newspaper NRC Handelsblad, under the title 'Emancipatie "faculteit der kunsten” nodig' (Emancipation of 'Arts Faculties' Needed). Later, in 20I0, the Netherlands Organisation for Scientific Research (NWO) funded a modest pilot project for two practice-based $\mathrm{PhD}$ studentships in fine art and design. 
This chapter develops a line of reasoning containing three elements:

I. To understand what research in the arts involves, we must be fully aware of the tension and interaction between artistic practice and theoretical reflection which are characteristic of the creative and performing arts.

2. Contrary to widespread belief, the unique nature of knowledge in art (as compared to more conventional forms of scholarly knowledge) does not justify any unique methodology of research. 'Art knowledge', as embodied in the practices

Two strands of thought, or 'agendas', pervade all the chapters of this book: the agendas of theoretical comprehension and political justification. Or more correctly, the emergence of the field of artistic research is characterised by the intertwinement of these two agendas. Ideas are mobilised and put into action, and they exert their performative force on institutions and situations. Institutions and situations, along with people and instruments, are brought to bear to make ideas happen. This constructivist realism (Latour) is characterised by contingency: it is a proposal to reinterpret and reconfigure the state of art and academia. and products of art, is accessed by artistic research through both cognitive and artistic means.

3. Research in the arts is of equal value to research on the arts, and should therefore be treated equally at the institutional level.

\section{Theory and practice}

To understand what artistic research is, it is vital to explore the relationships between practice and theory in the arts. By outlining four ideal-typical (but not mutually exclusive) perspectives on the relation between $[. .$.$] theory$ and practice, I will try to elucidate and refine the various viewpoints one can encounter in the world of higher arts education. I distinguish (a) the instrumental perspective, (b) the interpretive perspective, (c) the performative perspective and (d) the immanent perspective.
In chapter 2, these four perspectives will translate into three perspectives on research in the arts. In research where artistic practice serves as both a method and an epistemological resource, the performative and immanent perspectives merge together. Artistic practices and artworks are both instruments and outcomes here.
Subsequent chapters will focus more closely on the specificity of the knowledge embodied in art and on the methodological heterogeneity of artistic research. The opposition I implied here between 'cognitive' and 'artistic' is unfortunate, as the artistic itself - both the creative faculties and the aesthetic experience should be considered to belong to the domain of the cognitive. It would be better here to counterpose the artistic to the con$\checkmark$ ceptual, rather than to the cognitive (cf. chapter 2, page 48).

a) The instrumental perspective suggests that 'theory' serves the creative process or performance practice in the arts. This viewpoint, predomi- 
nant in professional arts schools, understands theory first of all as a body of technical professional knowledge. Each art discipline thus has its own 'theory' - instrumental knowledge specific to the craft, needed to practise the art form in question. Examples are the theory of editing in film, the theory of harmony and counterpoint in music, or Stanislavski's psycho-technique in theatre.

Yet beyond the technical know-how and professional knowledge often referred to as theory, the instrumental perspective also embraces theory or theoretical research of an exploratory or applied nature. This might, for instance, involve research into a specific use of materials in visual arts, dramaturgic research into a theatrical text, or even the current fad of applying information technology in artistic practice. In all such cases, theory or theoretical research, just like the body of technical knowledge, is used in the service of artistic practice. Theory, as it were,

This instrumental perspective is notably found in higher music education (at conservatoires). In visual arts schools, the interpretive perspective is more prominent. For a reflection on the Deleuzianisation of the art school, see Boomgaard 20I2. For the issue of research in higher music education, see Borgdorff and Schuijer 20 oro. furnishes the tools and material knowledge that are applied to the artistic process or product.

The primacy of this instrumental understanding of theory in higher professional art schools today also colours the discussions there on the relation between theory and practice. As a consequence, it influences beliefs about the relationship between art and science, as well as the ways that people perceive 'research in the arts'. In my view, the instrumental perspective reinforces the notion that artistic research should consist primarily of applied research, and that any results of theory development should serve artistic practices and products. Often this view is pervaded by what I would call the technical-scientistic paradigm - a frame of thought in which the laboratory, the conventions of the exact sciences, and the empirical cycle of discovery and justification form the benchmark for experimentation in the arts. I will return to this later.

To a considerable extent, the opacity and indeterminacy of the discourse on theory and practice in the arts, as well as on artistic research, derives from not knowing whether particular standpoints are drawing on the instrumental perspective and on the technical-scientistic model, or not. 
b) The interpretive perspective holds that theory provides reflection, knowledge, and understanding with respect to artistic practices and products. Historically, this view is associated with academic disciplines like theatre studies and musicology, which try to facilitate understanding of artistic practice from a certain 'retrospective' theoretical distance. In this sense, 'theory' basically involves any form of reflection on artworks, or on the production or the reception of art, that rises above the level of the craft itself. Such reflection has gained wide currency in the 'grand theories of the humanities' like hermeneutics, structuralism, semiotics, deconstruction, pragmatism, and critical theory.

In contexts such as fine arts academies or artists' workspaces, the central focus is on research in the arts, rather than on the arts. Such practice-based research does not stand in isolation, however, from theoretical reflections as referred to here. An understanding of artistic processes and products from a philosophical, ethical, historical, hermeneutic, reconstructive, deconstructive, or generally contextualising point of view is (or should be) part of any artistic research. That is why so many people are now arguing the importance of cultural studies.

In educational practice at schools for the arts, the amount of emphasis put on 'theory' in the interpretive sense seems inversely proportional to the amount of time spent on 'theory' in the sense of professional training. Music theory as professional and instrumental expertise, for instance, dominates musical training at the Dutch conservatoires, which have never developed any tradition of theoretical reflection that extends beyond the level of the craft. In developing and planning practice-based masters and $\mathrm{PhD}$ programmes in the arts (which I will return to below), one needs to devote far more attention to theory from the interpretive perspective, not least with a view to future academic accreditation.

I. The model and inspiration for this perspective and attitude is the Greek theoros, from which our word theory derives. A theoros was an official envoy sent by Greek cities to observe and report back on public festivities and ceremonies. His participation in social and religious gatherings consisted of distancing himself from what was going on, absorbing it and mentally registering it, so that he could later report on it in a particular way. Theoria - which involves consideration and contemplation, a scientific, philosophical or more generally intellectual task - is equally a part of art theory as technè, the received or acquired talent to practise the artistic profession on the basis of technical know-how and professional knowledge. 
A distinction is introduced here between world revelation and world constitution. This will return regularly in subsequent chapters. It often seems as if we have to choose between hermeneutics (or scientific realism) and constructivism. Towards the end of the book, however, and explicitly in chapters 9 and II, I will make it clear that this does not involve an opposition, but an 'articulation' that is at once real and artificial. Whenever this is explicitly or more indirectly at issue, I will provide an annotation ('constructivist realism') to point it out.

c) Whereas the interpretive approach addresses, in a sense, the 'world-revealing' nature of art theory and research, the performative perspective focuses on their 'world-constituting' quality. I am suggesting here the metatheoretical insight that theory is not 'innocent', and that the instrumental perspective, as well as the theoretical distance with respect to art that I subsequently discussed, both foster an understanding of art which itself constitutes a fertile ground and starting point for new art practices and products.

By highlighting this metatheoretical perspective, I wish to emphasise more specifically that theory itself is a practice, and that theoretical approaches always partially shape the practices they focus on. Whether we are dealing with the theory of linear perspective, classical rhetoric, the twelve-tone technique, set theory in serial music, or insights into the cultural meanings and societal functions of art, the performative power of theory not only alters the way we look at art and the world, but it also makes these into what they are.

Constructivist realism

That art practitioners can be sceptical about theory - even to the point of developing a misplaced aversion to it - is perhaps not just because some theories seem far afield from the actual practice of art, but also because the performative power of theory competes with the performative power of art. On the other hand, thinkers about art who take unnecessarily reticent or aloof attitudes towards artistic practice (especially that of the present day), and who develop their own codes to institutionally protect their 'profession' from artistic practice, may be exhibiting a similar perception. Both sides show a limited understanding of the interaction and reciprocal influence of theory and practice. Not only do thinkers and doers need each other, but in a certain sense thinkers are also doers, and vice versa.

d) The immanent perspective hence reminds us that there is also no such thing as 'innocent' practice. Practices are 'sedimented spirit' (Adorno). 
Action theory, phenomenology, and philosophy of science have taught us that every practice, every human action, is infused with theory. Naive practice does not exist in this respect. All practices embody concepts, theories, and understandings. Artistic practices do so in a literal sense, too - no practices and no materials exist in the arts which are not saturated with experiences, histories, or beliefs. There is no unsigned material, and that is one reason why art is always reflexive. There is no 'natural law' of art; its nature is second nature, preshaped by history, culture, and theory. This gives the lie to that modernist view in the arts which once championed the purification of the medium.

An additional consideration that applies in the arts is that the knowledge and experience embodied in their media will always, to some degree, manage to evade the identifying and levelling gaze of rationality, thereby escaping discursive translation. Philosophical aesthetics has always acknowledged this, from Baumgarten to Adorno and Derrida. Nevertheless, the unique nature of knowledge in art must not tempt us to oppose art practice to art theory. Doing is also thinking, albeit an exceptional form of thinking.

Common to artistic practice and theoretical reflection is that both relate to the existing world. But art knowledge is always also embodied in form and matter. Creative processes, artistic practices, and artworks all incorporate knowledge which simultaneously shapes and expands the horizons of the existing world - not discursively, but in auditory, visual, and tactile ways, aesthetically, expressively, and emotively. This 'art knowledge' is the subject, as well as partly an outcome, of artistic research as defined here.

\section{Research in the arts}

The frequent plea for convergence between artistic and academic research is a stark reflection of the equally lamented schism between those two spheres of activity. But in spite of the many recog-

'Partly

In the debate on research in the arts, there is disagreement about whether, or to what extent, the artistic outcomes of the research (the concrete artworks and art practices generated by the research) are to be discursively framed - that is, accompanied by a contextualisation, a theoretical frame, an interpretation, or a reconstruction or documentation of the research process. This is one of the issues of demarcation in the foundational debate. My position is that this discursive framing is necessary. The key arguments for this will 4 be given in chapters 2,7 , and Io. To forego such framing implies a departure from academia. That said, the discursive forms in which the framing may take place are highly varied. They do not confine themselves to conventional academic discourse.

The qualification 'partly' will be encountered regularly in subsequent chapters. 
nised areas of contiguity and overlap, some observers continue to insist on the (both theoretically and institutionally) sui generis nature of research in the arts in comparison to that in [traditional] universities. This is justified as follows: Even though the institutional division between university and art education is an unnatural one, and does not do justice to a field of practice in which thinking and doing are interwoven, the link between artistic research and artistic practice at schools of the arts is a very direct one. Artistic practice is already 'in house', as it were - embodied by the artists that teach there and in the practical training on offer. Art education thus already maintains intimate links to the world of art practice - to orchestras, ensembles, and theatre companies, to production companies and artists' workspaces, to galleries and studios. An additional argument is that the largely historical focus of the traditional academic humanities severely curtails any attention to the contemporary arts - and hence also to the creative process in the arts - whereas those very themes are central to both the training and the research in art schools. It is rightly pointed out that research and theory development in art academies and workspaces, by its close proximity to current artistic practice, makes a vital contribution to the discourse on art. It can also positively influence the nature and level of the public debate on the arts.

The sui generis nature of artistic research also fuels the international debate ${ }^{2}$ on whether to conform to the conventions of academic research, such as standards of methodology, verifiability, replicability, and reporting. Opinions on such issues are underlain to a significant extent by beliefs and misunderstandings about the supposed uniqueness of artistic research methods. I would argue as follows: Even if one accepts that the knowledge embodied in art is of a different order than the more 'conventional' forms of academic or scientific knowledge, that does not mean the methods for access-

The reports published by the UK Council for Graduate Education and Arts and Humanities Research Council not only influenced the creation of chapters I and 2 of this book, but they also aided the establishment of the docARTES doctorate programme.

2. See e.g. Davies 2002; Dallow 2005; Bauer 200I. For the debate in the UK, see also UKCGE 1997; UKCGE 200I; DES 2002; Nelson and Andrews 2003; AHRB 2003; and AHRC 2007. 
ing, retrieving, and disseminating such knowledge are also different. Both those who would welcome a convergence of artistic and academic research, and those who would oppose such a development, frequently show a limited (if not short-sighted) awareness of the broad diversity of methods and techniques in systematic research.

The limited scientific notion commonly held on both sides is that of the empirical-deductive approach. To make matters worse, both sides depict it in the form of an obsolete empiricist caricature. One of them would like any experimentation in the arts to be comparable to laboratory trials, while the other argues against submitting to the presumed constrictive frameworks of this scientific model. It is not really surprising that both sides have failed to take heed of recent trends in the theory of science, which have led to a 'liberalisation' and diversification of research approaches and to a critique of the 'fact-value dichotomy' (Putnam 2002). Most of the disputants come from the world of the art schools and are not yet sufficiently informed in this area.

In raising the issue of the specific place and quality of artistic research, we should not seek confrontations with experimental research in the empirical-deductive exact sciences, nor with socially engaged empirical-descriptive research in the social sciences, and also not with the cultural-analytical, aesthetic, or critical-hermeneutic interpretive approaches in the humanities. However, to adopt one-sidedly the 'natural science' model, the 'social science' model, or the 'humanities' model [...] will produce a myopic understanding of what is really going on in the arts. The many divergent approaches to artistic products and processes each have their own raison d'être - and that is also reflected in the widely varied research mandates of various professors who have begun doing research in art schools in recent years.

Not only experimentation in practice, but also reflection on practice and interpretation of practice, may be part of research in the arts as defined here. The sui generis place and nature of artistic research 
Here I touch upon three elements that are characteristic of artistic research: the type of knowledge at hand within this research, the method through which that knowledge is articulated, and the way in which it is disseminated. In chapter 2 , and later in chapter 7 , these three elements will be supplemented by four additional elements: the specific intent of the endeavour, the artistic research question, its originality, and the dual artistic and academic context of the research.

is legitimised in part by the four perspectives on theory and practice in the arts discussed above, as well as by the institutional intertwinement of theory and practice in art schools. This special position is legitimised more specifically by the exceptional nature of 'knowledge in art', as well as by the exceptional ways in which research findings are articulated and communicated.

When the familiar frameworks of work analysis, production analysis, and reception analysis are transposed from research on the arts into research in and through the arts, that reduces the distance to the object of research to such a degree that the work of art, the creative process, and the signifying context themselves all become constituent parts of the research. In the medium itself - in the creative process, the artwork, and its effects - perspectives are revealed and constituted, horizons are shifted, and new distinctions are articulated. The specific nature of artistic research can be pinpointed in the way that it both cognitively and artistically articulates this revealment and constitution of the world, an articulation which is nor-

both cognitively and artisti-

4 cally ...' See annotation on page 17.

Constructivist realism mative, affective, and expressive all at once - and which also, as it were, sets our moral, psychological, and social life into motion.

This demarcation of research in the arts - extending from abstract knowledge to instrumental know-how - now brings me to three recommendations for conducting such research. I hope they will provide a stimulus to further discussion.

I. Artistic processes or products are essential components of and in artistic research. The choice of research methods is free and will vary with the research questions. The methodological diversity referred to above, however, is always complementary to the use made of the medium itself. 2. Research results consist partly of one or more artistic productions or presentations. The results communicate the artistic outcomes both cognitively and artistically. Far from being a mere illustration accompa- 
nying the research, the artistic outcomes thus form an indispensable component of it.

3. Critical reflection on the research process, and documentation of it in discursive form, is also part of the research results. The researcher is obligated to the research community to situate each study in a broader research context and to elucidate both the process and the outcome in accordance with customary standards.
'The researcher is obligated At the expert meeting 'Art as Research' in Amsterdam, a heated debate erupted between proponents and opponents of such recommendations. Some people vehemently objected that such imperatives were being imposed on artistic practice by external forces (by 'Bologna'; cf. chapter 5, page II6).

\section{The conflict of the faculties ${ }^{3}$}

In I798, Immanuel Kant published his pamphlet entitled Der Streit der Fakultäten (The Conflict of the Faculties), in which he urged an end to the subordination of the 'lower faculties' in the universities to the 'higher faculties'. The lower faculties of Kant's day and age, which studied the natural sciences, humanities, and philosophy, were entitled to award only masters degrees, whereas the higher faculties, which dealt with theology, law, and medicine, could offer doctorates. The higher faculties were accountable to the church or the state, just as today the practice of religion, law, and medicine still falls under the jurisdiction of clerical or secular authorities, which protect the professions and regulate professional practice.

When the late eighteenth-century authorities tried to interfere with the content of Kant's philosophical treatise Religion innerhalb der Grenzen der bloßen Vernunft (Religion within the Boundaries of Mere Reason), published in $\mathbf{1 7 9 4}$, he resisted such interference, arguing vigorously for freedom of research in the lower faculties, which were oriented primarily to pure scientific research rather than to professional qualification. Kant's appeal helped to foster the intellectual climate that made possible the founding of the Friedrich Wilhelm (later Humboldt) University in Berlin in I809. Besides lending institutional legitimacy to freedom of research, the university also granted the lower faculties the right to educate students for the doctorate.

The time has now arrived to make a similar appeal for the liber-

3. I am indebted here to Ken Friedman (2002). 
ation of what we might provokingly call the 'lowest faculty' - that of art education and research. Just as the implicit hierarchy between fundamental and applied research was abandoned some time ago in the Dutch academic world - as reflected in the renaming of the Netherlands Organisation for Pure Scientific Research (zwo) to Netherlands Organisation for Scientific Research (Nwo) - it is now time to grant equal opportunities to artistic research as conducted in art education institutions. As a corollary, the Royal Netherlands Academy of Arts and Sciences (KNAW) should receive back its old name, the Royal Institute of Sciences, Literature and Fine Arts, by which we would acknowledge that science and art make equally vital, if dissimilar, contributions to culture.

In concrete terms this would mean, first of all, opening the existing direct and indirect academic funding mechanisms to support research in the arts as defined here. In other words, structural funding for research in higher professional art schools needs to be broadened, and augmented to a level similar to that available to other institutions of higher education. In addition, professional art schools must be eligible to compete for grants and other funding, to create research traineeships, and to allocate staff to assessment committees. The 'lowest faculty' should further be enabled to set up properly funded 'practice-based' masters and $\mathrm{PhD}$ programmes in the arts.

Eighteenth-century faculties psychology spoke of the different 'faculties' of the human mind. Present-day cognitive science has brought these faculties back onto an equal footing.

The faculties of the human mind are not subject to a value hierarchy. The institutional faculties, in which those human faculties are challenged and utilised, therefore have the right to equal treatment. 

Chapter 2

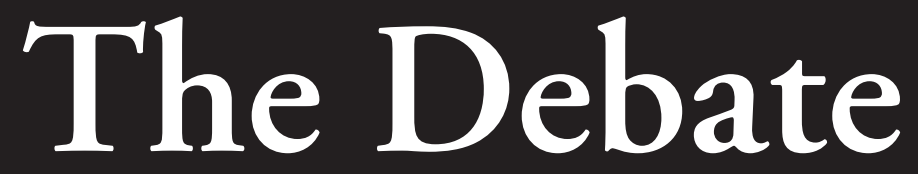

on Research

in the Arts 



\section{Context}

This text is based on a presentation I made in September 2005 to the think-tank EMPar (Enquiry into Musical Practice as Research) in Ghent. EMPaR was comprised of representatives from the Orpheus Institute, the Conservatorium van Amsterdam, the Royal Conservatoire in The Hague, Leiden University, the Katholieke Universiteit Leuven, the University of Oxford, Royal Holloway, London, and the Royal College of Music, London. I adapted and redelivered the presentation on several later occasions, including the ELIA conference entitled 'RE:SEARCH in and through the Arts', held at Berlin in October 2005. The text has been published in several places and in several languages. 
If the urgency of an issue can be measured by the ferocity of the debates surrounding it, then the issue of 'research in the arts' is an urgent one. Under labels such as 'art practice as research' or 'research in and through the arts', a discussion topic has arisen in recent years that has elements both of philosophy (notably epistemology and methodology) and of educational politics and strategies. That makes it a hybrid issue, and that does not always promote the clarity of the debate.

The crux of the matter is whether a phenomenon like research in the arts exists - an endeavour in which the production of art is itself a fundamental part of the research process, and whereby art is partly the result of research. More particularly, the issue is whether this type of research distinguishes itself from other research in terms of the nature of its research object (an ontological question), in terms of the knowledge it holds (an epistemological question), and in terms of the working methods that are appropriate to it (a methodological question). A parallel question is whether this type of research qualifies as academic research in its own right, and whether it appropriately belongs at the doctoral level of higher education.

The present urgency of the issue is partly

The distinction between the ontology, epistemology, and methodology of artistic research is a relative one. As I will point out in chapter 3 , page 69 , and chapter 8 , pages $180-8 \mathrm{I}$, the distinction serves a merely heuristic purpose. In practice, the defining of the research object, the knowledge involved in it, and the ways we gain access to it are intertwined. These perspectives converge in Hans-Jörg Rheinberger's epistemic thing as an instrument of research (chapter 9).

due to government policies affecting this field. As a result of higher education reforms in many European countries, research has now be-

The place of research in the arts within the wider realm of academic research is also the subject of chapter 4 . I shall argue there that artistic research merits a place in the research hierarchy and that it ought to be included as a field of its own in science and technology classifications. come part of the primary function in higher professional schools as well as in universities. Research in higher professional education differs from that in university education in the degree to which it is oriented to application, design, and development. As a rule, 'pure' or fundamental scholarly or scientific research (if indeed that exists) is and remains the province of the [traditional] universities. Research at theatre and dance schools, conservatories, art academies, and other professional schools of the arts
This is especially true in coun4 tries where the binary system is still firmly in place, such as the Netherlands. 
is therefore of a different nature to what generally takes place in the academic world of universities and research institutes. What that difference exactly entails is the subject of controversies - and not only the opinions, but also the motives are highly divergent here.

The first thing worth noting about the debate is that many of the contending parties tend to opt for the rhetorical force of 'knowing you are right' above the gentle power of convincing arguments. It is not entirely coincidental that people's personal opinions usually correlate with their own affiliations. Many contenders on one side are inclined to entrench themselves in established institutional positions, portraying themselves as defenders of quality standards on which they seem to have a patent. Some on the other side put up resistance against any form of 'academisation' (as it is sometimes scorn-

'Academia' is the term I will be using from chapter 3 onwards to denote the entire realm of higher education and research, including the field of artistic research. Far too often, the expressions 'scientific research' and 'academic research' imply an unnecessary opposition between them and artistic research.

fully called) - afraid of losing their own distinctiveness, wary of the perceived 'stuffy' confines of academia. The term 'academisation' refers here both to the dispirited reality of university bureaucracy and to an objectionable 'academic drift', whereby some of the vital spirit of artistic practice at the art academies has to be betrayed in order to 'cash in' on the greater social status and respectability that our culture still ascribes to intellectual work. ${ }^{\mathrm{I}}$

The shift in government policies is not the only factor that has put the issue of 'research in the arts' onto the agenda of public and academic debate; developments in art practice itself have also played a role. For some years now, it has been a commonplace to talk about contemporary art in terms of reflection and research. Although reflection and research were closely tied to the tradition of modernism from the start, they are also intertwined with art practice in our late modern or postmodern era - not only in terms of the self-perception of creators and performers, but increasingly in institutional contexts too, from

I. In Flanders, the 'academisation of higher professional arts education' is now being promoted under that very label. Collaborative arrangements between universities and professional arts schools are developing joint research programmes in the arts. 
funding regulations to the content of programmes at art academies and laboratories. Particularly in the last decade (following a period when 'cultural diversity' and 'new media' were the watchwords), research and reflection have been part of the verbal attire sported by both art practice and art criticism in public and professional fora on the arts. ${ }^{2}$ And so it could come to pass that 'research and development' are no longer an issue just for universities, businesses, and independent research centres and consultancy agencies, but that artists and art institutions are also now increasingly calling their activities 'research'. It is no coincidence that the art exhibition Documenta in Kassel presents itself as an 'academy', and that post-academic institutes like the Jan van Eyck Academie and the Rijksacademie van Beeldende Kunsten in the Netherlands are labelling their activities as 'research' and their participants as 'researchers'.

One of the issues figuring prominently in the debate about research in the arts is: When does art practice count as research? (and its possible corollary: Doesn't all art practice count as research to some extent?). Can criteria perhaps be formulated that can help to differentiate art practice-in-itself from art practice-as-research? And a concomitant question is: How does artistic research differ from what is called academic or scientific research? In the discussion to follow, I will try to introduce some clarity into the issue of research in the arts. I start by tracing the debate so far and citing the relevant sources. I then explore several terminological matters and the concept of 'research'. My analysis of the central question - the intrinsic

\footnotetext{
2. Another theme that has drifted ashore in the past decade is a rediscovered 'artistic engagement'.

3. The importance attached to $R \& D$ has been diminishing lately in the business world. Is the art world soon to follow?
} 
nature of research in the arts, especially in comparison to the currently more mainstream academic research - is based on the three perspectives referred to above: the ontology, the epistemology, and the methodology of research in the arts. I have already argued elsewhere in the Dutch context [reproduced in chapter I above] for direct and indirect public funding of research in the arts. In the present chapter, I will conclude my discussion by commenting on the aspects of this issue that pertain to educational politics and strategies - focusing primarily on the legitimacy of this type of research and on the implications that has for possible $\mathrm{PhD}$ programmes in professional art schools.

\section{The debate}

The granting of masters or doctorate degrees to artists (composers, architects, designers) on the basis of their art work is nothing new. It has been possible for decades in the United States, where a degree of this kind is often a prerequisite for appointments at professional arts institutions. ${ }^{4}$ It is common knowledge that these institutional constraints are not always beneficial to either the level of artistic practice on campus or the scholarly level of the staff. In the Netherlands it is possible to obtain a PhD at a university on the basis of a 'doctoral design' (proefontwerp), but artists have made little use of this option up to now. A new development, at least in terms of the European context, is that the

In Sweden, a new 'artistic doctorate' was introduced in 2010. Artists can now complete a third-cycle course at the national research school Konstnärliga Forskarskolan. In Norway, a national Artistic Research Fellowship Programme has been in operation since 2003. In Finland, a new doctorate programme will be launched in 20I2, supported by the three Helsinki art schools that are set to merge in 2013 . current institutional integration of research into professional art schools has made the distinctive nature of this 'practice-based research' into an item of debate.

This debate on art practice-as-research, and on the degree programmes in which that type of investigations can be carried out, has received a significant impetus from the university reforms made during the I990s in the United Kingdom and in Scandinavia. The academic and policy debates about research in the arts have

4. For criteria applying to practice-based masters and doctorate degrees in the USA, see, e.g. for the field of music, NASM 2010. 
therefore mainly taken place in those countries. In the UK, the reforms involved assigning the polytechnics (higher professional schools) officially equal status to the universities, thus enabling art schools to secure direct and indirect public funding for research (Candlin 200I). Comparable reforms occurred in Australia (cf. DEETYA 1998). In Scandinavia, some research programmes in professional arts schools now receive structural funding. Not all governments are ripe for these types of reforms just yet, and in some cases they are still tenaciously clinging to a rigid divide between academic education with research and professional training without research.

A second impetus, mainly relevant to the European continent, is the so-called Bologna Process - the ambition of the various member states of the European Community to forge a single framework for higher education, in three 'cycles' made up of bachelors, masters, and doctorate degree courses. The requirements in terms of learning outcomes that the three cycles will have to satisfy are currently being formulated, including the ones for arts education. One issue to be addressed in this process is the status and nature of the research in the creative and performing arts.

The first thing that is noticeable about the exchange of views about practice-oriented research in the arts is that the discussion mainly takes place within the fields of visual arts and design. It is less of an issue in the fields of theatre and dance education, architecture, and film and new media; and in music there was virtually no debate at all about practice-based research until recently. 5 The reason for that is pure speculation, but the fact remains that in the past Is years both the theoretical and philosophical dimensions of

This account has meanwhile been overtaken by reality. Artistic research is now on the agenda in all art disciplines. In music, the Orpheus Institute in Ghent is now home to a prominent research unit called овсім (Orpheus Research Centre in Music). The umbrella organisations ELIA (European League of Institutes of the Arts) and AEC (European Association of Conservatoires) offer platforms for artistic research. The academic network SHARE (Step-Change in Higher Arts Research and Education) was launched in 2010 under ELIA coordination, and EPARM (European Platform for Artistic Research in Music) was initiated in the AEC in 2OII.

5. Some discussion does seem to be stirring in the field of music in recent years. In 2004, a European network was set up consisting of music institutes with doctoral arts studies (MIDAS), and the AEC (European Association of Conservatoires) has also recently launched a working group to consider the doctoral (third) cycle. 
arts research and its more policy-related aspects have been the most widely debated in the world of visual arts and design.

The discussion - which, as noted, has been dominated by the situations in the UK and Scandinavia - has led to various forms of activity. An important source of information is the papers and reports produced by organisations involved in research funding and/or assessment, such as the UK Council of Graduate Education (UKCGE 1997, 200I), the Arts and Humanities Research Council (AHRB 2003; AHRC 2007), and the Research Assessment Exercise (RAE 2005), all in the UK. A number of

For a more recent overview of conferences, policy documents, and literature, see chapter 5 . The founding of the Journal for Artistic Research was an important juncture in the advancement of the field; see chapter II for an analysis of how it came into being.

conferences on arts research have also been convened, and their proceedings form a corpus of texts that have fed the debate. More and more journals are now publishing articles that deal with 'practice as research', and several collections of articles, monographs, and even manuals on research in the arts, and its methodology in particular, have appeared (among them Gray and Malins 2004; Sullivan 2005; Hannula, Suoranta, and Vadén 2005; Macleod and Holdridge 2006).

Two electronic mailing lists, $\mathrm{PhD}$-Design and PARIP, are also worth mentioning. PhD-Design is entirely devoted to discussions and

Ken Friedman, an active member of PhD-Design, corrected my description in e-mail correspondence in October 2010: 'The PhD-Design list is dedicated to discussion of PhD studies and related research in design.' This also includes practicebased research. information on developing practice-based doctoral degree courses in the field of design. PARIP (Practice as Research in Performance) is a project sponsored by AHRC at the University of Bristol that focuses mainly on topics involving practiceas-research, mostly in theatre and dance. In October 2002, a lively discussion took place on the PARIP list on a range of issues (institutional and organisational as well as more theoretical and philosophical) in relation to such research (see Thomson 2003 for a compilation of that discussion. $)^{6}$

The debate about research in the creative and performing arts has reached the rest of Europe in recent years. Not everyone, though, seems to realise that the issue we are just starting to confront has already been carefully considered in other countries. This is not to say that the 
correct answers by definition come from abroad. The art is always to learn from the insights and experiences that others have already gained.

\section{On terminology and research definitions}

\section{Terminology}

The essay that Christopher Frayling published in 1993 entitled Research in Art and Design introduced a distinction between types of arts research which has been referred to by many ever since. Frayling differentiated between 'research into art', 'research for art', and 'research through art'. ' I, too, will employ this trichotomy, albeit with a slightly different twist. I will distinguish between (a) research on the arts, (b) research for the arts, and (c) research in the arts.

a) Research on the arts is research that has art practice in the broadest sense of the word as its object. It refers to investigations aimed at drawing valid conclusions about art practice from a theoretical distance. Ideally speaking, theoretical distance implies a fundamental separation, and a certain distance, between the researcher and the research object. Although that is an idealisation, the regulative idea applying here is that the object of research remains untouched under the inquiring gaze of the researcher. Research of this type is common in the meanwhile established academic humanities disciplines, including

Although Frayling still serves as a point of reference for many, the 'twist' I gave was, and still is, not without reason. Frayling's 'research through art and design' 4 corresponds to my 'research for art'. It involves material research, experimental development, and practical action research. Frayling describes 'research for art and design' as follows: 'research where the end product is an artefact - where the thinking is, so to speak, embodied in the artefact, where the goal is not primarily communicable knowledge in the sense of verbal communication, but in the sense of visual or iconic or imagistic communication'. It thereby pertains to forms of thinking that are embodied in art and design. I believe this justifies my use of the term research in the arts.

6. There are also other projects, networks, and institutions focusing on this area. I will just mention two more groups in England that figure in the debate: the Performing Arts Learning and Teaching Innovation Network (PALATINE n.d.), based at Lancaster University (see e.g. Nelson and Andrews 2003); and the Research Training Initiative (RTI n.d.), based at Birmingham Institute of Art and Design. The PARIP (n.d.), PALATINE, and RTI websites contain broad-ranging bibliographies. Websites for all the projects, networks, and mailing lists mentioned in this paper can readily be found via any search engine.

7. Frayling 1993; Frayling's distinction referred in its turn to one made by Herbert Read in 1944 between 'teaching through art' and 'teaching to art'. 
musicology, art history, theatre studies, media studies, and literature. ${ }^{8}$ Social science research on the arts likewise belongs to this category. Looking beyond all the differences between these disciplines (and within the disciplines themselves), the common characteristics of these approaches are 'reflection' and 'interpretation' - whether the research is more historical and hermeneutic, philosophical and aesthetic, critical and analytic, reconstructive or deconstructive, descriptive or explanatory. Donald Schön (1982: 49-69, 275-83) has used the expression 'reflection on action' to denote this approach to practice. I have previously described it as the 'interpretive perspective' [see chapter I].

b) Research for the arts can be described as applied research in a narrow sense. In this type, art is not so much the object of investigation, but its objective. The research provides insights and instruments that may find their way into concrete practices in some way or other. Examples are material investigations of particular alloys used in casting metal sculptures, investigation of the application of live electronics in the interaction between dance and lighting design, or the study of the 'extended techniques' of an electronically modifiable cello. In every case these are studies in the service of art practice. The research delivers, as it were, the tools and the knowledge of materials that are needed during the creative process or in the artistic product. I have called this the 'instrumental perspective'.

c) Research in the arts is the most controversial of the three ideal types. Donald Schön speaks in this context of 'reflection in action', and I earlier described this approach as the 'immanent' and 'performative perspective'. It concerns research that does not assume the separation of subject and object, and does not observe a distance between the researcher and the practice of art. Instead, the artistic practice itself is an essential component of both the research process and the research results. This approach is based on the understanding that no fundamental separation exists between theory and practice in the arts. After all, there are no art practices that are not saturated with experiences, histories, and beliefs; and

8. In recent years these disciplines are also addressing what we might call the 'performativity of the theoretical gaze'. An example in theatre studies is a conference held in Amsterdam entitled 'The Anatomical Theatre Revisited' (ATR 2006). 
conversely there is no theoretical access to, or interpretation of, art practice that does not partially shape that practice into what it is. Concepts and theories, experiences and understandings are interwoven with art practices; and, partly for this reason, art is always reflexive. Research in the arts hence seeks to articulate some of this embodied knowledge throughout the creative process and in the art object.

Various terms and expressions have been used in the literature to denote artistic research. The most common of these are 'practice-based research', 'practice-led research', and 'practice as research'. Practice-based research is a collective notion that may cover any form of practice-oriented research in the arts. The AHRC currently prefers the term practice-led research to denote research that is practice-focused, and many are now following that example. The most explicit term of all is practice as research, as it expresses the direct intertwinement of research and practice as discussed under (c) above. The expression 'artistic research', which is sometimes chosen to highlight the distinctiveness of art research, evinces not only a comparable intimate bond between theory and practice, but also embodies the prom-

On the European continent and in Scandinavia, the expression 'artistic research', or equivalents in translation, is increasingly prevalent (even though it may sound peculiar to native English speakers). ise of a distinctive path in a methodological sense that differentiates artistic research from the more mainstream academic research.

It has been argued from various perspectives that the trichotomy proposed above - research on, for, and in the arts - does not exhaustively describe the possible forms of artistic research. ${ }^{9}$ After all, isn't one distinctive characteristic of the arts, and hence too of the research tied up with it, their very ability to elude strict classifications and demarcations, and to actually generate the criteria - in each individual art project and every time again and again - which the research is to satisfy, both in the methodological sense and in the ways the research is explained and documented? In this particular quality, it is argued, lies one of the major dis-

9. My colleague Marijke Hoogenboom, for example, in her remit at the Amsterdam School of the Arts, attempts to approximate what research could potentially be, starting from current artistic practice and arts education practice. 
tinctions vis-à-vis what is customary in the academic world - a fundamental openness for the unknown, the unexpected, which can also form a corrective to what is currently regarded as valid research.

This argument is based on a specific and limited concept of what scholarship and science are. More particularly, it assumes that mainstream scientific research is always based on an established protocol and that universal criteria exist for the validity of research. This derives from a misconception. Not only do academic researchers often develop the appropriate research methods and techniques as they go, but the rules for the validity and reliability of the research results also do not derive from some standard that is external to, and hence independent of, the research; they are defined within the research domain itself. Science at its best is less rigid and constrained than some participants in the debate would like to believe.

Obviously this overarching differentiation of three types of art research does not yet say very much. In the case of 'research in the arts', to which we are confining ourselves here, we still have to answer the question of when art practice qualifies as research. What do we mean here by 'research', and what criteria can we formulate to distinguish art practice-in-itself from art practice-as-research? ${ }^{\text {10 }}$ Before addressing the question of what we should understand by research, I would just like to comment briefly on the classifications used in art practice itself.

In the arts we are accustomed to differentiating in terms of activity or role (music, theatre), dimension (visual art), and various other aspects. The music world distinguishes, for example, between composing, performing, and improvising; ${ }^{\text {II }}$ the theatre world distinguishes between actors and directors, playwrights and stage designers; in the visual arts we can differentiate between two-dimensional, three-dimensional, and audiovisual work; and so on. In the debate about art re-

Io. The idea that all art practice is by definition research might sometimes be useful for underlining the reflexive nature of art, and it may arise in the uncertain quest contained in the creative process, but it is not fruitful for bringing clarity into the debate about research in the arts. If everything is research, then nothing is research any more. II. A fourth category could be called 'hybrid activities', inasmuch as, especially in the case of contemporary music, no clear distinction can be made between composing, performing, and improvising. 
search, it has proven fruitful to employ a different distinction - that between object, process, and context. Object then stands for the 'work of art': the composition, the image, the performance, the design, as well as for the dramatic structure, the scenario, the stage setup, the material, the score. Process stands for the 'making of art': creating, producing, rehearsing, developing images and concepts, trying out. Context stands for the 'art world': the public reception, the cultural and historical environment, the industry, et cetera. ${ }^{12}$ Especially in the assessing (and funding) of research in the arts, it makes quite some difference whether one exclusively examines the results in the form of concrete art objects, or whether one also looks at the documentation of the process that has led to those results or at the context which is partially constitutive of the meaning of both the object and the process.

\section{Research definitions}

The Research Assessment Exercise and the Arts and Humanities Research Council both employ research definitions (albeit different ones) that enable them to judge research projects in terms of eligibility criteria. I am intentionally drawing here again on the UK situation, because the official bodies charged with funding research there are explicit about their assessment standards. The definition of the RAE (2005:34) is briefly: 'original investigation undertaken in order to gain knowledge and understanding. ${ }^{13}$

For the Research Excellence Framework, which will supersede the RAE in 20I4, the short definition is '.. a process of investigation leading to new insights, effectively shared'. The rest of the definition ('It includes work ...') remains unchanged. RAE, Assessment Framework and Guidance on \Submissions, July 2011.

I2. As the visual artist Robert Klatser has pointed out to me, object, process, and context cannot be, or at least not always, distinguished from one another in the experience of the artists themselves, in their practice of art creation. Yet such a counterfactual distinction is an aid to clarification, and it helps to guide and regulate research practices.

I3. The full text is " Research" for the purpose of the RAE is to be understood as original investigation undertaken in order to gain knowledge and understanding. It includes work of direct relevance to the needs of commerce, industry, and to the public and voluntary sectors; scholarship; the invention and generation of ideas, images, performances, artefacts including design, where these lead to new or substantially improved insights; and the use of existing knowledge in experimental development to produce new or substantially improved materials, devices, products and processes, including design and construction.' 
If we also take this broad definition of research as a benchmark for research in the arts - and I see no reason not to do so as of yet then we can use it to derive the following criteria. (I) The investigation should be intended as research. Inadvertent (fortuitous) contributions to knowledge and understanding cannot be regarded as research results (cf. Dallow 2003). (2) Research involves original contributions - that is, the work should not previously have been carried out by other people, and it should add new insights or knowledge to the existing corpus (for a problematisation of this criterion, see Pakes 2003). (3) The aim is to enhance knowledge and understanding. Works of art contribute as a rule to the artistic universe. That universe encompasses not only the traditional aesthetic sectors; today it also includes areas in which our social, psychological, and moral life is set in motion in other ways - other performative, evocative, and non-discursive ways. We can hence speak of research in the arts only when the practice of art delivers an intended, original contribution to what we know and understand. ${ }^{\mathrm{I}}$

The Arts and Humanities Research Council (AHRB 2003, AHRC 2007) works with a different set of criteria to assess research proposals. This stems from the fact that the AHRC, in contrast to the RAE, does not judge the results of research in retrospect and does not assess outcomes, but looks primarily at what the research is to involve and how the study is to be designed (hence, assessment in advance). Four criteria are set as parameters. (I) The research must address clearly articulated research questions or problems. (2) The importance of these questions and problems for a specified research context must be explained, including the contribution the project will make and how the study will relate to other research in the area. (3) One or more research methods are to be specified that will be applied to address, and possibly answer, the questions and problems. (4) The results of the research study and the re-

I4. The Dublin Descriptors (JQI 2004), which set out educational criteria under the Bologna Process, define research in a comparable manner: 'a careful study or investigation based on a systematic understanding and critical awareness of knowledge'. This ostensibly broader definition of research is later, when the requirements for $\mathrm{PhD}$ research are discussed, narrowed down to read 'original research that extends the frontier of knowledge'. 
search process are to be appropriately documented and disseminated. It goes without saying that research questions, context, methods, documentation, and dissemination are all subject to change in the course of the study, but the assessment is based on the proposal for the study design at its inception.

Taken altogether, the definitions above provide discriminating criteria for assessing whether activities qualify as research: intent, originality, knowledge and understanding, research questions, context, methods, and documentation and dissemination. We can now employ these criteria to address the question of how art practice-as-research can be distinguished from art practice-in-itself. I shall do this in the form of a proposition which I hope others may see fit to challenge:

Art practice qualifies as research when its purpose is to broaden our knowledge and understanding through an original investigation. It begins with questions that are pertinent to the research context and the art world, and employs methods that are appropriate to the study. The process and outcomes of the research are appropriately documented and disseminated to the research community and to the wider public.

This 'definition' itself is little help as of yet. How do we know in our research, for example, what methods are 'appropriate to the study', and what 'appropriately documented' entails?' Opinions diverge on points like these in the debate on art research. The definition does at least furnish us with a negative criterion that we can use to distinguish art practice-in-itself (or protect it, if need be) from art practice intended-as-research. The next question is at least as important: In what respects does this type of research differ from the more mainstream academic research?

15. Does a visual portfolio suffice for a visual art project, for example, or is a verbal report or explanation always necessary to explain the study? 


\section{The intrinsic nature of research in the arts}

The issue of the intrinsic nature of research in the arts can indeed best be addressed by also asking how that type of research differs from what we normally understand by scholarly or scientific research (cf. e.g. Eisner 2003). That does not mean we ought to conform in advance to the frameworks defined by traditional scholarship or science, but it also does not mean we should counterpose something to that form of scholarship that eludes those frameworks by definition. Perhaps it does mean that

A modified notion of what academic research is.'

This broaches a new theme that will pervade the chapters to follow and that forms part of the theoretical and political 'agenda'. The introduction of artistic research into academia is not a disinterested operation. It alters (widens, enriches) our conception of academia, of what academic research is. At the moment when non-discursive (embodied) forms of knowledge, unconventional research methods, and alternative ways of documenting and communicating make their entry into academic research, changes ensue in the way that academia conceives of itself. Artistic research does not stand alone here. Allies can be found in areas such as cultural studies, visual anthropology, performance ethnography, and the cognitive sciences. we, in dialogue with that type of scholarship, will arrive at a modified notion of what academic research is. And there is nothing new about this: the history and theory of science have taught us that principles once considered absolute standards can be tempered under the influence of ascendant domains of knowledge, after which they remain as standards for one particular form of academic scholarship.

There are three ways to ask what makes art research distinctive in relation to current academic and scientific research: by posing an ontological, an epistemological, and a methodological question. The ontological question is (a): What is the nature of the object, of the subject matter, in research in the arts? To what does the research address itself? And in what respect does it thereby differ from other scholarly or scientific research? The epistemological question is (b): What kinds of knowledge and understanding are embodied in art practice? And how does that knowledge relate to more conventional types of academic knowledge? The methodological question is (c): What research methods and techniques are appropriate to research in the arts? And in what respect do these differ from the methods and techniques in the natural sciences, the social sciences, and the humanities?

Obviously one should not expect all these questions to be answered within the confines of this chapter. What I shall do below is to 
define the space inside which the answers can be given. These parameters could be an aid in the struggle for legitimacy and autonomy for the research domain of the arts.

\section{The ontological question}

As I have argued above, it is useful to distinguish objects, processes, and contexts when dealing with art practices. But the practice of art involves more than that. Artistic practices are at once aesthetic practices, which mean that matters such as taste, beauty, the sublime, and other aesthetic categories may be at issue and could form part of the subject matter for study. In addition, artistic practices are hermeneutic practices, because they always lend themselves to multiple or ambiguous interpretations and even invite them (cf. DEETYA I998: 46). Artistic practices are performative practices, in the sense that artworks and creative processes do something to us, set us in motion, alter our understanding and view of the world, also in a moral sense. Artistic practices are mimetic and expressive when they represent, reflect, articulate, or communicate situations or events in their own way, in their own medium. By virtue of their very nature, artistic practices are also emotive, because they speak to our psychological, emotional life. So whenever we have to do with artistic practices, all these perspectives could be at work. Not every artistic investigation will deal with all these points of view at once, but theoretically any of them could figure in the research.

As noted above, the focus of research in the arts may lie on the artwork itself or on the creative, productive process, in both of which cases the signifying context also plays a role. In the debate about artistic research, there is a tendency to emphasise the productive process, because it can potentially be replicated, or in any case documented. This spotlight on the process also derives from the requirements that some funding bodies set for the studies - in assessing proposals, they are often chiefly interested in what the study design will be like, whether the work will be methodologically sound, whether the research questions are meaningful in the research context, and how the research process will be documented and the results disseminated. The artistic outcomes in the form of concrete works of art are, after all, more difficult to 'objectively' assess than the rigour with which the research process is de- 
Notwithstanding this differentiation between types of facts, a hypostatisation of facts seems to occur here. Actually there are no pure scientific, social, historical, or artistic facts. All facts are also made, and are not merely given - they are facta, not data - and the making also involves the non-factual. As I shall argue in chapter 7 , the artistic universe is historically and systematically contingent. It is dependent on where, how, and by whom or what it is constituted.

signed and documented. The risk is that works of art will totally disappear from sight, as if research in the arts has nothing to do with the art itself. ${ }^{16}$ In respect of ontology, different types of academic research are concerned with different kinds of facts. Scientific facts differ from social facts, and both differ from historical facts. Artistic facts have their own intrinsic status which cannot be conflated with scientific, social, or historical facts, and which has been described in a range of different ways in philosophical aesthetics. One element of that status is its immateriality. More precisely, what is characteristic for artistic products, processes, and experiences is that, in and through the materiality of the medium, something is presented which transcends materiality. This insight, which recalls Hegel's sensory manifestation of the idea (sinnliches Scheinen der Idee), is also valid, paradoxically enough, even there where art professes to be purely material and resists any transcendence, as witnessed by the evolution of movements like the historical avant-garde or like minimalist or fundamental art. Research in the arts devotes attention to both: to the materiality of art to the extent that it makes the immaterial possible; and to the immateriality of the art to the extent that it is embedded in the artistic material.

Beyond the object and process of art research, the importance of context should also be underlined. Artistic practices do not stand on their own; they are always situated and embedded. No disinterested understanding of art practice is possible, or even a naive gaze. And conversely, no art practices exist that are not saturated with experiences, histories, and beliefs. Research in the arts will remain naive unless it acknowledges and confronts this embeddedness and situatedness in history, in culture (society, economy, everyday life), as well as in the discourse on art.

To summarise, art research focuses on art objects and creative processes. This can involve aesthetic, hermeneutic, performative, ex-

I6. Cf. Biggs 2003, and especially Pakes 2004, the latter of whom, citing Gadamer, urges a return to the work of art as an object of research. 
pressive, and emotive points of view. If the focus of investigation is on the creative process, one should not lose sight of the result of that process - the work of art itself. Both the material content and the immaterial, non-conceptual, and nondiscursive contents of creative processes and artistic products may be articulated and communicated in the research study. In all cases, art research should examine the embeddedness and situatedness of its object of investigation.

\section{The epistemological question}

With what kind of knowledge and understanding does research in the arts concern itself? And how does that knowledge relate to more conventional forms of scholarly knowledge? The short answer to the first question is: knowledge embodied in art practices (objects, processes). The answer to the second question will provide a closer understanding of what 'embodied knowledge' may be.

A first avenue of approach derives from a tradition, extending back to Greek antiquity, which distinguishes theoretical knowledge from practical knowledge. As early as Aristotle, the concept of episteme, intellectual knowledge, was contrasted with techne, practical knowledge required for making (poiesis) and doing (praxis). The concept of phronesis, or practical wisdom, in particular the knowledge of how to conduct oneself (particularly in a moral sense), can also be understood in opposition to intellectual knowledge, which was known to be deficient when it came to worldly wisdom (Carr 1999; Kessels and Korthagen 200I). In the twentieth century, this opposition was thematised in analytic philosophy as that between 'knowing that' and 'knowing how', between knowledge and skill. Notably Gilbert Ryle (1949), and after him Michael Polanyi (1958, 1967) and the art theoretician David Carr (1978, 1999), elevated practical knowledge - which, being tacit, implicit knowledge, finds no direct discursive or conceptual expression - to an epistemologically equal footing, and Polanyi even saw it as the foundation of all knowledge.

Since Alexander Baumgarten, the knowledge embodied in art has been a subject of speculation and reflection in philosophical aesthetics 
I will briefly touch on the kinship between artistic research and aesthetics in the 'Aesthetics' subsection of chapter 7 , pages I5I-54. Their relationship deserves to be investigated further.

as well. The non-conceptual knowledge embodied in art has been analysed in many different ways: in Baumgarten as 'analogon rationis', through which great art is able to manifest perfect sensory knowledge; in Immanuel Kant as 'cultural value' (Kulturwert), the quality through which art gives food for thought and distinguishes itself from mere aesthetic gratification of the senses; in Friedrich W.J. Schelling as the 'organon of philosophy', the art experience that rises above every conceptual framework and is the only experience that can touch on the 'absolute'; in Theodor W. Adorno as the 'epistemic character' (Erkenntnischarakter), through which art 'articulates' the hidden truth about the dark reality of society; and also in postmodern contemporaries like Jacques Derrida, Jean-François Lyotard, and Gilles Deleuze, who, each in their own way, counterpose the evocative power of that which is embodied in art to the restricting nature of intellectual knowledge.

Some contributors to the debate on the specificity of research in the arts entertain the belief that art comes into being purely on the basis of intuition, on irrational grounds, and via non-cognitive routes, and that this makes it inaccessible for investigation from within. This misconception arises when the non-conceptual content of artistic facts be-

This is a crucial passage. It involves the cognitive claim made by research that has non-discursive and non-conceptual characteristics. comes confused with their presumed non-cognitive form, and when the non-discursive manner in which that content is presented to us is presumed to betray its irrationality. Yet the phenomena at work in the artistic domain are decidedly cognitive and rational, even if we cannot always directly access them via language and concepts. Part of the specificity of art research therefore lies in the distinctive manner in which the non-conceptual and non-discursive contents are articulated and communicated.

The epistemological issue of the distinctive character of art knowledge is also addressed by phenomenology, by hermeneutics, and by the cognitive sciences. In the work of Maurice Merleau-Ponty, embodied knowledge is also concretely 'bodily knowledge'. The a priori of the body assumes the place of the a priori of intel-
For a discussion of the importance of the phenomenological legacy and its influence on the cognitive sciences, see the final section of chapter 7 . 
lectual knowledge, making the prereflexive bodily intimacy with the world around us into the foundation of our thinking, acting, and feeling. In the context of the current debate, Merleau-Ponty's insights have had strong influence in theatre studies (particularly dance studies; see e.g. Parviainen 2002) and also in gender studies.

I have already mentioned hermeneutics as a vehicle for accessing what is at work in art. The fundamental ambiguity of artworks renders interpretation an unfinished process in which the interpreter and the interpreted temporarily melt together in ever-receding interpretative horizons. This 'effective history' (Wirkungsgeschichte), as Hans-Georg Gadamer has called it, enables the productive interpretation of art research to generate new meanings, embodied in concrete works of art.

Embodied knowledge has also been one of the focuses of research in the field of cognitive psychology, as in the work of Howard Gardner (1985) on multiple intelligence or that of Hubert Dreyfus (1982) on artificial intelligence. The zone between cognition and creativity is now even under exploration in collaborative projects between scientists and artists. ${ }^{17}$

In sum, the knowledge embodied in art, which has been variously analysed as tacit, practical knowledge, as 'knowing-how', and as sensory knowledge, is cognitive, though non-conceptual; and it is rational, though non-discursive. The distinctive nature of the knowledge content has been analysed in depth in phenomenology, hermeneutics, and cognitive psychology.

\section{The methodological question}

Before I turn to the question of which methods and techniques of investigation are appropriate to research in the arts, and in what respects they may differ from those in other scholarly domains, it seems wise to draw a distinction between the terms 'method' and 'methodology'. In the debate on research in the arts, the term 'methodology' is frequently used at times when one simply means 'method' in the singular or plural. Although 'methodology' may sound more weighty, the procedures it refers to can usually be less mystifyingly called 'methods'. I am fol-

I7. See for example Choreography and Cognition (cC n.d.). 
lowing here the suggestion made by Ken Friedman in an exchange of views about research training in the arts, when he proposed using 'methodology' exclusively to refer to the comparative study of methods. ${ }^{18} \mathrm{~A}$ 'method' is then simply a well-considered, systematic way of reaching a particular objective.

The central question here is: Is there a characteristic, privileged way of obtaining access to the research domain of art practice and the knowledge embodied in it, a route that could be denoted by the term 'artistic research'? Under what premises can such research be done, and, in conjunction with this, should such research orient itself to or conform to approved academic (or scientific) standards and conventions? Here, too, opinions in the debate differ widely, and it is not always clear whether a person's stance is informed by considerations pertinent to the issue or by motives that are essentially extraneous to art research. Individuals and institutions that have an interest in using partly institutional means to protect their activities, for example against the bureaucratic world of the universities, may be more inclined to adopt an

The shortest definition of artistic research I have come across is used by the Orpheus Institute in Ghent: 'Artistic research is research where the artist makes the difference.' 'independent' course than those who are less afraid of selling their body and soul.

One distinction from more mainstream scholarly research is that research in the arts is generally performed by artists. In fact, one could argue that only artists are capable of conducting such practice-based research. But if that is the case, objectivity then becomes an urgent concern, as one criterion for sound academic research is a fundamental indifference as to who performs the research. Any other investigator ought to be able to obtain the same results under identical conditions. Do artists have privileged access to the research domain, then? The answer is yes. Because artistic creative processes are inextricably bound up with the creative personality and with the individual, sometimes idiosyncratic gaze of the artist, research like this can best be performed 'from within'. Moreover, the activity at issue here is research in art practice, which implies that

I8. See Ken Friedman's 9 April 2002 contribution to the PhD-Design mailing list (PhD-

Design n.d.). 
creating and performing are themselves part of the research process so who else besides creators and performers would be qualified to carry them out? Now this blurring of the distinction between subjects and objects of study becomes further complicated by the fact that the research is often of partial, or even primary, benefit to the artist-researcher's own artistic development. Obviously there must be limits. In cases where the impact of research remains confined to the artist's own oeuvre and has no significance for the wider research context, then one can justifiably ask whether this qualifies as research in the true sense of the word.

Just as with the ontology and epistemology of research in the arts, the issue of methodology may also be further clarified by a comparison with mainstream scholarship. Taking the broad classification into three academic domains as a reference, we can make the following rough generalisations about the different methods associated with them. As a rule, the natural sciences have an empirical-deductive orientation; that is, their methods are experimental and are designed to explain phenomena. Experiments and laboratory settings are characteristic of natural science research. The social sciences are likewise empirically oriented as a rule; their methods are usually not experimental, however, but are primarily designed to describe and analyse data. Quantitative

Much of the noteworthy research done today is interdisciplinary or transdisciplinary. New fields of research materialise in a productive combination of different disciplines, e.g. molecular biology, environmental studies, or science and technology studies. Transdisciplinary research extends out of academia into other life domains, and it integrates perspectives from the 'wider world' into the research - both in the methodological and epistemological senses and in the valorisation of the research. In chapter 4 , pages 9I-92, I will investigate to what extent artistic research is transdisciplinary; in chapter II, pages 235-36, I will examine the transdisciplinary nature of artistic research more closely in the context of JAR. and qualitative analysis exemplify social science research. One method developed in the social science disciplines of ethnography and social anthropology is participant observation. This approach acknowledges the mutual interpenetration of the subject and object of field research, and might serve to an extent as a model for some types of research in the arts. The humanities are as a rule more analytically than empirically oriented, and they focus more on interpretation than on description or explanation. Characteristic forms of research in the humanities are historiography, philosophical reflection, and cultural criticism. 
The contrasts and interrelationships with other academic disciplines will be discussed in more detail in chapter 7 .

If we compare various fields of scholarship with one another and ask (I) whether they are exact or interpretive in nature, (2) whether they seek to identify universal laws or to understand particular and specific instances, and (3) whether experimentation plays a part in their research, then we arrive at the following schematic structure. ${ }^{19}$ Pure mathematics is generally an exact, universally valid, and non-experimental science. The natural sciences likewise seek to generate exact knowledge that corresponds to universal laws or patterns, but which, contrary to mathematical knowledge, is often obtained by experimental means. These can be contrasted with art history (to cite just one example from the humanities), which is not primarily interested in formulating precise, universal laws, but more in gaining access to the particular and the singular through interpretation. Experimentation plays virtually no role there at all.

The distinctive position that arts research occupies in this respect now comes into view. Research in the arts likewise generally aims at interpreting the particular and the unique, but in this type of research practical experimentation is an essential element. Hence, the answer to the question of art research methodology is briefly that the research design incorporates both experimentation and participation in practice and the interpretation of that practice.

In summary, research in the arts is performed by artists as a rule, but their research envisages a broader-ranging impact than the development of their own artistry. Unlike other domains of knowledge, art research employs both experimental and hermeneutic methods in addressing itself to particular and singular products and processes.

If we now take together these explorations of the ontological, epistemological, and methodological facets of research in the arts and

19. I am indebted here to Nevanlinna (2004). I agree with the author in acknowledging that the comparison is rather rough. Moreover, especially in view of the evolution of modern science and recent insights in the philosophy of science, classifications like these should definitely be viewed with scepticism. For example, it is very common today, particularly for non-physicists, to point to the incommensurable paradigms of quantum mechanics, relativity theory, and classical mechanics in order to emphasise the interpretive nature of scientific knowledge. 
condense them into one brief formula, we arrive at the following characterisation:

Art practice - both the art object and the creative process - embodies situated, tacit knowledge that can be revealed and articulated by means of experimentation and interpretation.

In conjunction with the earlier answer to the question of how art practice-as-research can be distinguished from art practice-in-itself, we now arrive at the following definition:

Art practice qualifies as research if its purpose is to expand our knowledge and understanding by conducting an original investigation in and through art objects and creative processes. Art research begins by addressing questions that are pertinent in the research context and in the art world. Researchers employ experimental and hermeneutic methods that reveal and articulate the tacit knowledge that is situated and embodied in specific artworks and artistic processes. Research processes and outcomes are documented and disseminated in an appropriate manner to the research community and the wider public.

\section{Coda: Legitimacy}

Research on the supervision of practice-based research projects in the arts (Hockey and Allen-Collinson 2000; Hockey 2003) has shown that one difficulty experienced by both $\mathrm{PhD}$ candidates and their supervisors lies in the distrust and scepticism of those around them - individuals in their own institutions as well as those in wider circles - with respect to research of this type. Those involved in art research often have to 'sell' their research as a credible endeavour, and to consume much time and energy in having to repeatedly explain to all sorts of individuals and authorities what the research involves and what the rationale of this type of research is. Overcoming institutional barriers and persuading other people claim a disproportionate amount of time, quite apart from the fact that this usually has little to do with the actual topic of research. And the burden of proof always rests with the 'novices', 
whereas the legitimacy of mainstream academic research is seldom fundamentally challenged.

The issue culminates in the question of whether research in which the creation of art is intermeshed with the research process is indeed serious scholarly research, and whether it is $\mathrm{PhD}$-worthy (Candlin 2000a, 200ob). Some would argue that although research-like art practices in themselves can or do have value - a value comparable or even equivalent to that of scholarly research - we are nevertheless dealing with two unlike endeavours: true research on the one hand, and on the other hand an activity that must be kept distinct from research, even if it might be of equivalent value from a societal or other viewpoint. Opinions differ on this point in the debate on practice-based doctorates in the arts. Frayling (in UKCGE 1997), Strand (DEETYA 1998), and others have argued in this connection for introducing the concept

This still remains an issue. Is the Swedish artistic doctorate (konstnärlig doktorsexamen) equivalent to, or is it equal to, a $\mathrm{PhD}$ ? of 'research equivalence'. I would suspect that one motive of the 'research equivalence' proponents may be that practice-based research, with its non-discursive, performative, and artistic qualities, will then no longer have to be 'sold'.

Because art practices, irrespective of whether they present themselves as research, are considered of value to our culture, another argument goes, the practitioners perhaps deserve to be rewarded with a higher education degree as well as with funding - but the name of that degree ought to make clear that it is not based on 'true' scholarly research; in other words, it should not be a PhD but some sort of 'professional doctorate'. The distinction between $\mathrm{PhDs}$ and professional doctorates has existed in the United States for some time. Basically one could argue that the research-oriented academic world in that country regards professional doctorates as inferior, whereas the professional art world tends to look down on the more 'academic' degrees like MAs and PhDs.

In addition to equivalence, another theme in the $\mathrm{PhD}$-versus-PD debate in the arts involves the nature and orientation of the doctoral degree. Those who are inclined to compare research in the arts to endeavours like technical, applied research or design research will be more likely to argue for a professional doctorate than those who would em- 
phasise the kinship between art research and humanities or cultural studies research. Another proposal, partly aimed at avoiding an unwanted proliferation of titles and to keep the system of degrees transparent, is to introduce a so-called inclusive model (see e.g. UKCGE 1997: 2O-2I). The PhD would then signify that its holder is capable of conducting research at the highest level, but would leave open whether that was 'pure' academic research or practice-based research. The entire spectrum from theoretical research to design research, from the natural sciences to classical studies, from dentistry, food quality management, and civil engineering to theology, fiscal law, and creative arts, could all be encompassed within that $\mathrm{PhD}$ degree.

The misgivings about the legitimacy of practice-based research degrees in the creative and performing arts arise mainly because people have trouble taking research seriously which is designed, articulated, and documented with both discursive and artistic means. The difficulty lurks in the presumed impossibility of arriving at a more or less objective assessment of the quality of the research - as if a specialised art forum did not already exist alongside the academic one, and as if academic or scientific objectivity itself were an unproblematic notion. In a certain sense, a discussion is repeating itself here that has already taken place (and still continues) with respect to the emancipation of the social sciences: the prerogative of the old guard that thinks it holds the standard of quality against the rights of the newcomers who, by introducing their own field of research, actually alter the current understanding of what scholarship and objectivity are.

If the comparison with the emancipation of the social sciences is at all valid, then there is still a long way to go. Even after two centuries of debate about the fundamental premise of social science, some people, both inside and outside the universities, still question the autonomy (and legitimacy) of that domain of knowledge. On the other hand, the rapid development of a new discipline like cultural studies may also give cause for optimism. Perhaps I would be going too far to call for a paradigm shift, but I do know for sure that a shift in thinking is needed in the minds of some people. We knew we would face tough resistance, and though that may dampen our spirits from time to time, it is a challenge we can meet. 


\section{Chapter 3}

Artistic

Research and

Academia:

An Uneasy

Relationship 



\section{Context}

This chapter is an expanded version of a contribution I made to 'Music and Ideas Worldwide: A Symposium on Practice-Based Research' held at the Royal College of Music, London, on 24 October 2007. It enabled me to put into words some of my experiences during the creation of docARTES, the doctorate programme for musicians, as well as to look back at the conference 'The Third Cycle: Artistic Research after Bologna', which I had organised in Amsterdam's Felix Meritis centre on IO-II October 2007. The chapter introduction entitled 'Artistic Research and Academia' contains a hidden polemic with the stances adopted by some Dutch postgraduate institutes. At the end of the chapter, I introduce two themes - contingency and realism - that will return in chapter 5 and particularly in chapter 7 . 


\section{Artistic research and academia}

There is something uneasy about the relationship between 'artistic research' and the academic world. This has led some people largely to exclude artistic research from the realm of higher education and research and assign it, instead, to art institutions that serve art practice directly - such as funding bodies, postgraduate artists' laboratories, or exhibition venues. It has prompted others to work from within to expand or redefine the prevailing conception of academic or scientific research from the perspective of artistic research. Both these strategic and political agendas have their merits, but also their shortcomings.

In the former strategy, artistic research is in danger of becoming isolated from the settings in which society has institutionalised thinking, reflection, and research - particularly the universities. Under a guise of artistic nonconformity and sovereignty, some people put up resistance to the supposed disciplining frameworks of higher education and research. Let us not get into arguing about whether the word 'research' can justifiably be used here, or whether the idiosyncratic undertakings and appropriations that are so peculiar to the artistic quest might better be called explorations and discoveries. It is not uncommon to see superficial, theory-meagre borrowings from what happens to be on offer in intellectual life being put to use in artistic production.

In principle, of course, there is nothing wrong with that. After all, much is permissible in the context of artistic discovery that would not withstand the test of academic justification (the same can, incidentally, be said of mainstream research as well). Yet the logic and the internal dynamics of art practice do, in fact, differ from those of most academic disciplines - which at least keep up the pretension that explorations, findings, and insights need to be somehow connected to theoretical justification or further thought.

The question that needs addressing now is whether this type of 'research' (whatever one may think of it otherwise) does not actually prosper best in educational settings - in this case, institutions of higher education in the arts. The insistence with which some institutes claiming to conduct artistic research are positioning themselves outside the sphere of education (often driven by an unfounded, hyped-up Bolognaphobia) leads one to suspect that more is at play than mere oppor- 
tunistic protectionism. The vehement resistance to the 'education system' and 'academisation' seems also to be fuelled by a limited understanding of what higher education in the arts really is, or could be.

This educational field does have trouble

I used the same wordings in drafting the mission statement of the Amsterdam School of the Arts (АHK). I am aware that there is a difference between a task one sets for oneself and the ways it gets implemented in practice.

constantly reinventing itself in confrontation with the state of the art in practice; 'academism' is always a lurking danger. But at the same time, higher education in the arts is - or ought to be the place where the cultural past meets current practice, and the future is prepared; questions are asked that have no answers yet; and respect for the continuously reassessed wealth of cultural tradition joins with a keen sense of the urgent and with the exploration of the uncharted.

Artistic research benefits when carried out in such a context. Arts education also - fully consistent with Humboldtian ideals - benefits from the inspiration and impulses it receives from developments in artistic research practices. One already distinguishing feature of arts education (especially compared with what is customary in most of the higher education system) is its in-house integration of training with practice, as artists make their current work into part of the educational subject-matter. These bonds with art practice can be tightened further (a constant need) by creating links between artists' research practices and teaching practices at the academies. A fine example of such productive alliances may be witnessed in the research fellowship programmes now operating in the UK and in Norway. A modest start has been made in the Netherlands, too, by enabling artists to hold research posts in arts institutes. ${ }^{\mathrm{I}}$

The second strategy of positioning artistic research in academia is similarly problematic. Hypothetically, the introduction of artistic research into an academic environment could broaden and enrich our

I. I refer here to the Arts and Humanities Research Council Fellowships in the Creative and Performing Arts (AHRC n.d.), the National Norwegian Artistic Research Fellowships Programme (NARF n.d.), and the Artists in Residence programme (AIR n.d.) initiated by the Art Practice and Development Research Group at the Amsterdam School of the Arts. 
conception of what academic or scientific research truly is. ${ }^{2}$ On the face of it, universities would potentially benefit from the methods and perspectives characteristic of artistic research. ${ }^{3}$ To give an example, university research traditions as a rule devote little attention to the haphazard manner in which research paths are navigated and research results actually come about. In terms of both methodology and knowledge dynamics, the focus on the creative process that is characteristic of research in the arts, as well as the characteristic linkage and interpenetration of artistic practice and theoretical reflection, of doing and thinking, would be a valuable asset to universities. Furthermore, in artistic 'knowledge production', the emphasis lies on non-discursive modes of world disclosure embodied in concrete artefacts. Hence, in an epistemological sense as well, artistic research would provide a benefit, or even a correction to what many people regard as the doings and dealings in mainstream science and research.

But this positioning of artistic research also has its shortcomings. By this I am not referring to the understandable resistance in certain academic circles (interestingly enough, notably in disciplines such as art history) to the introduction of practices and mores that, at first glance, violate the received forms of scholarship and academic craft-work. It might take some getting used to for certain people, but the history of science shows that new research objects, methods, and claims always meet resistance. One just needs to steer a middle course between assimilating with what is already there and stressing one's own particularity. In this respect, the current institutional ad-

In humanities circles, one $\checkmark$ encounters both opponents and proponents of the emergent field of research. Although serious arguments do play a role here, far too often these can be seen to be corrupted by money and power. The new field is perceived as a threat by those who fear it will deprive them of funding. It is welcomed by those who perceive it as an academic ally.

2. I use the words 'academic' and 'scientific' interchangeably here, and both refer to the traditional university setting. 'Academia' and 'academy' refer in this essay to the entire field of higher education and research. Terminological questions like these are not without import. Science in English has a much more restricted meaning than the Dutch wetenschap or the German Wissenschaft, as the latter also encompass the humanities. The German Forschung, by contrast, is more likely to refer to the mores of the natural sciences than is the case with the Dutch onderzoek or the English research.

3. For an elaborated account, cf. Cobussen 2007. 
vance of artistic research does not differ in essence from the rise of disciplines like sociology, the technological sciences, or, more recently, cultural studies.

No, in referring to the shortcomings of university artistic research I mean something more fundamental - a fundamental deficiency that seems immanent in the relationship between art and the university. In a certain sense, this is even true of the relationship between artistic research and higher education as a whole, hence including institutions of arts education. It is a deficit in the relationship between the artistic and the academic. Thus, it almost seems as if the isolationists I was criticising earlier will turn out to be right after all. This deficit is best described as a certain unease, a restlessness, an agitation that arises because the contingent perspectives offered by artistic research practice are rather at odds with the quasi-universalistic knowledge claims of the academy, and even seem irreconcilable with them. Or are they? This is the question I want to address here.

\section{Practice-based doctoral programme in music}

Since 2002, I have been involved in developing and implementing docARTES, a practice-based doctoral programme in music. It is a cooperative arrangement involving the Conservatory of Amsterdam, the Royal Conservatoire of The Hague, and Leiden University (in the Netherlands) and the KU Leuven Association and Orpheus Institute, Ghent (in Belgium). ${ }^{4}$ The doctoral programme is designed for musicians, both composers and instrumentalists, whose research combines artistic practice with theoretical reflection, and whose artistic and theoretical research results are intended as a contribution both to art practice itself and to the discourse about it.

In developing the programme, we have made use of insights developed elsewhere in this field. Reports published by the UK Council for Graduate Education (UKCGE 1997; UKCGE 200I) on practice-based doctorates in the creative and performing arts and design were particularly helpful to us as we designed the research environment, put to-

4. See docartes n.d. for information on the programme and the various doctoral projects. 
gether the programme and constructed the curriculum, determined the admission and assessment procedures, and arranged for the students' supervision and guidance.

As it now operates, the programme starts with a two-year research training course as part of a pathway to the doctorate lasting four to six years. Meeting ten times a year in monthly sessions of two to three days, the students report on their work in progress and attend colloquia with guest artists and/or researchers. Seminars on the philosophy of science and on artistic research and the aesthetics of music are held, and there is a hands-on seminar on research in and through music. Students also learn how to collect data and to present and document their research. The programme is now in its fifth year, and twenty students are enrolled. The first degrees should be awarded in 2008.

Thirty-nine doctoral candidates were enrolled as of November 20II, and four had obtained their doctorates. More are to follow in 2012.

One matter that requires constant attention is the doctoral candidates' lack of academic training, particularly in writing skills. As a rule, their practice-based masters courses at the music colleges have prepared them inadequately for doing research. This problem is linked to a more general issue I would like to turn to now: the amount and kind of reflection that ought to be part of a practice-based doctoral course. How much attention should be devoted to 'theory'? And what do we mean by 'theory'? What kind of theoretical reflection should we expect from researching artists? And how does that relate to their artistic practice?

At a meeting of the European MIDAS (Music Institutions with Doctoral Arts Studies) network in Tallinn in May 2006, a central topic was 'How much theory can practice bear?' One participant remarked, provocatively, 'We're not trying to train the students as philosophers and make them into some kind of Derrida, are we?' We teach artist researchers the APA rules for reference lists, footnotes, and other style elements. We teach them to write and present academic papers. We introduce them to the standards of systematic research and the principles of philosophy of science. But could we be starting at the wrong end? And aren't we asking too much of our students? Are they meant to develop into fully fledged scholars, as well as reflective artists?

At the root of these continuing concerns are questions that 
seem inextricably bound up with the practice of artistic research - the issue of discursivity, the role and meaning of language in research; and the issue of the relationship between theory and practice. Before I discuss these further, let me highlight two recent occurrences that illustrate these issues.

\section{Text and theory}

In October 2007, the Arts and Humanities Research Council (AHRC 2007) in the UK launched a new research programme called Beyond Text. This five-year, £5.5-million scheme provides funding for research projects whose primary focus is on visual communication, sensory perception, orality, and material culture. The programme bears the subtitle Performances, Images, Sounds, Objects. Here, it seems, we have an initiative directly derived from the intentions of artistic research a programme that, by 'going beyond' text and taking artistic practice as its point of departure, assumes a clear stance on the issues addressed in this chapter. Yet as we delve further into the programme specifications, we read that beyond text does not mean without text. Indeed, 'while the creation [...] of performances, sounds, images, and objects $[\ldots]$ is the central concern, their translation [...] through texts remains key to their investigation.' Further on, the writer describes Beyond Text as aiming 'to enhance connections between those who make and preserve works and those who study them' (AHRC 2007). So in spite of its focus on practice, this scheme seems to do more to deepen the gulf between theory and practice than to bridge it. The governing principle in Beyond Text is still the 'humanities perspective', which elevates research on practice above research in and through practice.

On I5 October 2007, the e-mail discussion forum of PARIP (Practice as Research in Performance, a Bristol-based project earlier supported by the AHRC) carried an announcement for a forthcoming event at the University of Manchester entitled 'The Big Debate: "That's Not Research, It's Art"'. The forum moderator appended the following comment:

In Bristol we have noted an increasing number of these events and are somewhat concerned that the terms of reference are not mov- 
ing forward. I will not be attending these conferences and symposia, but wonder if those within the old PARIP communities might feed in? Particularly in the RAE run-up and following the summer's AHRC consultation 'Beyond Text' it is a little surprising to see that people feel as though there is still a significant battle to be won to convince the academy of its validity.

I am unsure how to read this, but one thing is clear: people (the PARIP community) think either that all the work of convincing academia of the validity of practice-based research in the arts has already been done (by them?) and the battle is now won, or that the battle has been lost. Either way, the sense of unease - the uneasy tension between artistic research and the academy - has seemingly vanished. Peace has been restored, and the feeling of dissonance overcome.

Second occurrence. Also in October 2007. I organised a two-day international conference in Amsterdam entitled 'The Third Cycle: Artistic Research after Bologna'. During a panel debate, one of the conference speakers, Johan Haarberg, founder of the Norwegian Artistic Research Fellowship Programme, was challenged to explain the relationship between theory and practice in the programme. 'No theory!' was his provocative assertion. 'Reflection? Yes. Some degree of contextualisation can be expected. But "theory"? No!'

The central issue addressed at the Amsterdam conference was whether and how research opportunities for artists could be created in the Netherlands after the masters degree. One of the talks at the conference described the creation of

The Netherlands Organisation for Scientific Research (NwO), in cooperation with the Netherlands Foundation for Visual Arts, Design and Architecture (вкув), has meanwhile initiated a doctorate programme for visual artists and designers. The development of the third cycle in the arts in Europe is the focus of the Erasmus academic network SHARE (Step-Change in Higher Arts Research and Education); see also my annotation in chapter 2, page 35 . a Graduate School at the Berlin University of the Arts (UdK Berlin), which offers a post-masters course. Neither the Berlin third-cycle course for artists nor the Norwegian programme awards a doctorate $(\mathrm{PhD})$. At the Berlin graduate

5. RAE = UK Research Assessment Exercise; see PARIP LIST n.d. 
school, that degree is reserved for more traditional disciplines like art history or music education. Practice-based research by artists such as musicians is not eligible for recognition as $\mathrm{PhD}$ research. This, of course, reconfirms once more the separation of theory from practice, and of research on the arts from research in and through the arts. Effectively, artistic research is not regarded here as 'real' research ('Forschung'), or is seen as a lesser form of it. The Norwegian programme, in contrast, views artistic research as a fully fledged, legitimate type of research at the third-cycle level. ${ }^{6}$ The programme is independent of university frameworks and sustained by the arts colleges. Although it does not culminate in a doctoral degree $(\mathrm{PhD})$, it is nonetheless deemed by the state to be of equal standing. The distinguishing feature of the Norwegian research fellowship programme is that it is founded not on the criteria for third-cycle research as set by the academic world, but on the question of what artists, as 'reflective practitioners', need for successful research practice. And the answer? Well, to start with, no theory ...

\section{Research and knowledge}

What do these two illustrations tell us? To begin with, we can at least gather from them that a debate is still in progress about the issues of discursivity and the relation between theory and practice - topics that generate a certain apprehensiveness and agitation both inside academia and outside it, in the world of art. Is this merely a temporary feeling of nervousness and unease that will dissipate once the struggle is over? That is, will it go away as soon as practice-based research in the arts research in and through art practice - has become a well-respected academic instance of an 'original investigation undertaken to gain knowledge and understanding'? $\mathrm{No}$, in my view there are good reasons to maintain that we are not dealing here with a transitory sense of unease.

\footnotetext{
6. For political reasons, however, the programme avoids using the word forskning (research) in its Norwegian texts, employing instead the term kunstnerisk utviklingsarbeid (artistic development work). The Swedish Research Council, in comparison, has been supporting research projects under the designation konstnärlig forskning och utveckling (artistic research and development) since 2003. See also my observations in note 2 in this chapter about variations of meaning between different languages.
} 
But before I say any more about the reasons why we should actually preserve a degree of restlessness and unease in the relations between artistic research and academia, I would like to make a few comments on why, after fifteen years of debate about research in the arts and about its institutional context, there are also good reasons to argue that some things have changed.

First there is the concept of research. Gradual but noticeable liberalisation has occurred in recent decades in terms of what is understood by 'research' in the academic world. Recent evidence for this is seen in the definition of research given by the European Joint Quality Initiative in its Dublin Descriptors for third-cycle education:

The word [research] is used in an inclusive way to accommodate the range of activities that support original and innovative work in the whole range of academic, professional and technological fields, including the humanities, and traditional, performing, and other creative arts. It is not used in any limited or restricted sense, or relating solely to a traditional 'scientific method'.

Research institutions and funding bodies, such as the Higher Education Funding Council for England (HEFCE) and the AHRC, maintain similarly 'inclusive' definitions of research, which ostensibly allow room for research taking place outside the established parameters of the natural sciences, social sciences, and humanities. In practice, however, the situation is more difficult, especially in the rat race for research funding, where such 'newfangled' activities as artistic research still tend to lose out.

7. The definition of research used by the Higher Education Funding Council for England (HEFCE) in its Research Assessment Exercise is: "Research" for the purpose of the RAE is to be understood as original investigation undertaken in order to gain knowledge and understanding. It includes work of direct relevance to the needs of commerce, industry, and to the public and voluntary sectors; scholarship; the invention and generation of ideas, images, performances, artefacts including design, where these lead to new or substantially improved insights; and the use of existing knowledge in experimental development to produce new or substantially improved materials, devices, products and processes, including design and construction.'

8. See JQI 2004. 
Chapter 4 will deal more extensively with the place of artistic research within the realm of science and technology, as well as with the possible kinship between artistic research and Mode 2 knowledge production.

A further sign of the changing research landscape is the diminishing authority of the hierarchy of basic research, applied research, and experimental development, concepts defined in the Frascati Manual (OECD 2002), a publication of the Organisation for Economic Cooperation and Development containing standards for surveys on research and development. Changes like this are partly attributable to the emergence and recognition of other forms of knowledge production. In particular, the phenomenon known as Mode 2 knowledge production has upset the traditional ways of thinking about the social and intellectual organisation of research. Mode 2 research is characterised by being carried out in contexts of application; it is predominantly interdisciplinary or transdisciplinary; it has no epistemological core and is methodologically pluralistic; and the direction and quality of the research is not determined by disciplinary peers alone. ${ }^{9}$

At a more theoretical, philosophical level these broader conceptualisations of research, and the accompanying shifts in research policy, have coincided with the liberation of knowledge forms and research strategies that are also capable of grasping what takes place in artistic research. At an epistemological level, one notices a growing interest (also in some 'traditional' knowledge domains) in the implicit, tacit knowledge that plays a part in our interaction with the world, in our actions and speech. Many scholars in such divergent disciplines as the cognitive sciences, phenomenology, and philosophy of mind consider the embodied (sometimes even bodily) non-conceptual or preconceptual forms of experience and knowledge to be a kind of a priori that underlies the ways in which we constitute and unConstructivist realism - derstand the world and reveal it to one another. And precisely these forms of experience and knowledge are embodied in artworks and practices, and play a part in both their production and their reception. Artistic research is the de-

9. See Gibbons et al. 1994. I write more about this in 'The Mode of Knowledge Production in Artistic Research', in Gehm et al. 2007, pp. 73-80, [and in chapter 4 below]. 
liberate articulation of such non-discursive forms of experience and knowledge in and through the creation of art. The intertwinement of ontological, epistemological, and methodological perspectives - the circumstance that defining an object is always at once both an epistemic act and an indication of ways to gain access to it - suggests not only that artistic practices and creative processes are themselves the most suitable instruments of artistic research. It also implies that the most effective way of articulating, documenting, communicating, and disseminating the research results is not the dominant discursive one, but the way that uses the medium itself as its mode of expression. One need not deny the inescapability of language to still give primacy to the art itself in the research process and as the research outcome. Discursive expressions may accompany the research, but they can never take the place of the artistic 'reasoning'. At best, they can 'imitate', suggest, or allude to what is being ventured in the artistic research, or

This 'imitative' form of discursivity is addressed, with refer4 ence to Adorno, in chapter 7 , pages 154 and 168. can be employed in a post hoc reconstruction of the research process.

It has meanwhile become a philosophical commonplace to say that there is no ultimate epistemological ground for our beliefs and knowledge claims, and that the edifice of science and research has been built on unstable ground. This is mirrored in a methodological pluralism and fallibilism whereby no rule has the final word, and where research pathways have been liberated that - without sinking into scepticism or relativism - have taken leave of the rigid opposition of subject and object of research, of fact and value, of action and interpretation. And it is precisely this type of methodology - which allows for the intertwinement of researcher and researched, object and objective, and practice and theory - that seems the most suitable framework for conducting artistic research.

The broadening of what we understand by research, the emancipation of non-discursive knowledge contents, and the growing appreciation of unconventional research methods all point to a more open and encompassing understanding of what science, university, and academia are. This 'liberalisation' is reflected in the fact that the highest de-

Cf. my annotation about this 4 'agenda' of artistic research on page 44 in chapter 2. 
gree in higher education, the $\mathrm{PhD}$ (which up to the nineteenth century, incidentally, was reserved for practice-oriented, protected professions in theology, medicine, and law) is increasingly no longer understood in terms of the fulfilment of specific academic criteria, but as a manifestation of a level of competence, irrespective of its domain and with due regard for the specific nature of the research objects, claims, and methods that are prevalent in that domain (cf. UKCGE 1997). And although resistance to this 'liberalisation' is still evident in some quarters, the expectation is that there, too, the awareness will dawn that research in and through art is a legitimate form of doctoral research.

In sum, after fifteen years of debate on the institutional and theoretical place of research in and through the arts, it now looks as if no fundamental obstacles exist to admitting this type of research to the ranks of the higher education and research establishment, and no longer any reason to feel uneasy about how artistic research relates to academia. At least, so it would seem.

\section{Contingency and realism}

What I am arguing here, though, is that the sense of unease and concern is more fundamental, and somehow inextricably bound up with the relationship between the artistic and the academic. There is something about the arts, and hence also about artistic research, that generates this uneasy, apprehensive feeling. In conclusion, let me focus on that 'something'.

Artistic practices are reflective practices, and that is what motivates artistic research in the first place. And this is not just because artists are now increasingly forced by external circumstances to position and contextualise their work and, as it were, justify it to funding bodies and to the public. The reflexive nature of contemporary art also lies enclosed in contemporary art itself. This art accepts no natural law; cannot base itself on an aesthetic foundation; has lost its normality; and makes its own rules. It is an art that continuously starts anew at every level, from the organisation of the material to the reality presented. This art is not only caught in the grip of autonomy and loss of function (Peter Bürger), but has also necessarily become transcendental. And this theme of art's conditions of possibility is not only an aberration from 
an introverted modernism - which was bid farewell as postmodernism made its merry entrée - but it has been characteristic of all contemporary art since Hegel's time. This is the inescapably abstract and reflexive quality of all art: that it traded (even behind the artists' backs) its overemphatic representations, created in the naivety of imitation and expression, for the contingent perspectives that stir our thinking in everchanging ways. Art (not only conceptual art) is also thinking, albeit of a special kind.

This kind of matter-mediated reflection has much in common with philosophical reflection. And that is a more compelling justification for the title of philosophia doctor than merely arguing for 'research equivalence' for a doctorate in the arts - the idea that practice-based research in the arts is just as $\mathrm{PhD}$-worthy as any other academic discipline. But the philosophy involved here is one that sees itself as an un-academic philosophy, as speculative philosophy. This artistic reflection, like philosophy, is a quasi-transcendental undertaking because it bears upon the foundations of our perception, our understanding, and our relationship to the world and other people. Art is thought, not theory. It actually seeks to postpone 'theory', to reroute judgments, opinions, and conclusions, and even to delay or suspend them indefinitely. Delaying, pausing, suspending, waiting - this 'modesty' now even necessarily characterises those unambiguous forms of art that want to be understood like this and not in any other way. Art says: 'It can also be different...' Artistic research is the deliberate articulation of this unfinished material thinking. This reinforces the contingent perspectives and world disclosures it imparts. In the debate on the epistemology of artistic research, an antithesis repeatedly surfaces: between explicit, manifest knowledge and implicit or tacit knowledge, and between knowing that something is the case and knowing how to do or make something. I propose to add a third side to this: not knowing. 'I don't know...' This is the more interesting position: not to know, or not to know yet. It creates room for that which is un-

'We don't know exactly what we don't yet know.'

\ Hans-Jörg Rheinberger (see chapter 9). thought, that which is unexpected: the idea that all things could be different... This is what we may call the radical contingency of artistic research. 
How much theory does artistic research need? Well, we should not say: 'Here is a theory that sheds light on artistic practice', but 'Here is art that invites us to think.' Immanuel Kant described the aesthetic idea as a 'representation of the imagination which induces much thought, yet without the possibility of any definite thought whatever, i.e., concept, being adequate to it, and which language, consequently, can never get quite on level terms with or render completely intelligible'. ${ }^{\text {Io }}$ This eighteenth-century expression of what the philosophy of mind would now call 'non-conceptual content' encompasses more than just the tacit knowledge embodied in the skilfulness of artistic work. That 'more' is the ability of art - deliberately articulated in artistic research - to impart and evoke fundamental ideas and perspectives that disclose the world for us and, at the same time, render that world into what it is or can be. If some form of mimesis does exist in art, it

Constructivist realism

The notions of non-conceptualism, realism and contingency will develop further throughout the chapters of this book, culminating in a tentative, still imperfect formulation at the close of chapter 7 . Work remains to be done here. is here: in the force, at once perspectivist and performative, by which art offers us new experiences, outlooks, and insights that bear on our relationship to the world and to ourselves. This articulation of the world we live in is what we may call the radical realism of artistic research.

The kind of reflection that artistic research is, the contingent perspectives it delivers, its performative power, and the realism it brings to bear - all these make artistic research into a distinctive instrument that will not readily conform to the established mores and conventions in the more traditional academic world. This is the fundamental uneasiness and restlessness that haunts relations between the artistic and the academic. But if the university, if academia, is willing and able to incorporate these unstable, uneasy attributes into its midst - along with the non-discursive artistic research practices - then we can say that progress has been made. Hence, the

Io. In Kant 1978 [1790/93], The Critique of Judgement (Kritik der Urteilskraft), $\$ 49$. The German passage is: 'Unter einer ästhetischen Idee [...] verstehe ich diejenige Vorstellung der Einbildungskraft, die viel zu denken veranlaßt, ohne daß ihr doch irgendein bestimmter Gedanke, d.i. Begriff, adäquat sein kann, die folglich keine Sprache völlig erreicht und verständlich machen kann.' 
question is not 'What is artistic research?' but 'What is academia?' Christopher Frayling (2006: xiv) recently made the following appeal: 'It is timely, in my view, to redefine and re-evaluate the academy - to emphasise the radical nature of some of its elements. Towards a radical academy.' This radical academy, to be sure, will always, to some extent, be characterised by restlessness - by a reflective, but also productive, state of unease and agitation. 


\section{Chapter 4}

Artistic

Research

within the

Fields of

Science 



\section{Context}

This chapter was born of bewilderment and unease.

I was bewildered about how artistic research was mentioned only in passing in the Frascati Manual and then shoved aside. I was uneasy both about the negative attitude towards artistic research that prevailed in levels of authority in Dutch arts schools as well as about the line adopted by officials and government advisers, who felt they needed to protect 'research' from appropriation by others. My work in the Strategic Working Group on Research in the Netherlands Association of Universities of Applied Sciences (HвO-Raad) enabled me to probe into issues of research policy, in particular as regards the form and dynamics of knowledge production. My bewilderment and unease are echoed by the rhetorical tone in which I presented and arranged the chapter's sections. 
Imagine the following scene. Back in the I970s, somewhere in the vast UNESCO complex in Paris, a public servant is cogitating one day about whether 'artistic research' should or should not belong to the field of science and technology, and specifically to 'research and development'. That official (assuming there is no more than one) is preparing the thirty-fourth agenda point for the Twentieth UNEsCo General Conference, to convene in October and November 1978. Agenda point 34 is entitled Draft Recommendation concerning the International Standardization of Statistics on Science and Technology. The preamble to the ultimate recommendation (UNESCO 1979: 23) will state that

it is highly desirable for the national authorities responsible for collecting and communicating statistics relating to science and technology to be guided by certain standards in the matter of definitions, classifications and presentation, in order to improve the international comparability of such statistics. ${ }^{\mathrm{I}}$

Part of the recommendation deals with the various ways in which member states should classify data in research and development. One approach is to categorise it in terms of the 'fields of science and technology in which institutions belonging to the higher education and general service sectors carry out [...] research and development [activities]' (UNESCO 1979: 27). This classification - later to be known as the 'distribution list' - contains the following main categories:
I. Natural sciences
2. Engineering and technology
3. Medical sciences
4. Agricultural sciences
5. Social sciences and humanities.

I. The text put before the delegates was later published in Annex I to the Resolutions of the conference (UNESCO I979). 
The recommendation further specifies which disciplines each of these areas should encompass. Natural sciences, for instance, includes 'astronomy, bacteriology, biochemistry, biology, botany, chemistry, computer sciences [... and] other allied subjects'. Social sciences and humanities is divided into two groups. Group II, the humanities, includes languages, philosophy, history, religion, as well as arts; the latter are further elaborated as follows: "history of the arts and art criticism, excluding artistic "research" of any kind' (emphasis added).

So at some point thirty years ago in Paris, someone decided that artistic research should be categorically banned from the field of endeavour known worldwide as research and development. And to prevent any misunderstanding - should anyone claim that some form of artistic research might qualify as research and development after all the exclusion was reinforced by adding 'of any kind', and the activity was negated yet again as a legitimate form of research by putting 'research' into inverted commas (which were rare in the rest of the text). In other words, no one should ever think this is real research, even though the term might be occasionally so misused.

Since 1979, the distribution list of science and technology fields has been an authoritative standard in the international world of institutions devoted to science and technology and to research and development. With a few minor changes, the list was later incorporated into the Frascati Manual (OECD 2002), a publication of the Organisation for Economic Co-operation and Development dealing with 'standard practice for surveys on research and experimental development'. The definitions and classifications laid down in the Frascati Manual now serve as the reference categories when it comes to describing and defining what research and development are. All self-respecting research institutes, and universities in particular, now use the manual as a guideline for their actions.

The Frascati Manual's distribution list (OECD 2002: 67) classifies Humanities as a separate category alongside Social Sciences, and subdivides it as follows:

- History

- Languages and literature

- Other humanities. 
'Other humanities' is further specified as 'philosophy (including the history of science and technology), arts, history of art, art criticism, painting, sculpture, musicology, dramatic art excluding artistic "research" of any kind, religion, theology [...]'(emphasis added). The modifications are noteworthy and odd, but they need no further comment here. The issue I am highlighting is the insistence with which artistic research is excluded here once again from the domain of research and development.

So what is actually wrong with artistic research to trigger such vehement reactions? Is it perceived as a threat? To what, to whom?

\section{Artistic research versus scientific research}

In the past ten to fifteen years, much has been said and written about artistic research, in relation to both philosophy of science and educational politics. A recurrent theme is to compare it with, or distinguish it from, what is generally understood as scientific or academic research. Can we identify elements of similarity or difference with respect to research in fields like humanities or natural sciences? Wherein lies the specific nature of artistic research? Is that in the research object - the uniqueness of artistic practice, of the work of art, of the creative process? Or does it lie in the research process - in the course it follows, the working procedures, the methods? Or, from a third point of view, does artistic research seek to reveal a special form of knowledge - tacit, practical, nonconceptual, non-discursive, sensory knowledge, as embodied in artistic products and processes?

In the world of academia, there is a broad degree of agreement as to what should be understood by research. Briefly it amounts to the following. Research takes place when a person intends to carry out an original study, often within a single discipline, to enhance our knowl- 
This paragraph brings together the seven 'criteria' from chapter 2 into a single formulation.

edge and understanding. It begins with questions or issues that are relevant in the research context, and it employs methods that are appropriate to the research and which ensure the validity and reliability of the research findings. An additional requirement is that the research process and the research outcomes be documented and disseminated in appropriate ways.

Does 'artistic research' satisfy these criteria? Ostensibly, at least, there is much to be said for excluding artistic research on these grounds. Let us look into it more closely. For one thing, much artistic research is conducted not with the aim of producing knowledge, but in order to enhance what could be called the artistic universe; as we know, this involves producing new images, narratives, sounds, or experiences, and not primarily the production of formal knowledge or validated insights. Although knowledge and understanding may

These three 'criteria' - intent, questions, methods - will be discussed in chapter 7 together with the four other criteria from chapter 2. At this point, they serve as a rhetorical stepping stone in order to emphasise below (under 'Kinship?') the often close relationships between artistic research and other academic research. well emerge as byproducts of artistic projects, this is not usually intended from the beginning.

Perhaps more important is that artistic research as a rule does not start off with clearly defined research questions, topics, or hypotheses whose relevance to the research context or to art practice has been established beforehand. Much such research is not 'hypothesis-led', but 'discovery-led' research (Rubidge 2005: 8), in which the artist undertakes a search on the basis of intuition and trial-and-error, possibly stumbling across unexpected outcomes or surprising insights or farsights. Moreover, because the researchers are intimately intertwined with what they are exploring - much artistic research actually serves their own artistic development - they do not have ample distance to the research topic, a distance that is supposedly an essential condition for achieving a degree of objectivity.

In terms of method - understood as systematic and reliable working procedures - artistic research also seems to diverge from the prescriptions set out in methodology manuals. It is the very practice of unsystematic drifting and searching - of which serendipity, chance in- 
spirations, and clues are an integral part - that takes artists onto new, unbroken ground. They thus do not operate within a well-circumscribed discipline that spells out what may and may not be part of the research strategy. In artistic research, both the research topic and the research questions and methods tend to become clear only bit by bit during the artistic search, which often transcends disciplines as well.

But does this really differ from 'scientific research'? As Robbert Dijkgraaf (2007: 3I), an expert on string theory, recently put it, 'I would say that scientific research is about doing unpredictable things, implying intuition and some measure of randomness. [...] Our research is more like an exploration than following a firm path.' The idea that the 'context of discovery' is more distinct from the 'context of justification' than was claimed by classical philosophy of science up to and including Karl Popper has been substantiated by Thomas Kuhn, Paul Feyerabend, and historians of science that succeeded them. In this light, artistic research may have more in common with scientific research than is often presumed.

\section{The research hierarchy}

Now let us step back for a moment. Research is currently a hot topic in Europe. In line with the political rhetoric about the knowledge society, the knowledge economy, knowledge management, knowledge circulation, and the like, heavy emphasis is now being put on research and knowledge production in our society, where the production of goods and services seems insufficiently competitive in the global economy, especially with the future in mind.

The art world and the field of arts education have also become afflicted by the research and knowledge virus. It is no longer sufficient just to master your trade, and from that basis to create beautiful objects, performances, compositions, or events. Artists are what are now being called 'reflective practitioners' (Donald Schön). This broadening of the artist's trade can be partly explained by prevailing external circumstances - the hybrid ('mixed') arrangements in which artists increasingly operate, their need to contextualise and position their work, their accountability to grant providers and to the public. Yet the focus on research and reflection can also be partly understood 
through developments in art practice itself. Some years ago, Theodor Adorno (1997 [1970]: I2) observed that 'today it goes without saying that nothing concerning art goes without saying, much less without thinking. Everything about art has become problematic; its inner life, its relation to society, even its right to exist.' ${ }^{2}$ The same still applies in our postmodern times, where it often only seems as though the art scene is not really worried about its own legitimacy. The current hype about knowledge and research in the arts is proof of the contrary. It can be understood as both an attempt to conform to the conditions that have been imposed on art and artists (an externalist perspective) and a manifestation of the reflexiveness of the arts themselves (an internalist perspective).

Yet at the same time we also witness here and there, and more and more, some irritation, or even aversion, arising in the art world and in arts education against the subject of 'research'. This can be attributed mainly to an understandable resistance to the disciplining effects of the frameworks defined in the academic world for the conduct of research. Artists are on their guard when it comes to issues that could impede their creativity, inventiveness, or freedom. This is not just an inconvenient legacy of an obsolete, late eighteenth-century notion of artistry (certainly it is that, too, but not that alone). There are good reasons to defend the framework-transcendent, destabilising, sometimes subversive effects of art against the ineradicable tendency of people and institutions to frame the unforeseen.

And so the art world, as well as the field of arts education, now find themselves caught in a balancing act. One minute they profess the importance and necessity of research and reflection, and the next minute they resist the real or imagined association with the perceived oppressive world of science and academia. This is an uncomfortable predicament, and the discomfort manifests itself in the agitated tone in which people waver between defending different standpoints.

2. In the German edition: 'Zur Selbstverständlichkeit wurde, daß nichts, was die Kunst betrifft, mehr selbstverständlich ist, weder in ihr noch in ihrem Verhältnis zum Ganzen, nicht einmal ihr Existenzrecht.' 
The legitimacy of artistic research is also at issue in an entirely different way, even as artistic research gains a stronger foothold in the system of higher education and research. In the wider debate about research - and notably when it comes to government investment in higher education and research - artistic research is no party to the discussion at all. The discussion is still first and foremost about investment in basic scientific research, and preferably in top-rated, ground-breaking research in areas like nanotechnology, biophysics, or subatomic science. Perhaps a slight shift can be seen over the years towards what was formerly known as applied research and is now often called socially robust, Mode 2, or practice-led research - studies whose research questions do not arise primarily from theoretical curiosity, but from everyday practice. But that does not alter the fact that the largest relative amount of emphasis and money still goes into types of research that can be labelled as basic. From this point of view, other research areas, if they are not outrightly seen as insignificant, at least have less value as investment targets. In this value hierarchy - where socially and culturally oriented fields like economics and history occupy a mid-range bracket - doubts are even being expressed about the status of activities that have managed to gain a place in the universities under names like cultural studies, media studies, or communications.

As we move down the hierarchy, the word 'research' takes on gradually different meanings (if not to say inferior meanings). And the activities known as artistic research, which accompany the production of art, are not at all taken seriously in the world of 'genuine' scientific research. The inverted commas around the word 'research' as quoted from the Frascati Manual say everything. They stand as a warning against devaluation. Although it may be understandable (they seem to say) that the respectable status of scientific research tempts people to present their 'research' as scientific or systematic in order to gain an equivalent standing, this 'academic drift' must not obscure the fact that these are two totally dissimilar domains and activities.

Fortunately, the reasoning continues, the scientific world has selfpurifying mechanisms. Against this tendency to promote any old thing into 'research' and into an academic discipline, there is movement in the opposite direction. In the ostensibly egalitarianised landscape of uni- 
versities and higher professional schools, where at first sight everything seems to be thrown together into an amorphous mass, the 'research universities' are now drawing sharper lines between themselves and the rest, and the research training programmes are setting themselves apart from professional training courses. It is argued that achievements at polytechnics and higher professional schools should no longer be referred to as 'research', but as 'design and development' (cf. AWT 2005). And that applies to the arts as to none other. After all, aren't they primarily just involved in designing and producing new artefacts and training artists? They have no reason to annex this commonly understood word 'research'; that just raises questions and causes misunderstandings - again, according to this line of reasoning.

This chapter was also published in Dutch in Krisis, a journal for contemporary philosophy (2009.I: 56-7I), in a special issue on science and technology studies. One reviewer rightly pointed out that the term 'rational reconstructions' has particular connotations in Habermas. To avoid associations with Habermas's ideas about the current tasks of philosophy, it is perhaps better to use the term 'rational justifications' here.

\section{Kinship?}

Let us leave the war of words behind us and concentrate on the essential issue here. What is artistic research all about? We have already seen in the explorations of artists and scientists - the 'contexts of discovery' - that they have something in common. Their ways of justifying research outcomes, however, seem highly different at first. Rational reconstructions (logical arguments, empirical-deductive inferences, quantitative and qualitative analyses, historical-critical interpretations) seem to have little in common with artistic, aesthetic evaluations. The latter, of course, belong the domain of art criticism. But some remarkable parallels do exist on closer inspection. For one thing, there is the manner in which a rational reconstruction or an aesthetic evaluation is itself assessed. In neither case is it possible to invoke an epistemological ${ }^{3}$ or an aesthetic ground that will provide the ultimate justification for the research findings. The rules for assessing the results are not derived from any criterion external to the research, and hence independent of it. They are defined within the research domain itself. That applies equally to scientific research and to

3. Nowotny, Scott, and Gibbons 200I: 179-200. 
artistic research. The basis for the assessments is furnished by intersubjective standards which are shared within what is called a forum, a community of equals. Peer review has just as much authority in the art world as it does in the world of science. The peers in both realms are very well able to pass judgments on quality.

But perhaps a more remarkable kinship between science and art, between scientific research and artistic research, becomes evident when we view the motives that underlie the re-
Peer review will be addressed further along in this chapter (on pages 89-94). It is also (more polemically) the topic of the first brief intermezzo in chapter 6 . The viewpoints and argu$\checkmark$ ments I have brought together in this book will ultimately culminate in a framework for the assessment of artistic research (chapter Io), which will then be tested and put into operation in the peer review guidelines for the Journal for Artistic Research. search, the issues that inspired it. In both cases (ignoring, for convenience' sake, false motives like money and power), these are driven both by a desire for a fundamental understanding and by a desire to develop new products, with the emphasis alternating between the two. These characteristic motives for conducting research will be discussed in more detail below. It will suffice for now to point out that both artistic research and scientific research are seeking to broaden our horizons and to enrich our world.

An additional similarity between scientific and artistic research, which is at least as important to the present context, is the function that the research fulfils within the respective professional fields. In both cases, successful research contributes to the development of the discipline and to the flourishing of talent within it. If there is an intimate bond between research and development, it is located here. Cuttingedge scientific and artistic research moves the frontier onto previously unexplored territory by discovering new paths and outlooks, by enabling new observations and experiences. We may therefore understand artistic research as a careful investigation, exploration, and testing of unbroken ground in function of developing the discipline and broadening perspectives as well as nurturing talent. Both scientific research and artistic research are capable of constituting worlds and disclosing worlds; therein lies their performative strength in generating and revealing new ideas, understandings, perceptions, and experiences. 


\section{The standard model of research and development}

The authoritative Frascati Manual (OECD 2002: 30) also provides the standard definitions of research and development that currently prevail in the world of science and technology. The generic definition is as follows:

Research and experimental development comprise creative work undertaken on a systematic basis in order to increase the stock of knowledge, including knowledge of man, culture and society, and the use of this stock of knowledge to devise new applications.

The manual goes on to distinguish three activities within this definition: basic research, applied research, and experimental development. It defines these as follows:

Basic research is experimental or theoretical work undertaken primarily to acquire new knowledge of the underlying foundations of phenomena and observable facts, without any particular application or use in view. Applied research is also original investigation undertaken in order to acquire new knowledge. It is, however, directed primarily towards a specific practical aim or objective. Experimental development is systematic work, drawing on existing knowledge gained from research and practical experience, that is directed to producing new materials, products and devices; to installing new processes, systems and services; or to improving substantially those already produced or installed.

This threefold distinction is encountered (always in the same hierarchy) in the mission statements of national and supranational research organisations that monitor research quality. The League of European Research Universities, for instance, is 'committed to the creation of new knowledge through basic research, which is the ultimate source for innovation in society' (LERU n.d.). The Royal Netherlands Acad- 
emy of Arts and Sciences states in its mission (which is 'to ensure the quality of scientific research in the Netherlands') that 'the fundamental research carried out today will provide a basis for the applied research of tomorrow and, in turn, for the practical application of science in the future' (KNAW n.d.).

The primacy of basic (pure) research over applied research (including strategic research and action research) and over experimental development which emanates from these statements can be traced back to governmental policies as formulated in the final years of the Second World War, particularly in the United States. In 1945 a report was published entitled Science: The Endless Frontier, which was commissioned by President Franklin D. Roosevelt and written by Vannevar Bush, director of the Office of Scientific Research and Development, which had been so important to the US war effort. Through this agency, Bush had already demonstrated that investment in (often secret) scientific research had substantially contributed to winning the war. He was now asked to extrapolate his findings to peacetime. 'There is [...] no reason why the lessons to be found in this experiment cannot be profitably employed in times of peace' (from Roosevelt's commissioning brief, cited in Bush 1945: 3). In his extrapolation, Bush employed two postulates which together would prove to be a golden formula: 'Basic research is performed without thought of practical ends' and 'Basic research is the pacemaker of technological progress' (pp. I8, I9). This formula - which defines basic scientific research as the motor of technological development, economic growth and public welfare, while prescribing that it should not be judged directly in terms of utility - represents the conceptual framework that, until recently at least, has inspired government policies with respect to scientific research in 
the Western world. The institutional mission statements quoted above still bear witness to this.

In recent decades, this conceptual framework has been expanded a little, as research funders and government bodies have gained more awareness of research that cannot immediately be associated with basic research, but which both generates knowledge and aims at results such as designs, images, and performances, and which employs a broader conception of what qualifies as a scientific method. The Research Assessment Exercise (RAE 2005: 34) in the UK, for example, applies the following definition:

'Research' [...] is to be understood as original investigation undertaken in order to gain knowledge and understanding. It includes work of direct relevance to the needs of commerce, industry, and to the public and voluntary sectors; scholarship; the invention and generation of ideas, images, performances, artefacts including design, where these lead to new or substantially improved insights; and the use of existing knowledge in experimental development to produce new or substantially improved materials, devices, products and processes, including design and construction.

And as part of the Bologna Process to integrate European higher education, the principles known as the Dublin Descriptors (JQI 2004: 3) emphasise that

the word [research] is used in an inclusive way to accommodate the range of activities that support original and innovative work in the whole range of academic, professional and technological fields, including the humanities, and traditional, performing, and other creative arts. It is not used in any limited or restricted sense, or relating solely to a traditional 'scientific method'.

Notwithstanding this wider concept of research, the standard model remains, for many people, the criterion for demarcating 'true' scientific research from research activities that some still prefer to label as design and development. 


\section{The standard model amended}

The standard model of scientific research as set out by Bush and as crystallised in guidelines such as the Frascati Manual has attracted criticism from various quarters. Research on the history of science and on science policy has shown that the factors now important to technological advancement and economic growth are more complex and multifarious than the standard model would lead us to believe. The intellectual and social organisation of the sciences in the early twentyfirst century is likewise highly diversified, and different types of knowledge are generated in different specific contexts (Whitley 2000: ix).

In their book The New Production of Knowledge from 1994, Michael Gibbons and his colleagues sparked considerable debate with their proposed amendment to this standard model. They described how 'Mode I science' must now make increasing room for 'Mode 2 knowledge production'. ${ }^{4}$ Mode I refers to traditional, discipline-bound research that takes place in academic contexts (mostly universities); it is characterised by organisational homogeneity, uniformity, and stability. The quality of Mode I research - which is primarily focused on the finding of truths or the justification of beliefs - is assessed and controlled within each discipline by a peer review system, in which largely individual contributions are assessed by colleagues who are considered competent to judge quality by virtue of their own previous individual contributions.

Mode 2 research, in contrast, is said to take place in the 'context of application'. It is interdisciplinary or transdisciplinary, involving both academics and other parties. Research is not conducted exclusively in homogeneous, uniformly structured universities, but is more localised in heterogeneous, diversified, often transitory configurations, made up of universities, governmental agencies, industrial research centres, non-governmental organisations, and other actors that assemble around a particular set of problems. Specific attention is given to whether the outcomes are socially, economically, or politically relevant, competitive, or feasible. The quality of the research is assessed

4. Gibbons et al. 1994; see also the sequels to this work, Nowotny, Scott, and Gibbons $200 \mathrm{I}$ and 2003 . 
and controlled by the various parties involved. Both 'disciplinary peers' and other stakeholders critically examine research questions and priorities as well as findings. This 'extended peer review' is one of the attributes that distinguish Mode 2 knowledge production, in conjunction with the demand for social robustness and reflexivity, the organisational diversity, and the problem-focused teamwork that transcends disciplines.

The Frascati Manual defines six fields of science: natural sciences, engineering and technology, medical sciences, agricultural sciences, social sciences, and humanities. The first five areas dominate the science debate. Although Gibbons and his coauthors did pay some heed to the status and role of the humanities in the academic system, they focused mainly on new developments in such areas as biomedical sciences, in-

Whitley: 'Previously combined in the universities, the humanities have largely remained there while natural science, and some of the social sciences, developed a considerable degree of institutional autonomy from academic ideals and structures. This autonomy and correlative prestige has increased the degree of dependence between scientific fields and sharpened the distinction between scientific knowledge and other forms of understanding. [The natural sciences] have today become a separate institutional entity claiming considerable resources and a monopoly over truth production and validation.' formation technology, and environmental studies. That makes it difficult to determine whether, and if so how, an activity like artistic research might be understood within the entire realm of 'knowledge production'. The growing institutional and intellectual autonomy of scientific research vis-à-vis academic research in the humanities (Whitley 2000: 278)' has sharpened the contrast between 'scientific' knowledge and other types of knowledge and understanding, thus further complicating any comparison. Artistic research has only just begun its 'academic advance', and much of this research still takes place in institutions of higher arts education that are organisationally and intellectually rather segregated from the rest of the academic and university world. Furthermore, its claim to have a unique research object, a specific kind of embodied knowledge, and a distinct methodological framework [see chapter 2 above] has kept artistic research outside the debate from the very beginning. On closer inspec-

5. Whitley opposes here 'scientific' research - increasingly accommodated in autonomous research institutes - to 'academic' research in universities. 
tion, artistic research does not even readily fit into the Mode I/Mode 2 dichotomy of knowledge production as proposed in Gibbons et al. With a bit of goodwill, artistic research can sometimes be understood within the frameworks of traditional Mode I academic research, and at other times as a prime example of Mode 2 'knowledge production' - depending on which topics, questions, objectives, and methods of research have been chosen. In the discussion that follows I will examine to what extent the five characteristics of Mode 2 knowledge production - context of application, transdisciplinarity, heterogeneity and diversity, accountability and reflexivity, and extended peer review - may be pertinent to artistic research.

\section{Artistic research and Mode 2 knowledge production}

Owing to its close ties with the art world and with art criticism, artistic research is not primarily an academic (university) matter, but is carried out in what Gibbons et al., in their description of Mode 2, call the 'context of application'. The research questions and topics, the methods, Context of application and the means of documenting and communicating the research are often motivated by what seems appropriate within art practice - a practice which, since it transects the realms of knowledge, morality (politics), beauty, and daily life, has its own dynamic and logic that cannot be corralled into traditional academic structures. Yet all this notwithstanding, artistic research can sometimes very well be understood as purely disciplinary experimental research into the aesthetic and formal qualities and universal regularities of elements that constitute an artwork or creative process. Materials research is one example, and so are the more conceptual research practices in traditions like fundamental art, experimental theatre, or electronic music.

If multidisciplinary research is understood as collaboration between different disciplines around a particular topic, whereby the theoretical premises and working methods of the separate disciplines 

ciplinary research is characterised by a partial interpenetration of practice, theory, and method, in response to research questions arising from highly specific, local contexts. Especially the type of artistic research that combines the aesthetic project and the creative process with questions and topics from broader areas of life (such as globalisation, identity, gender, or mediality, to mention some common ones) may be characterised as transdisciplinary research if the synthesis achieved in the artwork has something additional (or different) to offer, both conceptually and perceptually, as compared to the outcome that would have resulted from a disciplinary approach. Such transdisciplinary research is characterised by a relinquishment of one's own specific (epistemological or aesthetic) disciplinary ground (which wasn't there anyway), a continual adaptation of the recursive research process based on the input from the various fields of endeavour, and a certain pragmatism and diversity in the choice of concepts and methods. In the creation of images, sounds, narratives, and experiences, the research delivers context-related knowledge and understandings of the life domains it touches upon. But, as pointed out above in relation to the research context, intradisciplinary research (research operating within the frameworks defined by a particular discipline) is also very common in the realm of the arts. For instance, research in performance practice on the performance practice of historical music, or choreographic research in and on specific movement repertoires, often cannot be, and does not wish to be, understood as research that transcends disciplines. Hence, transdisciplinarity, the second attribute of Mode 2 knowledge production, is also not wholly compatible with what we understand by artistic research.

The remarkable growth in the number of collaborative ventures involving artists and scientists, artists and civic organisations or communities, or artists and businesses, seems to point towards a heterogeneous, diversified organisation of artistic research. Research no longer takes place exclusively in studios, rehearsal rooms, and workspaces, but also 'on site' - in the communities and settings where the collaboration arose. Many of the research findings, too, are disseminated 
beyond theatres, concert halls, and museums. Nevertheless, heterogeneity and organisational diversity are still not distinguishing characteristics Heterogeneity and diversity of artistic research. The bulk of the creation and transfer of knowledge and understandings which are articulated in artistic research still occurs in settings built or fitted out for artists - in places like studios, theatres, filmhouses, music venues, performance spaces, and galleries, which, for all their differences, are characterised by a certain organisational homogeneity and similarity. Obviously there are also 'alternative providers': creative workspaces, informal artspaces and organisations, fringe venues, and other locations. But such organisations and venues in the margins of the art world demarcate the mainstream. The institutional and social partitions between art practice, scientific practice, and moral practice that arose in the eighteenth century can still be seen today in the relative homogeneity and uniformity of the organisations and spaces where these practices are carried out.

Social accountability and reflexivity - that is, an awareness of the impact that research has (or might have) on the public sphere, and the associated feedback that may influence the choice of research topic, the direction of the research, and the interpretation and communication of the findings - are further characteristics of the type of research that Gibbons et al. call Mode 2. When the aim (to use Marx's words) is not just to Accountability and reflexivity interpret the world but to change it, then the research agenda is determined not only by the challenges arising within a discipline, but by the demands of the surrounding contexts as well. Yet the agenda of artistic research seems to run counter to this kind of accountability and reflexivity. Art often takes an antithetical stance towards the existing world, and it delivers the unsolicited and the unexpected. That is its very strength. At the same time, engagement and reflexivity are inseparably bound up with the production of art - not in the form of demand and supply, but in the conveyance of a 'narrative' in the materiality of the medium which can be understood as a commentary on what we have here and now and as an opening to the 'other', the unknown. That applies equally to text theatre as to the most abstract kinds of music. The performative, world-constituting, and world-revealing power of art lies 
in its ability to disclose to us new vistas, experiences, and insights that bear upon our relationship with the world and with ourselves.

On the assessment of quality in artistic research I have already made some remarks above. Just as peer review is the basis of quality control in the scientific world, the art world also conducts its own form of 'peer review'. The prominent role played today by mediators like curators, programmers, and critics might make us forget that the artists themselves ultimately also belong to the 'forum of equals' that determines what matters and what doesn't, what has quality and what does not. As we have seen, Mode 2 research is subject to extended peer review - the value and quality of the research is judged by the stakeholders involved in the research process. To a certain extent, the same is true of artistic research, albeit mainly where collaboration with others takes place or where the research is done in the service of others or is commissioned by them. And in activities like doctoral research, the tendency is to involve academics as well as artists in evaluating the artistic research, since they have qualified themselves in assessing the merits of the discursive practice that accompanies the research. This is not the right place to discuss this type of extended peer review. By and large, though, the quality of artistic research is judged by the art field itself, as is customary in Mode I. The fact that artists use other channels for this than academic articles in top-ranking journals does not alter this principle.

The five characteristics of Mode 2 knowledge production - context of application, transdisciplinarity, heterogeneity and diversity, accountability and reflexivity, and extended peer review - thus apply to artistic research only some of the time, and usually not at all or only partially. What can we learn from this? In one way, it could give support to the argument that artistic 'research' was kept out of the Frascati Manual for good reason. If it really does differ so much from Mode 2 research (and from Mode I research as well), then one might be justified in asking whether it is even research at all in the real sense of the word. Its context is entirely different - the context of the art world, not that of science or technology. Academic research on art (as performed in the meanwhile wellestablished humanities disciplines) is certainly a respectable undertaking, 
but even though sports sciences and political sciences also have their own places in the university system, no one would dream of elevating sports or politics per se to the status of research activities. Mutatis mutandis, that should apply to the arts as well, however reflexive or exploratory their practices might be. Hence, the interdisciplinary or transdisciplinary nature of many artistic practices, their organisational diversity, their engagement with other life domains, and their quality assessment procedures would not be sufficient grounds in themselves for lifting 'artistic research' to the level of academic or scientific research.

A second, opposing conclusion can also be argued. The sui generis nature of artistic research practices can actually be seen as casting a critical light on the very dichotomy between Mode I and Mode 2 as put forward in Gibbons et al. That dichotomy has already been criticised from various quarters (e.g. Whitley 200o) as excessively rigid. It does insufficient justice to the divergent ways in which knowledge and understandings are defined, generated, and disseminated in the widely different domains of research and development. The dissimilarities between academic disciplines as biotechnology, economics, historiography, and law are so great in terms of epistemology, methodology, internal dynamics, and social organisation that it is hard to identify either Mode I or Mode 2 research there. From this point of view, artistic research practice differs no more from the practices in laboratories or cultural historiography than the latter differ from econometrics or architecture. There are therefore no good reasons to exclude artistic research from the broad domain of academic and technological endeavour, or of research and development in the sense of the Frascati Manual. In fact, even though artistic research may not always be easy to incorporate into existing disciplinary or academic structures, its distinctive ontological, epistemological, and methodological framework, its social and intellectual organisation, and its specific forms of engagement, talent development, and quality control all serve to highlight what academic research could also potentially be - a thorough and sensitive investigation, exploration, and mobilisation of the affective and cognitive propensities of the human mind in their coherence, and of the artistic products of that mind. This means that artistic research, through its quest for fundamental understanding, is equally dedicated 
to broadening our perspectives and enriching our minds as it is to enriching our world with new images, narratives, sounds, and experiences.

\section{Artistic research and Pasteur's quadrant}

In an attempt to give artistic research a 'home' in academia, some people compare it to the kinds of applied research and experimental development we encounter in the field of engineering and technology; others compare it with the socially engaged strategic and action research more readily associated with the project of social engineering in the applied social sciences; and still others liken it to the search for fundamental understandings of specific phenomena which is characteristic of the humanities. Yet all such attempts remain caught up in the standard model of basic research, applied research, and experimental development that has been widely accepted since Bush and is codified by the Frascati Manual. As we have seen above, this model was criticised in Gibbons et al. for its limited capacity to describe the value of the types of research that are the motor of technological innovation and economic growth. In particular, the priority given to basic research over applied research and experimental development is seen to no longer reflect the diverse reality in the science system, where the relatively autonomous Mode 2 knowledge production is gaining increasing ground.

In his book Pasteur's Quadrant: Basic Science and Technological Innovation, Donald E. Stokes (1997) likewise opened the attack on the standard model of scientific research and development. He followed a different line of reasoning, however - one that might be better suited to understanding artistic research within the framework of research and development. In his criticism of the standard model, Stokes identifies two aspects of the model which he argues are dominant. He sees these as direct consequences of Bush's golden formula that basic research is the pacemaker of technological progress, and is performed without thought of practical ends. The first aspect concerns the model's orientation; its point of departure is basic research. This is viewed as the original source and motor both to progress in science and to offshoots of basic research like the more applied research and experimental development of new products that are important to economic and social life. As pointed out above, the ascendancy of basic research over applied re- 
search and experimental development is still recognisable in the mission statements of national and supranational research institutions. As a constraining paradigm both inside and outside the academic world, it continues to dominate the minds of many. The accomplishment of Stokes, as well as of Gibbons et al., is that they expose the inadequacy of this well-nigh causal logic. In reality, applied research is just as likely to elicit fundamental questions as basic research is likely to motivate the development of applications. At best, the standard model would have to operate in two directions.

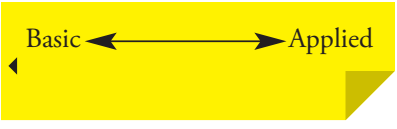

Basic research therefore does not constitute the foundation on which the edifice of science is built, but it is simply one form of scientific practice - a very respectable form, to be sure, but it is unwise to justify substantial government investment in this type of research solely on the grounds of its potential longer-term benefits for technological and economic development (which it unmistakably has). It stands here in competition with other types of research, and it might even risk losing out in the long run. No, the justification for subsidising basic research should also be founded on an appreciation of the never-diminishing need of human beings to ask fundamental questions - driven by curiosity, by a hunger to know. This quest for fundamental understanding is, as it were, indelibly programmed into the human species.

To be always seeking after the useful does not become free and exalted souls,

wrote Aristotle as early as 350 BC. $^{6}$ This maxim would better become the mission statements of the research institutions cited above than the implicit references they currently make to the economic profitability of the research efforts in fields of basic research.

Back to Stokes. His criticism is directed chiefly at the second characteristic of the standard model - its unidimensionality. The standard model leaves no choice: research must be positioned somewhere on a one-dimensional line running from pure 'basic research' to fully

6. Aristotle, Politics (1963), Book viII, I338 b3. 
'applied research'. Every study must be located at a single point somewhere along that line. Research that pretends to contribute both to fundamental understanding and to the development of applications is neither fish nor flesh in this model, since it is positioned near the middle of the line and is consequently less 'basic' and less 'applied' than the ideal cases at the two extremes. Stokes, in contrast, has good reasons to assume that much, if not most, scientific research is not classifiable as either basic or applied research, and that particularly those studies that seek to substantially contribute to societal development can often also be labelled as basic research. In his analysis, Stokes (1997: 7I-72) cites the impressive work of Louis Pasteur in the field of microbiology as a perfect synthesis of the aims of 'understanding' and 'use'. Pasteur strove to achieve a fundamental understanding of the bacteriological processes he studied, but he was equally interested in controlling the effects of those processes in humans and animals. The unidimensional model, for its part, forces Pasteur's research into a murky middle ground.

Against this linear model, Stokes posits a two-dimensional conceptual plane that does justice to research inspired both by the quest for fundamental understanding and by considerations of practical use and application.

\section{Quadrant model of scientific research \\ Stokes (1997: 73)}

Research is inspired by:

\section{Considerations of use?}

No Yes

Quest for

fundamental understanding?

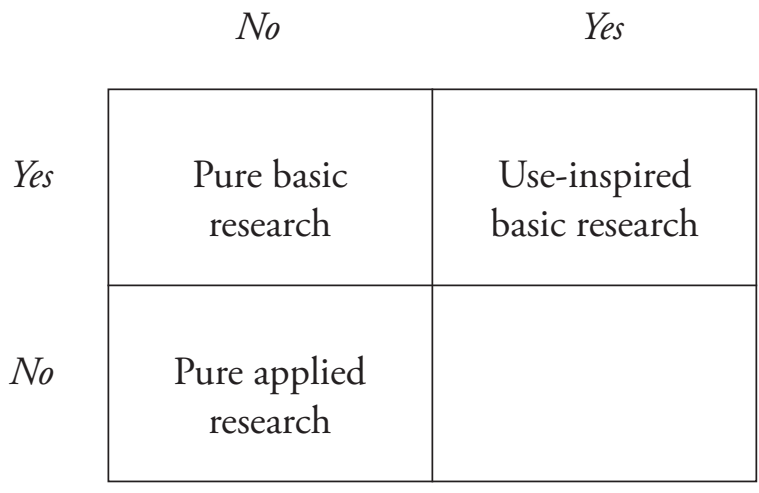


The work of the theoretical physicist Niels Bohr typifies the upper-left quadrant: pure, basic research carried out with no practical aim, even though many applications were potentially there. On the lower right is the quadrant of pure applied research, exemplified by the work of Thomas Edison, who, as Stokes observes, restrained his employees from investigating the deeper scientific implications of the findings they made in their pursuit of commercially profitable electrical light. In Pasteur's quadrant, we find research that both seeks to expand the frontiers of understanding and draws inspiration from practical considerations. In addition to Pasteur and others, Stokes cites here research by John Maynard Keynes and by the Manhattan Project.

The fourth quadrant is not empty, but is occupied, according to Stokes, by 'research that systematically explores particular phenomena without having in view either general explanatory objectives or any applied use to which the results will be put, a conception more at home with the broader German idea of Wissenschaft than it is with French or Anglo-American ideas of science' (Stokes 1997: 74, italics in original). This is the quadrant (if we may interpret Stokes in this way) of disciplines such as art history, which, in their focus on specific phenomena, are not primarily searching for the fundamental understandings referred to here, nor are they seeking any kind of practical application. Obviously this is a simplification. After all, interpretation, for example, often plays a significant role in describing artworks, while the results of the research can also be put to use for mediating purposes in the art world. Stokes himself cites Peterson's Guide to the Birds of North America, which systematically describes the characteristics and distribution of bird species, as an example of a worthy endeavour that neither pursues fundamental understanding nor envisages any direct application.

Now what help does this conceptual framework give us in understanding and positioning artistic research in the broad realm of research and development? Unlike Gibbons and

The irony will escape no one. By suggesting a connection here between art history and the writing of a bird guide, I show that I fell into the same trap in 4 preparing this chapter that I have criticised others for: unnecessarily and unproductively distancing oneself from people that could actually be allies. his colleagues, Stokes devotes virtually no attention to the field of humanities, let alone discussing an often small-scale activity like artistic 
research. This does not, however, relieve us of the task of investigating what significance his model could have for the type of research we are studying here. Although artistic research, as we have seen, operates on many of its fronts at a considerable distance from the practices and mores of 'science', the quadrant model can be interpreted in ways that can shed light on that synthesis of creative design, performative engagement, affective reflexivity, and talent development which is so unique to the artistic quest. In artistic research, art practices are deployed methodologically in the research process, and in part they are also outcomes of the research themselves. The research seeks both to broaden our understanding of the world and of ourselves as well as to enrich that world by experimentally developing new artefacts: compositions, designs, choreographies, images, art installations. Artistic research is (to borrow Stokes's words) motivated both by a 'quest for fundamental understanding' and by 'considerations of use'. It therefore belongs to Pasteur's quadrant.

In the Critique of Judgement, Immanuel Kant drew a distinction between pure aesthetic judgment and the judgment of art. Art judgment surpasses aesthetic judgment, because it focuses on the cultural value of artworks as well as on their beauty. That cultural value lies in their capacity to 'leave [something] over for reflection' and to 'dispose [...] the spirit to Ideas. ${ }^{3}$ Although these principally undefined, but fundamental, 'ideas' are a different type of insights to the scientific explanations or interpretations obtained through 'basic research', they are no less fundamental. That is because, as we experience art, we articulate what it means to have any experiences, knowledge, and understanding at all (to remain in the transcendental spirit of Kant). This is the reflexive nature of art; this is the engagement which is immanent in aesthetic distance. Hence, in addition to producing artefacts in the form of artworks and artistic practices, artistic research also generates fundamental ideas and understandings which, although non-discursive as a rule, make the world into what it is or could be. Here lies the performative and critical power of research in the arts.

7. Kant (1978 [1790/93]: \$53, \$52) alludes to a quality of artworks which 'etwas zum nachdenken übrigbleiben läßt', 'den Geist zu Ideen stimmt'. 


\section{'... excluding artistic "research" of any kind'?}

Officials at the OECD headquarters in Paris have recently held out the prospect of a new edition of the distribution list from which the phrase 'excluding artistic "research" of any kind' will be scrapped. The Humanities classification will then be as follows: History and Archaeology; Languages and Literature; Philosophy; Ethics and Religion; Art; and Other Humanities. What 'other humanities' is meant to include has not been specified. The Art section will then read:

The Revised Field of Science and Technology (FOS) Classification in $\checkmark$ the Frascati Manual has meanwhile been published on the website of the OECD.

Art (arts, history of arts, performing arts, music)

- Arts, Art History; Architectural Design; Performing Arts Studies (Musicology, Theatre Science, Dramaturgy); Folklore Studies

- Studies on Film, Radio and Television

A Dutch government spokesperson who took part in the revision explained that 'this must involve activities of a research nature - therefore not the specific subdivisions of the arts themselves, but the activities that study them'.

This explanation is only of limited help to us, and the classification remains peculiar. Nonetheless, it is definitely meaningful to distinguish between art practice per se and artistic research - assuming, at least, that not all art is also research, as some people claim. ${ }^{9}$ In the foregoing text I have mainly used the term artistic research to denote that domain of research and development in which the practice of art - that is, the making and the playing, the creation and the performance, and the works of art that result - play a constitutive role in a methodological sense. This type of research is also described as 'research in and through artistic practice', 'art research', or 'practice-based' or 'practiceled' research in the creative and performing arts. I have opted for the term 'artistic research' here because that succinctly, and rather provoca-

8. E-mail correspondence, 20 October 2006 (my translation from Dutch).

9. See chapter 2 for a discussion of this distinction. 
tively, claims a place for this endeavour in the world of research and development (as laid down in the Frascati Manual) - and also, of course, as a tongue-in-cheek reference to the OECD distribution list.

But let us come back to the issue at stake. What is artistic research all about? It is about cutting-edge developments in the discipline that we may broadly refer to as 'art'. It is about the development of talent and expertise in that area. It is about articulating knowledge and understandings as embodied in artworks and creative processes. It is about searching, exploring, and mobilising - sometimes drifting, sometimes driven - in the artistic domain. It is about creating new images, narratives, sound worlds, experiences. It is about broadening and shifting our perspectives, our horizons. It is about constituting and accessing uncharted territories. It is about organised curiosity, about reflexivity and engagement. It is about connecting knowledge, morality, beauty, and everyday life in making and playing, creating and performing. It is about 'disposing the spirit to Ideas' through artistic practices and products. This is what we mean when we use the term 'artistic research'. 



\section{Chapter 5}

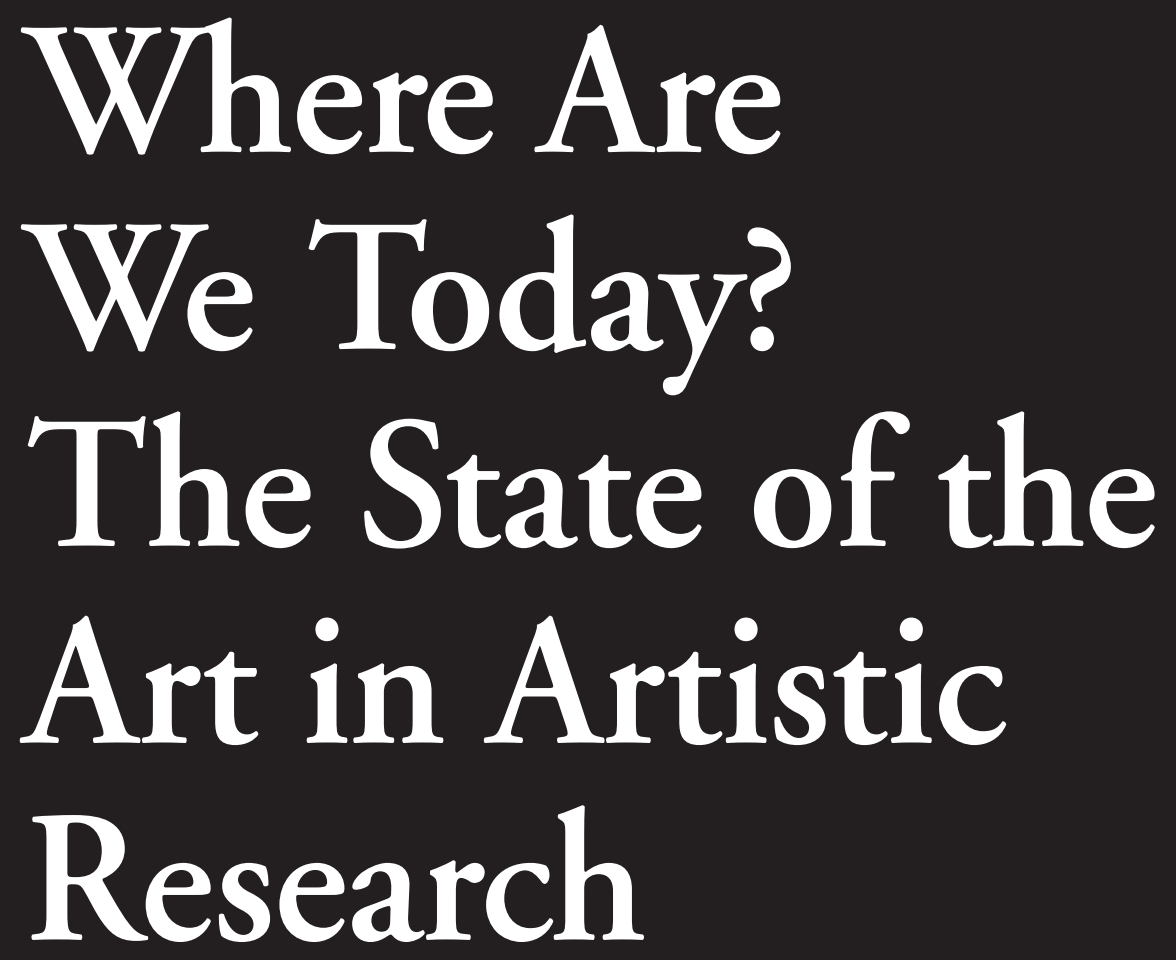




\section{Künstlerische Grundlagen- forschung jenseits markt- orientierter Kunstproduktion ist die Basis für die Zukunft der "Kulturnation Österreich".}

* From 'Money (f)or the Arts', an initiative by the rectors of the Austrian universities of the arts (see MONEY 2007). 'Fundamental artistic research, beyond market-oriented art production, is the basis for Austria's future as a "cultural nation"' (my translation). 


\section{Context}

It is now time for a brief stopover. I began my explorations in 2004 and will finish them in 2012 (for the time being). In 2008-2009, I was asked to summarise the current situation in artistic research in Reykjavík (October 2008), Vienna (December 2008), Copenhagen (February 2009), Saltsjöbaden near Stockholm (March 2009), and Berlin (June 2009). This chapter can hence be regarded as a further elaboration of chapter 2 , in which I broadly outlined the debate on research in the arts. Many topics discussed in previous chapters are summarised, reformulated or expanded on here. The present chapter is also a snapshot in time. But since some time had elapsed between my presentations and their eventual publication in Sweden (2010) and Austria (20II), I have chosen the Austrian publication for inclusion here. This is not only because it contains the most recent information, but also because it describes an interesting initiative by the Austrian Science Fund (FWF). I saw less need for annotations in the present text. 
Artistic research is a challenging but controversial subject. There are different views on what this type of research encompasses. Some people even doubt whether any such thing as 'artistic research' exists at all. Some people, both in academia and in the art world, oppose the very phenomenon of artistic research. Yet at the same time, artistic research is gaining recognition and support - in the academic world, in the art world, and also from government bodies that are supporting this new field of research with legislation and funding.

The controversies surrounding artistic research often turn on the problem of demarcation. What exactly distinguishes artistic research from art practice? And what distinguishes it from scientific or academic

The emergence of artistic research could be an excellent subject for a case study that would analyse, from a Habermasian point of view, how the political and economic subsystems penetrate into this still vulnerable field of research with their power and money mechanisms, and thus threaten to corrupt it. research? Underlying such demarcation problems is a question of legitimacy. Do practice-based research degrees, and especially a $\mathrm{PhD}$ in the arts, have a place? Who needs them? Which institutions should be vested with degree awarding power? And does artistic research, like all other research, deserve long-term funding? When it comes down to it, it all appears a question of power and money, as so often is the case. This constantly threatens to corrupt the debate on the substance of artistic research.

Some people think the battle is already over, that victories have been won, and that the time has now come to leave the debate on foundations behind us and get back to business. After all, there is still much work to be done to further establish the new field of research - infrastructural and institutional work, but also other work like building a corpus of best practices. Yet the debate on artistic research is still not over. Many people, both inside and outside academia, are still asking what artistic research really is, what place it deserves, and what significance it has. In fact, the subtitle of this essay might just as well have been 'The Issue of Artistic Research'.

In the pages below, I shall (I) describe artistic research as an emerging paradigm, against a backdrop of trends (2) in higher education and (3) in artistic practice. I will (4) say something about the place of artistic research in the science system and (5) pose the question of 
whether artistic research can indeed be considered academic research. I will then discuss some (6) epistemological and (7) methodological issues, and will (8) identify three aspects of artistic research that I view as characteristic. I will conclude with (9) some comments on the place of artistic research in the training of artists. I must limit myself here to a schematic description of artistic research. All these topics deserve to be treated in far more detail. My sketch of where we now stand in artistic research should provide a broad overall view, but not a comprehensive one.

Here and there in the text I shall refer to the situation in Austria, and in particular to the new Programme for Arts-Based Research (Programm zur Entwicklung und Erschließung der Künste, or PEEK) recently launched by the Austrian Science Fund (FWF). ${ }^{\mathrm{I}}$ In creating this programme, Austria has taken a step that deserves to be followed in continental Europe.

Before beginning my sketch, I would like to comment on the term artistic research. A variety of expressions exist to denote this form of research, but artistic research is now the most widely used. German speakers increasingly refer to künstlerische Forschung. In francophone Canada, the term recherche-création is in frequent use. In the world of architecture and product design, the expression research by design is common. Brad Haseman in Australia has proposed using performative research to distinguish the new paradigm from other qualitative research paradigms. In the United Kingdom, the terms practice-based research, and increasingly practice-led research, are often used, in particular by funding agencies like the Arts and Humanities Research Council. Sometimes the term practice as research is used to indicate the central place that artistic practice occupies in the research. The expression research in and through art practice is also used by some in order to distinguish this type of research from research into or for art practice.

What all these expressions have in common is the word research. Yet that does not go without saying. Research in the emphatic sense is an activity traditionally associated with what people do in universities and industrial laboratories, and not with what people do as they

I. See PEEK 2009. 
practise or teach art. In my country, the Dutch Advisory Council for Science and Technology Policy recently recommended using 'design and development' (ontwerp en ontwikkeling) to denote those research-like activities that take place in professional schools, including the schools of the arts; within higher education, the term 'research' (onderzoek) was to be restricted to universities. Reality has since overtaken this recommendation, however, and 'applied research' is now defined as one of the remits of higher professional education in the Netherlands, and is even recognised as such by law. ${ }^{2}$ This illustration of the reluctance to use the word research does not stand alone. In Norway, the Artistic Research Fellowship Programme has been operating since 2003. That is its English name, at least, but in their own language Norwegians avoid the term forskning and speak instead of kunstnerisk utviklingsarbeid ('artistic development work'). And in Austria, the term arts-based research is used in English to denote the new funding programme, whereas the German name is Entwicklung und Erschließung der Künste ('development and promotion of the arts').

To be sure, differences do exist in what words such as research, recherche, Forschung, or onderzoek normally denote and connote in English, French, German, or Dutch. By analogy, there are also considerable differences between what is meant by the English science and the German Wissenschaft, which also includes the humanities (Geisteswissenschaften). In the foundational struggle that is raging over artistic research, the uses and the meanings of words are of cardinal importance. As paradigms shift, not only do changes occur in the way of looking at things, but also in the meanings

One aim of this book is to argue for a broader notion of 'research' and an enhanced notion of 'academia' (cf. my annotation in chapter 2, page 44). of words. And who owns the language, anyway?

In the background of this semantic controversy, science policy continues to be informed by a rather obsolete model of what 'research and development' is. The classical notion, as laid down in sources such as the

2. This decision recently received support when the Conference of European Ministers Responsible for Higher Education issued an appeal known as the Leuven Communiqué (see LEUVEN 2009) in April 2009 to further strengthen the knowledge and research functions in European higher professional education. 
Frascati Manual, draws a distinction between 'basic research', 'applied research', and 'experimental development'. In the eyes of some, artistic research would have more to do with the experimental development of artefacts (works of art) than with research in the emphatic sense. This is a misunderstanding. Although artistic research certainly seeks to enrich our world with new artworks and new artistic practices, it additionally seeks to gain a fundamental understanding of our world and ourselves as embodied in those artworks and practices. Or, as the PEEK formulates it, 'Artsbased research should be understood as basic aesthetic research, involving knowledge acquisition and method development through artistic and aesthetic processes as opposed to purely scientific ones.'

\section{Artistic research as emerging paradigm}

A portrayal of artistic research from within as a new field of research, as an ascendant paradigm, would need to describe the types of objects or topics at which the research is directed, the sorts of questions asked, the types of methods applied, and the kinds of knowledge it generates. I have chosen here to describe the paradigm from outside. I therefore employ 'paradigm' in a loose sense, rather than in the strictly Kuhnian sense as used in the philosophy of science. As I intend to use 'paradigm', it denotes a conceptual and institutional framework that embodies its own practices, vocabularies, and theories. Such a framework gains a stable status once it is underpinned by the following elements: (I) institutions and organisations that support the paradigm and afford it legitimacy; (2) publications in books and journals which explicate the paradigm's basic principles and provide access to the research findings; (3) conferences in which cutting-edge developments within the paradigm are presented and discussed; (4) government bodies and funding agencies that support the paradigm through both formal and material means; ( 5 ) institutions of higher education which pass on the paradigm and initiate newcomers into it.

3. PEEK 2009: 3 (my translation). The German: 'Arts-based Research ist als ästhetische Grundlagenforschung zu verstehen und meint damit den Erkenntnisgewinn und die Methodenentwicklung mittels ästhetischer und künstlerischer im Unterschied zu rein wissenschaftlichen Erkenntnisprozessen.' 
I. In numerous countries, organisations have been founded (or sections set up within existing organisations) that are dedicated to artistic research. Within higher education, artistic research is now gaining a foothold within schools of the arts as well as in post-academic institutes. Arts institutions and events outside the education system, such as museums, dance companies, and biennales, are also giving increasing attention to artistic research. European network organisations like the European League of Institutes of the Arts (ELIA) and the European Association of Conservatoires (AEC) have strands and projects devoted to artistic research.

2. A growing number of journals are publishing on artistic research. Some are specifically dedicated to this field of research, especially in visual arts and design. At this writing, a journal on practice-based research in music is being founded, and plans also exist for an international Journal for Artistic Research. More and more books (readers, monographs, textbooks) are appearing on the market which deal with methodological and epistemological aspects of the research field. A voluminous collection of articles entitled The Routledge Companion to Research in the Arts will be published in October 2010 (see box for a list of recent books).

\section{Books on artistic research (2004-20II)}

- Carole Gray and Julian Malins, Visualizing Research: A Guide to the Research Process in Art and Design (Aldershot: Ashgate, 2004)

- Paul Carter, Material Thinking (Melbourne: Melbourne University Press, 2004)

- Graeme Sullivan, Art Practice as Research: Inquiry into the Visual Arts (London: Sage, 2005)

- Mika Hannula, Juha Suoranta, and Tere Vadén, Artistic Research: Theories, Methods, Practices (Helsinki: Academy of Fine Arts; Gothenburg: University of Gothenburg, 2005)

- Katy Macleod and Lin Holdridge (eds), Thinking through Art: Reflections on Art as Research (London: Routledge, 2006)

- Pierre Gosselin and Éric le Coguiec (eds), La Recherche créa- 
tion: Pour une compréhension de la recherche en pratique artistique (Québec: Presses de l'Université du Québec, 2006)

- Estelle Barrett and Barbara Bolt (eds), Practice as Research: Approaches to Creative Arts Enquiry (London: I.B. Tauris, 2007)

- Sabine Gehm, Pirkko Husemann, and Katharina von Wilcke (eds), Wissen in Bewegung: Perspektiven der künstlerischen und wissenschaftlichen Forschung im Tanz (Bielefeld: Transcript, 2007)

- Dieter Mersch and Michaela Ott (eds), Kunst und Wissenschaft (Munich: Wilhelm Fink, 2007)

- Shannon Rose Riley and Lynette Hunter (eds), Mapping Landscapes for Performance as Research (Basingstoke: Palgrave Macmillan, 2009)

- Ludivine Allegue and others (eds), Practice-as-Research in Performance and Screen, (Basingstoke: Palgrave Macmillan, 2009)

- James Elkins (ed.), Artists with PhDs: On the New Doctoral Degree in Studio Art (Washington DC: New Academia, 2009)

- Elke Bippus (ed.), Kunst des Forschens: Praxis eines ästhetischen Denkens (Zurich: Diaphanes, 2009)

- Anton Rey und Stefan Schöbi (eds), Künstlerische Forschung: Positionen und Perspektiven (Zurich: Institute for the Performing Arts and Film, Zurich University of the Arts, 2009)

- Corina Caduff, Fiona Siegenthaler, and Tan Wälchli (eds), Kunst und künstlerische Forschung: Musik, Kunst, Design, Literatur, Tanz, Jahrbuch Zürcher Hochschule der Künste, 6. Also in English within same volume: Art and Artistic Research: Music, Visual Art, Design, Literature, Dance, Zurich Yearbook of the Arts, 6 (Zurich: Scheidegger und Spiess, 2009)

- Kathleen Coessens, Anne Douglas, and Darla Crispin, The Artistic Turn: A Manifesto, Orpheus Research Centre in Music Series, I (Leuven: Leuven University Press, 2009)

- Michael Biggs and Henrik Karlsson (eds), The Routledge Companion to Research in the Arts (London: Routledge, 20II)

- Janet Ritterman, Gerald Bast, and Jürgen Mittelstraß (eds), Kunst und Forschung: Können Künstler Forscher sein? (Vienna: Springer, 20II) 
- Florian Dombois and others (eds), Intellectual Birdhouse: Artistic Practice as Research (London: Koenig Books, 20II)

- Janneke Wesseling (ed.), See It Again, Say It Again: The Artist as Researcher (Amsterdam: Valiz, 20II)

- Martin Tröndle and Julia Warmers (eds), Kunstforschung als ästhetische Wissenschaft: Beiträge zur transdisziplinären Hybridisierung von Wissenschaft und Kunst (Bielefeld: Transcript, 20II)

3. Conferences and symposia that focus on artistic research now constitute an international forum for the presentation and discussion of the latest developments and viewpoints. Often such gatherings have unusual formats that do justice to the specific nature of research in the arts. As well as the classical keynote addresses and paper presentations, they offer many workshops and demonstrations with hands-on opportunities to learn from one another. The proceedings of these meetings form a growing corpus of texts that further the debate on artistic research. At the same time, participants seek alternative forms of presentation, documentation, and dissemination that are more compatible with the practice of artistic research. The box below gives an (incomplete) list of such conferences held between October 2008 and June 2009.

Conferences on artistic research (October 2008 to June 2009)

- Sensuous Knowledge 5: 'Questioning Qualities'. Bergen, 2426 October 2008

- Research into Practice 5: 'Interpretation in Research in the Visual and Performing Arts'. London, 3I October 2008

- elia Biennial Conference: 'Talkin' Loud and Saying Something? Four Perspectives on Artistic Research'. Gothenburg, 29 October-2 November 2008

- Netherlands Organisation for Scientific Research (Nwo): ${ }^{\mathrm{PhD}}$ in de kunsten' (PhD in the Arts). The Hague, 2r November 2008

- Austrian Science Board (öwr): 'Kunst und Forschung' (Art and Research). Vienna, 4 December 2008

- Association of Nordic Music Academies (anma), Annual Meeting 2009: 'Research and Artistic Work'. Copenhagen, 5 February 2009 
- Swedish Research Council (Vetenskapsrådet): 'Konstnärlig forskning inför framtiden' (Artistic Research in the Future). Stockholm, I2-I3 March 2009

- Zürcher Hochschule der Künste (Zurich University of the Arts, ZHdK): 'The Difference of Art and Art Research across the Disciplines'. Zurich, 23-24 April 2009

- Die Junge Akademie (The Young Academy): 'Salon Kunst und Wissenschaft'. Berlin, 20 June 2009

4. The national science and research councils and funding agencies are increasingly amenable to artistic research, supporting it both substantively (by formulating standards and quality criteria) and materially (by providing funding). The box below lists reports and programmes that give an impression of developments in various European countries. Some of the financial support is ongoing, lump-sum funding to universities of the arts; some is channelled through national programmes that issue grants on a competitive basis. The support may focus on projects initiated inside or outside the schools of the arts, on research by staff members, on $\mathrm{PhD}$ studentships in the arts, or on fellowship programmes for artists. In some countries, the accent is on collaboration between the arts and sciences, and in others between the arts and 'industry' (particularly the smaller- and middle-scale enterprises in the cultural sector).

Artistic research in international perspective: State of the art 2010

- In the United Kingdom, ongoing funding has been provided since the early 1990 os for staff research in arts education institutions. The Arts and Humanities Research Council also provides grants for 'practice-led' doctoral research, and there is a special Research Fellowship programme for artists.

- Universities and art schools in Belgium work together in partnerships known as Associations, which give funding and support for research in the arts and for doctoral research by artists. From 20IO, the National Fund for Scientific Research (NFWO/FNRS) will have a specialised committee known as Cult2 to assess applications involving artistic research.

- In Austria, the Fonds zur Förderung der wissenschaftlichen 
Forschung (Austrian Science Fund, FWF) has recently launched the Programm zur Entwicklung und Erschließung der Künste (Programme for Arts-Based Research, PEEK) to support artistic research. In May 2009, the Wissenschaftsrat (Austrian Science Board) issued the report Empfehlung zur Entwicklung der Kunstuniversitäten in Österreich (Recommendations for the Development of Art Universities in Austria), which included proposals for promoting research in the art universities.

- In March 2009, the Rektorenkonferenz der Fachhochschulen der Schweiz (Rectors' Conference of the Swiss Universities of Applied Sciences, KFH) published the report Forschung an Schweizer Kunsthochschulen (Research at Swiss Universities of the Arts) which urges the promotion of 'künstlerische Forschung' (artistic research) and the development of third-cycle (doctoral-level) programmes.

- German federal states are working at varying paces to develop doctoral programmes in the arts. One of the first initiatives was the Promotionsstudiengang Kunst und Design (Doctoral Programme in Art and Design) at the Bauhaus-Universität Weimar. In November 2008, the Universität der Künste Berlin (Berlin University of the Arts) launched a third-cycle programme in the form of a Graduiertenschule (Graduate School).

- From January 20I0, a new law in Sweden permits establishment of doctoral programmes in higher arts education. The Swedish Research Council has decided to fund a national school for artistic research, administered by Lund University. The Swedish National Agency for Higher Education will decide which universities and/or university colleges will be entitled to confer doctoral degrees.

- In Norway, an Artistic Research Fellowship Programme has been operating since 2003. It enables artists, in affiliation with one of the higher arts schools, to do full-time research for three years which is recognised as equivalent to doctoral study.

- The Academy of Finland published an

The German Research Foundation (DFG) is to organise a workshop on artistic research on 4-5 May 2012 in the Haus der Kulturen der Welt in Berlin. One purpose is to consider creating facilities for artistic research. 
English report in March 2009 entitled Research in Art and Design in Finnish Universities, setting out strategies for the future that might be of interest elsewhere in Europe.

5. Artistic research has made its entry into European higher education in the arts. The pace of the initiatives, as well as the emphases laid, may vary from country to country. One important theme is the introduction of a third cycle in arts education, which sometimes takes the form of a doctoral degree course and sometimes of a fellowship programme. At the end of this essay I will return to the status of artistic research in arts education.

\section{Artistic research and higher education policy}

If you talk about higher education policy in Europe today, you talk about Bologna (or Dublin, Berlin, Lisbon, Leuven). That reflects the goal of forty-six European nations to create a European Higher Education Area (EHEA) by 20IO. This homogeneity of higher education systems is intended to improve transparency in education. It facilitates comparison of programmes, degrees, and diplomas. It promotes mobility of students and staff, as well as other forms of international exchange and cooperation. The higher education reforms have varying consequences for the countries adopting the Bologna process, and they are also proceeding at different speeds. For some countries, this development signifies a farewell, or at least drastic adaptations, to the binary system that here and there stubbornly divides the world into thinkers and doers.

The Bologna process also entails the full introduction of an education framework common in English-speaking countries, which consists of three cycles: bachelors, masters, and doctorate. In particular for professionally or practically oriented schools of higher education, this is a major shift. It is a step that has long been taken in the UK, where the former polytechnics were promoted to university status in 1992. Arts education has followed this trend in many countries.

With the introduction of the three-cycle structure, research has also made its entry into those realms of higher education that previously had little or no experience with research. These include arts education. The question now arises as to whether Bologna is a dictate and threat 
targeted at arts education from outside, or whether it represents an opportunity and challenge for the arts schools. My appraisal is that the entry of research into higher arts education could help create a free space for artistic research, for what Paul Carter has called 'material thinking'. But first the arts education sector has to articulate what it understands by artistic research.

\section{Artistic research and art practice}

Research today seems like a craze. It provokes quite some scepticism here and there in the art world. How can this 'academisation' (as some disdainfully call it) be in the interest of artistic practice? Won't this 'academic drift' lead slowly but surely to some new kind of 'academism', to an art form and an art discourse that are isolated from the art in the 'real world' (even if they mean something within academia)? That danger should not be played down. Especially since the historical avant-garde, there is a justifiable reticence amongst artists, and within the broader art world, towards every form of academism. And indeed, artistic research deserves to be banned forthwith if it heads in that direction, if it is no longer propelled by developments within artistic practice itself.

The artists of today are what Donald Schön has called 'reflective practitioners'. The current dynamic in the art world demands that artists be able to contextualise their work, and to position themselves vis-à-vis others in the art world, vis-à-vis current trends and developments in artistic practice, vis-à-vis grant providers and the general public. This outside perspective complements the view from inside. A naïve conception of art, of artworks, art production, and art reception, is a thing of the past. We have left behind us any pre-critical conception of art, such as persisted even within modernism. Art (and not just conceptual art) is highly reflexive, even though pre-reflective (tacit) aspects also figure in its production and reception. This reflexiveness of art, in conjunction with the reflexive stance of the artist, is one of the most important rationales for research in the arts.

Artistic research is inseparably tied to the artistic development of the artist as well as to the development of the discipline or disciplines in which he or she works. Through artistic research, artists create room for fundamental reflection - a free space to think - in and through their 
practice of creating and performing. In the art world, in artistic practice, there is a real need for this free space for material thinking. Both the pressure of the art market and the strains of art production leave artists little room to 'stop and contemplate' what they are doing. Many artists must operate as free enterprisers in the market of the 'creative industry', a market that is not oriented to reflection, but which expects its suppliers to deliver a constant stream of new products and projects. Introducing artistic research into higher arts education would mean creating room, within this haven at least, where artists and trainees can grow and thereby contribute to the development of the arts. Or, as a pamphlet jointly published by the rectors of the Austrian art universities has recently put it: 'Fundamental artistic research, beyond market-oriented art production, is the basis for Austria's future as a "cultural nation".'4

A book with a subtitle such as 'Perspectives on Artistic Research and the Art World' could . take this impact as its primary focus. Just as academia is not a stable system, but one that is continually evolving, the art world and the things we understand by 'art' are also in a constant state of transformation. The present book focuses on the transformation of academia.

The art world therefore needs artistic research with a certain sense of urgency. But there is also a tension between artistic practice and academia, between the relatively autonomous art world, with its distinctive culture and dynamic, and the world of research, of reflection. That tension need not be unproductive. Interesting things can happen when those two worlds meet. The advent of artistic research will have its impact on academia, on the self-understanding of arts academies and universities, and on our understanding of what academic research is. And there will likewise be an impact on artistic practice, on our conceptions of art creation and of what art is.

\section{Artistic research within the science system}

The world of science and technology, of research and development, can be categorised in various ways. As we have seen, the classical subdivision between basic research, applied research, and experimental development is no longer appropriate in the light of the present diversity of academic fields, research strategies, and knowledge forms. Various suggestions have

4. See MONEY 2007. 
been made for different ways of looking at science and knowledge production. One proposal highlights the emergence and importance of 'Mode 2 knowledge production'. In contrast to the more traditional research in university disciplines, Mode 2 production involves interdisciplinary or transdisciplinary research in the context of application (see Gibbons et al. 1994). It also implies the substantive and organisational involvement not just of academics, but of other stakeholders as well, who help plan the research and evaluate its societal relevance.

Because of its close ties with art practice and the central role that that practice plays in the research, it sometimes seems as if artistic research is a type of Mode 2 knowledge production. Indeed, some forms of artistic research, such as research in architecture or product design, can be considered Mode 2 production. But other forms, like research on historical performance practice in music or research in and through choreographic practices, might more readily be seen as intradisciplinary basic research intended to contribute both materially and cognitively to the development of the art form in question.

As noted, much artistic research focuses simultaneously on enriching our world by developing new products (like compositions, images, performances, installations) and on broadening our understanding of reality and of ourselves - an understanding that is embodied in the products generated by the research. This dual research aim likewise transcends the classic dichotomy of applied versus basic research. Stokes's (1997) quadrant model provides a conceptual framework for understanding this type of research. In Stokes's analysis, much valuable research, today and in the past, embraces both these aims: achieving a fundamental understanding of what is being studied, as well as developing products and services that benefit society. This multidimensional model of the science system enables us to understand that unique intertwinement of 'development and promotion of the arts' (Entwicklung und Erschließung der Künste) and 'basic aesthetic research' (ästhetische Grundlagenforschung) that is characteristic of artistic research. The new Austrian Programme for Arts-Based Research (РEEK) allows for both: "Typical artistic "products" such as concerts, performances, exhibitions, or compositions may certainly serve as an aesthetic laboratory or a proof-of-concept within a PEEK 
arts-based research project.'s And, as noted above: 'Arts-based research should be understood as basic aesthetic research, involving knowledge acquisition and method development through artistic and aesthetic processes as opposed to purely scientific ones. ${ }^{36}$

\section{Artistic research as academic research}

Can artistic research be understood as a form of academic research? Such a question presumes that a stable concept exists of what academic research is. By and large, there is rough agreement within academia about what is understood by academic research. But as has more often been the case in history, such understandings are subject to change as new research traditions arrive on the scene that offer an enhancement or adjustment to what has been passed down. It is quite conceivable that the introduction of artistic research into academia will influence our understanding of academic research, and even our understanding of what academia is.

Academic research is characterised by an 'original investigation in order to gain knowledge and understanding' (RAE 2005: 34). Thus begins the definition employed by the former Research Assessment Exercise in the UK. Such research is guided by well-articulated questions, problems, or topics which are relevant in the research context - which in our case includes both art practice and the academic discourse on the arts. The research employs methods that are appropriate to the research and which assure the validity and reliability of the research results. The findings are presented, documented, and disseminated in appropriate ways. This is the way that every academic research study answers the questions: What is being studied? Why is it being studied? How is it studied? In what form are the results presented? If artistic research is described in this way, there is not yet any reason to exclude it, even though its object, context, method, and knowledge production may be unconventional.

The emergence of artistic research runs parallel to what might be called the liberalisation of research in academia. One witness to this lib-

5. PEEK 2009: 3 (my translation). The German: "Typische Kunst-"Produkte" wie Konzerte, Aufführungen, Ausstellungen oder Kompositionen [können] im Sinne eines ästhetischen Labors oder eines Demonstrators des proof-of-concept sehr wohl Teil eines PEEK-Projekts sein.'

6. See note 3 . 
eralisation is the definition given in the European Higher Education Area standards known as the Dublin Descriptors (JQI 2004: 3), which set out the intended learning outcomes of the first, second, and third cycles:

The word [research] is used in an inclusive way to accommodate the range of activities that support original and innovative work in the whole range of academic, professional and technological fields, including the humanities, and traditional, performing, and other creative arts. It is not used in any limited or restricted sense, or relating solely to a traditional 'scientific method'.

In the case of artistic research, it is important to stress that the object of research, the context of the research, the method of research, and the way the research results are presented and documented are inextricably bound up with the practice of making and playing. Indeed, artistic practice is central to the research itself. The subject of research is the artist's creative or performative practice. The study is relevant in the context of artistic practice, the art world. The research takes place in and through the artist's creative and performative actions, and the research findings are, in part, artistic products and practices. The PEEK programme description also recognises this quality as an important distinction between artistic research and the more traditional academic research on the arts. 'Arts-based research differs fundamentally from academic disciplines like literary studies, art history, and musicology.'7

Artistic research thus occupies a place of its own in the world of academic research. The Austrian Science Fund has an extensive classification scheme listing different types of academic art studies, from Angewandte Kunst (applied arts) to Theaterwissenschaft (theatre studies) to Produktgestaltung (product design) to Jazzforschung (jazz research) a total of twenty-seven disciplines. At the very least, Künstlerische Forschung (artistic research) deserves to be added to that list.

7. PEEK 2009: 3 (my translation). The German: 'Entwicklung und Erschließung der Künste unterscheidet sich prinzipiell von Wissenschaftsdisziplinen wie z.B.

Literaturwissenschaft, Kunstgeschichte und Musikologie.' 


\section{The epistemology of artistic research}

If research is an original investigation undertaken to gain knowledge and understanding, then in the case of artistic research we could add the synonyms insight and comprehension, in order to emphasise that a perceptive, receptive, and verstehende engagement with the subject matter is often more important to the research than getting an 'explanatory grip'. Such an investigation also seeks to enhance our experience - in the rich sense of the word 'experience': the knowledge and skills accumulated through action and practice, plus apprehension through the senses.

In the history of epistemology, the distinction is made between knowing that something is the case - theoretical knowledge, propositional knowledge, explicit knowledge, focal knowledge - and knowing how to do something, to make something - practical knowledge, embodied knowledge, implicit knowledge, tacit knowledge. Artistic research operates mainly in the latter sphere. This is not to say that explicit, propositional knowledge plays no part in artistic research. It generally does. Yet the accent lies on those forms of knowledge and understanding that are embodied in artistic practices and products.

So artistic research could be described as first and foremost an articulation of the non-propositional forms of knowledge and experience in and through the creation of art. The obvious question is what

Another key to it lies possibly in Adorno's insight that thoughts and concepts assemble around art in such a way that the artworks themselves begin to speak. This will return in chapter 7, pages 154 and I68 (and cf. also my annotation in chapter 3 , page 69). 'articulation' means here - and more specifically, what the role of discursivity is, of language, of the verbal. How can the research be understood and evaluated if language does not at least play a mediating, explanatory role? One key to this question is intersubjectivity. In the domain of artistic research, as in other research domains, the last word is spoken in a peer-group assessment process. As the PEEK programme description puts it: 'To qualify as arts-based research, the creative process and its reception have to be intersubjectively assessed, documented, and presented in order to ensure lasting accessibility for discourse and for systematic research.'8 


\section{The methodology of artistic research}

Sometimes artistic research is closely related to humanities research, in particular to that in art studies and cultural studies. These disciplines may provide interpretive frameworks that can also figure in research in and through artistic practice, such as hermeneutics, semiotics, critical theory, or cultural analysis. Sometimes artistic research has much in common with technological, applied research, particularly where the research is aimed at improving materials and techniques or at designing new instruments or applications. And sometimes artistic research has a strong affinity with social science research, and more particularly with ethnographic research or action research - whereby, in both cases, the subject and object of study are intertwined, and the researcher is both a participant and an observer.

All these forms of investigation have their place in the emerging tradition of artistic research, and it would seem logical to therefore argue for methodological pluralism. Artistic research does not have any one distinct, exclusive methodology. But there is one qualifying condition: artistic research centres on the practice of making and playing. Practising the arts (creating, designing, performing) is intrinsic to the research process. And artworks and art practices are partly the material outcomes of the research. That is what 'material thinking' means.

\section{Three aspects of artistic research}

The contiguities between artistic research and other research domains are manifold. These open many opportunities for productive liaisons, as can be widely observed in practice. Some artist-researchers orient themselves to academic art studies, some to philosophical aesthetics. Others feel affinities with cultural studies or performance studies, and action research and ethnographic field research may also be integrated with artistic research. Some take phenomenology or cognitive sciences as a source of inspiration, and others focus on engineering and tech-

8. PEEK 2009: 3 (my translation). The German: 'Der kreative Prozess und dessen Rezeption müssen jedoch intersubjektiv reflektiert, dokumentiert und präsentiert werden, um im Sinne der Arts-based Research nachhaltig dem künstlerischen Diskurs und der wissenschaftlichen Forschung zur Verfügung zu stehen.' 
What is meant here is 'metaphysics ... after its fall'. I first used this notion in my article 'Solidarität mit Metaphysik nach ihrem Sturz: Einige Bemerkungen anläßlich Albrecht Wellmers Adorno-Lektüre' (Solidarity with Metaphysics after its Fall: Some Remarks with Reference to Albrecht Wellmer's Reading of Adorno) (Borgdorff I998b). I will say a little more about this in the two chapters to follow. Non-conceptualism, realism, and contingency are discussed at the end of chapter 7 .

nology. In my view, research in and through artistic practice has three characteristic attributes, which constitute the 'metaphysics' of artistic research: (I) Artistic research concerns and affects the foundations of our perception, our understanding, and our relationship to the world and other people. I would call this the realism of artistic research. (2) Artistic research is 'material thinking': the articulation of non-propositional knowledge and experience, embodied in artworks and creative processes. This is the non-conceptualism of artistic research. (3) Artistic research is not about theory, but about thought. It is not primarily directed at 'knowing that ...' or 'knowing how ...'. It is directed more at a not-knowing, or a notyet-knowing. It creates room for that which is unthought, that which is unexpected - the idea that all things could be different. This is the contingency of artistic research.

\section{Artistic research and the schools of the arts}

A distinction needs to be made between research and research training. Within the arts academies, the schools of the arts, this translates into the difference between research by staff and research by students during their training. And within the latter it is important to distinguish between the bachelors, masters, and doctoral levels. Clearly the bachelors curriculum will teach elementary research skills like argumentation, information, communication, and presentation (thinking, searching, writing, speaking). The masters and doctoral programmes can then focus more directly on doing research. In 200I, an informative report was published by the UK Council for Graduate Education (UKCGE 200I) entitled Research Training in the Creative and Performing Arts and Design. It makes lucid recommendations for building research training programmes at arts schools. Suggestions involve the research environment, research seminars, programme content, admission procedures, supervision of researchers and research projects, and assessment of the research. This report could provide support and inspiration to those who are currently working to introduce research into arts education. 
As pointed out above, there are many variations in the ways artistic research is embedded into European higher education in the arts. One issue involves whether arts education has university status or takes place in professional schools - or more precisely, whether the institutions in question have degree-awarding power, including the right to offer research training programmes at the $\mathrm{PhD}$ level. Another issue is whether the institutions have the material capacities to create a research environment, whether their staff members have opportunities for research, and whether there is adequate funding. In closing I shall highlight several examples that illustrate the variations that now exist in Europe.

In the UK, ongoing support is provided for both staff research through the Higher Education Funding Councils and doctoral research through the Arts and Humanities Research Council (AHRC) and other bodies. Every six years, a Research Assessment Exercise (RAE) takes place that forms the basis for allocating research funding to the institutions. Some organisations operate thematic programmes as well, including programmes which focus on research in the arts, such as the AHRC's recent Beyond Text programme.

At the Universität der Künste Berlin (Berlin University of the Arts, UdK), a Graduiertenschule (Graduate School) was established in November 2008 which offers a third-cycle programme. The awarding of the doctorate, however, is reserved for the more traditional disciplines, such as art history or music education. Creative and performing artists are still not eligible for that degree, but receive a diploma on completion of the postgraduate programme. Part of the focus in the $\mathrm{UdK}$ is on collaboration between artists, academics, and scientists.

In the Netherlands, research chairs known as lectoraten have been created since 2002. Before that, no research at all occurred at arts academies, conservatories, or theatre schools. Currently, thirty such research chairs in the arts exist throughout the country - amounting to no more than one professor per 650 students. In addition to research, the remits of these professors include special emphases on innovation in arts education, strengthening ties with professional practice, and in-service research training for staff at the academies. A pilot project initiated by the Netherlands Organisation for Scientific Research (Nwo) for a limited number of PhD studentships for visual artists was started in 2009. 
Regrettably, the Fellowships in the Creative and Performing Arts scheme, operated by the AHRC in the UK, was closed in September 2009. In Norway, by contrast, the government has announced plans to fund additional projects in the field of artistic research alongside the fellowship programme.
A final example involves the fellowship programmes for artists that exist in the UK and in Norway. They are designed for mid-career artists who are enabled to do full-time artistic research in affiliation with one of the arts schools. This formula directly benefits both the artists' practice and the educational institution. The artists are temporarily freed from the pressure of producing for the market, and can work on their artistic development by doing research. The arts school benefits from the artists' presence through the seminars and workshops they teach and the best practices they convey. In Norway, these programmes have governmental recognition as being on par with $\mathrm{PhD}$ programmes.

And now we are back to where we started. 'Fundamental artistic research, beyond market-oriented art production, is the basis for the future', not just for Austria as a cultural nation, but for the development of arts and culture throughout Europe. 



\section{Chapter 6}

Artistic

Research as

Boundary

Work 


\title{
Das ist eben die große Frage: Wo steht die Kunst? Welchen Ort hat sie?
}

\author{
Martin Heidegger*
}

* Martin Heidegger 1976, 'Nur noch ein Gott kann uns retten' [in conversation with Rudolf Augstein and Georg Wolff on 23 September 1966], Der Spiegel, 30.23 (3I May), pp. 193-219 (p. 219). The entire conversation appears in Antwort: Martin Heidegger im Gespräch, ed. by Günther Neske, and Emil Kettering (Pfullingen: Neske I988), pp. 8I-III. 


\section{Context}

Three of my areas of interest intersect in this chapter, which was written as a sort of pamphlet. My interest in the currency of Hegel's thesis on 'the end of art' dates to the early 1990s. The issue of the potential of metaphysics, after its fall, engaged my thoughts in the late I990s. In the same period, I also developed my interest in the newer analytic philosophy, in particular in the wake of the late Ludwig Wittgenstein. It formed the inspiration for my ideas about non-conceptualism, realism, and contingency. In part, these are an elaboration of an older publication of mine entitled 'Holismus, Wahrheit und Realismus: Adornos Musik-Denken aus amerikanischer Sicht' (Holism, Realism and Truth: Adorno's Musical Thought from an American Point of View). An invitation to the conference 'The Difference of Art and Art Research across Disciplines', held at Zurich in April 2009, gave me the opportunity to link these interests to artistic research. In this chapter I argue that artistic research acknowledges the epistemic (and moral) import of art. This chapter likewise required fewer annotations. 


\section{The difference between art and artistic research}

Asking how artistic research differs from art is a corollary of a broader question: How does the domain of art differ from the domain of science? Or where does art stand in relation to science, or to politics and morality, to the economy or to everyday life?

How art relates to science may seem obvious at first glance. Just as there is an obvious difference between playing sports and studying them in sport sciences, or between politics and political science, the distinction between art practice and artistic research would seem as clear as day. Yet drawing boundaries like these is not always easy. Consider the domain of the courts as compared to the legal sciences, or that of religion

The 'sport argument' is used 4 more often. It could also be heard during an afternoon seminar on artistic research in July 2009 at the University of Amsterdam's Department of Philosophy. in comparison to theology. And the recent financial crisis has made us painfully aware that the distinction between the economy and economics is highly relative.

The attempt to distinguish what belongs to art practice from what belongs to artistic research is reminiscent of what in the philosophy of science is known as the demarcation problem. It involves delimiting what can be considered part of science from what cannot, or distinguishing what qualifies as science from mere pseudoscience. Karl Popper's influential views on this question are well known; he argued that openness to falsification was the quality that distinguished science from pseudoscience.

Demarcating our subject matter would amount to formulating one or more principles that distinguish art from pseudo-art - or rather, that distinguish art from non-art. Arthur C. Danto is one writer who has expressed views on this. One of his insights is worth highlighting in our context: no essentialist definition is possible of what art is. The distinction between art and non-art is a construed one, and it depends on what is recognised as such in the 'art world' (the totality of artists, art criticism, art theory, and art industry) at a particular point in time (cf. Danto 1986). Such constructivism, which we also encounter in post-Popperian philosophy and sociology of science in thinkers like Paul Feyerabend, Pierre Bourdieu, and Bruno Latour, radically qualifies the problem of demarcation. And this should 
be a lesson to us as we examine the difference between art and artistic research.

We are interested here not so much in the difference between art and non-art as we are in demarcating the domain of art practice from the domain of science or research, or the domain of morality, or that of daily life. Here, too, demarcations, dichotomies, definitions, and identities are problematic - an insight also celebrated in poststructuralism. The issue of the essence of art has been supplanted by that of the dynamics of the art world, where different life domains may meet and interpenetrate one another. Attempts to address this question may be labelled as 'boundary work' (Gieryn 1983). In trying to fathom something of the dynamics of the art world, one cannot assume a stable concept of art; the presumed boundaries of that world are the subject of constant debate.

Artistic research also qualifies as such boundary work - and in two different directions. Artistic research is an activity undertaken in the borderland between the art world and the academic world. The topics, the questions, as well as the results of such research are judged, and have meaning, both in the art world and in academia. And in this respect artistic research appears to differ from more traditional academic research, whose relevance and validity is determined primarily within the community of peers, within the walls of academia, within the world of the universities.

At least that was the image many people had of academic research until recently. That image is now substantially altered. The international debate on the relevance and valorisation of academic research, the advent of transdisciplinary research programmes, and the recognition of non-traditional forms of knowledge production (such as Mode 2; Gibbons et al. 1994) have all shown that the context of justification of academic research lies in both academia and society. The quality of the research is determined by an extended peer group in which stakeholders from the context of application also have a voice. I say 'also' because the basis on which research is judged, as well as the final word over that judgment, still resides in the academic community of peers. 


\section{Intermezzo I: On peer review}

The peer review system may be regarded as a sign of the independence and maturity of the domain of science. Within that domain, the forum of peers is the first to decide what is relevant and what the quality standards will be. Mutual peer assessment of quality and validity is also required in the case of newer forms of knowledge production, preferably in an open and blind assessment process in accepted academic channels.

So how, then, is the relevance and the quality of art and artistic research assessed? When asked which people judge the quality of artistic research, the head of a prestigious postgraduate art institute in the Netherlands recently replied 'artists and experts'. By 'experts' he meant curators, critics, theoreticians...

It is true that what art is is not determined by artists alone, but is 'defined' in the 'art world' (to follow Danto and Howard Becker), in the 'field of cultural production' (to follow Pierre Bourdieu), in the 'network of actors' (to follow Bruno Latour). Yet the question remains: Who are the experts? Who are the peers? Wouldn't it attest to the maturity of artistic research if the dominant influence of curators and other 'secondary' actors were to come to an end? Or, more cautiously perhaps, shouldn't the artist-researchers themselves accede to the forum of peers that determines what has relevance and quality? Fortunately, we now see the phenomenon of the artist-curator popping up here and there. Emphasising the importance of the artist-researcher as part of the community of peers would greatly benefit the emerging field of artistic research.

\section{The idea of art as an autonomous sphere (and the story of its eighteenth-century emancipation)}

The following tale may be told of the relationship between art and the domains of science and morality. Once upon a time, in Greek antiquity, thinkers like Plato emphasised the unity of beauty, truth, and goodness. But over the course of history, the life spheres of art, science, and morality grew apart, until, in the eighteenth century, they became 
not only institutionally, but also theoretically, autonomous. This differentiation between aesthetics, epistemology, and ethics - which Kant provided with an impressive foundation in his Critiques - still persists today, although 'the unity of reason in the diversity of its voices' ${ }^{\text {' }}$ was also emphasised from Kant onwards.

The birth of the autonomous spheres of Art and Aesthetics (duly capitalised) in the eighteenth century was signalled by two publications: Charles Batteux's Les Beaux Arts réduits à un même principe (The Fine Arts Reduced to a Single Principle) from 1748 and Alexander G. Baumgarten's Aesthetica from 1750. Batteux's work raised three issues. First, the system of fine arts constitutes an autonomous sphere (for Batteux, it comprised painting, sculpture, music, poetry, and dance). Second, these arts converge on a single principle. Third, that principle is the subject matter of philosophical aesthetics. Here ends our little history of Art's emancipation in the eighteenth century.

That history has especially made itself felt since Paul O. Kristeller published his two-part article 'The Modern System of the Arts: A Study

Kristeller is a Renaissance specialist, but his 'Modern System' extends beyond his own professional sphere. 'Classic is perhaps too modest a description, as the leading ideas in Kristeller's piece were subsequently adopted as established orthodoxy among historians and philosophers of art and by intellectual and cultural historians, and they are now more or less legion' (Porter 2009, pages I-2). in the History of Aesthetics' in the Journal of the History of Ideas in I95I and 1952. This study, which traces the history of the system of arts from Greek antiquity to the twentieth century, is still broadly authoritative in art history circles today. It often also figures as an implicit assumption in the broader discourse on art. Kristeller's system of arts, by the way, consists of painting, sculpture, architecture, music, and poetry, with dance relegated to the second rank (with engraving, gardening, theatre, opera, and prose) (Kristeller 195I/52).

Very recently (in the spring of 2009), a remarkable article by James I. Porter (2009) appeared in the British Journal of Aesthetics entitled 'Is Art Modern? Kristeller's "Modern System of the Arts" Reconsidered'. It presents a radical challenge to Kristeller's 'system'. Porter claims first of all that 'the system of the arts' is a historical construction - and more likely an invention of Kristeller than

I. Jürgen Habermas, 'Die Einheit der Vernunft in der Vielheit ihrer Stimmen' (2009). 
an accurate description from the historical sources. He then argues that the bond between the presumed autonomous spheres of the arts and of philosophical aesthetics was not as tight as Kristeller claims, and that aesthetic formalism was a twentieth-century aberration. Finally, he attempts to show that the arts are always, and have always been, linked in one way or another to intellectual or moral content. Interestingly, he supports this with evidence from the likes of Clement Greenberg, who, in his well-known appeal for materialistic objectivity, flatness, and physical quality, refers to the eighteenth century, claiming that the arts concealed their 'mediality' at that time by focusing on literature - that is, on intellectual and moral content and meaning (Porter 2009: 4-6).

\section{Intermezzo 2: The end of art (or how art connects to other life domains)}

In the discourse on art, the issue of 'the end of art' crops up from time to time, for instance in the work of Danto. In the transition from Greenbergian modernist abstraction to postmodernist art that began in the mid-196os, Danto saw a rupture that signalled the end of the immanent developmental history of art. Post-historical art had become conceptual; assessing it was based not primarily on sensory perception, but on intellectual consideration (whereby Danto assumes that the two are fundamentally separate). This brought the history of the narrative, pictorial tradition to an end (Danto I986: 8I-II7).

Danto varies a theme that has accompanied the project of the modern' since Georg W.F. Hegel. But the distance to Hegel has grown rather wide. Here is Hegel's (1975, vol. I: IO, II, IO3) voice in his Lectures on Aesthetics in the I820s:

Art no longer affords that satisfaction of spiritual needs which earlier ages and nations sought in it, and found in it alone.

Art is and remains for us, on the side of its highest vocation, something past.

For us, art counts no longer as the highest mode in which truth fashions an existence for itself. 
Those 'spiritual needs', 'highest vocation', and 'truth' have certainly slipped away from us in the course of history. Or at least, few people would venture to utter such grand terms today. But Hegel's 'end of art' does not mean that art is not to develop further. Here is Hegel (p. 130) again:

We may well hope that art will always rise higher and come to perfection, but the form of art has ceased to be the supreme need of the spirit.

Here, 'the end of art' is the end of art's ability to give appropriate expression to the Absolute Spirit. It is a farewell to transcendence, to a glorification of art which had been so celebrated by early-Romantic philosophising intellectuals but a short time previously.

But perhaps it is better to speak of a 'naturalisation' or 'humanisation' of transcendence. Here is Hegel (p. 607) once more:

Art [...] makes Humanus its new holy of holies: i.e., the depths and heights of the human heart as such, mankind in its joys and sorrows, its strivings, deeds, and fates.

After the end of art, art concerns itself with 'Humanus'. A bond with our concrete human life now steps into the stead of art's bond with the absolute, the infinite. The end of art means a reconfirmation of art's bond with who we are and where we stand - a reassertion of the connectedness of art to our intellectual and moral life. Today we can endorse this, without referring to Hegel.

\section{Naturalisation of transcendence: \\ A metaphysics of art - after its fall}

Our current situation lies in the wake of the linguistic and pragmatic turns in theory. The constitutive roles of language and action have superseded 'reason' and 'reality', which, in traditional epistemology and metaphysics, were the foundations on which the edifice of our knowledge rested. We find ourselves in the wake of the farewell to the grands récits (Lyotard) - in the wake of postmodernism, understood as a poignant, melancholic farewell to modernism, or as a cheerful inau- 
guration of Nietzschean perspectivism. We have discarded our naive belief in meta-narratives, and have grown more modest about our potential to get a grip on physical and social reality. We are now in a time that follows the clean-up work done by deconstructivism and ordinary language philosophy. The remnants of the once stable framework of meaning, knowledge, and reality that buttressed the edifice of art, science, and morality have now been permanently abandoned on the junk heap of history.

What we now need is a metaphysics of art, after its fall. Also after Hegel's time, naturalisation of transcendence means both taking leave of overly high pretensions (which still linger today in the minds of many) as well as preserving the awareness that art has the power, or gives us the power, to critically transcend the reality in which we find ourselves and which we are. That is meta-

'Metaphysics of art - after its

$\checkmark$ fall' refers to Theodor W. Adorno, who concluded his book Negative Dialectics with the statement 'There is solidarity between such thinking and metaphysics at the time of its fall.' Cf. my annotation in chapter 5 , page I22. physics as it is possible after its fall. There is a sense in which the task is to overcome metaphysics and a sense in which the task is to continue metaphysical discussion (cf. Putnam 1990: 19).

Cognizant of the bond between art and our intellectual and moral life, artistic research seeks to achieve a reflective articulation of that critical transcendence. It thereby concerns and affects our relationship to the world and to ourselves. That is what I have elsewhere called the 'realism' of artistic research.

In all this, we should keep two things in mind. First, we experience more than we can say. That does not just apply to art, of course, but to our whole relationship to the world and to other people. Art has no exclusive rights here, but this pre-reflective immediacy particularly manifests itself in creative processes, in works of art, and in artistic experiences. The early-Romantic echo in this wording is no accident. Of course we can no longer fall back on an uncritical understanding of art, and of course art has become reflexive. But here, too, there is a sense in which we are now beyond the vaulting claims of early Romanticism, and a sense in which we are still the heirs of this now naturalised realm of thought. The reflexivity of art - its quality of both questioning itself and giving food for thought, and of thus also showing a 'concep- 
tual' dimension - must not be construed in opposition to the, in a philosophical sense, non-conceptual content that lies enclosed in it. In artistic research, we are concerned directly with that pre-reflective, nonconceptual content, as enacted in creative processes and embodied in works of art. In this way, art invites us to critically transcend what is. Artistic research is the acceptance of that invitation.

But at the same time we should bear in mind that we might be wrong in our critical transcendences. That is the fallibilism of artistic research. After all, it offers a fundamentally open perspective on what is or could be. That is the contingency of artistic research - a contingency that derives directly from the fact that the content of art cannot entirely be captured in any epistemological project whatsoever.

Metaphysics of art - after its fall, after the end of art, after postmodernism - means an understanding of art as a critical reflective practice, encompassing non-conceptual content, which sets our aesthetic, intellectual, and moral life into motion. It also means an understanding of artistic research as the practice of that fundamentally unfinished critical reflection. 

Chapter 7

The Production

of Knowledge

in Artistic

Research 



\section{Context}

This is a chapter in which many themes from preceding chapters come together. After an introduction and a preliminary account, I position artistic research in academia as a field of endeavour that has both kinships and contrasts with other disciplines. In the second half of the chapter, I critically examine the criteria for doing research in the new field, possibly amending or at least refining them. Such refinements will be needed as I later weigh up the assessment criteria for artistic research in terms of the reviewers' guidelines for the Journal for Artistic Research (chapters IO and II). Like the previous chapter, this one concludes with subsections on non-conceptualism, realism, and contingency in artistic research. These reflections invite additional research. The voices of Theodor W. Adorno, Ludwig Wittgenstein, and also Stanley Cavell can be heard here. 
This chapter examines artistic research as a form of knowledge production. It will conclude, however, by saying that artistic research seeks not so much to make explicit the knowledge that art is said to produce, but rather to provide a specific articulation of the pre-reflective, nonconceptual content of art. It thereby invites 'unfinished thinking'. Hence, it is not formal knowledge that is the subject matter of artistic research, but thinking in, through, and with art.

The reader might skip this introduction and the next section (pages I43-I49) of the chapter, as it is mostly a recap of what was said before, and continue the reading with 'Affinities ...'.

The expression 'artistic research' connects two domains: art and academia. Obviously the term can also be used in a general sense. Every artist does research as she works, as she tries to find the right material, the right subject, as she looks for information and techniques to use in her studio or atelier, or when she encounters something, changes something, or begins anew in the course of her work. Artistic research in the emphatic sense - and as used in this chapter - unites the artistic and the academic in an enterprise that impacts on both domains. Art thereby transcends its former limits, aiming through the research to contribute to thinking and understanding; academia, for its part, opens up its boundaries to forms of thinking and understanding that are interwoven with artistic practices. These specific 'border violations' can spark a good deal of tension. The relationship between art and academia is uneasy, but challenging. That is one reason why the issue of demarcation between the artistic and the academic has been one of the most widely discussed topics in the debate on artistic research in the past fifteen years. ${ }^{\mathrm{I}}$

A related issue of demarcation is at play in the relationship between academia and 'artistic development' and 'artistic practice'. In

\footnotetext{
I. The demarcations and dichotomies employed in this chapter should not be interpreted too absolutely, but rather taken as imperfect dialectical tools to put the subject matter into perspective. See [chapter 2 of this volume] for a discussion of this problem of demarcation; and see Candlin (2000) [and chapter 3] for insights into the uneasy relationship between art and academia. The relationship between the seemingly undisciplined artistic and the ultimately disciplinary academic makes the project of artistic research into an endeavour in which that relationship is a constant focus. Is this state of uneasiness and reflexivity something to be overcome, or is it intrinsic to the place of artistic research in academia?
} 
some quarters, one prefers to speak not of artistic research, but of 'artistic development'. ${ }^{2}$ The word 'research' stays reserved for activities in traditional universities or industrial research centres. Indeed there is something to be said for preferring the term 'artistic development'. Artistic research certainly contributes to the development of the arts, just as all other research tries to contribute to the discipline in question. Research and development are intimately entwined, and it may sometimes make sense to highlight the developmental aspect, especially when one is inclined to question the importance of research for art practice. One issue that continually resurfaces in the debate involves where, precisely, the distinction lies between art practice in itself and art practice as research. Although I will not address this question explicitly here, it will be present in the background. The entanglement of artistic research with art practice and with artistic development is so close that a conceptual distinction often appears contrived. ${ }^{3}$

In discussing artistic research as a form of knowledge production, I begin by tentatively describing this type of research - in terms of sub-

The four E's - embeddedness, enclosure, enactment, embodiment - correspond to four dimensions: the context, the reception, the production, and the artwork. ject, method, context, and outcome - as research in and through art practice. Embedded in artistic and academic contexts, artistic research seeks to convey and communicate content that is enclosed in aesthetic experiences, enacted in creative practices, and embodied in artistic products.

In the second section, I explore similarities and differences between artistic research and other spheres of academic research, in the domains of humanities, aesthetics, and social sciences and in fields of natural science and technology. Artistic research, so I will claim, distinguishes itself in specific respects from each of these

2. In the Netherlands, a government advisory committee has advised using the term ontwerp en ontwikkeling (design and development) to denote research activities in nonuniversity professional schools. Norway uses the term kunstnerisk utviklingsarbeid (artistic development work), Austria uses Entwicklung und Erschließung der Künste (development and promotion of the arts), and some people in Denmark and Germany also tend to avoid words for 'research' such as forskning or Forschung.

3. Such distinctions are usually made by people who first create a caricature of the one activity, believing they are protecting the other activity by doing so. 
research traditions, whereby neither the natural science model, the humanities model, nor the social science model can serve as a benchmark for artistic research.

The third section addresses the issue of whether artistic research can be considered academic research. By virtue of its distinctive context, its studio-based research practice, the specific types of knowledge and understanding it deals with, and its unconventional forms of documentation and dissemination, artistic research occupies its own place in the realm of academic research.

I conclude the chapter with a series of observations on the epistemology and metaphysics of artistic research. The current programme of phenomenologically inspired cognitive science offers tools for examining the issue of the non-conceptual content ${ }^{4}$ enclosed in artworks and art practices. Clearly research in and through artistic practices is partly concerned with our perception, our understanding, our relationship to the world and to other people. Art thereby invites reflection, yet it eludes any defining thought regarding its content. Artistic research is the acceptance of that paradoxical invitation. It furthermore enhances our awareness of the pre-reflective nearness of things as well as our epistemological distance from them. This makes artistic research an open undertaking, seeking the deliberate articulation of unfinished thinking in and through art.

\section{A preliminary account of artistic research as research in and through art practice: Subject, method, context, outcome}

Despite all the differences of opinion that exist within the ascendant programme of artistic research, there seems to be general agreement about one thing: the practice of the arts is central to artistic research. On the surface, such an assumption seems commonplace. After all, doesn't all research that engages with the arts concentrate on 'the prac-

4. The reflexivity of art - its quality of both questioning itself and giving food for thought, and of thus also showing a 'conceptual' dimension - must not be construed in opposition to the (in a philosophical sense) non-conceptual and pre-reflective or unreflective content that lies enclosed in it. For an anthology on this subject, see Gunther 2003. 
tice of the arts'? Even disciplines like historical or sociological research on the arts focus on that.

In the case of artistic research, however, art practice plays a different role - and in terms of science theory a more fundamental one. Characteristic of artistic research is that art practice (the works of art, the artistic actions, the creative processes) is not just the motivating factor and the subject matter of research, but that this artistic practice the practice of creating and performing in the atelier or studio ${ }^{5}$ - is central to the research process itself. Methodologically speaking, the creative process forms the pathway (or part of it) through which new insights, understandings, and products come into being.

Another distinguishing feature is that contemporary art practice constitutes the relevant context for the research, alongside the academic forum. The research derives its significance not only from the new insights it contributes to the discourse on art, but also from the outcomes in the form of new products and experiences which are meaningful in the world of art. In part, then, the outcomes of artistic research are artworks, installations, performances, and other artistic practices; and this is another quality that differentiates it from humanities or social science research, where art practice may be the object of the research, but not the outcome. This means that art practice is paramount as the subject matter, the method, the context, and the outcome of artistic research. That is what is meant by expressions like 'practice-based' or 'studiobased' research.

In the literature on artistic research, we regularly see a distinction made between research on the arts, research for the arts, and research in the arts. This differentiation, which derives from, but also deviates from, categories proposed by Frayling (1993) [and cf. chapter 2 of the present volume], expresses different perspectives on the status of art practice. The interpretive perspective ('research on the arts') is common to the research traditions of the humanities and social sciences,

5. I use an expanded notion of 'studio', referring to artistic experimental practice in which the studio or atelier might be an element, but does not always need be. Many contemporary artists are not physically located in the studio, or they even oppose such an isolated, non-situated position and condition. 
which observe a certain theoretical distance when they make art practice their object of study. The instrumental perspective ('research for the arts') is characteristic of the more applied, often technical research done in the service of art practice; this research delivers, as it were, the tools and the material knowledge that can then be applied in practice, in the artistic process, and in the artistic product itself. In this case, art practice is not the object of study, but its objective. And as we see, the place of artistic practice becomes more central to the research here.

We can justifiably speak of artistic research ('research in the arts') when that artistic practice is not only the result of the research, but also its methodological vehicle, when the research unfolds in and through the acts of creating and performing. This is a distinguishing feature of this research type within the whole of academic research.

This is not to say that viewpoints in art criticism, social and political theory, or technology play no part in artistic research. As a rule they do play a part. The discourses about art, social context, and the materiality of the medium are in fact partially constitutive of artistic practices and products. The distinctiveness of artistic research, nevertheless, derives from the paramount place that artistic practice occupies as the subject, context, method, and outcome of the research. Methodological pluralism - the view that various approaches deriving from the humanities, social sciences, or science and technology may play a part in artistic research - should be regarded as complementary to the principle that the research takes place in and through the creation of art.

Behind the four specified dimensions of artistic research - subject, method, context, and outcome - are a range of problems that require more detailed analysis. First, the content of what artistic research investigates seems to elude direct access. It has an experiential component that cannot be efficiently expressed linguistically (cf. Biggs 2004). The subject of the research is partly the je ne sais quoi of artistic, aesthetic experience; ${ }^{6}$ as a matter of principle, it refuses every ex-

6. No distinction is made in this context between the artistic, aesthetic experience of the artist during the production process and the experience the audience has in receiving the artwork. Both the production and the reception of art have an experiential component that evades the conceptual grip. 
planatory gaze. What ontological status does this research object have? What sort of content lies enclosed in artistic experience? And how can one articulate that content?

Second, the focus, in the research process, on the practice of creating and performing is in line with what has been called the 'practice turn in contemporary theory' (Schatzki et al. 200I). Knowledge and experiences are constituted only in and through practices, actions, and interactions. In the context of discovery, pre-reflective artistic actions embody knowledge in a form that is not directly accessible for justification. What is the methodological import of this 'enacted approach' in artistic research? Is the researcher trying to reveal something of the secrets of the creative process, of artistic practice, or is the methodological deployment of the artistic creative process best suited because it takes an unmediated route to investigate from inside what is at work in art?

Third, works of art and artistic practices are not self-contained; they are situated and embedded. The meaning of art is generated in interactions with relevant surroundings. As noted above, the context in which artistic research takes place is formed both by the art world and by academic discourse; the relevance of the subjects and the validity of the outcomes are weighed in the light of both those contexts. Yet the situatedness of artworks and art practices also raises the question of the situatedness of practice-based research done within them. Does that research always aim to shed light on the way that artworks and practices affect our relationship to the world and to other people? Or can that research also confine itself to articulations that do not go beyond the domain of the artistic and the aesthetic?

Fourth, the experiences and insights that artistic research delivers are embodied in the resulting art practices and products. In part, these material outcomes are non-conceptual and non-discursive, and their persuasive quality lies in the performative power through which they broaden our aesthetic experience, invite us to fundamentally unfinished thinking, and prompt us towards a critical perspective on what there is. What is the epistemological status of these embodied forms of experience, knowledge, and criticism? And what relation does the material-performative have to the rational-discursive and the engaged-critical in the research?

In the debate on artistic research, these ontological, method- 
ological, contextual, and epistemological issues are still the subject of extensive discussion. In anticipation of a more elaborate account, the following preliminary characterisation can already be given: artistic research - embedded in artistic and academic contexts - is the articulation of the unreflective, non-conceptual content enclosed in aesthetic experiences, enacted in creative practices, and embodied in artistic products.

\section{Affinities and differences to other academic research traditions}

Artistic research has both historical and systematic affinities to a range of philosophical and scientific research traditions. A historiography of artistic research (which remains to be undertaken) might show that, from the Renaissance to the Bauhaus, there has always been research conducted in and through artistic practices. The fact

Cf. my annotation in chapter 4 , 4 page 77. that such research in retrospect often does not qualify as 'academic research' may say less about the research itself than about what we currently understand by 'academic'.?

The domain of art has long been interlaced with that of academia, from the practice of the artes in the late medieval monastery schools right up to today's postmodern farewell to the separation between the life domains of art, knowledge, and morality that has characterised modernity since the eighteenth century. In the current discourse on art, the realm of the aesthetic has reconnected with the epistemic and the ethical. The emergence of artistic research is consistent with this movement to no longer subordinate the faculties of the human mind to one another, either theoretically or institutionally.

In the previous chapter, I examined the engagement of art and artistic research with our intellectual and moral life. The 'agenda' of The Conflict of the

4 Faculties involves both the elucidation and the enhancement of the relationship between artistic research and academia.

7. Historiography needs to show modesty in two directions. The normative structure of today's academia should be neither a measure for evaluating the past nor a predictor to judge how intellectual and artistic efforts will be valued in the future. Current developments within academia, such as those involving commercialisation of academic research or the advent of hybrid transdisciplinary research programmes, show that the edifice of science is under constant reconstruction. 
On the contemporary research agenda at the interface of phenomenology, cognitive sciences, and philosophy of the mind, we now encounter a theme that is also central to artistic research: non-conceptual knowledge and experience as embodied in practices and products. I will come back to this in [the] final section [of this chapter]. I shall now make a series of comparisons between artistic research and research in the humanities (cultural and arts studies in particular), philosophical aesthetics, qualitative social science research, and technology and natural science research.

\section{Humanities}

There is a self-evident kinship between artistic research and the research in musicology, art history, theatre and dance studies, comparative literature, architectural theory, and moving image and new media studies, as well as the research in cultural studies or sociology of the arts. In all such academic disciplines or programmes, art (the art world, art practice, artworks) is the subject of systematic or historical research. A wide array of conceptual frameworks, theoretical perspectives, and research strategies are employed, which one might summarise with the umbrella term 'grand theories of our culture' among them hermeneutics, structuralism, semiotics, deconstruction, pragmatism, critical theory, cultural analysis. To study its research objects, each such approach has its own specific instruments availableiconography, musical analysis, source studies, ethnomethodology, actor-network theory.

Important for a comparison with artistic research is that those frameworks, perspectives, and strategies generally approach the arts with a certain theoretical distance. That is even true of fields like hermeneutics, which acknowledge that the horizons of the interpreter and the interpreted may temporarily merge, or cultural analysis, where theory may be seen as a discourse that 'that can be brought to bear on the object at the same time as the object can be brought to bear on it' (Bal 2002: 6I; italics in original). Obviously the dividing lines cannot always be clearly drawn, and any delimitations will always be partly artificial. In the research agendas just mentioned, however, the interpretive, verbally discursive approach appears to 
prevail above research strategies that are more practice-imbued. And precisely here lies a characteristic feature of artistic research: the experimental practice of creating and performing pervades the research at every turn. In this respect, artistic research has more in common with technical design research or with participatory action research than with research in the humanities.

The kinship with the humanities is often reflected in institutional proximity. Research centres, research groups, and individual researchers that engage in practice-based research in the arts are often accommodated in arts and humanities faculties and departments. Funding for their research often also comes from humanities research councils and funding agencies (and this partly explains the impassioned nature of the demarcation debate between art scholars and artist-researchers). Outside the traditional universities, at professional schools of the arts, artistic research can develop more freely, although here, too, it may be accommodated in a separate department for art theory and/or cultural studies. The importance of interpretation, theory, and reflection in artists' training cannot be emphasised

This is also the case with the 4 Academy for Creative and Performing Arts at Leiden University and the PhD Research in the Arts programme of the Netherlands Organisation for Scientific Research (Nwo), which are accommodated in a humanities faculty or section. A contrasting example is the Committee for Artistic Research and Development of the Swedish Research Council, which broke away from the Scientific Council for the Humanities and Social Sciences in 2010 and now continues as an independent entity under the council's executive board. too strongly, just as technical knowledge of artistry is also a sine qua non. But the prime focus in artistic research is on concrete creative practice. The research aims to make a substantial, preferably cutting-edge contribution to the development of that practice - a practice that is just as much saturated with histories, beliefs, and theories as it is based on skilful expert action and tacit understanding.

\section{Aesthetics}

A rich source for the artistic research programme is philosophical aesthetics, which has studied the non-conceptual knowledge embodied in art since the eighteenth century. I will highlight three examples from this tradition: the liberation of sensory knowledge in Baumgarten, the cultural value of the aesthetic idea in Kant, and the epistemic character of 
art in Adorno. ${ }^{8}$ The purpose of my brief review here is to show that the issue of the non-conceptual content in art has not appeared out of the blue, but has been thought through in many ways in centuries past.

Alexander Baumgarten called it analogon rationis: the ability of the human mind, analogous to reason, to obtain clear, but purely sensory,

The title of the Sensuous Knowledge conference series in Norway (2003-2009) was inspired by Baumgarten's term (see also chapter II, page 220). knowledge about reality. Great art is pre-eminently capable of manifesting that perfect sensory knowledge. In our context, the significance of Baumgarten's views lies in his accentuation of the sensory, experiential knowledge component in artistic research (cf. Kjørup 2006). In post-Baumgarten art research and aesthetics, the links to epistemology and perception became less prominent. The theme of sensory, non-discursive knowledge has regained currency in our times in research taking an embedded, enacted, and embodied approach to mind and perception. ${ }^{9}$

Immanuel Kant's critical investigation of what today is called the non-conceptual content of aesthetic experience culminated in his legendary articulation of the aesthetic idea as a 'representation of the imagination which induces much thought, yet without the possibility of any definite thought whatever, namely concept, being adequate to it, and which language, consequently, can never get quite on level terms with or render completely intelligible' (Kant 1978 [1790/93]: \$49). Kant assigned greater cultural significance to this non-conceptual realm of the artistic, which in Baumgarten had remained limited to sensory knowledge. Characteristic of artistic products, processes, and experiences is that - in and through the materiality of the medium - something is presented which transcends materiality. (Kant identifies here one of the links connecting the worlds of imagination and pure reason to the intelligible world' - a transcendence later elevated by Hegel into the 'sensory manifestation of the Idea'. After the linguistic and pragmatic turns in philosophy, what now matters is a naturalised understanding of this tran-

8. A more extensive reconstruction of philosophical aesthetics in its relation to artistic research would draw on topics from Hegel, Heidegger, Lyotard, and others.

9. For an overview of this cognitive science agenda, see Kiverstein and Clark (2009) in a special edition of Topoi dedicated to the subject. 
scendence; it all depends, of course, on what we mean by 'naturalised'.) Artistic research focuses both on the materiality of art - to the extent that this makes the immaterial possible - and on the 'Naturalised' - see chapter 6, 4 page $136-39$. immateriality of art - to the extent that this is embedded in the art world, enacted in creative processes, and embodied in the artistic material.

The significance of Kant's analysis lies in part in the distinction he drew in his Critique of Judgement between judgment of art and judgment of taste. Taste judgment (as analysed in 'Analytic of the Beautiful') focuses on the formal aspects of beauty, including disinterestedness and purposiveness without purpose. Art judgment surpasses taste or aesthetic judgment, because it focuses on the cultural value of artworks as well as on their beauty. That cultural value lies in their capacity to 'leave [something] over for reflection' and to 'dispose [...] the spirit to Ideas' (Kant 1978 [1790/93]: \$53, \$52). This is the quality through which art gives food for thought and distinguishes itself from a mere aesthetic gratification of the senses. The content of the aesthetic experience is identified more specifically here as that which brings thinking into motion, as it were, or as that which invites to reflection. Artistic practices are therefore performative practices, in the sense that artworks and creative processes do something to us, set us in motion, alter our understanding and view of the world, also in a moral sense. We encounter this performative aspect of art in artistic research to the extent that it involves the concrete articulation of what moves and engages us.

The ability of art, as articulated in artistic research, to speak to us is compellingly present in the work of Theodor W. Adorno. Here, the cultural value of art lies in its 'epistemic character' (Erkenntnischarakter), through which art reveals the concealed truth about the dark reality of society. Whereas in Baumgarten the non-conceptual content of art liberates itself from explicit rational knowledge, and whereas in Kant the non-conceptual aesthetic content invites us to reflection, Adorno assigns this content an even more potent and critical valence as the only thing that is capable - because it is antithetical to societal reality - of keeping alive the utopian perspective of a better world, and of recalling the original (albeit broken) promise of happiness. As no one after him, Adorno thought through art's engagement with the world 
and with our lives. Even if we distance ourselves from his dialectics and his philosophy of history, all engagement that lies enclosed in contemporary art and art criticism must take account of his legacy.

Art's epistemic character resides in its ability to offer the very reflection on who we are, on where we stand, that is obscured from sight by the discursive and conceptual procedures of scientific rationality. Noteworthy in Adorno is that thoughts and concepts are still always

'Entäußerte wirklich der Gedanke sich an die Sache [...], so begänne das Object unter dem verweilenden Blick des Gedankens selber zu reden' (Adorno I966: 36). needed - thoughts and concepts which, as it were, assemble themselves around a work of art, in such a way that the art object itself begins to speak under the lingering gaze of the thought. Herein may lie a key to exploring the relationship between the discursive and the artistic in artistic research. ${ }^{\text {.0 }}$

\section{Social science}

In the discourse about knowledge in artistic research, some observers emphasise the types of knowledge acquisition and production that derive from models of natural science explanation, quantitative analysis, and empirical logical deduction, which are encountered in the exact sciences, as well as in types of social science that follow natural science methods. Contrasting with this tradition of explanation and deduction is the academic tradition which, especially since the rise of interpretive (verstehende) sociology, seeks to 'understand' social and

The bulk of social science research, nonetheless, is mainly quantitative. cultural phenomena. In the past hundred years, a qualitative research paradigm, inspired by - hermeneutics, has developed which in many ways gives direction to social science research being done at present. It regards verstehende inter-

I0. Adorno 1966: 36, and cf. Borgdorff I998a: 300. The debate on the relationship between the discursive and the artistic, between the verbal and the demonstrable, often centres on whether the research process should be documented in writing and whether a verbal interpretation can be given of the research results. A third option is perhaps more interesting: a discursive approach to the research which does not take the place of the artistic 'reasoning', but instead 'imitates', suggests, or alludes to what is being ventured in the artistic research. See also the subsection 'Documentation, Dissemination' in the third section of this chapter. 
pretation and practical participation as more relevant than logical explanation and theoretical distance.

Artistic research shows a certain kinship to some of these research traditions. In ethnographic and action research in particular, strategies have been developed that can be useful to artists in their practice-based research; these include participant observation, performance ethnography, field study, autobiographical narrative, thick description, reflection in action, and collaborative inquiry. The often critical and engaged ethnographic research strategy acknowledges the mutual interpenetration of the subjects and objects of field research. It might serve as a model for some types of research in the arts, given that the artist's own practice is the 'field' of investigation.

Action research aims at transforming and enhancing practice, and as such it also has affinities with artistic research, as the latter seeks not only to increase knowledge and understanding, but also to further develop artistic practice and enrich the artistic universe with new products and practices. Artistic research is inseparably linked to artistic development. In the intimacy of experimental studio practice, we can recognise the cycle of learning in action research, where research findings give immediate cause for changes and improvements. This is also recognisable in the engaged outreach and impact of the research - artistic research delivers new experiences and insights that bear on the art world and on how we understand and relate to the world and ourselves. Artistic research is therefore not just embedded in artistic and academic contexts, and it focuses not just on what is enacted in creative processes and embodied in art products, but it also engages with who we are and where we stand.

The 'practice turn' in the humanities and social sciences not only sheds light on the constitutive role of practices, actions, and interactions. Sometimes it even represents a shift from text-centred research to performance-centred research, whereby practices and products themselves become the material-symbolic forms of expression, as opposed to the numerical and verbal forms used by quantitative and qualitative research. Artistic research also fits into this framework, since artistic practices form the core of the research in the methodological sense, as well as part of the material outcome of the research. This broadening 
of qualitative social science research to include research in and through art practice has led some observers to argue for a new distinguishing paradigm (Haseman 2006). ${ }^{\text {II }}$

The methodological and epistemological issues of artistic research are also addressed in the key writings relating to arts-based research in the tradition of the Eisner school (Eisner 198I; Knowles and Coles 2008). In studying the role of art in educational practice and human development, these social scientists use insights from cognitive psychology to argue the importance of artistic-cognitive development of the self, in particular in primary and secondary education.

\section{Science and technology}

Art practices are technically mediated practices. Whether this involves the acoustical characteristics of musical instruments, the physical properties of art materials, the structure of a building, or the digital architecture of a virtual installation, art practices and artworks are materially anchored. Artistic practices are technically mediated at a more abstract level of materiality as well. Consider the knowledge of counterpoint in music, of colour in painting, of editing in filmmaking, or of bodily techniques in dance. Technical and material knowledge are therefore indispensable components in the professional training and practice of artists.

Research that focuses on this technical and material side of art in order to improve applications, develop innovative procedures, or explore new artistic possibilities can rightly be called applied research. The knowledge obtained in exploratory technological and scientific research is put into practice in artistic procedures and products. This is research done in the service of artistic practice.

In artistic research itself, by comparison, art practice is not only the test of the research, but it also plays a critical role methodologically.

II. Whether artistic research constitutes a new paradigm is not something that can be decided here and now. Biggs and Büchler (2008: 12) rightly point out that the 'criteria that define academic research per se' must be met whether research is conducted under a new or an existing paradigm. I concur with Kjørup (2OII: 4I) that the characteristic of artistic research is 'a specific perspective on already existing activities' - a 'new perspective [which] in the longer run [will] have consequences for the direction of the development of art.' And of academia, I would like to add. 
In other words, as well as generating new or innovative art, the research is conducted in and through the making of art. The boundary between applied research in the arts and artistic research is thin and rather artificial, just as the dividing line between artistic research and performance studies or ethnography may also seem contrived. In the practice of artists, or even in their training, such a distinction is not always useful; the reality is more like a continuum that provides leeway for a variety of research strategies. But as argued above, methodological pluralism is merely complementary to the principle that artistic research takes place in and through the creation of art. For conceptual clarity, I would argue in this case that what sometimes does not hold true in practice may still be useful in theory.

The Dutch cartoon characters Fokke \& Sukke, examining an experiment in a laboratory setting: ' ... very impressive, colleague ... but does it also work in theory?'

I am also alluding here to Immanuel Kant's 1793 essay On the Old Saw: That May Be Right in Theory but It Won't Work in Practice (Ueber den Gemeinspruch: Das mag in der Theorie richtig sein, taugt aber nicht für die Praxis) (Kant 1974 [I793]).

Especially in the world of design and architecture, the methodological framework of applied research seems suitable. Many of the training programmes in these fields have strong ties to technical universities, or are even part of them. At first sight, it would seem that one must choose: either an orientation to art or to science, engineering, or technology. In practice, though, most design academies and architecture schools aspire to a fruitful combination. 'Research by design' is the peer of artistic research; there, too, the debate is still underway about the methodological and epistemological foundations of the research. ${ }^{12}$

An artistic experiment in a studio or atelier cannot simply be equated with a controlled experiment in a laboratory. Nonetheless, in many artistic research studies we can discern an affinity with fields like engineering and technology that use methods and techniques with origins in scientific research. In that case, the empirical cycle of observation, theory and hypothesis development, prediction and testing, and the model of the controlled experiment serve as an ideal type in the of-

I2. See, for example, the discussions about research by design on the PhD-Design mailing list (PhD-Design n.d.). 
ten haphazard context of artistic discovery (just as such principles are often applied in empirical social science research as well). Values inherent in scientific justification - including reliability, validity, replicability, and falsifiability - are also relevant in artistic research when it is inspired by the science model.

When artistic research has technological or scientific attributes, collaboration between artists and scientists seems only natural, since artists, as a rule, have not been trained to do those types of research. Bringing together expertise from these two worlds can lead to innovative findings and inspiring insights. Collaboration between artists and other researchers does not, however, confine itself to areas like technology, engineering, and product design. Research in other fields may also serve art practice or form productive ties with art. Consider the cooperation between artists and philosophers, anthropologists, or psychologists, as well as economists and legal theorists; projects involving artists are also conducted in areas such as the life sciences, artificial intelligence, and information technology. ${ }^{13}$

Roughly speaking, multidisciplinary cooperation between artists and scientists can take two different forms: either the scientific research

Here the artist is an 'outsider', 'visitor', or 'participant' in scientific practice. See Kitty Zijlmans, Robert Zwijnenberg, and Krien Clevis (eds), CO-OPs: Exploring New Territories in Art and Science, 2007; and cf. my remark in the Introduction to the present volume, page 3 . serves or illuminates the art; or the art serves or illuminates what is going on in the science. Currently there is great interest in the latter mode in particular. The assumption is that the arts will be able to elucidate, in their own unique ways, the procedures, results, and implications of scientific research. BioArt can exemplify this; this art form, whereby artists make use of biotechnological procedures like tissue and genetic engineering, leans heavily on scientific research, while often training a critical light on the ethical and social implications of research in the life sciences.

In the debate on research in the arts, these and other kinds of artand-science collaboration are often wrongly classed together with artistic research as explored in this chapter. Although the term 'art-and-science' may imply convergence at first glance, if anything it represents a

I3. For a detailed review, see Wilson 2002. 
reinstatement of the partition between the domain of art and the domain of science, between the artistic and the academic, between what artists do and what scientists do. There is nothing wrong with that, of course; it can only be applauded that these oft-segregated spheres and cultures are now meeting each other in projects where people learn from one another and where critical confrontations can take place. Yet multidisciplinary research projects like these must still be understood as collaboration between different disciplines around a particular topic, whereby the theoretical premises and working methods of the separate disciplines remain intact. The scientist does her thing, and the artist does hers. Even if the artist borrows right and left from the scientist, the aesthetic evaluation of the material, the artistic decisions made in creating the artwork, and the manner in which the results are presented and documented are still, as a rule, discipline-specific. Only very rarely does such multidisciplinary research result in any real hybridisation of domains.

Whilst artistic research is not entirely at odds with these types of art-science collaboration, it should still be regarded as an academic research form of its own. The science model cannot be a benchmark here, any more than artistic research could conform to the standards of the humanities.

\section{Artistic research as academic research}

Even if one accepts that artworks somehow embody forms of knowledge or criticism, and that such knowledge and criticism is enacted in artistic practices and creative processes, and also that the knowledge and criticism is embedded in the wider context of the art world and academia, then that still does not mean that what artists do may be construed as 'research' in the emphatic sense. 'Research' is 'owned' by science; it is performed by people who have mastered 'the scientific method', in institutions dedicated to the systematic accumulation of knowledge and its application, such as universities and industrial or governmental research centres.

It is indeed the case that 'what artists do' cannot automatically be called research. In the debate about artistic research, the discussions often turn on the distinction between art practice in itself and art practice as research [cf. chapter 2 above]. Few would contend that each work 
of art or every artistic practice is an outcome of research in the emphatic sense of the word. I shall confine myself here to the question of which criteria must be satisfied if artistic research is to qualify as academic research. I will show that artistic research incorporates both the interests of practice and those of academia. ${ }^{14}$

See also chapter 4 , pages $79-80$.

In the world of academia, there is broad agreement as to what should be understood by research. Briefly it amounts to the following. Research takes place when a person intends to carry out an original study to enhance knowledge and understanding. It begins with questions or issues that are relevant in the research context, and it employs methods that are appropriate to the research and which ensure the validity and reliability of the research findings. An additional requirement is that the research process and the research findings be documented and disseminated in appropriate ways.

This description of academic research leaves room for a great diversity of research programmes and strategies, whether deriving from technology and natural science, social sciences, or the humanities, and whether aiming at a basic understanding of what is studied or a more practical application of the knowledge obtained. Artistic research also falls within this characterisation of academic research. Let us focus more closely on the various components of this description. ${ }^{\text {Is }}$

I4. See Biggs and Büchler 2008, who argue for a balance between academic values and artistic values. To strongly simplify the matter, I would suggest that academic values have dominated in the British discourse thus far, whilst on the European continent the emphasis has lain more on artistic values. In their analysis of values, demonstrated through actions that are meaningful and potentially significant, in relation to the two communities (practice and academia), Biggs and Büchler appear to hold 'artistic practice' and 'academic research' constant, whereas in fact our notions of what both artistic practice and academic research are become enriched under the emerging 'paradigm' of artistic research.

15. An ontological, epistemological, and methodological exploration of artistic research [in chapter 2 above] culminated in the following definition: 'Art practice qualifies as research if its purpose is to expand our knowledge and understanding by conducting an original investigation in and through art objects and creative processes. Art research begins by addressing questions that are pertinent in the research context and in the art world. Researchers employ experimental and hermeneutic methods that reveal and articulate the tacit knowledge that is situated and embodied in specific artworks and artistic processes. Research processes and outcomes are documented and disseminated in an appropriate manner to the research community and the wider public.' 


\section{Intent}

The research is undertaken for the purpose of broadening and deepening our knowledge and understanding of the discipline or disciplines in question. Artistic practices contribute first of all to the art world, the artistic universe. The production of images, installations, compositions, and performances as such is not intended primarily for enhancing our knowledge (although forms of reflection are always entwined with art). This points to an important distinction between art practice in itself and artistic research. Artistic research seeks in and through the production of art to contribute not just to the artistic universe, but to what we 'know' and 'understand'. In so doing, it goes beyond the artistic universe in two ways. First, the results of the research extend further than the personal artistic development of the artist in question. In cases where the impact of research remains confined to the artist's own oeuvre and has no significance for the wider research context, one can justifiably ask whether this qualifies as research in the true sense of the word. Second, the research is expressly intended to shift the frontiers of the discipline. Just as the contribution made by other academic research consists in uncovering new facts or relationships, or shedding new light on existing facts or relationships, artistic research likewise helps expand the frontiers of the discipline by developing cutting-edge artistic practices, products, and insights. In a material sense, then, the research impacts on the development of art practice, and in a cognitive sense on our understanding of what that art practice is.

This refers to the dual context discussed on page 165 below.

\section{Originality}

Artistic research entails original contributions - that is, the work should not have previously been carried out by others, and it should add new knowledge or understandings to the existing corpus. Here, too, we must distinguish between an original contribution to art practice and an original contribution to what we know and understand - between artistic and academic originality. Yet artistic and academic originality are closely related. As a rule, an original contribution in artistic research will result in an original work of art,

This criterion will later be eased during my discussion of the review guidelines for the Journal for Artistic Research (in chapter II, pages 233-35). 
as the relevance of the artistic outcome is one test of the adequacy of the research. ${ }^{16}$ The reverse is not true, however; an original artwork is not necessarily an outcome of research in the emphatic sense. In the concrete practice of artistic research, one must determine case by case in what way and in what measure the research has resulted in original artistic and academic outcomes. ${ }^{17}$ In any research study that pretends to make a difference, it is important to realise that it is hard to determine at the outset whether it will ultimately result in an original contribution. It is an inherent quality of research that 'one does not know

Rheinberger's insights (footnote I8) will be discussed in relation to artistic research in chapter 9 . exactly what one does not know'. ${ }^{18}$ Consequently, guiding intuitions and chance inspirations are just as important for the motivation and $\mathrm{dy}$ namism of research as methodological prescriptions and discursive justifications. Contributing new knowledge to what already exists is characteristic of the open-ended nature of every research study.

\section{Knowledge and understanding}

If artistic research is an 'original investigation undertaken in order to gain knowledge and understanding', ${ }^{19}$ then the question arises as to what kinds of knowledge and understanding this involves. Traditionally, the central focus of epistemology is on propositional knowledge - knowledge of facts, knowledge about the world, knowing that such and such is the case. This can be distinguished from knowledge as skill - knowing how to make, how to act, how to perform. A third

I6. This is mainly a theoretical distinction to help clarify the principle of originality. As with other demarcations and dichotomies, it needs to be interpreted freely in the light of the diversity of practice. It is important to avoid any overly close association with the early Romantic originality principle as held by the eighteenth-century aesthetics of genius, which still haunts in the minds of many as a sort of implicit paradigm.

I7. See Pakes 2003 for a more detailed critical analysis of the originality principle in artistic research.

18. Rheinberger 2007. The full quote is: 'Das Grundproblem besteht darin, dass man nicht genau weiss, was man nicht weiss. Damit ist das Wesen der Forschung kurz, aber bündig ausgesprochen.' ('The basic problem is that one does not know exactly what one does not know. Put succinctly, that is the essence of research' (my translation)). Cf. also Dallow 2003: 49, 56. 19. This is the wording used by the Research Assessment Exercise in the UK; for the full RAE definition of research, see RAE 2005: 34 . 
form of knowledge may be described as acquaintance: familiarity and receptiveness with respect to persons, conditions, or situations 'I know this person', 'I know that situation'. In the history of epistemology, these types of knowledge have been thematised in a variety of ways, ranging from Aristotle's distinction between theoretical knowledge, practical knowledge, and wisdom to Polanyi's (1958) contrast between focal and tacit knowledge. Different notions exist as to the relationships between the three types of knowledge - notions which are also identifiable in the debate about artistic research. Sometimes the emphasis lies on propositional knowledge, sometimes on knowledge as skill, and sometimes on 'understanding' as a form of knowledge in which theoretical knowledge, practical knowledge, and acquaintance may intersect.

In the case of artistic research, we can add to the knowledge and understanding duo the synonyms 'insight' and 'comprehension', in order to emphasise that a perceptive, receptive, and verstehende engagement with the subject matter is often more important to the research than getting an 'explanatory grip'. Such an investigation also seeks to enhance our experience, in the rich sense of the word 'experience': the knowledge and skills accumulated through action and practice, plus apprehension through the senses. In the debate on the status of the experiential component of artistic research, disagreement exists as to whether this component is non-conceptual, and therefore non-discursive, or whether it is a cognitive component that definitely resides in the 'space of reasons' (cf. Biggs 2004). The dispute between epistemological foundationalism and coherentism, which mainly concerns propositional knowledge,

The Norwegian fellowship programme requires, in addition to I critical reflection on the research process and its outcomes, that the work [of art] must contribute to new insight, knowledge and/or experience'.

This expression from Wilfrid Sellars is used by John Mc4 Dowell (see page I70 below). does not figure at all in the debate about artistic research. Many observers, though, do not view knowledge primarily as 'justified true belief' or 'warranted assertibility', but as a form of world disclosure (a hermeneutic perspective) or world constitution (a constructivist perspective). I shall return to these epistemological questions in the final section below. 


\section{Questions, issues, problems}

The requirement that a research study should set out with well-defined questions, topics, or problems is often at odds with the actual course of events in artistic research. Formulating a question implies delimiting the space in which a possible answer may be found. Yet research (and not only artistic research) often resembles an uncertain quest in which the questions or topics only materialise during the journey, and may often change as well. Besides not knowing exactly what one does not know, one also does not know how to delimit the space where potential answers are located. As a rule, artistic research is not hypothesis-led, but discovery-led (Rubidge 2005: 8), whereby the artist undertakes a search on the basis of intuition, guesses, and hunches, and possibly stumbles across some unexpected issues or surprising questions on the way.

In the light of the actual dynamics of current academic research, the prevailing format for research design (such as that required in

I am fully aware that we have to live with this inadequacy. In the practice of research training it is useful to learn to formulate research questions. funding applications) is basically inadequate. Especially in artistic research - and entirely in line with the creative process - the artist's tacit understandings and her accumulated experience, expertise, and sensitivity in exploring uncharted territory are more crucial in identifying challenges and solutions than an ability to delimit the study and put research questions into words at an early stage. The latter can be more a burden than a boon.

As we have seen, research studies done in and through art may be oriented to science and technology or more to interpretation and social criticism, and they may avail themselves of a diversity of methodological instruments. By the same token, the topics and questions addressed by the research can vary from those focusing purely on the artistic material or the creative process to those that touch on other life domains or even have their locus and their telos there. The subject matter of the research is enclosed, as it were, in the artistic material, or in the creative process, or in the transdisciplinary space that connects the artistic practices to meaningful contexts. The research, then, seeks to explore the often non-conceptual content that is em- 
bodied in art, enacted in the creative process, or embedded in the transdisciplinary context.

\section{Context}

Contexts are constitutive factors in both art practice and artistic research. Artistic practices do not stand on their own; they are always situated and embedded. Artworks and artistic actions acquire their meaning in interchange with relevant environments. Research in the arts will remain naive unless it acknowledges and confronts this embeddedness and situatedness in history, in culture (society, economy, everyday life), as well as in the discourse on art; herein lies the merit of relational aesthetics and of all constructivist approaches in artistic research.

Contexts figure in artistic research in another way too. The relevance and urgency of the research questions and topics is determined in part within the research context, where the intersubjective forum of peers defines the state of the art. This formally invested, or abstractly internalised, normative forum assesses what potential contribution the research will make to the current body of knowledge and understanding, and in what relationship the research stands to other research in the area. Every artistic research study must justify its own importance to the academic forum, which, like the artistic forum, looks over the researcher's shoulder, as it were.

To emphasise the equilibrium between these two contexts, I would now phrase it more adequately: what potential contribution the research will make to $\checkmark$ the art world and to the current body of knowledge and understanding ...'

.. justify its own potential to the academic forum and the art forum, which look over the researcher's shoulder...'

\section{Methods}

I have commented above on the distinctive nature of artistic research in terms of methodology. This is characterised by the use, within the research process, of art practice, artistic actions, creation, and performance. Experimental art practice is integral to the research, just as the active involvement of the artist is an essential component of the research strategy. Here lies the similarity of artistic research to both laboratory-based technical research and ethnographic field study. The erratic nature of creative discovery - of which unsystematic drifting, serendipity, chance inspirations, and clues form an integral part - is 
such that a methodological justification is not easy to codify. Just as in many other academic research studies, it involves doing unpredictable things, and this implies intuition and some measure of randomness. Research is more like exploration than like following a firm path. ${ }^{20}$

Much artistic research does not limit itself to an investigation into material aspects of art or an exploration of the creative process, but pretends to reach further in the transdisciplinary context. Experimental and interpretive research strategies thus transect one another here in an undertaking whose purpose is to articulate the connectedness of art to who we are and where we stand. Much of today's visual and performing art is critically engaged with other life domains, such as gender, globalisation, identity, environment, or activism; philosophical or psychological issues might be addressed in artistic research projects as well. The difference between artistic research and social or political science, critical theory, or cultural analysis lies in the central place which art practice occupies in both the research process and the research outcome. This makes research in the arts distinct from that in other academic disciplines engaging with the same issues. In assessing the research, it is important to keep in mind that the specific contribution it makes to our knowledge, understanding, insight, and experience lies in the ways these issues are articulated, expressed, and communicated through art.

\section{Documentation, dissemination}

The academic requirement that the research process and the research findings be documented and disseminated in appropriate ways raises a number of questions when it comes to artistic research. What does 'appropriate' mean here? What kinds of documentation would do justice to research that is guided by an intuitive creative process and by tacit understandings? What value does a rational reconstruction have if it is far removed from the actual, often erratic course taken by the research? What are the best ways to report non-conceptual artistic findings? And what is the relationship between the artistic and the discursive, between what is presented and displayed and what is described? What audience does the research want to target, and what impact does it hope to achieve? And which com-

20. Theoretical physicist Robbert Dijkgraaf (2007: 3I) in an interview. 
munication channels are best-suited for putting the research results into the limelight? Questions like these have been the subject of ongoing discussion for the past fifteen years in the debate on practice-based research in the creative and performing arts and design - not least in the context of academic degree programmes and funding schemes, which demand clear answers in their admission and assessment procedures.

Because artistic research addresses itself both to the academic forum and to the forum of the arts, the research documentation, as well as the presentation and dissemination of the findings, needs to conform to the prevailing standards in both forums. Usually, though, a double-blind reviewed academic journal will not be the most appropriate publication medium; the material and discursive outcomes of the research will be directed first of all to

The founding of the Journal for Artistic Research is one response $\checkmark$ to this issue. the art world and the art discourse, one that extends beyond academia. But a discursive justification of the research will be necessary with the academic discourse in mind, while the artistic findings will have to convince the art world as well. Even so, the discursive space of reasons need not remain confined to that of traditional scholarly writings. The artist can also use other, perhaps innovative forms of discursivity that stand closer to the artistic work than a written text, such as an artistic portfolio that maps the line of artistic reasoning, or argumentations coded in scores, scripts, videos, or diagrams. What matters most is the cogency of the documentation with respect to both intersubjective forums. For all that, language does remain a highly functional complementary medium to help get across to others what is at issue in the research - provided one keeps in mind that there will always be a gap between what is displayed and what is put into words. Or more precisely: given that the meaning of words often remains limited to their use in the language, a certain modesty is due here in view of the performative power of the material outcomes. ${ }^{2 \mathrm{I}}$

Ludwig Wittgenstein (1958: \$43) in Philosophical Investigations: 4 'The meaning of a word is its use in the language.'

2I. Language-based creative practice (poetry, prose) is a challenge in this respect. Here the performative power of the art is intermingled with and indissolubly connected to the play with the meaning of the words. 
The written, verbal, or discursive component that accompanies the material research outcome may go in three directions. ${ }^{22}$ Many people place emphasis on a rational reconstruction of the research process, clarifying how the results were achieved. Others use language to provide interpretive access to the findings - the material products and the practices generated by the research. A third possibility is to express something in and with language which can be understood as a 'verbalisation' or 'conceptual mimesis' of the artistic outcome. The concepts, thoughts, and utterances 'assemble themselves' around the artwork, so that the artwork begins to speak. ${ }^{23}$ In contrast to an interpretation of the artistic work or a reconstruction of the artistic process, the latter option involves an emulation or imitation of, or an allusion to, the non-conceptual content embodied in the art.

\section{Some remarks on the epistemology and metaphysics of artistic research: Non-conceptualism, realism, contingency}

\section{Non-conceptualism}

To begin this final section of the chapter, I return to the provisional description of artistic research I proposed at the beginning. Artistic research - as embedded in artistic and academic contexts - is the articulation of the unreflective, non-conceptual content enclosed in aesthetic experiences, enacted in creative practices, and embodied in artistic products. The theme of unreflective action, non-conceptual content, and embodied knowledge is explored in phenomenology, which, starting with Husserl and continuing via Heidegger and Merleau-Ponty, has focused attention on the nature of perception and the constitution of intentionality and normativity, beyond an ontology in which the world was thought to be independent of our situatedness.

In the work of Maurice Merleau-Ponty, embodied knowledge is

22. I decline to discuss here any numerical ratio of the verbal to the material. Any general prescription of the number of words to be required for an artistic $\mathrm{PhD}$ does no justice to the subject. An adequate and suitable relationship between the two needs to be determined separately for each artistic research project.

23. Cf. note Io in this chapter. 
also concretely 'bodily knowledge'. The a priori of the body assumes the place of the a priori of intellectual knowledge, making the pre-reflective bodily intimacy with the world around us into the foundation of our thinking and acting. By virtue of our bodily constitution and our bodily situatedness in the world, we are capable of 'getting a grip on reality' as we observe, learn, and act, and of 'acting in flow' prior to any reflection and without following rules. ${ }^{24}$ Conversely, pre-reflective knowledge and understanding already lie enclosed in how we understand and engage with reality. ${ }^{25}$ That is why the world is familiar to us, even before we gain access to it via concepts and language.

Part of the significance and singularity of artistic research seems to lie in its appraisal and articulation of this pre-reflective knowledge as embodied in art practices and products. Some argue that artistic research targets these non-conceptual forms of knowledge and understanding, which emerge in and through the creation of art, without wanting or being able to explicate them further. Others feel that it seeks to give explicit discursive (that is, verbal) expression to the

It would be beyond the scope of this book to delve more deeply into the phenomenological tradition, its impact on the cognitive sciences, and the criticisms that might be made of it. knowledge that is embodied and enacted in works and practices of art. If the artistic research programme were to confine itself solely to explicating this non-propositional knowledge, it would, as a consequence of its epistemological gaze, risk losing the research object along the way. It would risk shrinking the programme into a sort of decoding exercise, rendering it doubtful whether the research would even be useful at all to art practice and our understanding of it. After all, the dynamic of art practice seems to be inseparably bound to its categori-

\footnotetext{
24. In the current debate, key Merleau-Pontian notions as 'maximum grip', 'intentional arc', or 'motor intentionality' play an important part. Merleau-Ponty's insights have had strong influence in theatre studies, particularly dance studies; see e.g. Parviainen 2002. But the voices of poststructuralist and neo-Marxist critiques of phenomenology can also be heard in the debate on artistic research. The pre-reflective engagement with the world is a theme often encountered in the writings of philosophers influenced by Wittgenstein's 'rule-following considerations'.

25. Charles Taylor (2005: 34), in discussing the importance of the phenomenological heritage for contemporary philosophy of mind, speaks in this connection of 'pre-understanding'.
} 
cal je ne sais quoi; secrets have a constitutive function both in the creative process and in the artistic outcome. For this reason, many observers argue for not making these secrets explicit at all, but for articulating and communicating them solely in and through the production of art. Clearly the standpoint we adopt here will partly determine which demands we put on the content and form of the documentation in contexts such as doctoral research in the arts.

The implicit, pre-reflective knowledge and understanding embodied and enacted in art practice is also at issue in that particular strand of post-Heideggerian cognitive science that distances itself from the predominant physicalism. A recent dialogue between Hubert Dreyfus (2005, 2007a, 2007b) and John McDowell (2007a, 2007b) has compellingly highlighted the core issue here: Does the phenomenological account of our embodied coping skills and our immediate expert intuitive understanding (which are also pre-eminent issues in art practice) point to an essentially non-conceptual, and hence non-discursive, content in research? Or is a smooth transition conceivable between pre-reflective forms of knowledge and experience and their linguistic-conceptual translation or conversion within the space of reasons ${ }^{26}$

The same question re-emerges here which has been pivotal to the debate on artistic research from the very outset. Is it possible to achieve a linguistic-conceptual articulation of the embedded, enacted, and embodied content of artistic research? The significance of the current discussion at the intersection of phenomenology, cognitive sciences, and philosophy of mind lies in the prospects it may open for liberating the content of research in and through artistic practices from the explicit, explanatory, descriptive, or interpretive approaches that are so common in other research in the arts. Artistic research might just prove to be an ideal sphere for testing the scope and fecundity of this contemporary phenomenological research agenda. And conversely, artistic research might benefit from the insights that the phenomenological agenda has to offer.

26. See Rietveld 2008; cf. also the debate between Luntley (2003) and Säätelä (2005) on aesthetic experiences and non-conceptual content. 


\section{Realism}

A distinctive characteristic of artistic research is that it articulates both our familiarity with the world and our distance from it. It owes this ability to a special quality of art practice, which at once elicits and evades our epistemic stance. This Kantian theme links the programme of artistic research to the current broader interest in theories of knowledge and strategies of research which leave room for our implicit, tacit, non-conceptual, non-discursive relations with the world and with ourselves. Artistic research articulates the fact that our natural relationship with things we encounter is more intimate than what we can know. At the same time, it also familiarises us with the fact that those things are in some way foreign to us. In art, we sense something of our pre-reflective intimacy with the world, while realising simultaneously that we will never explicitly understand what lies there in such plain view. When we listen to music, look at images, or identify with body move-

'Our natural relation to the world's existence $[. .$.$] is closer,$ or more intimate, than the ideas of believing and knowing are made to convey.'

'Our relation to the world as a whole [...] is not one of knowing.'

Stanley Cavell I996: 25 and I979: 45 .

'We want to understand something that is already in plain view. For this is what we seem in some sense not to understand.' Ludwig Wittgenstein 1958: \$89. ments, we are brought into touch with a reality that precedes any representation in the space of the conceptual. That is the abstractness of all art, even after the long farewell to the aesthetics of early Romanticism. In a certain sense, this reality is more real, and nearer to us, than the reality we try to approach with our epistemological projects. This is the concreteness of all art, even in its most abstract forms and contents. In the critical and aesthetic distance to the world of representations that arises in the unfinished process of material thinking in and through art, art invites us to think, 'without the possibility of any definite thought whatever, i.e. concept, being adequate to it'.

Artistic research is the acceptance of that paradoxical invitation. The artistic, pre-reflective, non-conceptual content enclosed in aesthetic experiences, embodied in artworks, and enacted in artistic practices is articulated, amplified, contextualised, and thought through in the research. That content encompasses more than just the tacit knowledge embodied in the skilfulness of artistic work. This 'more' is 
world for us and, at the same time, render that world into what it is or can be. If some form of mimesis does exist in art, it is here: in the force - at once performative and perspectivist - by which art offers us new experiences, outlooks, and insights that bear on our relationship to the world and to ourselves. Artistic research concerns and affects the foundations of our perception, our understanding, our relationship to the world and to other people, as well as our perspective on what is or should be. This articulation of the world we live in is what we may call the realism of artistic research.

\section{Contingency}

The non-conceptual content that is addressed in artistic research is by nature undefined. Although it is materially anchored (in a broad sense of the word 'material'), it simultaneously transcends the materiality of the medium. Here lies not only the je ne sais quoi of the aesthetic experience, but also a call to reflection. Artistic research provides room for a multidimensional unfolding of this undefined content - in and through creating and performing, in and through discursive approaches, revelations, or paraphrasings, in and through criticism encountered in the artistic and academic research environment.

At least two perspectives can be adopted on what artistic research has to offer: a constructivist and a hermeneutic perspective. The constructivist perspective holds that objects and events actually become constituted in and through artworks and artistic actions. Only in and through art do we see what landscapes, soundworlds, histories, emotions, relations, interests, or movements really are or could be. Here lies the performative and critical power of art. It does not represent things; it presents them, thereby making the world into what it is or could be. The hermeneutic perspective assumes that artistic practices and artworks disclose the world to us. The world-revealing power of art lies in its ability to offer us those new vistas, experiences, and insights that affect our relationship with the world and with ourselves. Artistic research addresses this 
world-constituting and world-revealing power of art - the ways in which we constitute and understand the world in and through art.

The fundamentally non-conceptual nature of this act of constitution and revelation - which comes before any theoretical reflection about the world - is what enables art to set our thinking into motion, inviting us to unfinished reflection. Artistic research is the deliberate articulation of such unfinished thinking. It reinforces the contingent perspectives and world disclosures which art imparts. Artistic research therefore does not really involve theory building or knowledge production in the usual sense of those terms. Its primary importance lies not in explicating the implicit or non-implicit knowledge enclosed in art. It is more directed at a not-knowing, or a not-yet-knowing. It creates room for that which is unthought, that which is unexpected - the idea that all things could be different. Especially pertinent to artistic research This points ahead to chapter 9 , where I discuss this as the 'epi4 stemic thing' in artistic research. is the realisation that we do not yet know what we don't know. Art invites us and allows us to linger at the frontier of what there is, and it gives us an outlook on what might be. Artistic research is the deliberate articulation of these contingent perspectives. 
Chapter 8

Boundary

Work: An

Interview 



\section{Context}

This interview, conducted by Michael Schwab, postconceptual artist and philosopher at the Royal College of Art, London, took place in Brussels on 16 November 20IO, at a time when I was beginning to study the theoretical work of the historian of science Hans-Jörg Rheinberger (chapter 9). I explicitly qualify here some earlier distinctions I made between ontology and epistemology and between artistic facts and other types of facts. This brought me increasingly closer to the constructivist realism that I had begun to value in actor-network theory. 
In a recent text in the Zurich Yearbook of the Arts [chapter 6 above] you mention the concept of 'boundary work' in relation to artistic research. Could I ask you to expand on your ideas?

I took the concept from Thomas F. Gieryn (1983). I did not study his work in detail and just stumbled across the concept of 'boundary object', which is the term he actually uses. I use 'boundary work' in the article to highlight the negotiations that are required along boundaries, but I think the more challenging concept is 'boundary object', which is an object that changes its ontological and epistemological nature depending on the context in which it is used. This is especially interesting along the borderlines between different disciplines, within academia, for instance. 'Boundary object' means that an object has some meaning in a certain research environment and another meaning in another research environment. Moreover, in the sociology of science, where the concept is used, it also has a role to play between academic disciplines per se and fields outside academia. This is interesting for artistic research, because artistic research places itself on the border between academia and the art world. As a consequence, artistic research as boundary work has two contexts: one context is academia, meaning that artistic research has to acknowledge that it is part of academia and its ways of doing; the other context is the art world, where artistic research has to be relevant for things that happen within the 'real world' outside.

Taking this into account, what impact does a concept such as 'boundary work' have on artistic research as a discipline? Is artistic research a discipline; or rather, can it be a discipline if it operates with 'boundary objects?

The notion of 'discipline' has become contested not only in the case of artistic research but also in other areas of contemporary research. When you ask a question about 'disciplines', you are really enquiring about traditional disciplinary academic research, whereas a lot of advanced academic research nowadays challenges the notion of 'discipline' - it is postdisciplinary or transdisciplinary research. Artistic research is better understood as something that represents this kind of border violation, rather than being a new discipline alongside other art-related disciplines. 
Part of the notion of 'discipline' is the way in which it safeguards its borders through, for example, reviewing processes or the adherence to certain modes of writing. Is such safeguarding also challenged through the advanced concept of 'boundary work'?

There is a misunderstanding here. When I say that artistic research is not a discipline in the usual sense of the word, I am referring to the old con-

I made this statement at a time when we were just devising such an approach. Schwab and I were in Brussels for an editorial board meeting of the future Journal for Artistic Research. The trial issue later appeared in March 20II, and the first peer-reviewed issue in November of the same year (see chapter II). cept of scientific research as organised in specific scientific disciplines, which is not the case with artistic research. This does not mean that it is not disciplined - that there is no quality assurance or refereeing process - although no one at the moment knows how to do that in the best possible way. I am just referring negatively to the old concept of what is called Mode I science, which is disciplined and organised in a homogeneous way. Chemistry laboratories in Helsinki or Barcelona, for example, all look the same, and the quality of their research is exclusively assessed by disciplinary peers (that is, academics). This is not at all the case in artistic research: it is more heterogeneously organised, more diversified, with a form of extended peer review - which in our case means that both academics and artists judge the quality and the direction of the research, and even the research agenda at large. This character makes it an example of 'Mode 2 knowledge production', although I will not say that artistic research is the example of Mode 2 knowledge production (I have written extensively about this elsewhere [in chapter 4 above]). There are all kinds of problems attached to that. To answer your question briefly: yes, it is not a discipline in the usual sense of traditional, disciplinary academic research; but academic customs, like quality assurance through a refereeing process, are still in place.

Can boundary works be reviewed in the same way as other types of objects? Normally, when you are reviewing something, doesn't it have to have some form of identity? In other words, is there not a potential methodological problem when reviewing processes refer to a shifting object, so that the way you would talk about it has to adapt in some form or other? 
I don't think so. The fact that the object is floating, or not a real object at all if looked at on closer inspection, is not a problem within academia. Not even the different perspective (for instance from the artist's side) towards the same phenomenon - as compared to an academic looking at the same object - creates a problem. Once an object is approached in order to review its research quality, it is already inscribed in academic discourse, making no difference whether the reviewer is an artist or not. The whole point is rather that the borderline between artists and researchers is being blurred. The moment you are refereeing or judging the quality of an artwork as research, you brand it within academic discourse. However, there are two other things I want to stress that relate to the concept of 'artis-

We are so accustomed to making a distinction between artists and academics, between art and science, that we find it hard to think any differently. Yet both these spheres transform (La4 tour) as the network of artistic research develops. The point is not to do away with the dualism altogether, but to understand both of these spheres in a new way. tic research' as boundary work. Artistic research is a good example of a form of academic research in which the context is not just the disciplinary environment of university-based research. The outside world, in this case the art world, plays a central role in formulating the research agenda, formulating the direction the research has to take, evaluating the outcomes of the research, and assessing the quality of the research. Thus, artistic research has two contexts, and that makes artistic research a very good example of modern contemporary academic research, where more and more people realise that the quality of academic research is not assessed only within the boundaries of university institutions.

The second aspect has to do with the blurring of art and other life domains. The text I published in Zurich has to do with the boundaries of what art is and what the realm of knowledge and research is, and also what art is in comparison to our moral stance or to issues of daily life. I think that artistic research is an opportunity to address specifically the interrelationship between what is at stake within art and other domains of life. In artistic research projects, things are articulated that bear on who we are, where we stand, what our relation is to other people and the environment. In that sense, artistic research is also transdisciplinary research, because it reaches out to the wider community, making it a good example of what people call Mode 2 knowledge production. 
When you say that the 'boundary work' is not a real but a floating object, what are the implications in relation to the work's materiality? Are there particular modes that bring out the 'boundary work'? How can a 'boundary work' appear, and how might it be threatened?

The starting point is: there is no work - at least not in a strict ontological sense. Artworks become concrete only in specific settings, contexts. Artworks and artistic actions acquire their status and meaning in interchange with relevant environments. The art world is one such environment; academia is another. It all depends on what you are looking for. The research context might invite us to identify a work as 'work', either material or immaterial. Again, it all depends on the issues addressed, the questions raised, and the methods used. There are no particular modes that bring out the 'boundary work', but the 'research mode' will bring out the work on this side of the boundary; the 'market mode', for instance, on the other.

There are two aspects I am interested in when it comes to artistic research and the question of boundary work. One aspect is the discipline - it sounds very much like artistic research is a transdisciplinary exercise that transgresses all possible disciplines; the other aspect is that the boundary work as you describe it might equally lack identity, and that only by pragmatically accepting provisional identities such as 'artworks' can we even talk about it. Does a 'boundary work' - in spite of its floating or shifting character - have a stable identity that functions as a point of reference within different contexts; or are there more complex ontological consequences to be drawn from the concept of 'boundary works?

The distinction I make in the essay 'The Debate on Research in the Arts' [chapter 2 above] between an ontological, an epistemological, and a methodological question served a mere heuristic aim: to differentiate between different aspects of research in the arts, which one might encounter in this emerging research field. In fact, there is no such a thing as an 'ontology of artistic research' independent of its epistemology and methodology. Identifying a research object is always at the same time an epistemic act - that is, knowing at least roughly the kind 
of knowledge the object might convey or embody - and a methodological act - that is, knowing how to get access to the knowledge the object is said to convey or embody.

In your question you refer to 'a boundary work', thereby already more or less objectifying the 'object' of research. In my essay 'Artistic Research as Boundary Work' [chapter 6 above], I emphasise the more active use of the term: the work to be done, both on the border of art and academia and on the border of art research and other life domains. Precisely because no sharp boundThis active use of 'work' corresponds to the interpretation of academia as continually evolving, as 'science in action' (Latour). aries can be drawn between art on one side and academia and other spheres of life on the other, research in art has to acknowledge that its 'objects' are fuzzy, preliminary, contingent on the project at hand. One might say that the epistemological core of the artistic research programme is empty, or [more accurately] crowded and heterogeneous - terms used by Helga Nowotny, Peter Scott, and Michael Gibbons (200I: 179) to describe the new production of knowledge - and that it is dependent on the specific perspective or the 'implication' of the research project. This fuzzy epistemology of artistic research is in line with recent investigations into the history and epistemology of science. HansJörg Rheinberger's notion of an 'epistemic thing' tries to capture something of the contingency inherent to research in science:

As long as epistemic objects and their concepts remain blurred, they generate a productive tension: they reach out into the unknown and as a result they become research tools. I call this tension 'contained excess'. François Jacob speaks of a 'play of possibilities'. (Rheinberger 2010: 156).

The artistic research programme is a case in point where we acknowledge from the start that the research 'object' or 'issue' does not have a fixed identity - which invites, in principle, unfinished thinking. Especially due to the non-conceptual content of artistic research - the fact that what is at stake here can only partially be 'captured' discursively it evades any definitive epistemological 'grip', while at the same time opening up a possible perspective on what we do not yet know. 'Artis- 
Together with Latour's sociology of science, Rheinberger's epistemology lent support both to artistic research as an undertaking and to my contribution to and explanation of this undertaking.

tic things' are epistemic things par excellence; they create room for that which is unthought. In 'The Debate on Research in the Arts' [chapter 2] I made a distinction between scientific facts, social facts, historical facts, and artistic facts in order to highlight the sui generis nature of the object of research in the arts. As with the distinction between ontology, epistemology, and methodology, I would now like to play down that distinction. There are no such things as basic artistic facts on which the edifice of the artistic is build. The realm of the artistic is historically and systematically contingent on where and how it is constituted. Here we can learn something from science and technology studies, for instance from actor-network theory, where the artistic realm is a network and something that is performed through the active involvement of its actors, both human and non-human. To paraphrase Bruno Latour: the artistic research programme is a programme to 'reassemble the artistic', which in itself is an unfinished project.

If the 'artistic' is a project-to-come, what are the characteristics of 'artistic research' that make it different from other forms of research?

When it comes to discriminating or demarcating artistic research from other advanced Mode 2 forms for knowledge production, I would simply say that there are two features that are characteristic of artistic research when compared to other approaches. Firstly, there are methodological prescriptions; and you could say that artistic research takes place in and through the making of art, making it distinct from, for instance, humanities research into the same issues. Secondly, there is the outcome of artistic research, which, partly at least, is art. I say 'partly', because people differ in opinion about the extents to which discursive aspects may be added to the artistic outcome. For sure, if there is no concrete practice or artwork as a part of the outcome of an artistic research project, then in my opinion it could not count as artistic research. Here we have two negative criteria which distinguish artistic research from other advanced forms of knowledge production that might address the same issues: one is that the research is done in and through creating or performing; and 
the other is that the outcomes of artistic research are partly also concrete artistic products - artefacts, installations, compositions, and so on.

In this case, would you not worry about the potential impact of art market structures - that is, what is counted as art or artwork in the marketon artistic research? Does artistic research not have to buy into limited forms of artmaking then, whilst the more advanced or more ephemeral practices (which might not necessarily produce a work or anything identifiable as such) would actually be disadvantaged? Would we not rather expect the opposite; namely, that artistic research, if anything, would mount a challenge against any traditional definition of art and its objects?

Yes, I see the danger, but then again I think that, by introducing artistic research, we have created, and are still creating, a free space that is also in $o p$ position to the demands of the market, to the creative industries, to the daily strains of production - a free space for 'material thinking', to use the term from Paul Carter. As a consequence, I am not that afraid that the whole endeavour of artistic research will be corrupted in one way or another by the demands of the market. On the contrary, I think it might be the case that in performing artistic research we can have some influence over what counts as art, and as an interThis was not really an answer $\checkmark$ to the question. Not only here, but also in other questions (on discipline, identity, materiality), Michael Schwab's intention was to question the 'object' nature of art in the light of artistic research as 'boundary work'.

The central place of the 'work' - even when it is 'floating' and epistemologically vague - may serve to obscure art that does not wish to be understood as 'work'. 'Work', however, is not just an 'object', but also 'practice'.

esting outcome not only within academia but also within the art world. That is rather optimistic, I think; but it could well be that not only our understanding of what academia is might change in the future, but also our understanding of what art is.

So, you see artistic research as having a strategic role in these transformations?

Well, this is a part of the subsidiary agenda. It is not the first thing I think about, but it might add some extra benefits. Whether or not to call it 'strategic', I am not that sure. 


\section{Chapter 9}

Artistic

Practices and

Epistemic

Things 



\section{Context}

I wrote this chapter as a discussion paper for a working meeting with Hans-Jörg Rheinberger entitled 'Exposing Practice', held at Zurich on 17 June $201 \mathrm{I}$ as part of the Artistic Research Catalogue project (see chapter II). Rheinberger and Christoph Hoffmann, both from the Max Planck Institute for the History of Science in Berlin, gave their responses there to the discourse on artistic research, with special attention to the meaning that 'research' and 'publication' appear to have in that discourse. I have appended an additional section at the end of this chapter to briefly address this issue.

A dialogue with experts in philosophy of science or in science and technology studies is of vital importance to the process of establishing and justifying the field of artistic research. This chapter and my final chapter are early steps in such a dialogue. 
What does it mean to present art as research? What relationship exists between art - artworks, artistic practices - and the presentation of art as research in an academic context? This demarcation question is a hot item in the debate on the emergent field of artistic research. The debate often concerns issues of institutional or educational politics that are thought to be important for determining whether artistic research can be recognised as a type of academic or scientific research. Prominent issues are the standards needed to assess research by artists, the institutional rights to award third-cycle (doctoral) degrees in the arts, and the criteria to be applied by funding bodies in deciding whether to support research by artists.

Sometimes the focus is on issues from philosophy of science that pertain to artistic research. Do the usual criteria for doing academic research (concerning research questions, methods, and justification) automatically apply to this new field of research? To what extent and in what respects do artistic research activities differ from those in other types of academic or scientific research? What are the similarities and differences between artistic research and research in the natural sciences, the social sciences, or the humanities?

I will focus here on the fundamental question of the epistemological status of artworks and art practices as research. How can things that are fundamentally polysemic - that seem to elude every attempt to tie them down, to define them - still function as vehicles of research? That is, how can they function not just as objects of research, but as the entities in which, and through which, the research takes place - and in which and through which our knowledge, our understanding, and our experience can grow. What is the nature of such an 'object of research', particularly in terms of epistemology? What gives art the ability to generate new knowledge and understandings?

The foundational debate on artistic research needs input from the disciplines that concern themselves with the history, the theory, and the practice of the sciences: sociology of science, science and technology studies (STS), historical epistemology. By the same token, the philosophy of science - or more broadly, our understanding of what academia is - can be furthered by the things that take place in the emergent field of artistic research. To help clarify the epistemological 
status of art in the research process, I shall draw on some recent insights achieved in research in the theory of science, focusing primarily on the work of Hans-Jörg Rheinberger, director of the Max Planck Institute for the History of Science in Berlin. Rheinberger studies the history and epistemology of experimentation in the life sciences, in particular molecular biology. I will argue that Rheinberger's ideas about the dynamics of experimental scientific practice - and the special status he assigns to 'epistemic things' within those dynamics - may help to elucidate the status of art within artistic research practices.

Rheinberger's work may be attributed to the movement in the philosophy of science that seeks to emancipate the 'context of discov-

See the final section of this chapter for comments on the difference between these two contexts.

ery' in relation to the 'context of justification'. It distances itself from the more empiricist and critical-rationalist notions of science that were in vogue until two decades ago. The goal is not only to understand the dynamics of scientific conduct, but to clarify the epistemology involved - that is, how knowledge is constituted in and through practices.

This 'practice turn in contemporary theory' (Schatzki et al. 200I) - inspired by Edmund Husserl, Martin Heidegger, and phenomenological tradition, as well as by the later work of Ludwig Wittgenstein and the pragmatist tradition - is manifest in a number of fields, including the cognitive sciences (e.g. Noë 2004), science and technology studies (e.g. Latour 1988, 1999; Latour and Woolgar 1986; Shapin and Schaffer I989; Knorr Cetina 1999) and the study of social and cultural practices. ${ }^{1}$ As the context of discovery becomes liberated, practices and things take the place of theories and mental states. Embodied, situated, and enacted forms of cognition become more important to our understanding of research than world-mind representations and detached modes of rationality and objectivity.

I. Helga Nowotny (in her foreword to Biggs and Karlsson 20II, pp. xxii-xxiii) has highlighted the importance of STS, and in particular of actor-network theory (ANT), for understanding artistic research 'in this changing epistemological, institutional, and normative landscape in the bewildering zones of uncertainties'. 


\section{Experimental systems}

What is the epistemological status of art in artistic research? Are artworks or art practices capable of creating, articulating, embodying knowledge and understanding? And, if so, what kinds of artworks and practices do this (what is the ontological status of art here?) and how do they do it (the methodological status)?

As I have suggested above, work in an entirely different academic research domain - theoretical and historical research on experimental practice in the life sciences - can help to clarify these issues. ${ }^{2}$ In his study of the history and practice of research in the natural sciences, Hans-Jörg Rheinberger has demonstrated that 'experimental systems' are the centre and the motor of modern scientific research. Rheinberger's historical case studies, extending from the pre-war genetic experiments to present-day molecular biology, show that the dynamics of experimental systems can only be understood as an interplay of machines, preparations, techniques, rudimentary concepts, vague objects, protocols, research notes, and the social and institutional conditions in which these are employed. Experiments are not merely methodological vehicles to test (confirm or reject) knowledge that has already been theoretically grounded or hypothetically postulated, as classical philosophy of science would have it. Experiments are the actual generators of that knowledge - knowledge of which we previously had no knowledge at all. Experimental systems are 'machines for making the future', as Rheinberger (2006a: 25/283) has observed, citing François Jacob, the French biologist and Nobel Prize winner.

Experimental systems are characterised by the interplay and entwinement of 'technical objects' and 'epistemic things' - the technical conditions under which an experiment takes place and the objects of knowledge whose emergence they enable. The distinction is functional, not material: 'Whether an object functions as an epistemic or a technical en-

\footnotetext{
2. In some quarters of the art world, the life sciences are a subject of keen interest. I will not be concerned here with crossovers between life sciences and the arts, such as in BioArt, but with the more fundamental question of the very relationship between art and knowledge.

3. Dual page references to Rheinberger's texts refer respectively to the German and the English versions (which may slightly differ).
} 
tity depends on the place or "node" it occupies in the experimental context.' In this way, 'epistemic things' may turn into technical objects or instruments, thereby ensuring the relative stability in the experimental system that enables new epistemic things to appear. Systems must be 'differentially reproducible', Rheinberger argues, 'if they are to still be arrangements where knowledge can be generated that lies beyond anything we could conceive or anticipate.'s But it also works the other way round. Technical things, if deployed differently, may sacrifice their stability and diffuse into epistemological questions. In molecular biology, for instance, organisms, or other entities such as genes, could sometimes be things we want to know (epistemic things) and at other times be objects through which we can know (technical objects). Rheinberger speaks in this context of a synchronic intertwinement of the epistemic and the techni$\mathrm{cal}$, and of a diachronic intertwinement of difference and reproduction. ${ }^{6}$

Rheinberger has deliberately chosen the term 'thing' rather than 'object', in order to signify the indeterminate, not yet crystallised status of the knowledge object. Epistemic things are 'chronically underdetermined' (2008: I4'30"). Experimental systems must be sufficiently open to allow these indistinct things to come into view; enough space

Towards the end of chapter 7 , I discussed this not (yet ) knowing as 'contingency'.

must be present to produce what we do not yet know. This openness and room for not-knowing, or not-yet-knowing, cannot be imposed by stern methodological procedures. As Rheinberger points out, serendipity, intuition, and improvisation are at least as important in laboratory practice as the attempts that are made to stabilise the technical conditions in which experiments take place. That openness also implies 'a kind of subsidiary awareness that may serve to mitigate the classical notion of dualism of thinking and being

4. Rheinberger 2006a, 27/30. The German: 'Ob ein Objekt als epistemisches oder als technisches funktioniert, hängt von dem Platz oder dem Knoten ab, den es im experimentellen Kontext besetzt.'

5. 2008: 19'28" (my translation). The German: 'Experimentalsysteme müssen differentiell reproduzierbar sein, wenn sie Arrangements bleiben sollen in denen Wissen generiert wird, das auch einmal jenseits dessen liegt was man sich hat vorstellen und was man hat antizipieren können.' Cf. also Rheinberger 2004: 5.

6. Rheinberger's ideas have been significantly influenced by the writings of Jacques Derrida (he translated De la grammatologie into German) and Gilles Deleuze. 
(though not entirely transcending it) as a borderline case in a relativistic epistemology' (2005: 72, italics added). By 'subsidiary awareness' (nicht-fokale Aufmerksamkeit) Rheinberger, commenting on Michael Polanyi, 7 is referring to a form of thinking that is obliquely based on tacit knowledge, on implicit understanding that is partly sedimented in the technical apparatus of the experimental system. This form of awareness, Rheinberger says, 'would enable us to let our thinking blend into the things, and the things into our thinking, with hybrid forms in the middle that allow neither formalisation nor quantification, and which thereby keep the research moving. ${ }^{8}$ Epistemic things are precisely these hybrid forms in which thinking and things are interwoven.

\section{Artistic experiments}

As I have pointed out elsewhere [in chapter 7, pp. I05-06], an artistic experiment cannot be simply equated with a scientific experiment. In fact, it would often appear that two different meanings of the word 'experiment' are being employed. In an essay entitled 'Kunst als epistemische Praxis' (Art as Epistemic Practice), Dieter Mersch (2009) has attempted to draw a clear distinction between artistic and scientific experiments. Making reference to artists like John Cage, Karlheinz Stockhausen, and Joseph Beuys, he argues that artistic experiments are not reproducible, and are in fact usually at variance with such a requirement. Nor do they primarily seek to augment knowledge, but rather to engage in a specific form of 'experimental reflexivity' that touches on the foundations of our perception (and not our understanding).

This and other descriptions of artistic experiments portray scientific experiments as method-driven, systematic, repeatable, and uni-

\footnotetext{
7. Rheinberger 2005: 62. 'Forschung beruht auf wildem Denken, und wildes Denken setzt stummes Wissen voraus.' ('Research relies on untamed thinking, and untamed thinking assumes tacit knowledge' (my translation).)

8. 2005: 72 (my translations). The full quote in German is: '... eine Form nicht-fokaler Aufmerksamkeit, von der aus sich das klassische Konzept des Dualismus von Denken und Sein zwar nicht aufheben, aber vielleicht entschärfen lässt als ein erkenntnistheoretischer Grenzfall im Rahmen einer relativistischen Epistemologie. Diese würde es erlauben, das Denken in die Dingen übergehen zu lassen wie die Dinge ins Denken, mit hybriden Bildungen in der Mitte, die sich weder formalisieren noch quantifizieren lassen, und die gerade dadurch das Forschen in Gang halten.'
} 
The discourse on artistic research is significantly hampered by the limited images that the participants have of one another. See also my comment about this in chapter I, page 23 .

versalisable, as rational and causal activities. Yet as research by Rheinberger, Bruno Latour, Karin Knorr Cetina, and others has shown, ordinary laboratory practice, in the context of discovery, is far less method-based than this, and many attributes normally associated with artistic discovery - such as instability, indeterminacy, serendipity, intuition, improvisation, and a measure of 'fuzziness' - also apply to scientific laboratory experiments (Rheinberger 2005: 66). Cage's assertion that 'it is simply an action the outcome of which is not foreseen'9 also describes the scientific experiment. The similarities are striking, and they invite closer investigation, without automatically giving reason to fully equate scientific experiments with artistic ones.

The term 'experimental system' could give the impression of a fixed structure, whose elements relate with one another in clearly ordered, stable arrangements. In using this term, however, Rheinberger does not have a systems theory in mind, such as that of the German sociologist Niklas Luhmann. He is simply highlighting a loose coherence between the various elements of the experimental system (technical, epistemic, social, institutional elements), in both a synchronic and a diachronic sense. ${ }^{\mathrm{I}}$ In the historical and philosophical literature on science, the interest in experimental systems arose at the point where the theory-dominated view of scientific research began to make way for ideas centring on practice (cf. Schatzki et al. 200I; Rheinberger 2004: 2). Now practices generally manifest the same characteristics as Rheinberger's systems. Practices also show a certain coherence and persistence. The $O x$ ford English Dictionary defines 'practice' in one sense as 'an established procedure or system'. One can therefore just as well speak of 'experimental practices' as of 'experimental systems', not least because Rhein-

9. Quoted in Mersch 2009: 43.

IO. In his online essay 'Experimental Systems', Rheinberger (2004) gives a more detailed description of such a system. (a) It is the smallest discrete working unit of research; (b) it must be capable of undergoing 'series of differential reproductions'; (c) it is the entity 'within which the material signifying units of knowledge are produced'; and (d) if experimental systems merge together or branch out, that can result in 'ensembles of such systems, or experimental cultures'. 
berger also applies his findings on experimental systems to academic practices outside the laboratory, such as interpretation in the humanities, and notably writing. ${ }^{\text {II }}$ In the literature on the practice turn in thinking about science, practices are not regarded as mere routines guided by rules that are founded on well-ripened, if sometimes tacit, knowledge and skills. They are also recognised as dynamic, creative, constructive, and normative actions (Knorr Cetina 200I: 187; Rouse 200I: 189). In and through practices, knowledge comes into being. Scientific research is therefore anything but static; it is always 'science in action' (Latour 1988).

In artistic practices, too, experience and expertise that have sedimented into tacit knowledge form a fertile ground for a dynamic, creative, and constructive process that enables the emergence of the new and the unforeseen. At the same time, artistic practices - even the most conceptual and the most transitory of them - are always technically and materially mediated [cf. chapter 7 , p. 156 above]. Such artistic practices constitute the centre and the motor of research in the arts, just as experimental systems are the centre and motor of scientific research. This will now enable us to sharpen the focus of our question about the epistemological status of art within artistic research.

\section{Artworks as epistemic things}

An experimental system thus involves the realisation and articulation of epistemic things that derive their propelling force in the research from their very indeterminacy (we don't know exactly what we don't yet know, Rheinberger 2006b). Similarly, within artistic practices, artworks are the hybrid objects, situations, or events - the epistemic things - that constitute the driving force in artistic research. To para-

II. 'Das Schreiben, so behaupte ich, ist selbst ein Experimentalsystem. Es ist eine Versuchsanordnung. Es ist nicht nur ein Aufzeichnen von Daten, Tatbeständen oder Ideen. Es ist auch nicht einfach der billige Ersatz für die lebendige Rede. Es ist nicht einfach das transparente Medium der Gedanken. Es gibt ihnen eine materielle Verfassung und zwar eine, die das Entstehen von Neuem ermöglicht' (2006b: 5) ('Writing, I would argue, is an experimental system in its own right. It is the set-up of an experiment. It is not merely the recording of data, facts, or ideas. Nor is it just a cheap substitute for the spoken word. It is not simply the transparent medium of thoughts. It gives them a material substance, and specifically one that enables something new to emerge' (my translation).) 
phrase Rheinberger, as long as artworks and their concepts remain vague, they generate a productive tension: in reaching out for the unknown, they become tools of research..$^{12}$ In the context of artistic research, artworks are the generators of that which we do not yet know. They thereby invite us to think. Artistic research is the articulation of this unfinished thinking.

It is a commonplace to argue that art transforms things and situations and robs them of their unproblematic status. Yet therein lies its epistemic potential. Artistic practices, like experimental systems, are 'vehicles for materialising questions' (Rheinberger 2006a: 25/28). Knorr Cetina ascribes to epistemic things the ability to infinitely unfold: 'I want to characterize objects of knowledge ("epistemic objects") in terms of a lack in completeness of being that takes away much of the wholeness, solidity, and the thing-like character they have in our everyday conception' (Knorr Cetina 200I: I8I). This fundamental incompleteness (Adorno would say 'non-identity') points us towards an 'unfolding ontology' (ibid.). Artworks as epistemic things can never become fully transparent, and it is this structural lack of completeness that is the fuel and the motor of a creative, constructive practice, in which meanings emerge and realities are constituted.

In the context of artistic research, artworks are epistemic things and events that have not yet been 'understood' or 'known' - or, to be sure, that resist any such epistemological grip. Art's knowledge potential lies partly in the tacit knowledge embodied within it and partly in its ability to continuously open new perspectives and unfold new realities. I have elsewhere described this 'knowing' as pre-reflective and non-conceptual. I would now like to characterise it, with Rheinberger, as a productive not-yet-knowing against the backdrop of an ever-receding knowledge horizon.

What is the reality of these epistemic things? What reality is being unfolded here? Rheinberger: 'We might tentatively say that the

I2. 'As long as epistemic objects and their concepts remain blurred, they generate a productive tension: they reach out into the unknown and as a result they become research tools' (2010: 156). 
"epistemic thing" is to scientific activity what a "statue" is to the art of sculpture, a "picture" to the art of painting, a "poem" to the art of poetry. It is the "scientific real" that is engendered by scientific activity. Research in the arts, then, articulates the 'artistic real' as engendered by art practices. In some sense, this artistic real is more real than our everyday reality. ${ }^{\mathrm{I} 4}$ And this is exactly where the importance and the urgency of research in the arts lies. The artistic real is an engendered reality - a factum, something that has been made, not a datum, something that was given beforehand (2008: 22' 36 "). An artistic 'fact', like a scientific, social, or historical fact, is what we make real with our epistemological undertakings.

This does not mean that we must lapse

Cf. also my remarks on 'facts' in 4 my annotation on page 46 of chapter 2 and in chapter 8 , page I82.

Constructivist realism into some kind of relativism, idealism, or crude constructivism: 'Experimental scientists', writes Rheinberger (and I argue that this also applies to artists), 'do not read the book of nature, they do not depict reality. But they do not construct reality either. They are not engaged in platonistic exercises, in asymptotic approximations to an always presupposed essence of reality, or in bluntly social constructivist endeavours' (2006a: 282; cf. English version, 225). The dynamics of both artistic and scientific research lies in the dialectics of revelation

13. 1992: 69 (my translation). Rheinberger has adopted the term 'scientific real' from Gaston Bachelard. The German: 'Man könnte versuchsweise sagen, das "epistemische Ding" sei für die wissenschaftliche Tätigkeit das Äquivalent zur "Skulptur” für die Bildhauerei, zum "Bild” für die Malerei, oder zum "Gedicht" für die Poesie. Es ist das in der wissenschaftlichen Aktivität hervorgebrachte "Wissenschaftswirkliche".'

I4. 'The particular reality of the scientific real is [...] its capacity to drive beyond itself, to give space to unprecedented events. It is exactly in this sense that experimental arrangements are, in a way, "more real" than our good everyday reality. The reality of an epistemic thing explored within an experimental system resides in its resistance, its resilience, its capacity, as a joker and obstacle of practice, to turn around our previsions as well as our imprevisions, in a word, to give birth to unprecedented events' (Rheinberger 2004: 8). Cf. my own observations [above in chapter 7, p. I7I]: 'When we listen to music, look at images, or identify with body movements, we are brought into touch with a reality that precedes any re-presentation in the space of the conceptual. That is the abstractness of all art, even after the long farewell to the aesthetics of early Romanticism. In a certain sense, this reality is more real, and nearer to us, than the reality we try to approach with our epistemological projects. This is the concreteness of all art, even in its most abstract forms and contents.' 
The fundamental incompleteness or non-identity of artworks as epistemic things - of art as research - creates room for what is unthought and unexpected. 'The endless game of realization of the possibles' (2006a: 283/225) invites us to dwell at the frontier of what is, and of what we know or can know. The condition of art as research is a condition of contingency. The openness of art is what invites us, again and again, to see things differently.

\section{'Research' and 'publication'}

At the working meeting entitled 'Exposing Practice' (Zurich, I7 June 20II), Hans-Jörg Rheinberger, in response to the discussion about the meaning of the term 'artistic research', drew a distinction between the epistemic and the artistic. Traditionally - that is, in the history of the sciences - the term 'research' has been applied to the domain of the scientific and the epistemic, and not to that of the artistic or the arts. The term 'artistic research' would seem to conflate the epistemic interest and the artistic interest. Christoph Hoffmann added that 'knowledge' should be understood as propositional knowledge, and as such it is tied to epistemological standards and cannot simply be merged with conviction, belief, or aesthetic experience. I have sufficiently treated the latter issue in previous chapters.

At the same time, Rheinberger saw potentials for linking the epistemic to the artistic (or the aesthetic). He cautioned against mak-

It is important to keep in mind that links can be laid between the artistic and the epistemic specifically (with reference to Latour) through transformations that occur in a chain of interactions. As I will show in my final chapter, artistic research involves precisely this type of transformations - from artistic product to artistic argument. ing the distinction between the epistemic and the aesthetic too sharp, as there are gradations, intermediate forms. There could also be mutually incompatible extremes, but in a chain of interactions à la Latour these might eventually be brought together. It may therefore be insufficient to think about the sciences without aspects of the artistic. And, on the other hand, in thinking about the arts one would also consider the epistemic. ${ }^{\text {Is }}$ 
Rheinberger was right, of course, to point out that the term 'research' is historically associated with the domain of the sciences (although it is also used in other contexts). As for the epistemic, however, there are also historical ties with the artistic, in particular in the tradition of philosophical aesthetics, as I have discussed in chapter 7. Moreover, it is quite possible, though perhaps not very common, that the meaning of particular words changes because their usage changes, either now or in future. Often, in fact, the very history of what is denoted by those words, or at least our interpretation of that history, may change.

A second issue addressed at the meeting was what the word 'publication' might mean in the context of artistic research. Hoffmann drew a clear distinction here between research and publication - in other words, between the context of discovery and the context of justification. Scientific and academic publications, including those in the humanities, according to Hoffmann, always involve the presentation of the ultimate findings or results, in the sense of produced facts, which stand at the end of a possibly long research chain.

Ultimate findings, however, can only be conceived of at the extreme - as unreachable limiting cases or as regulative ideas or ideals for no ultimate research results actually exist, just as no ultimate foundation exists for our knowledge claims. In this sense, every produced and justified fact is a tentative fact, and therefore always part of a continuing discovery, part of a science that is transforming itself.

Contemporary theory of science (and science and technology studies in particular) shows us that it is untenable, and not even defensible, to maintain a strict separation between the context of discovery and the context of justification (and between values and facts). Publications are not terminal stations in a scientific quest; they are always tentative representations of what is surmised. This basically open nature of 'publications' is not a shortcoming that we have to live

This is a crucial issue that goes 4 to the heart of what artistic research is. The outcomes of artistic research are in part artefacts - they are artworks. As I have pointed out, such artefacts are fundamentally open in nature, and this is the very quality that invites us to 'unfinished thinking'. The contexts of discovery and justification melt together here.

I5. Based on an audio recording of the working meeting. 
with, rather - in the case of artistic research - it is the starting point. Publications in the sphere of artistic research are better understood as contributions to a discursive field that is constantly in motion. As epistemic things, artworks not only play a constitutive role in a process of discovery that eventually culminates in produced and justified facts. They are not just generators of knowledge. They are also (and I differ here with Rheinberger's view) that which is generated. This alliance of constitution and realisation, of discovery and justification, may be called, with Latour, constructivist realism. 



\section{Chapter Io}

Ingredients for the

Assesment

of Artistic

Research 



\section{Context}

Neither this chapter nor the following contains annotations. They were written for the completion of the book. The present chapter serves as a springboard to the next, which will be a reconstruction and evaluation of the process of founding the Journal for Artistic Research. The ingredients for the assessment of artistic research have been compiled here from the preceding chapters, and will be put into operation and tested in the final chapter. Although I am aware that this is not an impartial undertaking, I still think it wise to refrain from mentioning here the more political and institutional issues involved. 
In previous chapters I have examined artistic research from many different angles. It is now time to give a brief synopsis of the key issues I have discussed up to now. The present chapter will serve as a pivot between the topics dealt with so far (the theoretical framework) and the analysis to follow (the case study).

\section{Résumé}

In chapter I, 'The Conflict of the Faculties', I provided an initial blueprint of my research domain, drawing on four different perspectives on the relationship between theory and practice in the arts. These were the instrumental, the interpretive, the immanent, and the performative perspectives. This culminated in three recommendations for the conduct of research in the arts, focusing on method, the type of outcome, and the form of the documentation.

My second chapter, 'The Debate on Research in the Arts', explored the background of the foundational debate on artistic research in the light of its institutional context and of philosophy of science. After discussing several terminological matters and research definitions, I raised the issue of the specific nature of research in the arts. This resulted in a preliminary determination of the conditions that art practice must meet in order to qualify as research.

In chapter 3, 'Artistic Research and Academia', I highlighted the fundamental tension between the artistic and the academic worlds and went on to argue for a broader conception of research and academia that allows for non-discursive knowledge forms and unconventional research methods. That chapter also provided a tentative characterisation of the non-conceptuality, the realism, and the contingency of artistic research.

In a critique of the standard model of research and development - and in debate with prevailing policy on science - I examined in chapter 4, 'Artistic Research within the Fields of Science', to what extent artistic research may be understood as a form of Mode 2 knowledge production. I emphasised here that artistic research is a research field that involves both the quest for fundamental understandings and the production of artefacts that have meaning in the art world, as well as the relationships between those two aims. 
Chapter 5, 'Where Are We Today?', surveyed the current status of this emerging field and the gradual establishment of the new paradigm of artistic research within institutional frameworks. In the section on the epistemology of artistic research, I examined the goal of enhancing our experiential world in juxtaposition to the goal of advancing knowledge and understanding.

The hybrid nature of artistic research - attributable to its field of operation in two contexts: the world of art and the world of science - was the starting point of chapter 6, 'Artistic Research as Boundary Work'. Written more as a pamphlet, it expands the theme of artistic research to other life domains and to the role that artistic research might play there.

In chapter 7, 'The Production of Knowledge in Artistic Research', I discussed similarities and contrasts with other fields of research in the humanities (aesthetics in particular), the social sciences, and the natural sciences and technology. The second part of the chapter drew on the premises set out in chapter 2 to address the question of whether artistic research can qualify as academic research. I concluded by elaborating in more detail on the characterisation of artistic research as nonconceptual, realistic, and contingent, which I introduced in chapter 3 .

In the interview I have included as chapter 8, 'Boundary Work', I emphasised once again the open, unfinished nature of artistic research. An important observation here was that artistic facts are necessarily epistemologically vague - the very reason why they are productive.

In 'Artistic Practices and Epistemic Things' (chapter 9), I explored this epistemological incompleteness in more depth in a comparison with the theoretical work of the science historian Hans-Jörg Rheinberger. Artworks and art practices are 'epistemic things' par excellence that point towards what we do not yet know and that invite us to unfinished thinking.

Throughout the book, sometimes explicitly, sometimes more implicitly, I plead the case for the institutional recognition of research in the arts, to include both the awarding of academic degrees and the funding of artistic research.

In my concluding chapter, to follow this one, I will apply the insights I have accrued up to now in a specific case study: the creation and 
development of the Journal for Artistic Research (JAR). The assessment of concrete artistic research in the context of JAR is at once the operationalisation and the touchstone of the claims I have made above. In $J A R$ praxis, the theory of artistic research is verified or put to work, as it were. But prior to that case analysis I first need to gather together and regroup the ingredients we have examined so far that are pertinent to the assessment of art as research. My point of departure will be the tentative definition of research in the arts I have formulated in chapter 2:

Art practice qualifies as research if its purpose is to expand our knowledge and understanding by conducting an original investigation in and through art objects and creative processes. Art research begins by addressing questions that are pertinent in the research context and in the art world. Researchers employ experimental and hermeneutic methods that reveal and articulate the tacit knowledge that is situated and embodied in specific artworks and artistic processes. Research processes and outcomes are documented and disseminated in an appropriate manner to the research community and the wider public.

This definition was developed on the basis of an exploration of (I) what it means to do academic research and (2) what then the specific ontological, epistemological, and methodological characteristics of research in the arts are. In subsequent chapters, I refined, or in some cases broadened, that definition on certain points. In the present chapter I will again focus on the elements of this definition with specific reference to the assessment of art as research, also taking my elaborations into account. I will start from the issue raised in chapter 2 of the ontological, epistemological, and methodological status of art in the research - of art as research.

\section{Towards evaluation criteria}

In chapter 3 ('Artistic Research and Academia'), page 69, I already highlighted 'the intertwinement of ontological, epistemological, and methodological perspectives - the circumstance that defining an object is always at once both an epistemic act and an indication of ways to gain 
access to it'. The distinction I made between these perspectives in chapter 2 therefore served mainly a heuristic purpose: to focus the reader's attention on the particular aspects or perspectives that may play a role in research in the arts (cf. chapter 8).

The intertwinement of ontology, epistemology, and methodology is also manifest in the theoretical work of Hans-Jörg Rheinberger (chapter 9). The diffuse ontological status of Rheinberger's epistemic things (which he called 'things' for good reason), their unfinished nature, is fundamental: epistemic things derive their very knowledge-generating power from the fact that they are indistinct, not yet fully crystallised. And whereas the one time these things are, in a methodological sense, vehicles through which we can know, the next time they are, in an ontological sense, things we want to know; and then another time they are, in an epistemological sense, things that embody knowledge. The phrase 'research in and through the arts' captures this intertwinement of perspectives: it is about the knowledge, understandings, experiences, and perspectives that are embodied in art objects and practices, and which manifest themselves through the praxis of the arts, the praxis of making and playing. In artistic research practice, art lets us know what it is and what perspective it offers.

I have also described the open nature of the 'object' of artistic research as 'boundary work' (chapters 6 and 8). From this viewpoint, too, artworks and art practices are polysemic and contingent. Depending on the context in which they are placed, they may manifest themselves as artefacts and actors in the network of the art world, the field of cultural production, or they may reveal themselves as epistemic things that generate insights in an academic context. The term 'boundary work' alludes to the negotiations that are continuously underway along the borderline between art and academia (and between art and other life domains), where the presumed stability of things is relinquished in favour of an open outlook on what is possible and what we do not yet know. This contingency of artistic research is inseparably bound up with the nondiscursive and non-conceptual nature of its content (chapter 7). The object at issue partly eludes our epistemological grip. Even in the most abstract forms of art, the reality that unfolds in this artistic research (cf. chapter 9) is an articulation of the world we live in. With Rheinberger 
in mind, I refer to this reality as the 'artistic real'; in chapter 7 I call it the 'realism' of artistic research.

We may conclude from all this that artistic research is ontologically, epistemologically, and methodologically an open undertaking, and that any assessment of whether a particular artistic practice qualifies as research must take this fundamentally open nature into account. No stable boundaries exist that delimit in advance what belongs to the domain of artistic research and what does not. There is always work to be done along the borderline of art and academia. But this does not mean that no criteria or guidelines can be formulated that may help in the assessment process.

Here again we are dealing with the issue of demarcation: the criteria we can set out, or the guidelines we can apply, to distinguish artpractice-as-research from art-practice-in-itself. One possible approach to this issue lies in the word 'as' in the phrase 'art as research'. The classical distinction between artwork, art production, and art reception (which I discuss in chapter I in connection with research in the arts) and the heuristic distinction between object, process, and context (introduced in chapter 2) will be helpful here.

At the moment when art claims to be research in the emphatic sense (when artists assert that their artwork is also intended as research) - thereby making an epistemological claim - the art situates itself in academia. This inscribes the artwork, the concrete objects or practices, on the other side of the border separating art and academia. One can then justifiably ask what knowledge, what understanding, what insight, what experience this work embodies or attempts to put across. One may expect of the artist-researcher that she or he will substantiate this claim before the 'academic forum of peers'.

The positioning of art as research is a purposive act. The production of the work, the artistic creative process, is carried out not only for the purpose of creating artefacts that can circulate in the art world, but also as a means of generating insights that contribute to what we know and understand about ourselves in the world, and which also further the development of the discipline in question (cf. chapter 4). In research in the arts, the insights and understandings are interwoven in the artistic material and are disclosed through the artistic creative process. 
If the thus positioned art is perceived as research, the signifying context comes into play. Naturally this includes the context of the art world, the public reception of the art, and the cultural and historical environment, but it also includes academic discourse - the discourse in art history, philosophy of art, and other disciplines. The academic context is not, however, exclusively a context of justification. As we have seen, it is also a context of discovery and application. How an artwork has come into being and what meaning it has in the art world is academically relevant in the case of artistic research. In this way, art as research is embedded in social, artistic, and theoretical contexts with which it engages. The signifying context of artistic research also involves the work of others and the artistic and theoretical stances that work represents, and possibly also the artist's own prior work that has led up to the present work of art.

Thus, in the assessment of whether particular artistic practices qualify as research, the artworks themselves (the artistic objects and practices), their production (the creative artistic process), and their reception (the interpretive context) will all be weighed.

The definition of art as research that I formulated in chapter 2 and have quoted above can now serve as a template as we draw up criteria or guidelines that can aid in assessing whether artworks and art practices qualify as research. The elements in that definition have been the subject of separate discussions in chapter 7 . These are the intent of artistic practice, the originality criterion, the contribution to knowledge and understanding, the research question, the context of the research, the research methods, and the documentation and dissemination of the findings. The broadened conception of what research is (addressed in particular in chapters 3 and 4) also informs the discussion of those separate elements, slightly refining or qualifying them at times. Those refinements or qualifications, which I will not recapitulate here, need to be considered in both the formulation and the application of the guidelines. The elements will nonetheless continue to serve as a sort of checklist, guiding us, as it were, to the questions we can and may ask of every artistic practice that claims to be research. In the case study in the next chapter, we will see if and how this translates into the editorial policies and the content of the Journal for Artistic Research. I will 
now go into more detail about the elements of art as research and the questions we can derive from those elements.

\section{The questions we may ask}

The first element is the intent of artistic practice. At the moment an artistic practice claims to be research as well as art (in the emphatic sense of the word 'research'), the artist in question affirms academic discourse; and that is no equivocal matter. All too often, artists claim to be doing research while at the same time opposing (for a variety of reasons) what academia stands for, or what they think it stands for. One aim of this book is to show that such resistance is unnecessary - no more than the opposition is justified, still pervasive within academia, to artistic practice that claims to be research. I have broadly described the forms of resistance and tried to refute them, particularly in chapters 3 and 4 . The obvious, but also fundamental, question that needs to be posed as a guideline to any artistic research is: It is indeed research? An affirmative answer implies that the research engages with that which the academic world considers research, assuming that an enriched conception of 'academic' and 'research' is being used.

The second element is the criterion of originality and its corollary that the research must not lapse back behind what others have already done. There is not much to add to this observation. One should recall the distinction I have introduced in chapter 7 between artistic and academic originality. True artistic research is original both artistically and academically, in the sense that it gives us something we did not yet have - new knowledge about the world, about ourselves, or about the art form in question; a new perspective on what we thought we knew and understood; a new experience that makes us see, hear, perceive things differently. Or perhaps also a new form in which something can be cast or a new technique through which something can be addressed. At the same time, one must bear in mind that a researcher is often partly or entirely unaware of what is being sought at the time the research begins. This calls for a measure of caution when judging a research design or evaluating work in progress. The question that may be asked as a guideline is therefore: Does the research deliver or promise to deliver new insights, forms, techniques, or experiences? 
On the third element - the contribution to knowledge and understanding - I have already expounded a great deal in previous chapters. It seems good to repeat here in different wordings that, with the emancipation of experiential knowledge (in the sense of tacit, non-conceptual knowledge that lies enclosed in bodily and sensory experience and in pre-reflective action), the experience of rational knowledge has been extended or supplemented by experiences of embodied forms of knowledge (including aesthetic experiences), and that these are now coming back to claim their epistemological status, two centuries and a half after Baumgarten. A fully developed notion of academia will reincorporate these forms of knowing and knowledge within its walls. In the preceding chapters, from the first onwards, I have left open the question of whether the production of knowledge, understanding, and experience should be examined from a hermeneutic or a constructivist point of view. Do we discover what exists, or does what we discover exist? Here, again, I must leave this question open, although the identified intertwinement of ontology and epistemology would seem to dissolve this very antithesis. In previous chapters I have repeatedly (with reference to Latour) called attention to this with the annotation 'constructivist realism'. What is important here, however, is the question we can use as a guideline in assessing the art as research: What knowledge, what understanding, and what experience is being tapped, evoked, or conveyed by the research?

The fourth element is the research question, the subject or object of the research, the issue addressed in the research study. Keeping in mind the refinements I have made in chapter 7 , but leaving these aside for the moment, one might, with respect to this element, expect every researcher to present the study in a way that makes clear to the assessor that something is at stake here, that something of interest is being mooted or that a particular development is to be furthered. The form this presentation takes may vary; it does not always have to include a closely defined research question or well-constructed hypothesis. The artistic-academic forum may also be addressed with a non-linguistic exposition of the subject that employs other forms of discursivity to pose the 'question'. Just as for the other elements, a criterion of persuasiveness pertains here: Is the description or exposition of the topic, 
issue or question sufficiently lucid to make clear to the forum what the research is about?

The fifth element involves the context of the research. As has often been pointed out, one characteristic of research in the arts is its dual context - that of the art world and that of academia. Much artistic research is also transdisciplinary, in the sense that it links the art to other domains (academic or non-academic). Moreover, the contexts of discovery, justification, and application are interwoven in artistic research practice. In assessing art as research, one can inquire about these contexts: What relationship does the research have to the artistic or the social world, to theoretical discourse, and to the contributions that others are making or have made on this subject?

The sixth element is the research method. Artistic research can take on widely divergent forms. Depending on the topic, the contexts, the aim, and the scope of the research, the artist can also employ research methods and techniques derived from other fields of endeavour, including science. This methodological pluralism is still coupled, however, with the requirement that the research must take place in and through artistic practice. The implication is that the artist will often be actively engaged in the research process. Experimentation, participation, interpretation, and analysis are thereby intertwined in the research. In assessing the research, one should judge how well-suited the chosen methods are to addressing the research question: Does this experiment, participation, interpretation, or analysis provide answers to the question posed and, by so doing, does it contribute to what we know, understand, and experience?

The seventh element involves documenting and disseminating the research results. In some part, the outcomes of artistic research are artworks or artistic practices, including images, compositions, designs, installations, choreographies, productions, or performances, but also more abstract artistic products such as concepts, interventions, or processes. The documentation provided with these research findings will need to show respect for the ways in which artists document, expose, and publish their work, that is, respect for how the art is conveyed. The documentation of artistic research is not the same, however, as the documentation of artistic work. It additionally requires discursive elab- 
oration, in which, of course, artistic material can be used. As explained in chapter 7 , the discursive documentation may be devoted to a reconstruction of the research process, to an interpretation of the 'material' research outcome, or to a discursive approximation of or allusion to the artistic work. The documentation may also be expected to conform to what the academic world considers responsible publication; if provided in text form, for example, that might include conventions relating to the structure and reasoning of the argumentation, to references, to quotations, and to style. In view of the intertwinement of the artistic and the academic in the research, however, this is not an ironclad rule; but artist-researchers who decide to deviate from the guideline may well be expected to demonstrate through artistic or traditional means why they have done so. The question that can be asked in assessing the artistic research is therefore: Does the nature and design of the documentation support the dissemination of the research in and outside academia?

To recapitulate, here are the seven questions again that can and may be asked in the assessment of a particular artwork or practice as research:

I. It is indeed research?

2. Does the research deliver or promise to deliver new insights, forms, techniques, or experiences?

3. What knowledge, what understanding, and what experience is being tapped, evoked, or conveyed by the research?

4. Is the description or exposition of the topic, issue, or question sufficiently lucid to make clear to the forum what the research is about?

5. What relationship does the research have to the artistic or the social world, to theoretical discourse, and to the contributions that others are making or have made on this subject?

6. Does this experiment, participation, interpretation, or analysis provide answers to the question posed and, by so doing, does it contribute to what we know, understand, and experience?

7. Does the type and design of the documentation support the dissemination of the research in and outside academia? 
Together with the criterion that artistic research takes place in and through the practice of art and that the outcome of the research is also art, we can now put these questions to work as a kind of assessment framework for the case study on the Journal for Artistic Research. 


\section{Chapter II}

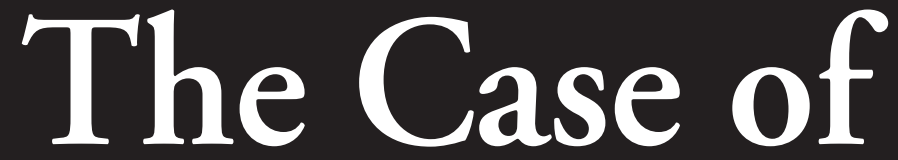

the Journal

for Artistic

Research

Or how a new field of research is articulated 


\section{We are allowed to speak}

interestingly by what we allow to speak interestingly.

We have taken science for realist painting, imagining that it made an exact copy of the world. The sciences do something else entirely paintings too, for that matter. Through successive stages they link us to an aligned, transformed, constructed world.

Bruno Latour* 


\section{Context}

This chapter describes an undertaking in which many people are involved, yet it is written from one participant's point of view. It is important to remember that the JAR editorial board members, the colleagues from the Society for Artistic Research, and partners from the Artistic Research Catalogue project have all made their contributions to the creation as well as to the conceptual and material design of the journal.

This is also a chapter in which, occasionally, I employ the insights provided by Bruno Latour's sociology of science. One such insight involves the nullification of the antithesis between theory and practice. JAR is the realisation of an idea, the articulation of a proposition. Theory and practice are inseparably tied together in JAR. This constructivist realism enables me to partially answer the question I raised at the beginning of chapter I about the relationship between theory and practice. 
This is a story about the creation and workings of a new peer-reviewed journal in a new field of research. Or better, it is a story about how people, institutions, works of art, and discursive practices meet to form a heterogeneous network - a network in which the new field of research is performed, enacted, and made real. And it is a story about how software development, funding arrangements, legislation, and review procedures and criteria transact and interact, thereby transforming the network actants (both human and non-human), while at the same time providing the artistic research network with temporary material, strategic and discursive stability, and durability.

By choosing these words to report on the Journal for Artistic Re$\operatorname{search}(J A R)$, I reveal the influence that actor-network theory (ANT) an influential variant within science and technology studies (STS) has had on my work. Any narrative told against the backdrop of a theoretical framework will serve to sustain that framework (or perhaps to undermine it). It is not my intention, though, to prove that ANT is right, nor to modify or enhance it. In my choice of words, my angle of approach, or the ways I tie things together, I will employ ANT 'loosely', like a bricoleur - an image that STS, as it happens, sometimes makes positive use of.

I am thereby taking up the advice recently given by Helga Nowotny, president of the European Research Council, to researchers in the arts:

STS has unravelled many heterogeneous networks that extend throughout society and among its actors and institutions. In these heterogeneous networks, 'humans' and 'things', i.e. artefacts, are linked in multiple and mutual relationships. By extending the concept of 'agency', ANT or actor-network theory claims that the production of new knowledge is taking place in numerous sites and through many transactions and transformations that extend throughout society and its institutions without losing sight of the 'objects' and their materiality. From an ANT perspective, humans and the artistic phenomena they produce and interact with, can also be seen as constituting continuously reconfigured assemblages. Researchers in the arts are therefore 
well advised - and invited - to delve into the burgeoning sTs literature. There they will find much that appeals to them intuitively, but also much that allows them to 'make sense' of their own artistic practices. ${ }^{\mathrm{I}}$

\section{JAR, RC, SAR}

The Journal for Artistic Research ${ }^{2}$ is an enhanced, open-access, international peer-reviewed journal for the identification, dissemination, and discussion of artistic research, its methodologies and outcomes, in all the disciplines of art. Issue o of JAR was launched at a conference in Bern in Switzerland on 4 March 20II. The contributions to that inaugural issue were invited by the editorial board and were not peer-reviewed. As I wrote the present report, the peer-reviewed issue number I was in the making and was to be published in November 2011.

My account will not directly examine the individual JAR contributions. The assessment of those contributions was, and is, in the hands of peer reviewers, and it is not my task to do their work over again. Central to my analysis in this short history of JAR is the way that assessments are carried out, what 'peer review' means in the context of $J A R$, and what considerations were involved in formulating the peer review guidelines.

$J A R$ is the material and conceptual outcome of a process - the artistic research field in action (to paraphrase Bruno Latour). To understand how JAR came about and what was mobilised to achieve it, we must go back to the autumn of 2009, to Solstrand, on the Norwegian west coast near Bergen. Here - at a crucial developmental moment in the new field of research - people, instruments, institutions, and ideas all played their part in creating and articulating a network, and at the same time transforming its constituents into allies in an exciting, challenging new endeavour.

I. Helga Nowotny, 'Foreword', in Michael A.R. Biggs and Henrik Karlsson (eds), The Routledge Companion to Research in the Arts (London: Routledge, 20II), p, xxii. 2. See JAR n.d. <www.jar-online.net>. Some formulations in this chapter are drawn from the wordings used on the JAR website. 
For six successive years, the Bergen National Academy of the Arts, with support from the Research Council of Norway, organised conferences entitled Sensuous Knowledge in Solstrand. ${ }^{3}$ The title explicitly refers to Alexander G. Baumgarten, retrospectively regarded by one of the conference initiators, Professor Søren Kjørup of Bergen and of Roskilde University in Denmark, as an originator of the new research paradigm. Kjørup's ideas were later published as Another Way of Knowing, the first in a book series also entitled Sensuous Knowledge, published by the project at Bergen Kunsthøgskolen. ${ }^{4}$

The sixth and final conference at Solstrand (sk6) was held from 23 to 25 September 2009. The formula was similar to that of previous meetings: the focus was on the presentation of concrete artistic research in small-scale workshops with plenty of discussion. The sK conferences were not the only ones of their kind. Several other conference series had been held in the past decade that likewise focused on the new research field. These included the Research into Practice (R2P) conferences (every other year from 2000 to 2008), convened by the University of Hertfordshire; and the Practice as Research in Performance (PARIP) conferences in 200I, 2003, and 2005, organised by the University of Bristol, both with support from the Arts and Humanities Research Council in the United Kingdom. 5 Two Dutch initiatives should also not go unmentioned: the symposium entitled 'Artistic Research', organised by the Global Vernunft Foundation, in Amsterdam's Maison Descartes (III2 April 2003); and the expert meeting entitled 'Kunst als Onderzoek', held a year later in Amsterdam's Felix Meritis centre (6 February 2004) on the initiative of the Art Theory and Research Group at the Amsterdam School of the Arts.

The sk6 conference in Norway was also the scene of a renewed encounter between three people of varied backgrounds that were to play a critical role in the development of JAR. They were Florian Dombois, an artist and geophysicist who at the time headed the Y Institute for Transdisciplinarity at the Bern University of the Arts; Michael Schwab,

3. See sK n.d. <http://sensuousknowledge.org/>.

4. See Kjørup 2006.

5. See R2P n.d.; PARIP n.d. 
artist and philosopher, lecturer at the Royal College of Art, London; and myself, Henk Borgdorff, who specialises in research in the arts at the University of the Arts, The Hague, and the University of Gothenburg, and who, in writing the present report, is privileged to serve as a kind of participant ethnographer.

From autumn of 2008 on, Michael Schwab had been receiving support from Florian Dombois to work at the Bern University of the Arts on developing an online journal for the publication of artistic research. I had met Dombois earlier at a lecture I gave in Berlin in October 2005, as well as at a seminar I held in Zurich in December 2006. All three of us were working to conceptually clarify the phenomenon of artistic research, had occasionally communicated by e-mail, and had been intending to speak more extensively at some point.

In 2008, Dombois, Schwab, and I had been invited to contribute to a conference at the Zurich University of the Arts (ZHdk), held under the auspices of the European League of Institutes of the Arts (ELIA), the network organisation for arts education in Europe. The theme of the conference was the distinction between art and artistic research, an issue of demarcation that had been surfacing again and again in the international debate. ${ }^{6}$ During that conference in Zurich on 2324 April 2009, a lively debate arose in the corridors about artistic research, and in particular about the ways it should be documented. Around that same time, Schwab had drafted a 'call for support' for the creation of a journal, and from June 2009 onwards the three protagonists were in intensive contact about the proposed journal and about who and what would be needed to make it happen. ${ }^{7}$

This 'who and what' came together in a productive way at the Norway conference in the autumn of 2009. One part of the development plan for the journal was the design of a digital database for the

6. The proceedings of the conference were published as Caduff et al., 2009.

7. We were all three heavily interested in the theoretical and political rationale of artistic research. Beyond this, Dombois brought his managerial and his financial expertise to the project, while Schwab concentrated more on the conceptual framework. I was happy to contribute, too, with my growing network in the artistic research field. It is not always easy to distinguish between the voices of Dombois, Schwab, and myself when reporting on the development of JAR. 
documentation and 'exposition' of artistic research. The Journal for Artistic Research was to be an enhanced publication that would store and give integrated access to images, audio files, and videos as well as texts. An essential requirement was that the artistic research was to be displayed in ways that would fulfil artists' expectations. Clearly, new software had to be developed for that purpose, as the existing repositories did not meet the requirements we had set for the future platform. ${ }^{8}$ The envisaged database was seen as the mainstay of the journal. Two months previously, in July 2009, Schwab and I had conceived the idea of creating a strategic separation between the development of the Research Catalogue (RC), as the digital database was called in the plans, and the proposed journal. For the RC, I saw opportunities to apply for financial support from the international Regional Attention and Action for Knowledge Circulation (RAAK) programme operated by the Stichting Innovatie Alliantie (SIA) of the Netherlands Ministry of Education, Culture and Science.

There were also content-based reasons to set the RC apart from the journal, reasons that were intrinsic to the nature of the two initiatives. JAR had been conceived as a peer-reviewed academic periodical for artistic research. In the art world, among artists and curators, a good many reservations existed (and still exist) towards 'artistic research', and definitely towards academia. To build bridges between the worlds of art and academia is one of the very purposes of the entire project of JAR and RC. Or more precisely, once artistic research is introduced into the art world and into academia, the latter two domains might not only find more common ground, but might even alter slightly in character. Notions of what the art world is, and what the academic world is, could be broadened and enriched by the emergence of the new field of research. The network surrounding JAR could make significant contributions to that transformation, as well as to the stability and durability of the research field. ${ }^{9}$ The RC is

8. It was Michael Schwab who developed the idea and the conceptual and material framework of the Research Catalogue.

9. JAR does not stand alone. Other journals that focus on the field of artistic research are Art and Research, Inflexions, Studies in Material Thinking, MaHKUzine, and Art Monitor. Mostly they do not publish artistic research work itself, but critical reflections on it. Published conference proceedings, such as the Working Papers in Art and Design, are also available. 
a material actor here, an 'immutable mobile' (Latour), that ensures stability, mobility, and combinability in the new field.

This Research Catalogue (RC), then, is inclusive, bottom-up, and open-ended. That is to say, in principle any person can gain access to the database to document or expose their work; it is a resource or tool for self-publishing; and there are no other restrictions other than those attached to the use of the software. Artists (or anyone else) can make use of this platform to provide access to and disseminate their work, without first having the work assessed by others. In JAR, by contrast, assessment by others is crucial. But who are those 'others'? And what criteria do they apply in their assessments? These were issues to be addressed later in the journal's editorial policy.

The database is searchable at various levels - from keywords to documented work. Artworks and art practices that are documented as part of an RC exposition can be located and cited by others. By publishing their work in the RC, artists not only document it, but they also establish links to the growing community of artist-researchers worldwide who are committed to communicating their work as research. The RC provides a platform for artistic research. Documentation and publication of work in that context implies that it is also intended as research, and that it can be 'read' as such without someone first having to determine where the lines of demarcation are. This makes the RC an interesting instrument for the emergent research field. It is this very absence of previously defined boundaries that will enable the new research field to develop.

In Solstrand, the JAR network took further shape. The application for Dutch developmental funding for the Research Catalogue was a topic of discussion. For the application to succeed, it was important to have sufficient support from the field itself. The president of ELIA pledged support via his network organisation. The initiative would later be presented at the ELIA biennial conference in Nantes in October 2010. Support was also garnered during the Norway conference from two other network organisations, the SLSAeu (the European section of the Society for Literature, Science, and the Arts) and the AEC (European Association of Conservatoires). They, too, enabled JAR and the RC to be introduced at respective conferences in Riga (June 20IO) and Warsaw (November 20IO). 
Ultimately, the following partner in-

After Norway, the organisers continued to work intensively in late 2009 on creating a network of artists, arts institutions, arts schools, universities, and research centres which, with support from the Dutch funding body, would begin building the RC. The application for a two-year grant was approved in January 20IO, and the project was launched on I March 2010 with financial support of more than 400,000 euros. It bore the name Artistic Research Catalogue and operated from The Hague.

In the course of the project, it became clear that the distinction between 'work' and 'exposition' would be crucial for the RC (and for JAR). ${ }^{\mathrm{IO}}$ In every academic research publication, the work that is done in the context of discovery or that is critically scrutinised (in the laboratory, in the field, at the researcher's desk) is 'exposed' in ways that both fulfil the standards of scholarly dissemination and involve a transformation (Latour) of the content. Whether the work concerns empirical data collection, ethnographic field research, historiography, or technical design, the research topic is always transformed and modelled into an object of knowledge and is made to speak through academic publication. In this way, objects of proto-knowledge - indistinct things and situations - acquire tentative ontological and epistemological forms (cf. chapter 9).

The same applies to research in the arts. What first belongs to the art world (and has its own place there) is transformed in the context of

IO. This was also the theme of a working conference of the Artistic Research Catalogue project in December 2010 in Gothenburg. Michael Schwab deserves credit for coining the term 'exposition' as described here. stitutions were to participate in developing the Research Catalogue:

- University of the Arts, The

Hague, Department of Research in the Arts

- Zuyd University, Research Centre on Autonomy and the Public Sphere in the Arts, Maastricht

- Gerrit Rietveld Academie,

Research Group on Art and Public Space, Amsterdam

- Utrecht School of the Arts,

Utrecht Graduate School of Visual Art and Design (maHкu), Utrecht

- De Theaterschool, Amsterdam Master of Choreography, Amsterdam

- Leiden University, Academy for

Creative and Performing Arts, Leiden

- Van Abbe Museum, Eindhoven

- Basis voor Actuele Kunst (BAK),

Utrecht

- Het Huis van Bourgondië, Maastricht

- $\mathrm{V}_{2}$ Institute for the Unstable

Media, Rotterdam

- Royal College of Art, Curating

Contemporary Art, London

- Bern University of the Arts, Y Institute for Transdisciplinarity, Bern

- Max Planck Institute for the History of Science, Berlin

- Karlsruhe University of Arts and Design, Project gamma, Karlsruhe - Massachusetts Institute of Technology, Program in Art, Culture and Technology (АСТ), Cambridge, Massachusetts

- Journal for Artistic Research (JAR), hosted at Bern University of the Arts, Bern

- Vrije Universiteit Brussel,

Department of Research and Development, Brussels

- European League of Institutes of the Arts (ELIA)

- European Association of Conservatoires (AEC)

- European Society for Literature, Science and the Arts (sLSAeu) 
academic discourse into a conveyor of, or embodiment of, knowledge and understanding. This makes artworks into 'boundary objects' - hybrid objects or practices whose status varies according to the context in which they appear. In the view of the RC, 'works' are not just documented, but exposed. That is, in the RC one may 'stage, perform, curate, translate, unfold or reflect practice as research'. ${ }^{\text {II }}$

The Journal for Artistic Research - built as a portal on the Research Catalogue - is an online, open-access periodical. It has no subscribers, and anyone can consult the journal at any time. It hence has no subscription income either. The call for support that went out through many channels on 23 November 2009 was partly intended to garner support from people and institutions that were willing to provide material support to the project. In the early months of 20I0, it became increasingly clear that a legal entity would need to be created. Innumerable people worldwide - artists, academics, and others - had declared their support, and a growing number of institutions had expressed willingness to assist JAR financially. The launch of JAR and RC in March 2010 therefore coincided with the establishment of the Society for Artistic Research (SAR). Its mission is

to display and document work in a manner that respects the artist's modes of presentation while fulfilling the expectations of scholarly dissemination, and to re-negotiate the relationship of art to academia, and the role and function of research in artistic practice. ${ }^{12}$

At this writing, more than thirty institutions worldwide (chiefly universities and academies of the arts, but also national research institutes) support the Society. This has fostered a closely knit but dynamic network of relations between ideas, concepts, instruments, artefacts, people, and institutions surrounding the proposed journal.

Since March 20I0, work on the Research Catalogue has been in progress,

II. Michael Schwab, 'Editorial', Journal for Artistic Research, o <http://www.jaronline.net/index.php/issues/editorial/480>.

I2. See the JAR webpages for information about the Society for Artistic Research. 
Instruments

$\mathrm{RC}$

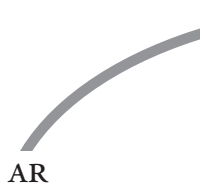

Research Catalogue

Artistic

$J A R$

Journal for

Ideas

Artistic

Artistic Research and Practices

ART

Concepts Research

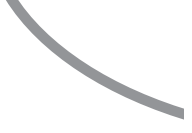

SAR
Society for Artistic
Research

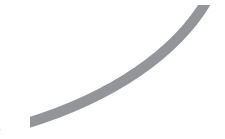

Artworks

Artefacts

\section{People \\ Institutions}

parallel to preparations for the initial (trial) issue of JAR and for building the Society. Artists and curators collaborated (both independently and via their institutions and art schools) in the Artistic Research Catalogue project with academics and software developers. Their guiding question was:

What kind of instrument for the documentation, dissemination and discursive signification of artistic research projects can meet the interests of professional artists, art institutes and art students engaged with forms of art practice as research? And how to build an instrument, which, at the same time, is inclusive towards the specific needs and demands that originate from the different art disciplines?

The project description further elucidates this as follows:

[RC] positions itself between art practice and academia, between the world of art and higher arts education. Artistic research occupies a discursive field linking extensive documentations of both 
research and art work with expositions and comments that engage with the signification of the work as research. Adding work to this catalogue makes a claim that the work can be seen as research; through expositions, comments and articles the initial claim is transformed into an argument. Finding a suitable structure in which to develop the relationship between documentation and exposition plays a difficult but important part in artistic research. ${ }^{13}$

Feedback from established and trainee artists and from academics led to recommendations and software adaptations. Practical and conceptual issues were discussed in workshops and conferences in Leiden, Gothenburg, Bern, and Zurich. A first version of the software was released in March 20II, after which artists 'from outside' were able to access the RC and use it to document their artistic research work. By August 20II, about I25 artist-researchers worldwide were actively using the RC. In November 20II, a new release of the software was launched, which was more user-friendly and offered possibilities for pre-publication collaboration, extended forms of commenting, and the publication of review reports.

Because JAR is a peer-reviewed academic journal, submitted contributions are subjected to the critical scrutiny of external reviewers who are considered experts on research in the arts or specific areas within it - research, that is, in which artworks or art practices constitute the heart of the research from a methodological and epistemological point of view. JAR's policy is to carefully seek out, for each contribution, the expertise appropriate to the topic in question. For every submission, at least three reviewers are requested to write evaluation reports, guided by a standard peer review form (another 'immutable mobile' in the JAR network). ${ }^{I 4}$ Because the artistic and the academic are interwoven when art is exposed as research, both artists and academics

13. These are extracts from the project application, which is unpublished. See ARP 20 IO <http://innovatie-alliantie.nl/projectenbank/raak-project/724-artistic-research.html> and ARC $2010<$ http://www.kabk.nl/pageEN.php?id=0485> for more information about the Artistic Research Catalogue project.

I4. The peer review guidelines can be accessed through the JAR website. 
will normally take part in every assessment. This type of extended peer review is increasingly common outside the arts domain as well. ${ }^{\text {is }}$ In the field of artistic research, the 'community of peers' is still in development. The creation of JAR is a significant step in that process. ${ }^{16}$

JAR currently uses a single-blind review process, with open-review publication. During the review process, the reviewers are anonymous; the artists/authors are not. In the field of art, a double-blind review process would be unrealistic, as artworks often carry the 'signature' of the artist who created them. When a submission is accepted for publication in JAR, we publish the review reports, edited by the reviewers. The reviewers have the option to publish their names with the report or to stay anonymous. Most reviewers opt to make public both the review report and their identity. The ambition of JAR is that not only the editors, but also the reviewers engage with the submitted material without relinquishing the 'external scrutiny'. Open dialogue is vitally important in the emerging field of artistic research. In future, JAR will therefore seek to facilitate open-process collaboration and commentary through the Research Catalogue platform. A further ambition is to include real-life events (such as exhibitions or performances) in the assessments. A working group in the Society for Artistic Research is currently studying that possibility, but it is still uncertain whether the limited confines of the online journal would allow for that.

The criteria or guidelines for the assessment of JAR submissions focus on three main issues. First - and the order of the criteria is not without import - an exposition should be able to effectively impact upon, and artistically and intellectually engage, a targeted audience. Second, peer reviewers are to judge whether the contribution exposes art as research. The third, more specific requirement is that the artistic and

15. Cf. Gibbons et al. 1994.

I6. Building a community of peers is likewise one objective of the SHARE academic network. SHARE (Step-Change for Higher Arts Research Education) is a project supported by the European Commission in which thirty-five graduate schools and other institutions involved in third-cycle research in the arts in twenty-six European countries work together. The project runs from October 2010 to October 2013 and is coordinated by ELIA and the Graduate School of Creative Arts and Media (Gradcam) in Dublin. See SHARE n.d. $<$ http://www.sharenetwork.eu/>. 
intellectual proposition underlying a contribution should be supported by the design of the exposition and the mode of navigation through it.

The peer review form additionally requires reviewer self-assessment. Could a conflict of interest exist? What expertise does the reviewer have and what weight does the reviewer attach to that expertise in relation to the subject of the submission? A further question is whether there are possible ethical or legal issues that need to be allowed for in the assessment. Finally, each reviewer is asked to provide feedback to JAR to help improve the review process. As the review form makes clear, the JAR editorial board is aware of the limitations and pitfalls of any review process, especially anonymous ones. An annexe therefore provides some 'notes on constructive reviewing'. In my discussion of the peer review guidelines that will now follow, I shall confine myself to the three main criteria.

\section{Artistic and intellectual interest}

This is what the guidelines for reviewers say about the first criterion:

Is the exposition of artistic/intellectual interest? Although difficult to assess, expositions are sought that endeavour to address important artistic issues or intellectual problems in a specifically artistic manner and which engage others in the field. Please tell us whether or not the submission is interesting in its subject, methods or outcomes.

Interestingly, few differences of opinion emerged about this criterion. In the discourse surrounding JAR, everyone agreed that the contributions should be artistically and intellectually interesting or challenging. Within this criterion, the emphasis lies on the artistic manner in which the issues and problems are approached. This is the quality through which JAR distinguishes itself from other academic platforms that publish on art. Following the publication of issue $\mathrm{O}$, this was a topic of some concern. One member of the Society's executive board wrote, for example,

I am concerned about the quality of JAR contributions. I had real trouble with [title omitted]: to be honest, I found it neither 
artistically nor intellectually satisfying. [...] Forgive me this directness, and it is not against anybody. Last year we came really, really far, but I see quite a way to go before issue I. I see JAR not as a $\mathrm{PhD}$ publication journal, but as an international professional journal of the highest calibre that sets the pace for artistic research, challenging both the art market and academia. ${ }^{17}$

By stressing professionalism and by referring to the art market, the writer makes clear that his prime focus is on artistic quality. If JAR is not artistically convincing, it is doomed to fail. Many, if not all, commentators were convinced of that. It is therefore literally the first and foremost criterion.

For JAR I and subsequent issues, an extensive pool of available reviewers has been created. An important objective was to ensure a sufficient range of expertise. In the JAR context, 'extended peer review' means that both the artists' perspective and the academic perspective have to be represented. The number of artists worldwide who now occupy academic posts or hold academic doctorates is considerable, especially in the anglophone world and in Scandinavia. Their number is also clearly increasing on the European continent and in parts of Asia and South America. But the idea was also to call on the expertise of artists who are rather further away from academia, who are unfamiliar with academic mores, or who have reservations about academic culture and practice. In addition, it was necessary to mobilise both specialist knowledge from the various disciplines of art as well as generalist methodological knowledge.

Artistic research is a relatively new research field, and JAR, by virtue of its exceptional format, constitutes a singular and challenging platform within that field. JAR is challenging not only to the artist-authors, who have to work with a beta version of the RC editor that is none too userfriendly as of yet, but also to the reviewers. Some familiarity with artistic research, or at least a willingness to engage with it, is essential.

$J A R$ is inclusive, also in terms of the divergent views that exist with respect to artistic research. Roughly speaking, one can discern three

I7. From private email correspondence. 
such points of view: (I) the academic perspective, (2) the sui generis perspective, and (3) the critical perspective.

I. The academic perspective - associated by some with how the new research paradigm is institutionalised in the English-speaking world, notably in the UK - puts value on traditional academic criteria when it comes to differentiating art practice as research from art practice in itself.

2. The sui generis perspective - associated by some with how artistic research made its entry into academia in the Nordic countries - foregrounds artistic values when it comes to assessing research in the arts.

3. The critical perspective - associated by some with how one is struggling with the Bologna imperatives in the German-speaking countries - emphasises the critical, or even subversive, force that research in the arts might exercise in opposition to the neo-liberal tendency in our post-Fordist knowledge economy to subsume everything deviant under a single umbrella.

All these considerations have been taken into account in putting together the pool of reviewers and referring submissions to them. ${ }^{18}$

\section{Art as research}

The second guideline for reviewers invites them to judge whether the contribution exposes art as research. Affirming this implies that the contribution addresses (though it does not necessarily conform to) the prevailing academic standards for the conduct of research. Clearly this criterion (or perhaps 'guideline', as some participants had misgivings about the term 'criterion') constituted one of the most challenging topics in the discourse. The discourse has been pursued, among other places, since July 2010 on the online forum operated by $J A R^{19}$ and in March $201 \mathrm{I}$ at the meeting in

I8. The twelve submissions that went into peer review for JAR I were eventually judged by forty external experts. One submission was accepted in the first round, needing only small changes. Most submissions were sent back for modification or improvement on the basis of the reviews. Ultimately, JAR I appeared in November $201 \mathrm{I}$ with eight expositions and twenty-six published review reports.

I9. See <http://www.jar-online.net/blog/category/peer-review/> [accessed 7 January 20I2]. 
Bern that launched JAR O. Naturally it has been a topic of continual discussion in the JAR editorial board, as well as online and during face-toface or Skype conferences. This is what the peer review form as of August $20 I I$ asks of the reviewers with the respect to the second criterion:

Does the submission expose practice as research? In the Research Catalogue, practice is exposed, translated, transformed, performed, curated etc. as research. The claim to be research implies a relationship in one way or another to academic criteria for the conduct of research. The submission need not comply with all (or even one) of the points listed here. But one might question whether it does, and if not, what the artistic, aesthetic or intellectual rationale is.

Please take into account:

- whether or not the submission contains a description or exposition of the question, issue or problem the research is exploring, and if not, if such an omission matters;

- whether or not the submission shows evidence of innovation in content, form or technique in relation to a genre of practice;

- whether or not the research issue is contextualised, which may include social, artistic, and/or theoretical issues that the work responds to, a discussion of a range of positions taken by other artists to whom this work contributes a particular perspective, and some documentation of work by the artist that led to the present submission, and if not, if such an omission matters;

- whether or not the submission provides new knowledge, interpretation, insights or experiences, and what (kind of) new knowledge, interpretation, insights or experiences these comprise;

- the adequacy and soundness of the methods used and the thoroughness of research, analysis, and/or experiment.

In the light of this criterion (or better, these criteria), the task is now to examine whether they are consistent with the 'assessment framework' proposed in the previous chapter. Here, again, are the seven elements of that framework: 
I. intent

2. originality

3. enhancement of knowledge

4. research question

5. contextualisation

6. methodology

7. documentation and dissemination

The first element, intent, involves not so much whether art is research, but whether a particular artistic practice is intended as research. At the point where an artist exposes her work in JAR or in the RC, she inscribes that work, as it were, into the research discourse. By so doing, she asserts that the work is also to be regarded as research. In the context of the peer-reviewed journal, such a claim is subject to intersubjective evaluation. And something exceptional occurs here, in an epistemological and an ontological sense. The work exposed in the Research Catalogue 'transforms' (Latour) from an artistic product to an artistic argument, to a potential bearer of knowledge and understanding. At this moment, artworks and art practices explicitly become epistemic things (Rheinberger), exposed as research in order to set our thinking into motion.

The intent criterion is captured in the all-encompassing question 'Does the submission expose practice as research?' The remainder of the sub-criteria may be seen as more specific refinements of this question. The explanatory notes accompanying the question make it clear that the JAR editors have an open conception of what academic research is. 'The submission need not comply with all (or even one) of the points listed here.' In line with the liberalisation of academia as traced in previous chapters, JAR not only endorses the emancipation of non-discursive knowledge forms, unconventional research methods, and enhanced modes of presentation, but it also assumes that the boundaries of academia are not fixed. As science and technology studies also have shown us, academia is not a stable system, but one that is constantly evolving, one whose boundaries are continually shifting.

That is not to say, however, that no boundaries exist. Even if our beliefs and knowledge claims have no ultimate ontological or epistemological ground, the temporary stability of the academic system is 
safeguarded by the methodological criterion of reflexivity (in the context of justification, at least; in the context of discovery, that stability is temporarily ensured by 'immutable mobiles' (Latour) or 'technical objects' (Rheinberger), and in the context of application by the effect or impact of the research). Like Neurath's ship, artistic research is chronically underdetermined. A revision or rejection of criteria is possible only if some criteria are held constant, including the reflexivity criterion. Letting go of it would lead to a departure from academia. In this sense, JAR is also reflexive: 'But one might question whether [the submission] does [comply with the points listed], and if not, what the artistic, aesthetic or intellectual rationale is.' In the words of Catharina Dyrssen (2OII: 9I), in a review of JAR in the artistic research yearbook of the Swedish Research Council:

How then should the demands be stipulated, by whom and why, and what does this mean for JAR? Obviously it is not a question of pre-defined or self-appointed authorities who decide the game-rules but of a gradual debate, in which the arguments - in artistic and rhetorically critical form - hopefully increase sharpness and depth.

On the other elements of the assessment framework, I can be briefer. With respect to the originality criterion, which refers to innovation in content, form, or technique, some commentators wondered whether this is a permissible criterion for the field of artistic research. As one contributor to the JAR forum argued:

This one is problematic; whether a body of art must involve innovation (or novelty?) as a necessary condition for its being a valid part of a research process is not clear to me. A valid research process could use well-tried art processes (i.e. not innovative ones). Success in the art world does not require being a reflexive researcher (though that is not excluded).

Seemingly, then, there is indeed something to be said for relaxing this criterion, if not actually removing it. Although JAR intends to publish 
significant work, that significance does not necessarily dwell in artistic newness. It may also lie in qualities such as an exceptional, original way in which the artistic is used as an instrument, as a method, as an argument, or is made to speak or to connect to other discursive or nondiscursive parts of the exposition.

The originality criterion gains additional import, however, when viewed in relation to two other elements from the assessment framework: enhancement of knowledge and contextualisation. One may ask of every contribution what insights or experiences it delivers and how it relates to the current state of the art in the field it is relevant to. Originality pertains here primarily to these aspects.

With respect to knowledge enhancement, the guidelines ask whether or not the submission provides new knowledge, interpretation, insights or experiences, and what (kind of) new knowledge, interpretation, insights or experiences these comprise'. One thing worth noting from this wording is that experiences are treated on a par with knowledge, interpretations, and insights. As I have pointed out in chapter 8 , it is a point of debate of whether this experiential component of artistic research - the aesthetic experience - can be considered to belong to the space of reasons. Or does this experience, which, although cognitive, is non-conceptual and non-discursive, have no epistemological bearing? In itself, perhaps it does not, though opinions differ. Now this just happens to bring into focus one of the particular dimensions that the Research Catalogue and JAR are intended to address. At the moment that the exposition links the artwork to other non-discursive and discursive elements, the artistic work that evokes aesthetic experiences becomes transformed into an epistemic thing (Rheinberger). And precisely because the work is not fully transparent, our thinking is set in motion, meanings may loom, and realities may be constituted. The knowledge that lies enclosed in the aesthetic experience and that is embodied in the art, and the reality that is enacted and constituted in artistic practices, both manifest and articulate themselves in and through the artistic research as exposed.

With regard to the question of 'whether or not the submission is contextualised', one participant in the debate commented: 
[It] is debatable how explicitly or implicitly the artistic researcher needs to demonstrate that s/he is aware of the context and how much s/he needs to give explicit connections. I can imagine here also non-verbal or semi-verbal solutions [...]

Analogously to the other criteria, what is especially important here is how convincing the contextualisation is to the research community, and not a predetermined mould in which that contextualisation is to be cast. That said, this criterion does seem to demand much of the artist-researcher: a positioning with respect to social, artistic, and/or theoretical issues and to relevant work by oneself and other artists. Here too, however, the wording of the question leaves room for the artist to make a reflexive choice that is appropriate for the exposition - 'which may include ...', 'and if not, if such an omission matters'.

A similar qualification applies to the criterion about the research question - 'and if not, if such an omission matters'. At first glance, this would seem to nullify the criterion, but in fact it testifies to the reflexivity and openness of JAR. An issue may often, but not necessarily always, be raised in the form of a written question that is then addressed using research methods. The guidelines refer to 'a description or exposition'. JAR deliberately invites artists to consider presenting their research topic (issue, question, problem) by artistic means. And here, again, the power of persuasion is the ultimate measure: Is the problem pertinently, convincingly, and compellingly introduced and articulated? The topics addressed by the JAR contributions can and will, of course, be widely divergent. Focuses may lie on the artistic material, on the creative process, or (as will frequently be the case) on social or other issues that may initially seem to be outside the true domain of the artistic, but which are brought forward, or even rendered 'visible', by the artwork or artistic practice.

This also highlights the transdisciplinary character of JAR (without, of course, precluding intra-disciplinary research). Transdisciplinarity is distinguishable from multidisciplinarity or interdisciplinarity by the fundamental ways in which the premises of the discipline(s) are, or can be, challenged in the light of a situation that is indeterminate. Transdisciplinarity may be understood in three ways in the context of JAR. Art research can form ties with other academic, scholarly, or scientific disciplines, and this 
partly involves rendering the methodological and epistemological viewpoints of artistic research fruitful and fluid in the other academic context (and vice versa). Within the domain of the arts, transdisciplinarity may also concern the relationship between the artistic research and current concerns in art, what is important in the art world (and how 'research' is understood there) - briefly, the relationship between academia and art which is always a turbulent one. Finally, transdisciplinarity in the context of JAR refers to ways in which artistic research may engage with other life domains, with the physical or social environment, with politics, with globalisation, with identity or other realms.

All these forms and instances of transdisciplinarity also always involve transformations (Latour). Academic research is transformed by the 'practice turn' that is ideal-typically performed in artistic research. Our understanding of the art world and academia is transformed by the entry of artistic research into both domains. And, more modestly, the world we live in is transformed by the artistic-reflexive constitution of alternatives.

The methodological element in the JAR assessment framework is examined by the question about 'the adequacy and soundness of the methods used and the thoroughness of research, analysis, and experiment'. In the workshop held to discuss the review process for JAR, conducted at the conference in Bern where issue o of JAR was launched, several participants registered their objections, not so much to the idea that the research must be methodologically justifiable, but to the way this 'criterion' was formulated in terms like 'adequacy' and 'thoroughness'. The workshop summary put it as follows:

There were suggestions within the group that the guidelines for the peer reviewers not be overly prescriptive, allowing scope for individual interpretation, and there were contestations that the peer review guidelines were academic in a 'scientific' fashion in describing what research was. [...] It is felt that the guidelines as written have the possibility of frightening artists away from presenting that material for review. ${ }^{20}$

20. See: <http://www.jar-online.net/app/webroot/uploads/SAR\%2oAGM\%2oMinutes\%2O2OII.pdf> II [accessed 7 January 20I2]. 
It is important to note that those attending in Bern were mainly people who are amenable towards artistic research and towards JAR. Though such warning signals have not yet led to adaptations to how the criterion is formulated, to a different choice of words, that is expected to happen later. After all, part of the mission of JAR (and of the Society for Artistic Research) is to also connect to those artists and art practices that stand further away from academia.

The final element of the assessment framework, documentation, and dissemination, brings us to the third guideline for peer reviewers, which specifies that the artistic and intellectual proposition underlying a contribution should be supported by the design of the exposition and the mode of navigation through it.

\section{Design and navigation}

This is the question that the peer review form puts to the assessors:

Does the exposition design and navigation support the (artistic) proposition? A basic, legible design is preferred, provided it does not pose an obstacle to the presentation of the exposition. Whenever design choices differ from basic design, they will have to make sense (even if this sense might be 'confusion' at times).

Please take into account:

- if the design and navigation support the exposition;

- if you think a correct or feasible use of referencing is used in the submission;

- the readability of the submission (including the use of the written English language).

It is not necessary to comment here on the language issue (JAR is officially multilingual, but all expositions must also be submitted in copyedited English) nor on the guidelines pertaining to the use of footnotes and references, the citation method, and the composition and format of bibliographies. JAR expects these to be consistent and asks authors to use the author-date citation style of the Modern Humanities Research Association (MHRA). Yet the format of JAR itself does necessitate 
an exceptional way of making references from and to JAR. This calls for a brief explanation.

The publications in JAR (and in the RC) are called 'expositions' in order to make it clear that a transformation occurs from an aesthetic project to an artistic argument. Expositions in JAR consist of one or more 'pages'. These are web pages on which the research material (text, images, sound recordings, videos) is interwoven in ways that allow the artistic work to manifest itself as research. The ways in which the material is arranged on the pages may have meaning for what is being told; the content of the exposition does not stand in isolation from the design of the exposition, nor from the ways that the 'reader' is able to navigate through the exposition. In this way, JAR enables the artist to deviate from the standard format of journal articles. In the first place, this is because images and sounds are not subordinate to, but fundamentally on a par with the text; but it is also because the opportunity is provided to break out of linear narrative structure. JAR does offer the artist-authors a basic design guide, but everyone is free to diverge from it if they can make clear why.

Pages can theoretically stretch out infinitely in two dimensions. What appears on the computer screen is an 'aspect' of the page, a selection. Navigation tools make it possible to move that aspect to other parts of the page, just as one scrolls through web pages. The computer screen can be shifted, as it were, over the page in all directions. JAR makes it possible to make references to these 'aspects'; each aspect has a unique URL that can be retrieved by a simple mouse click and cited elsewhere. Hyperlinks in and between pages expand the battery of navigation and citation options. Artworks and art practices, or representations of them, which are identified uniquely in the database by different media files, can also be 'cited'. The Society for Artistic Research, which runs the journal, has devoted considerable attention to the copyright issues involved here. The files in the database, the elements of the page (including images, texts, and sound clips), the pages themselves, and the entire exposition are tagged with meta-data, making the expositions in JAR and in the RC retrievable in bibliographic searches and compatible in principle with the formats of other academic repositories. This makes JAR an 'enhanced publication', whose multifarious 
research materials are accessible to others in accordance with the openaccess principle.

Usually, the design of a publication (for instance, the way a text is arranged on a page) is not a subject of peer review. What is important in JAR is the manner in which artists expose their work as research. This warrants the inclusion of a separate section on this dimension in the reviewers' guidelines. At present, most artist-researchers are still choosing a 'classical' format and hierarchy: a continuous vertical or horizontal text running parallel to visual or sound elements. Some, however, have chosen different approaches, such as inviting the user to more associative navigation or building in well-reasoned choices into the navigation route.

\section{Improving the peer review; feedback from reviewers}

$J A R$ was created to support the emerging field of artistic research, in and beyond academia. The 'open submission' process (the opportunity to self-publish art as research in and through the Research Catalogue), the planned provision for open-process collaboration and commentary in the RC, and the publication of peer review reports alongside the expositions - all these are aimed at creating a discursive field where research can flourish and develop. JAR's policy is to seek possibilities to strengthen artistic research and its culture. The aim is not in the first place to decide what does and does not belong to the field, but to encourage those working in the field to progress. In the course of events, we have realised that JAR needs to ask its reviewers more explicitly to seek the potential in submissions and to seek ways of improving the research expositions. The guidelines for reviewing - as sedimented in the peer review form - have therefore been adjusted since November 20II: a specific section on 'recommendations' has been added, in which reviewers are asked to state what the potential of the submission is and how improvements might be made.

When reviewers were asked whether their reviews could be published (under their name or anonymously), the overall response was very positive. Two examples: 
I am happy for you to publish the process in the way that you describe. That seems to me to be a very innovative thing to do, and I hope that the other reviewers agree. It will make a very useful resource for writers and reviewers, and will be of particular interest to research students and early career researchers.

I am impressed with the efficacy of this reviewing system. Proceeding case by case, we have here a tool for improving the level of artistic research projects as a whole. My congratulations for this very valuable work! $!^{21}$

Of the thirty reviewers who worked on the published exposition, twenty-six responded positively to the request to publish the reports. Their reports can be accessed via the expositions in JAR.

\section{Close}

This brings the story of the creation and workings of the Journal for Artistic Research, focusing on the assessment criteria for submissions, to a close. JAR is still in a germinal stage. I have traced how JAR came into being - how a dynamic network of human and non-human actors grew up around the new journal, becoming materially and strategically more stable and durable all the time. I have examined the role played by 'immutable mobiles' - particularly the research catalogue and the peer review form - in the development of JAR. And I have shown how these and other ( $f$ )actors bring about transformations in the emerging field of artistic research. Documented artistic practices transform into exposed artistic research. Academia transforms into a reflexive domain in which non-discursive knowledge forms, unconventional research methods, and enhanced modes of presentation have a place. The art world transforms, slowly coming to understand itself in a different light with the advent of artistic research. And the human actors in this field - artists and academics, editors and reviewers, software designers, and policymakers - transform into allies in a common cause. In JAR, the new field of research is articulated, a new

2I. From email correspondence with two reviewers. 
reality is shaped. JAR is not so much a response to an altered reality as the articulation of a proposition - a proposal made by artistic research to academia and the art world. Latour has conceived for this the expression 'constructivist realism'. 
Bibliography 



\section{Literature}

Adorno, Theodor W. 1966. Negative Dialektik (Frankfurt am Main: Suhrkamp)

— 1997. Aesthetic Theory, ed. by Gretel Adorno and Rolf Tiedemann; newly trans., ed., and intro. by Robert Hullot-Kentor (London: Athlone Press). German original Ästhetische Theorie (Frankfurt am Main: Suhrkamp, 1970)

Allegue, Ludivine, and others (eds). 2009. Practice-as-Research in Performance and Screen (Basingstoke: Palgrave Macmillan)

Aristotle. 1963. Politics, trans. by Benjamin Jowett (Oxford: Clarendon Press)

Bal, Mieke. 2002. Travelling Concepts in the Humanities: A Rough Guide (Toronto: University of Toronto Press)

Barrett, Estelle, and Barbara Bolt (eds). 2007. Practice as Research: Approaches to Creative Arts Enquiry (London: I. B. Tauris)

Bauer, Ute Meta (ed.). 200I. Education, Information, Entertainment: Aktuelle Ansätze künstlerischer Hochschulbildung (Vienna: Selene)

Biggs, Michael A. R. 2003. 'The Role of "the Work" in Research', paper presented at the PARIP 2003 Conference, Bristol, II-I4 September <http://www.bris.ac.uk/parip/biggs.htm> [accessed 30 December 20II]

- 2004. 'Learning from Experience: Approaches to the Experiential Component of Practice-Based Research', in Forskning-Reflektion-Utveckling, ed. by Henrik Karlsson (Stockholm: Swedish Research Council), pp. 6-2I

Biggs, Michael A.R., and Daniela Büchler. 2008. 'Eight Criteria for Practice-Based Research in the Creative and Cultural Industries', Art, Design and Communication in Higher Education, 7.I: 5-18

- 20II. 'Communities, Values, Conventions and Actions', in Biggs and Karlsson (eds), pp. 82-98

Biggs, Michael A.R., and Henrik Karlsson (eds). 20II. The Routledge Companion to Research in the Arts (London: Routledge)

Bippus, Elke (ed.). 2009. Kunst des Forschens: Praxis eines ästhetischen Denkens (Zurich: Diaphanes)

Bippus, Elke. 20II. 'An Aestheticization of Artistic Research', Texte zur Kunst (special issue, Artistic Research), 20.82: 98-IO4 
Boomgaard, Jeroen. 2012. 'Het zoeken van regels die niet bestaan', in Denken in kunst: Theorie en reflectie in het kunstonderwijs, ed. by Henk Borgdorff and Peter Sonderen (Leiden: Leiden University Press, forthcoming)

Borgdorff, Henk. 1998a. 'Holismus, Wahrheit, Realismus: Adornos Musikphilosophie aus amerikanischer Sicht', in Mit den Ohren denken: Adornos Philosophie der Musik, ed. by Richard Klein and Claus-S. Mahnkopf (Frankfurt am Main: Suhrkamp), pp. 294320

— 1998b. 'Solidarität mit Metaphysik nach ihrem Sturz: Einige Bemerkungen anläßlich Albrecht Wellmers Adorno-Lektüre', in Das gebrochene Glücksversprechen: Zur Dialektik des Harmonischen in der Musik, ed. by Otto Kolleritsch, Studien zur Wertungsforschung, 33 (Vienna: Universal Edition), pp. 80-I03

Borgdorff, Henk, and Michiel Schuijer. 20Io. 'Research in the Conservatoire', Dissonanz: Swiss Music Journal for Research and Creation, IIO: I4-I9

Busch, Kathrin. 20II. 'Generating Knowledge in the Arts: A Philosophical Daydream', Texte zur Kunst (special issue, Artistic Research), 20.82: 70-79

Bush, Vannevar. 1945. Science: The Endless Frontier (Washington DC: National Science Foundation)

Caduff, Corina, Fiona Siegenthaler, and Tan Wälchli (eds). 2009. Art and Artistic Research: Music, Visual Art, Design, Literature, Dance, Zurich Yearbook of the Arts, 6 (Zurich: Scheidegger und Spiess). Also in German in the same volume.

Candlin, Fiona. 2000a. 'Practice-Based Doctorates and Questions of Academic Legitimacy', International Journal of Art and Design Education (JADE), I9.I: 96-IOI

— 200ob. 'A Proper Anxiety? Practice-Based PhDs and Academic Unease', Working Papers in Art and Design, I <http://www.herts.ac. uk/artdesi/research/papers/wpades/voli/candlin2full.html> [accessed 2 January 20II]

- 200I. 'A Dual Inheritance: The Politics of Educational Reform and $\mathrm{PhDs}$ in Art and Design', The International Journal of Art and Design Education (JADE), 20.3: 302-10 
Carr, David. 1978. 'Practical Reasoning and Knowing How', Journal of Human Movement Studies, 4: 3-20

- 1999. 'Art, Practical Knowledge and Aesthetic Objectivity', Ratio, I2.3: $240-56$

Carter, Paul. 2004. Material Thinking (Melbourne: Melbourne University Press)

Cavell, Stanley. 1979. The Claim of Reason (Oxford: Oxford University Press)

— 1996. 'The Ordinary as the Uneventful', in The Cavell Reader, ed. by Stephen Mullhall (Oxford: Blackwell), pp. 253-59

Cobussen, Marcel. 2007. 'The Trojan Horse: Epistemological Explorations Concerning Practice-Based Research', Dutch Journal of Music Theory (special issue, Practice-Based Research in Music), I2.I: $18-33$

Coessens, Kathleen, Anne Douglas, and Darla Crispin. 2009. The Artistic Turn: A Manifesto, Orpheus Research Centre in Music Series, I (Leuven: Leuven University Press)

Dallow, Peter. 2003. 'Representing Creativeness: Practice-Based Approaches to Research in the Creative Arts', Art, Design and Communication in Higher Education, 2.1: 49-66

- 2005. 'Outside the "True": Research and Complexity in Contemporary Arts', in New Practices, New Pedagogies: A Reader, ed. by Malcolm Miles (London: Routledge), pp. I33-42

Danto, Arthur C. 1986. The Philosophical Disenfranchisement of Art (New York: Columbia University Press)

Davies, Allan (ed.). 2002. Enhancing Curricula: Exploring Effective Curriculum Practices in Art, Design and Communication in Higher Education, CLTAD First International Conference, London, IOI2 April (London: Centre for Learning and Teaching in Art and Design / London Institute)

Dijkgraaf, Robbert. 2007. Interview by Annette W. Balkema and Henk Slager. Mahkuzine: Journal of Artistic Research, 2: 3I-37

Dombois, Florian, Ute Meta Bauer, Claudia Mareis, and Michael Schwab (eds). 20II. Intellectual Birdhouse: Artistic Practice as Research (London: Koenig Books) 
Dreyfus, Hubert L. 1982. Husserl, Intentionality and Cognitive Science (Cambridge, MA: MIT Press)

- 2005. 'Overcoming the Myth of the Mental: How Philosophers Can Profit from the Phenomenology of Everyday Expertise', Proceedings and Addresses of the American Philosophical Association, 79: $47-65$

— 2007a. 'Response to McDowell', Inquiry, 50.4: 371-77

- 2007b. 'The Return of the Myth of the Mental', Inquiry, 50.4: 352-65

Dyrssen, Catharina. 20II. 'JAR: A New Journal for Artistic Research', in Form och Färdriktning: Strategiska frågor för den konstnärliga forskningen, Årsbok KFoU 2OII [Yearbook for Artistic Research and Development] (Stockholm: Swedish Research Council), pp. 89-91

Eisner, Elliot W. 2003. 'On the Differences between Scientific and Artistic Approaches to Qualitative Research', Visual Arts Research, 29.57: 5-II (original in Educational Researcher, IO.4 (I98I): 5-9)

Elkins, James (ed.). 2009. Artists with PhDs: On the New Doctoral Degree in Studio Art (Washington DC: New Academia)

Frayling, Christopher. 1993. Research in Art and Design, Royal College of Art Research Papers series, I.I (London: Royal College of Art)

— 2006. 'Foreword', in Macleod and Holdridge (eds), pp. xii-xiv

Friedman, Ken. 2002. 'Design Curriculum Challenges for Today's University', in Davies (ed.), pp. 27-63

Gardner, Howard. 1985. Frames of Mind (New York: Basic Books)

Gehm, Sabine, Pirkko Husemann, and Katharina von Wilcke (eds). 2007. Wissen in Bewegung: Perspektiven der künstlerischen und wissenschaftlichen Forschung im Tanz (Bielefeld: Transcript)

Geimer, Peter. 'Das große Recherche-Getue in der Kunst: Sollen Hochschulen "Master of Arts"-Titel und Doktorhüte für Malerei verleihen?', Frankfurter Allgemeine Zeitung, 20 April 2011, Forschung und Lehre section, p. $\mathrm{N}_{5}<$ http://www.hkb.bfh.ch/ uploads/media/Das_grosse_Recherche-Getue_in_der_Kunst. pdf> [accessed I2 January 2OII]

Gibbons, Michael, and others. 1994. The New Production of Knowledge: The Dynamics of Science and Research in Contemporary Societies (London: Sage) 
Gieryn, Thomas F. 1983. 'Boundary Work and the Demarcation of Science from Non-Science', American Sociological Review, 48: 78I-95

Gosselin, Pierre, and Éric le Coguiec (eds). 2006. La Recherche création: Pour une compréhension de la recherche en pratique artistique (Québec: Presses de l'Université du Québec)

Gray, Carole, and Julian Malins. 2004. Visualizing Research: A Guide to the Research Process in Art and Design (Aldershot: Ashgate)

Gunther, York H. 2003. Essays on Nonconceptual Content (Cambridge, MA: MIT Press)

Habermas, Jürgen. 2009. 'Die Einheit der Vernunft in der Vielheit ihrer Stimmen', in Jürgen Habermas, Kritik der Vernunft, Philosophische Texte, 5 (Frankfurt am Main: Suhrkamp), pp. II7-55

Hannula, Mika, Juha Suoranta, and Tere Vadén. 2005. Artistic Research: Theories, Methods, Practices (Helsinki: Academy of Fine Arts; Gothenburg: University of Gothenburg)

Haseman, Brad. 2006. 'A Manifesto for Performative Research', Media International Australia incorporating Culture and Policy (special issue, Practice-Led Research), in8: 98-106

Hegel, Georg W. F. 1975. Aesthetics: Lectures on Fine Art [delivered I817I829], trans. by T. M. Knox, 2 vols (Oxford: Clarendon Press). In German, Vorlesungen über die Aesthetik, 3 vols (Frankfurt am Main: Suhrkamp, 1986)

Heidegger, Martin. 1976. 'Nur noch ein Gott kann uns retten' [in conversation with Rudolf Augstein and Georg Wolff on 23 September 1966], Der Spiegel, 30.23 (31 May), pp. 193-219. The entire conversation in Antwort: Martin Heidegger im Gespräch, ed. by Günther Neske and Emil Kettering (Pfullingen: Neske, 1988), pp. 8I-III

Hockey, John. 2005. 'Practice-Based Research Degree Students in Art and Design: Identity and Adaptation', International Journal of Art and Design Education (JADE), 22.I: 82-9I

Hockey, John, and Jacqueline Allen-Collinson. 2000. 'The Supervision of Practice-Based Research Degrees in Art and Design', International Journal of Art and Design Education (JADE), 19.3: 345-55

Kant, Immanuel. 1978 [1790/93]. The Critique of Judgement, trans. by James Creed Meredith (Oxford: Clarendon Press). German orig- 
inal Kritik der Urteilskraft, ed. by Karl Vorländer (Hamburg: Meiner, 1974 [1913])

— 1974 [1793]. On the Old Saw: That May Be Right in Theory but It Won't Work in Practice, trans. by E. B. Ashton, intro. by George Miller (Philadelphia: University of Pennsylvania Press). German original 'Ueber den Gemeinspruch: Das mag in der Theorie richtig sein, taugt aber nicht für die Praxis', Berlinische Monatschrift, 2 (September 1793): 20I-84 <http://www.ub.unibielefeld.de/diglib/Berlinische_Monatsschrift/index-e.htm> [accessed 26 January 20I2]

Kessels, Jos, and Fred Korthagen. 200I. 'The Relation between Theory and Practice: Back to the Classics', in Linking Practice and Theory, ed. by F. A. J. Korthagen and others (New York: Routledge), pp. 20-3I

Kiverstein, Julian, and Andy Clark. 2009. 'Introduction: Mind Embodied, Embedded, Enacted: One Church or Many?', Topoi, 28: I-7

Kjørup, Søren. 2006. Another Way of Knowing, Sensuous Knowledge series, I (Bergen: Bergen National Academy of the Arts)

- 20II. 'Pleading for Plurality: Artistic and Other Kinds of Research', in Biggs and Karlsson (eds), pp. 24-43

Knorr Cetina, Karin. 1999. Epistemic Cultures: How the Sciences Make Knowledge (Cambridge, MA: Harvard University Press)

— 200I. 'Objectual Practice', in Schatzki, Knorr Cetina, and von Savigny (eds), pp. 175-88

Knowles, J. Gary, and Ardra L. Coles (eds). 2008. Handbook of the Arts in Qualitative Research (London: Sage)

Kristeller, Paul O. 1951/52. 'The Modern System of the Arts: A Study in the History of Aesthetics', parts I and 2, Journal of the History of Ideas, I2.4 (October 195I): 496-527, and I3.I (January 1952): 17-46

Latour, Bruno. 1988. Science in Action: How to Follow Scientists and Engineers in Society (Cambridge, MA: Harvard University Press)

- 1999. Pandora's Hope: Essays on the Reality of Science Studies (Cambridge, MA: Harvard University Press)

Latour, Bruno, and Steven Woolgar. 1986. Laboratory Life: The Construction of Scientific Facts (Princeton: Princeton University Press) 
Luntley, Michael. 2003. 'Non-Conceptual Content and the Sound of Music', Mind and Language, I8.4: 402-26

Macleod, Katy, and Lin Holdridge (eds). 2006. Thinking through Art: Reflections on Art as Research (London: Routledge)

McDowell, John. 2007a. 'Response to Dreyfus', Inquiry, 50.4: 366-70 — 2007b. 'What Myth?', Inquiry, 50.4: 338-5I

Mersch, Dieter. 2009. 'Kunst als epistemische Praxis', in Bippus (ed.), pp. 27-47

Mersch, Dieter, and Michaela Ott (eds). 2007. Kunst und Wissenschaft (Munich: Wilhelm Fink)

Nelson, Robin, and Stuart Andrews. 2003. 'Practice as Research: Regulations, Protocols and Guidelines' [including 'Draft "Best Practice" Guidelines on PaR PhDs' and 'Ten Steps to a "Perfect" PaR PhD'] (Lancaster: PALATINE) <http:// 78.158.56.IoI/archive/pala tine/files/903.pdf> [accessed 5 January 2012]

Nevanlinna, Tuomas. 2004. 'Is Artistic Research a Meaningful Concept?', in Artistic Research, ed. by Annette W. Balkema and Henk Slager, Lier en Boog: Series of Philosophy of Art and Art Theory, I8: 80-83

Noë, Alva. 2004. Action in Perception (Cambridge, MA: MIт Press)

Nowotny, Helga. 2oII. 'Foreword', in Biggs and Karlsson (eds), pp. xviixxvi

Nowotny, Helga, Peter Scott, and Michael Gibbons. 200I. Re-thinking Science: Knowledge and the Public in an Age of Uncertainty (Cambridge: Polity Press)

— 2003. "Mode 2" Revisited: The New Production of Knowledge', Minerva, 4I: I79-94

Pakes, Anna. 2003. 'Original Embodied Knowledge: The Epistemology of the New in Dance Practice as Research', Research in Dance Education, 4.2: 127-49

- 2004. 'Art as Action or Art as Object? The Embodiment of Knowledge in Practice as Research', Working Papers in Art and Design, $3<$ http://www.herts.ac.uk/artdesi/research/papers/wpades/vol3/ apfull.html $>$ [accessed 4 January 20I2]

Parviainen, Jaana. 2002. 'Bodily Knowledge: Epistemological Reflections on Dance', Dance Research Journal, 34.I: II-22 
Polanyi, Michael. 1958. Personal Knowledge: Towards a Post-Critical Philosophy (London: Routledge and Kegan Paul)

— 1966. The Tacit Dimension (London: Routledge and Kegan Paul)

Porter, James I. 2009. 'Is Art Modern? Kristeller's "Modern System of the

Arts" Reconsidered', British Journal of Aesthetics, 49.I: I-24

Putnam, Hilary. 1990. Realism with a Human Face (Cambridge, MA: Harvard University Press)

— 1995. Pragmatism (Oxford: Blackwell)

- 2002. The Collapse of the Fact/Value Dichotomy and Other Essays

(Cambridge, MA: Harvard University Press)

Rey, Anton, and Stefan Schöbi (eds). 2009. Künstlerische Forschung: Positionen und Perspektiven (Zurich: Institute for the Performing Arts and Film, Zurich University of the Arts)

Rheinberger, Hans-Jörg. 1992. Experiment, Differenz, Schrift: Zur Geschichte epistemischer Dinge (Marburg an der Lahn: BasilikenPresse)

- 2004. 'Experimental Systems', The Virtual Laboratory <http:// vlp.mpiwg-berlin.mpg.de/essays/data/encı9? $\mathrm{p}=\mathrm{I}>$ [accessed 5 January 20I2]

- 2005. Iterationen (Berlin: Merve Verlag)

- 2006a. Experimentalsysteme und epistemische Dinge: Eine Geschichte der Proteinsynthese im Reagenzglas (Frankfurt am Main: Suhrkamp). Earlier version originally published as Toward a History of Epistemic Things: Synthesizing Proteins in the Test Tube (Stanford: Stanford University Press, 1997). Dual page references in the text refer respectively to the German and English versions (which may slightly differ).

— 2006b. 'Über die Kunst, das Unbekannte zu erforschen' (Wollerau, $\mathrm{CH}$ : Cogito Foundation) <http://www.cogito foundation.ch/ pdf/2006/06IO25DieKunst_dasUnbekannte.pdf> [accessed 5 January 20I2]. Also published as 'Man weiss nicht genau, was man nicht weiss. Über die Kunst, das Unbekannte zu erforschen', Neue Zürcher Zeitung (NZZ Online), 5 May 2007, p. B3 <http: //www.theologie.uzh.ch/faecher/neues-testament/rueegger/ qvu-dokumentation/Rheinbergero7.pdf $>$ [accessed 5 January 2OI2] 
— 2007. Historische Epistemologie zur Einführung (Hamburg: Junius)

— 2008. 'Epistemische Dinge, technische Dinge', video recording, 58:57, of lecture at Bochum Media Science Colloquium, 2 July $<$ http://vimeo.com/235I486> [accessed 5 January 20I2]

— 2010. An Epistemology of the Concrete: Twentieth-Century Histories of Life (Durham, NC, and London: Duke University Press)

Rietveld, Erik. 2008. 'Unreflective Action: A Philosophical Contribution to Integrative Neuroscience' ( $\mathrm{PhD}$ thesis, Institute for Logic, Language and Computation, University of Amsterdam) Riley, Shannon Rose, and Lynette Hunter (eds). 2009. Mapping Landscapes for Performance as Research (Basingstoke: Palgrave Macmillan)

Ritterman, Janet, Gerald Bast, and Jürgen Mittelstraß (eds). $201 \mathrm{I}$. Kunst und Forschung: Können Künstler Forscher sein? (Vienna: Springer)

Rouse, Joseph. 200I. 'Two Concepts of Practice', in Schatzki, Knorr Cetina, and von Savigny (eds), pp. I89-98

- 2002. 'Vampires: Social Constructivism, Realism, and Other Philosophical Undead', History and Theory, 4I: 60-78

Rubidge, Sarah. 2005. 'Artists in the Academy: Reflections on Artistic Practice as Research' <http://ausdance.org.au/ articles/details/ artists-in-the-academy-reflections-on-artistic-practice-as-research $>$ [accessed 5 January 20I2]

Ryle, Gilbert. 1949. The Concept of Mind (Chicago: University of Chicago Press)

Säätelä, Simo. 2005. 'Aesthetic Experience and "Non-Conceptual" Content', in Perspectives on Aesthetics, Art and Culture: Essays in Honour of Lars-Olof Åhlberg, ed. by C. Entzenberg and S. Säätelä (Stockholm: Thales), pp. 292-312

Schatzki, Theodor R., Karin Knorr Cetina, and Eike von Savigny (eds). 200I. The Practice Turn in Contemporary Theory (London: Routledge)

Schön, Donald. 1982. The Reflective Practitioner: How Professionals Think in Action (New York: Basic Books)

Schwab, Michael. 20IIa. 'Editorial', Journal for Artistic Research, o $<$ http://www.jar-online.net/index.php/issues/editorial/48o > [accessed 4 January 20I2] 
— 2orrb. 'Editorial', Journal for Artistic Research, I <http://www.jar-on line.net/index.php/issues/editorial/483> [accessed 4 January 20I2] Shapin, Steven, and Simon Schaffer. 1989. Leviathan and the AirPump: Hobbes, Boyle, and the Experimental Life (Princeton: Princeton University Press)

Stokes, Donald E. 1997. Pasteur's Quadrant: Basic Science and Technological Innovation (Washington DC: Brookings Institution Press) Sullivan, Graeme. 2005. Art Practice as Research: Inquiry into the Visual Arts (London: Sage)

Taylor, Charles. 2005. 'Merleau-Ponty and the Epistemological Picture', in The Cambridge Companion to Merleau-Ponty, ed. by T. Carman and M. B. N. Hansen (London: Cambridge University Press), pp. 26-49

Thomson, Peter. 2003. 'Practice as Research', Studies in Theatre and Performance, 22.3: 159-80

Tröndle, Martin, and Julia Warmers (eds). 20II. Kunstforschung als ästhetische Wissenschaft: Beiträge zur transdisziplinären Hybridisierung von Wissenschaft und Kunst (Bielefeld: Transcript)

Wehling, Peter. 2006. 'The Situated Materiality of Scientific Practices: Postconstructivism - A New Theoretical Perspective in Science Studies?' Science, Technology and Innovation Studies (Special Issue, I): 8I-IOO

Wesseling, Janneke (ed.). 20II. See It Again, Say It Again: The Artist as Researcher (Amsterdam: Valiz)

Whitley, Richard. 2000. The Intellectual and Social Organization of the Sciences (Oxford: Oxford University Press)

Wilson, Stephen. 2002. Information Arts: Intersections of Art, Science and Technology (Cambridge, MA: MIT Press/Leonardo Books)

Wittgenstein, Ludwig. 1958. Philosophical Investigations, 2nd edn (Oxford: Basil Blackwell)

Zijlmans, Kitty, Robert Zwijnenberg, and Krien Clevis (eds). 2007. COops: Exploring New Territories in Art and Science (Amsterdam: De Buitenkant) 


\section{Policy documents and other sources}

AEC 2007 European Association of Conservatoires, Polifonia Research

Working Group <http://www.polifonia-tn.org/Content.aspx? $\mathrm{id}=\mathrm{I}$ II9> [accessed 5 January 20I2]

AHRB 2003 Arts and Humanities Research Board. 'The RAE and Research in the Creative and Performing Arts' [no longer publicly accessible]

AHRC 2007 Arts and Humanities Research Council. Beyond Text: Performances, Sounds, Images, Objects <http://www.ahrc.ac.uk/ FundingOpportunities/Pages/BeyondText.aspx $>$ [accessed 5 January 20I2]

AHRC (n.d.) Arts and Humanities Research Council. Fellowships in the Creative and Performing Arts <http://www.ahrc.ac.uk/Funding Opportunities/Pages/FCPA.aspx $>$ [accessed 5 January 20I2]

AIR Artists in Residence, Art Practice and Development Research Group, Amsterdam School of the Arts (AHK) <http://www. ahk.nl/en/research-groups/art-practice/artists-in-residence/> [accessed 8 February 20I2]

AKA 2007 Suomen Akatemia (Academy of Finland). Research in Art and

Design in Finnish Universities <http://www.aka.fi/Tiedostot/ Tiedostot/Julkaisut/04_09\%2oResearch\%20in\%2oArt\%20and \%20Design.pdf> [accessed 5 January 20I2]

ANMA 2009 Association of Nordic Music Academies. Annual meeting,

Research and Artistic Work, Copenhagen, 5 February <http:// www.nkinfo.org/annual-2009.html> [accessed 5 January 20I2] ARC 20 IO Artistic Research Catalogue <http://www.kabk.nl/pageEN. php?id=0485> [accessed 5 January 2012]

ARP 2010 Project: Artistic Research, Stichting Innovatie Alliantie $<$ http://innovatie-alliantie.nl/projectenbank/raak-project/724artistic-research.html> [accessed I3 February 20I2]

ATR 2006 The Anatomical Theatre Revisited, conference held at Amsterdam, 5-8 April <http://www.anatomicaltheatrerevisited. com> [accessed I3 February 20I2]

AWT 2005 Adviesraad voor het Wetenschaps- en Technologiebeleid (Advisory Council for Science and Technology Policy). Ontwerp 
en ontwikkeling. De functie en plaats van onderzoeksactiviteiten in hogescholen (The Hague: AWT) <http://www.awt.nl/uploads/fi les///Adviezen/a65.pdf> [accessed 5 January 20I2]

BauHaus Bauhaus-Universität Weimar. Promotionsstudiengang Kunst und Design/Freie Kunst <http://www.uni-weimar.de/gestal tung/studiengaenge/promotion-phd-drphil/> [accessed 5 January 20I2]

CC Choreography and Cognition <http://www.choreocog.net/> [accessed 8 February 20I2]

DeETya 1998 Research in the Creative Arts, by Dennis Strand (Canberra: Evaluations and Investigations Programme, Higher Education Division, Department of Employment, Education, Training and Youth Affairs) <http://www.dest.gov.au/archive/highered/eippubs/ eip98-6/eip98-6.pdf> [accessed 29 January 20I2]

DES 2002 Department for Education and Skills. Review of Arts and Humanities Research Funding: Report of the Steering Group to Education Ministers <http://www.education.gov.uk/consultations/ downloadableDocs/SOR_I43_I.doc> [accessed 7 February 20I2]

Docartes Doctoral Programme in Musical Arts <http://www.doc artes.be/en/welcome> [accessed 5 January 20I2]

ELIA 2008 European League of Institutes of the Arts. The Importance of Artistic Research and its Contribution to 'New Knowledge' in a Creative Europe. Strategy Paper <http://www.elia-artschools. org/images/products/13/research_paper_08.pdf> [accessed 5 January 20I2]

EPARM European Platform for Artistic Research in Music, European Association of Conservatoires <http://www.aecinfo.org/Con tent.aspx?id=2279> [accessed 5 January 20I2]

FWO Fonds Wetenschappelijk Onderzoek - Vlaanderen (Research Foundation - Flanders). Cult2: Arts and Literature <http:// www. fwo.be/Panel-Kunsten-en-literatuur.aspx $>$ [accessed 5 January 20I2]

FWF Wissenschaftsfonds FWF (Austrian Science Fund). Österreichische Systematik der Wissenschaftszweige <http://www. statistik.at/ $\mathrm{kdb} /$ downloads/pdf/OEFOS2002_EN_CAL_20070226_00000 o.pdf> [accessed 5 January 20I2] 
GOS 2009 Regeringskansliet (Government Offices of Sweden). Doctoral Level Studies in the Fine and Applied Arts <http://www. sweden.gov.se/sb/d/574/a/I23213> [accessed 7 February 20I2]

JA 2009 Die junge Akademie. Erster Salon Kunst und Wissenschaft, Berlin, 20 June <http://www.diejungeakademie.de/pdf/Pro gramm-KaF_20-6-09.pdf> [accessed 5 January 20I2]

JAR Journal for Artistic Research <http://www.jar-online.net> [accessed 5 January 20I2]

JQI 2004 Joint Quality Initiative. Dublin Descriptors <http://www.joint quality.nl/content/descriptors/CompletesetDublinDescriptors. doc> [accessed Io February 20I2]

KFH 2008 Rektorenkonferenz der Fachhochschulen der Schweiz. Forschung an Schweizer Kunsthochschulen 2008: Bericht und Empfehlungen <http://www.kfh.ch/content/stable.cfm?stb=I26\& trg=I> [accessed 7 February 20I2]

KNAW Koninklijke Nederlandse Akademie van Wetenschappen (Royal Netherlands Academy of Arts and Sciences) <http://www. knaw.nl/> [accessed 5 January 20I2]

LERU League of European Research Universities <http://www.leru.org> [accessed 5 January 2012]

LEUVEN 2009 Communiqué of the Conference of European Ministers Responsible for Higher Education, Leuven and Louvain-la-Neuve, 28-29 April <http://europa.eu/rapid/pressReleases Action.do?ref erence $=\mathrm{IP} / 09 / 675 \&$ format $=\mathrm{HTML} \&$ aged $=0 \&$ language $=\mathrm{EN}>$ [accessed 5 January 20I2]

MONEY 2007 Money (f)or the Arts. Rektoren der Österreichischen Kunstuniversitäten <http://www.reko.ac.at/upload/MONEY _\%28F\%29OR_THE_ARTS.pdf> [accessed 5 January 20I2]

NARF Program for kunstnerisk utviklingsarbeid (National Norwegian Artistic Research Fellowship Programme) <http://www.kunst stipendiat.no/en> [accessed 5 January 20I2]

NASM 2010 National Association of Schools of Music [USA]. NASM Handbook <http://nasm.arts-accredit.org/index.jsp?page $=$ Stan dards-Handbook> [accessed 5 January 20I2]

NESTI Working Party of National Experts on Science and Technology Indicators. Revised Field of Science and Technology (FOS) Classifi- 
cation in the Frascati Manual <http://www.oecd.org/data oecd/36/44/38235I47.pdf> [accessed 5 January 20I2]

Nwo Nederlandse Organisatie voor Wetenschappelijk Onderzoek (Netherlands Organisation for Scientific Research) <http:// www.nwo.nl> [accessed 5 January 20I2]

OECD 2002 Organisation for Economic Co-operation and Development. Frascati Manual: Proposed Standard Practice for Surveys on Research and Experimental Development <http://browse.oecd bookshop.org/oecd/pdfs/free/920208Ie.pdf> [accessed 7 February 20I2]

ÖWR 2008 Österreichischer Wissenschaftsrat (Austrian Science Board). Tagung 'Kunst und Forschung' (Art and Research Conference), 4 December <http://www.wissenschaftsrat.ac.at/news/Programm _Tagung\%2oKunst\%2ound\%2oForschung.pdf> [accessed 5 January 20I2]

ÖWR 2009 Österreichischer Wissenschaftsrat (Austrian Science Board). Empfehlung zur Entwicklung der Kunstuniversitäten in Österreich $<$ http://www.wissenschaftsrat.ac.at/dokumente.html> [accessed 5 January 20I2]

palatine Performing Arts Learning and Teaching Innovation Network $<$ http://www.palatine.ac.uk/> [accessed 5 January 20I2]

PARIP Practice as Research in Performance <http://www.bris.ac.uk/ parip/> [accessed I3 February 20I2]

PARIP LIST Practice as Research in Performance mailing list <https:// www.jiscmail.ac.uk/cgi-bin/webadmin?Ao=PARIP $>$ [accessed I3 February 20I2]

PeEK 2009 Wissenschaftsfonds FWf (Austrian Science Fund). Programm zur Entwicklung und Erschließung der Künste (PEEK): Programmdokument <http://www.fwf.ac.at/de/ projects/peek.html> [accessed 5 January 2012]

PhD-Design PhD-Design mailing list <https://www.jiscmail.ac.uk/ cgi-bin/webadmin?Ao=PHD-DESIGN $>$ [accessed 5 January 20I2] R2P Research into Practice Conferences, Centre for Research into Practice, School of Creative Arts, University of Hertfordshire $<$ http://sitem.herts.ac.uk/artdes_research/res2prac/confhome. html> [accessed 5 January 20I2] 
RAE 2005 Research Assessment Exercise. 'RAE 2008: Guidance on Submissions' <http://www.rae.ac.uk/pubs/2005/03/rae0305.pdf> [accessed 5 January 20I2]

REF Research Excellence Framework. 'Assessment Framework and Guidance on Submissions' <http://www.hefce.ac.uk/research/ ref/pubs/2OII/O2_II/> [accessed 5 January 20I2]

RTI Research Training Initiative, Birmingham Institute of Art and Design $<$ http://www.biad.bcu.ac.uk/research/rti/> [accessed 5 January 20I2]

SAR Society for Artistic Research <www.jar-online.net> [accessed 5 January 20I2]

SHARE Step-Change for Higher Arts Research Education (elia/ GradCAM) <http://www.sharenetwork.eu/> [accessed 5 January 20I2]

SK Sensuous Knowledge conferences <http://sensuousknowledge. org/> [accessed 5 January 20I2]

SRC 2009 Vetenskapsrådet (Swedish Research Council). 'Konstnärlig forskning inför framtiden' (Artistic Research in the Future), conference held at Stockholm, I2-I3 March <http://www.vr.se/hu vudmeny/pressochnyheter/nyhetsarkiv/nyheter2009/konferen somkonstnarligforskning.5.ead945birf699b508580006or3.html> [accessed 5 January 20I2]

UdK Universität der Künste Berlin (Berlin University of the Arts). Projekt Graduiertenschule <http://www.udk-berlin.de/sites/grad uiertenschule/content/index_ger.htlm $>$ [accessed 5 January 20I2] UKCGE 1997 UK Council for Graduate Education. Practice-Based Doctorates in the Creative and Performing Arts and Design, by Christopher Frayling [no longer publicly accessible]

UKCGE 200I UK Council for Graduate Education. Research Training in the Creative and Performing Arts and Design [no longer publicly accessible]

UNESCO I979 'Recommendation concerning the International Standardization of Statistics on Science and Technology', in Records of the General Conference, 2oth Session, Paris, 24 October-28 November 1978. Volume I: Resolutions (20C/Resolutions I5.I), Annex I (Paris: UNESCO), pp. 23-35 <http://unesdoc.unesco.org/images/ ooII/ooII4O/II4O32e.pdf\#page $=$ I88 $>$ [accessed 5 January 20I2] 
ZHdK 2009 Zürcher Hochschule der Künste (Zurich University of the Arts). 'The Difference of Art and Art Research across the Disciplines', conference held at Zurich, 23-24 April <http://www. zhdk.ch/fileadmin/data_zhdk/hochschule/Rektorat/Transdiszi plinaeres_Atelier/ArtResearch_ZHdK_Aprilo9.pdf> [accessed 5 January 20I2] 
Index 

absolute, the: in Schelling 48; in Hegel I36

abstract(ness): artistic products 2II; modernist I35; music 93; quality of art 7I, I7I, I95nI4, 206

academia: the term 32, 6In2, I49, I49n7; (self-) understanding of 4, 9, $44,69,72-73, \mathrm{II} 8, \mathrm{I} 83, \mathrm{I} 87,210$, 236; reconfiguration, transformation of I2; 17, II8, 240; modified, enriched, enhanced, broader, open conception of 44, 59, 6o-6I, I09, I6onI4, 203, 208-09, 22I, 232-33; uneasy relationship to 9, 56-73, I43, I43ni, 203; opposition, resistance, aversion to, reservations, scepticism towards 45, 82, IO7, II7-I8, 209, 22I; opposition, resistance from, scepticism in 53, 6I-62, 209; departure from 2I, 233; confines, walls, boundaries, borders of 32 , I32, 2IO, I43, I77, 206-07, 232; boundaries within I77; and other life domains 8, 9, 51, 92; and art world 33, 9I, II7, I32, I77, 221, 223; and artistic development see artistic development

academic advance/drift 32, 83, 90, II7 academic forum 55, 85, I65, 167, 207, $2 \mathrm{IO}$

academisation 5, 3I, 3InI, 60, II7 academism 60, II7 academy I8-26, 3I, 32, I08, I24-25, I5I see also academia; radical 73; design see design accountability 25, 8I, 89-90, 93-94

acquaintance 163

action research see research

actor-network theory I33, I50, I76, I82, I88nI, $2 \mathrm{I} 7$

admission procedures $63, \mathrm{I} 24, \mathrm{I} 67$

Adorno, Theodor W. 4, 20, 2I, 48, 69, $82, \mathrm{I} 23, \mathrm{I} 3 \mathrm{O}, \mathrm{I} 37, \mathrm{I} 42, \mathrm{I} 52, \mathrm{I} 53-54$, I54nio, 194

aesthetic(s) 2I, 38, 45, 46, 47-48, I23,

I34-35, I44, I5I-54, I97, 203;

distance I00, I7I; of music 63;

Hegel's lectures on $135-36$;

relational 165 ; of early

Romanticism I35, 137, I62ni6, I7I agency 2, IO, 2I7 agenda 17, 44, 59, 69; research 93, I50, I7O, I78-79; UNESCO conference 77 Allegue, Ludivine II2 Allen-Collinson, Jacqueline 53 analogon rationis $48, \mathrm{I} 52$ analysis: work, production, reception I9, 24, 207; qualitative/quantitative $5 \mathrm{I}$, 84, I54, I55; cultural see cultural analysis; musical see musical analysis Andrews, Stuart 22n2 anthropology 9; visual 44; social 5I application 99, I60; applied research see research; context of see context; funding see funding apprehension I22, I63 architecture, architects 34, 95, I34, I57; design IOI, II9; theory I5O; schools $35, \mathrm{I} 57$ Aristotle 47, 97, I63 art, artwork, art practice 4I, 45, I45, 
207, 223; status, concept, nature, identity of $4,9,82,87$, IOI, II7, II8, I32, I33, I46, I87, I80-8I, I83, 22I; ambiguity of 49; end of see end of art; knowledge, content, thinking embodied in I7 2I, 24, 7I, I5I, I64, I89, 206; fundamental 9I; minimalist 9I; conceptual 7I, 9I, II7, I35, 193; contemporary 22, 70, 7I, I54; post-historical I35; natural law of 2I, 70; visual see visual art; system of see system of the arts; as epistemic thing see epistemic thing; art practice-in-itself vs art practice-as-research 7, 33, 40, 43, 53, I44, I59, I6I, 207, 230; in research (process) 24, 38; performative force of 20,93 ; cultural value of 48, I00, I5I, I53; materiality/immateriality of 46,93, I47, I53, I56, I66, I72, I80, I83; originality of see originality; as boundary object see boundary object; signature of 227

art criticism 4, 78, 84, 91, 94, I3I, I33, I $47-48, \mathrm{I} 54$

art(s) education I7-26, 59-60, II6 art forum 33, 55, 85, 94, I65, I67 art history 4, 38, 52, 6I, 99, IOI, I2I, I24, I34, I46, I5O

art industry see industry art market II8, I25, I80, I83, 229 art school, academy see academy art-science collaboration 3, 92, II4, I5859 art theory 4, I3I art world 3-4, 4I, I3I, 223, 236; artistic universe 42, 80, I6I; and academia see academia; context of 94, I2I, I48, I65, I77, I80, 203, 208; margins of 93; and peer review 94, I33, I65; scepticism in see academia; success in 233; (self-)understanding of 236,240

articulation 2, II-I2, 20, 24, 39, 45, 48, 69, 72, I00, I22, I37, I43, I53, I66, I7I, I89, I93, 206, 2I8, 234-35, 240$4 \mathrm{I}$

artificial intelligence 49, 158 artist-researcher 50-52, 94, I23, I33, I5I, I79, 207, 2I2, 222, 226, 235, 239 artistic development 5I, 80, 85, II7, I26, I43-44, I55, I6I artistic doctorate see doctorate artistic real 195, 207 artistic reasoning see reason artistic universe see art world artistry 6, 52, 82, I5I see also skills, craft arts-based research see research assessment: research assessment 8, II, 36, 4I-43. 85, 89, 94, I24, I66, I67, 200-I3, 222-23; framework 8, IO, II, 43 , 2I2-I3, 23I-39; of quality 32, 55 , 68, 86-87, 94-95, I33, I78-79, I87, 229; committees 26; of journal submissions 218, 222, 227-40; procedures in education 63, 124; by peers 8, 68, 88, I22, I65, 207 see also peer review; funding see funding; criteria, standards, guidelines see criteria

atelier I43, I46, I46n5, I57 
Augstein, Rudolf I29n

autobiographical narrative 155

autonomy: of artistic research 45; of art

4, 70, 133-35; of scientific research

90 ;

avant-garde, historical 46, II7

Bachelard, Gaston I95nI3

Bal, Mieke I5O

Barrett, Estelle Iı2

basic scientific research see research

Bast, Gerald II2

Batteux, Charles I34

Bauer, Ute Meta 22n2

Bauhaus I49

Baumgarten, Alexander G. 2I, 47-48,

I34, I5I-53, 2IO, 219

beauty 45, 9I, IOO, IOI, I33, I53

Becker, Howard 133

behavioural science see science

Beuys, Joseph I9I

Biggs, Michael A.R. 7, 46ni6, II2, I47, I56nit, I6oni4, I63, I88ni, 218ni

binary system 3I, 35, II6

BioArt 158, i89n2

biology 78, I88; biotechnology 79, 95, I58; biomedical science see science; biophysics 83 ; biochemistry 78 ; microbiology 98; molecular biology 5I, I88, I89-90

Bippus, Elke 4nI, II2

Bohr, Niels 99

Bologna 25, 35, 42ni4, 58, 59, 65, 88, II6-I7, 230

Bolt, Barbara II2

Boomgaard, Jeroen 18
Borgdorff, Henk I8, I24, I54nIo, 220

boundaries/borders 9, I43, I57, I77-83, I9I, 206-07, 222, 232

boundary work 129-38, 174-83, 206; boundary object I77, 223

Bourdieu, Pierre I3I, I33

Büchler, Daniela I56nıI, I6oni4

Bürger, Peter 70

Busch, Kathrin 4nI

Bush, Vannevar 87, 89, 96

Caduff, Corina II2, $220 n 6$

Cage, John I9I, 192

Candlin, Fiona 54, I43nI

Carr, David 47

Carter, Paul III, II7, I83

Cavell, Stanley I42, I7I

chance $80,162,165$

choreography 49, 92

Clark, Andy I52n9

classification 8, 39, 40, 52nI9, I2I see also field(s) of science and technology

Clevis, Krien 3, 158

Cobussen, Marcel 6in3

Coessens, Kathleen II2

cognition, cognitive $17,24,48-49,95$, II9, I56, I6I, I63, 234; non-cognitive 48; science/psychology 26, 44, 4849, 68, I23, I45, I5O, I52n9, I56, I69, I70, 188

Coguiec, Éric le III coherentism I63 Coles, Andra L. 156 composer, composition 34, 62 comprehension $17, \mathrm{I} 22, \mathrm{I} 63$ 
conceptual I7, 47, I45n4, I7I, I95ni4; non-conceptual 47-49, 69, 72, I38, I45, I45n4, I47n6, I48-50, I5I-54, I63, I64, I66, I68-73, I8I, I94, 206, 210, 234; concept of research, science, knowledge see research, science, knowledge; conceptual art see art; conceptual framework 48 , 87-88, 99, IIO, II9, I5O, 220n7; conceptual mimesis see mimesis concrete(ness) I7I, I95nI4 constitution IO, 20, 24, 85, 93-94, I73, I82, I95, I98, 217, 234, 236

constructivism I0, 20, I3I, I63, I65, I72, I95, 210

constructivist realism II, I7, 20, 24, 68, $72,85,163,172,176,194-95,198$, 2IO, 2I6, 24I

context I2-I3, 25, 4I, 45, I45-49, I65; of application 68, 89, 9I-92, 94, II9, 208, 2II, 233; of discovery 59, 8I, 84, I48, I58, I65-66, I88, I92, I97, 208, 2II, 223, 233; of justification 59, 8I, I32, I88, I97, 208, 2II, 233; academic, research 42-43, I48, I6I, I65, I77, I79, I80, 203, 207-08, 2II; art world, artistic see art world; arts education 59-60

contextualisation I9, 2I, 70, 8I, 234-35 contingency IO, I2, I7, 62, 70-73, I23, I30, I38, I68, I72-73, I8I-82, I9O, 196, 203, 204, 206

conventions 6, 22, 50, 72, 212, 229

craft I8, i9 see also skills creative industry II 8,183 creativity 49,82
Crispin, Darla II2

criteria, standards, guidelines 4, 8, II, 25, $32,33,39,40,4 \mathrm{I}-43,44,50,55,68$, 70, 77, 80, I56nir, I6o-68, I82-83, I87, I96, 200-I3, 222, 223, 227-40 critical perspective see perspective critical rationalism 188 critical theory I9, I23, I50, I66 criticism: (art) criticism, critique, critics see art criticism cultural diversity 33 cultural studies, analysis, criticism 9, I9, $44,51,55,62,83, \mathrm{I} 23, \mathrm{I} 50, \mathrm{I} 5 \mathrm{I}, \mathrm{I} 66$ cultural value 48, IOO, I5I, I53 culture 2I, 25, 46, I65; of knowledge, academia, science, research 9, I2, 229, 239; material 64; grand theories of our culture see humanities curator, curatorial, curating 94, I33, 22I, 224, 225, $23 \mathrm{I}$

curiosity 83, 97, IOI

cycle: empirical cycle I8, I57; action research cycle see research, action; third cycle see doctorate

daily life 9I, IOI, I3I, I32, I65, I79 Dallow, Peter 22n2, 42, I62ni8 dance III, I34, I56; dance education, school 3I, 35; dance research, studies 36, 49, I50, I69n24

Danto, Arthur C. I3I, I33, I35

Davies, Allan 22n2

deconstruction $19,38,137,150$ deduction, empirical 23, 5I, 84, I54 definition: of research/artistic research 
4I-43, 53, 79-80, I6o, I6onis, 203,

205, 208; of art I3I, I83; of research

and development (Frascati) 68, 77-

79, 86-88, 89, 96-100, 203; of

research in UK Research

Assessment Exercise 4InI3, 66,

67n7, 88, 120, I6Ini9; in UK

Research Excellence Framework 4I;

in Dublin Descriptors 42ni4, 67,

88 , I2I

degree: masters 25, 34, 54, 65, I07;

doctorate see doctorate, courses see

doctorate

degree-awarding power I07, I25, I87, 204

Deleuze, Gilles 5, I8, 48, I90n6

demarcation, discrimination 2I, 24, 33,

39, 79, I07, I3I-32, I43-44, I43nI,

I5O, I5I, I59-68, I82-83, I87, 207,

220,222

Derrida, Jacques 5, 2I, 48, 63, I90n6

description, descriptive 38 ; empirical

23; thick 155

design, designer 34, 35, 88, I23, I57;

design and development 3I, 84, 88, IO9, I44n2; design research,

research by design see research;

doctoral design (proefontwerp) 34;

of study, research 42, 164, 209; of

documentation, publication 2II-I2, 228, 237-39; research into, for, through design see research; in definition of research 4InI3, 88;

architectural design see

architecture; product design II9;

design academy 157 dichotomy IIn2, 23, 9I, 95, II9, I32

Dijkgraaf, Robbert 8I, I66

disciplinarity: multi-; inter- ; trans- ;

intra-; post- see research

disciplination 4-5, 59, 82, I78

discovery I8; context of see context;

discovery-led research see research

discursivity IO, 25, 55, 64, I22, I50, I67, I8I, I82, 2IO, 2II-I2; non-discursivity 2I, 42, 44, 47-49, 69, I00, I48, I52, I63, 170, 203, 206, 232, 234, 240; discursive frame, practice, field II, 94, 198, 217, 225, 239

dissemination see documentation and dissemination

distance: theoretical see theoretical distance; aesthetic see aesthetics

distribution list see field(s) of science and technology

doctoral see also doctorate: design see design; level 3I, 55, 66, I24; research 42ni4, 94; student 53

doctorate: degree 25, 34, 54-55, 69-70, 7I, 107, 229; professional 54-55; practice-based, practice-led 54-55, 62-64; artistic 34, 54; programme, course $16,19,26,34,36,62-66$

documentation 2I, 25, 4I, 203, 220; and dissemination 23, 43. 69, 91, I45, I66-67, 208, 2II-I2, 222, 224-25, 237-39; alternative, enhanced modes of 44, 232, 240

Dombois, Florian II3, 219-20, $220 n 7$

Douglas, Anne II2

Dreyfus, Hubert L. 49, I70

Dyrssen, Catharina 233 
economy 8I, I3I, I65; economic growth

87, 89, 96-97; economics 83, 95, I31

Edison, Thomas 99

education: $\operatorname{art}(s)$ see $\operatorname{art}(s)$ education;

music see music education

education, higher 5, 62, 70, 83, I07, IIO

education, primary, secondary 156

educational politics see policy

Eisner, Elliot W. 44, 156

Elkins, James II2

emancipation 55, 232

embeddedness 46, I44, I48-49, I52, I65

embodiment I7, 2I, I44, I49, I5I-52,

I64, I88, 224, 234

emotions, emotive 2I, 45, 47, I72

empirical: cycle see cycle; deduction see

deduction; description see

description

empiricism, empiricist 23, I88

enactment I44, I49, I52, I65, I88, 217 ,

234

enclosure I44, I49, 234

end of art 130, I35-38

engagement $2,93,95$, IOO, IOI, I48, I53-

$54,155,166,227,229$

engineering 9, 77, 90, 95, I23, I57;

genetic, tissue 158

enhanced publication see publication

environmental studies 5I, 90

episteme 47

epistemic character 48, I5I, I53-54

epistemic thing IO, I73, I8I-82, I84. I89-

98, 204, 206, 232, 234; object I8I,

I94, I94nI2

epistemology 7, 8, 3I, 34, 44, 47-49, 6I,

$68,69,95, \mathrm{I0} 8, \mathrm{I} 22, \mathrm{I} 34, \mathrm{I} 36, \mathrm{I} 45$,
I48, I52, I62-63, I68-73, I76, I77,

I80-8I, I87-98, 203, 205-07, 208,

$210,223,225,232$

equivalence 54 , 7 I

ethics I9, I34, I49, 228

ethnography 44, 5I, I23, I55, I57, I65,

223

ethnomethodology I5O

everyday life see daily life

evocation 42, 48, 72, I72, 210, 234

exact science see science

experience 17, 2I, 38, 46, 48, 85, 94, I0O,

I47-48, I52, I53, I63, I64, I7I-72,

I96, 206, 207, 209-IO, 234

experiment 5I, I57; artistic 157, I9I-93;

scientific I9I-92 see also

experimental system

experimental development $68,86-87$,

96, IIO, II8

experimental practice I50, I55, I65-66,

I88, I92-93; system I89-98

experimentation I8, 23, 5I-52, 9I, 2II

explanation 38, 5I, IOO, I54-55

explanatory grip, gaze $147-48,163,169$,

I8I, I94, 206

exposition 22I, 223-24, 226, 23I, 235,

237-39

expression, expressiveness 2I, 24, 45, 7I

extended peer review see peer review

fact (artistic, historical, scientific, social) 46, I76, I82, 195, 198, 204

fact-value dichotomy 23

faculty, department 25-26, I5I

faculty of the mind $17,26,149$

fallibilism 69, 138 
falsifiability, falsification I3I, I57

feasibility 89

fellowships 34, 60, II4, I25, I63

Feyerabend, Paul 8I, I3I

field research, study see research

field(s) of science and technology 9, 3I,

$68,73,77-79$, IOI-O2

film I8; education, studies 35 , IOI, I5O

finding see outcome

Fokke \& Sukke I57

food for thought 48, I37, I45n4, I53

forum see academic forum, art forum

Foucault, Michel 5

foundation see ground

foundational debate 2I, I07, I57, I87, 203

foundationalism I63

Frascati Manual 68, 76-79, 86-89, 9496, IOI, IIO

Frayling, Christopher 37, 54, 73, I46

free space II7-I8, I83

Friedman, Ken 25n3, 36, 50

fundamental understanding see understanding

funding $26,33,34,35,36,41,54,61,64$, 67, 83, 97, I07, I09, II4-I5, I25, I64, I67, 204, 217, 222 see also assessment

funding agency $45,59,67,70,8 \mathrm{I}, 88$, IO8, IIO, II4-I5, I5I, I87

fuzziness I8I, I92

Gadamer, Hans-Georg 46ni6, 49

Gardner, Howard 49

Gehm, Sabine 68n9, II2

Geimer, Peter 4nI gender, gender studies 49, 92, 166 genetic engineering see engineering Gibbons, Michael 68n9, 84n3, 89-9I, 89n4, 95-97, II9, I32, I8I, 227ni6

Gieryn, Thomas F. 132, 177

globalisation 92, 166, 236

Gosselin, Pierre III

grant provider see funding agency

Gray, Carole 36, III

Greenberg, Clement 135

ground 69, 97, I36, I69, I9I;

epistemological 69, 157, 232;

aesthetic 70, 84, 92, 232, 197

guidelines see criteria

Gunther, York H. I45n4

Haarberg, Johan 65

Habermas, Jürgen 84, I07, I34nI

Hannula, Mika 36, III

Haseman, Brad 156

Hegel, Georg W.F. 46, 7I, I30, I35-36, I37, I52, I52n8

Heidegger, Martin 5, I29, I52n8, I68, I70, I88

hermeneutics I0, I9, 20, 38, 45, 48-49, I23, I5O, I54, I63, I72, 210

heterogeneity $6, \mathrm{I} 7,89,92-93,178$ hierarchy 26, 239; research see research history, historical research,

historiography 3, 38, 51, 77, 78-79, 83, 95, I49, I49n7, I50, 223; art see art history; of science see science and technology studies history, histories 5, I9, 2I, 38, 46, I5I, I65; effective (Wirkungsgeschichte) 49 
Hockey, John 53

Hoffmann, Christoph I86, I96-97

Holdridge, Lin 36, III

homogeneity 89, 93, II6

Hoogenboom, Marijke 39n9

humanities 22, 23, 25, 37-38, 5I, 55, 6I, $64,67,77-79,87,90,94,95,99$, IO8, I23, I44, I46, I5O-5I, I82, I87, 193, 197, 203; grand theories of 19 , 150

Humanus $\mathrm{I} 36$

Humboldt University 25

Hunter, Lynette II2

Huseman, Pirkko II2

Husserl, Edmund I68, I88

hybridity 3I, 4OnII, 8I, I59, I9I, I93, 204, 224

hypothesis I57, I89, 210; hypothesis-led research see research

idea, aesthetic 72, IOO, I52

identity 92, I32, 166, 236; of art object see artwork

imitation 69, 7I, I54, I68

immediacy $137, \mathrm{I} 70$

immutable mobile 222, 225, 233, 240 impact 5I, 93, II8, I43, I55, I6I, I66, I83, 227, 233

improvisation I9O, I92

inclusive model 55

indeterminacy I92, 193

industry 4InI3, 67n7, 88, II4; art 4I, I3I; creative see creative industry information technology see technology innovation 86, 87, 96, I25, 23I, 233 insight I22, I63, I72, 207, 209, 234 intelligence, artificial 49, I58, multiple 49

intent 24, 42-43, 80, 16I, 207, 208, 209, 222, 232

intentionality 168

interdisciplinarity see research

interpretation II, 38, 45, 49, 5I, 84, 99,

I54-55, I64, I66, I97, 2II-I2

intersubjectivity $85, \mathrm{I} 22,232$

intimacy 49, I69, I7I

intuition 48, 80-8I, I62, I64, I66, I90,

192

investment see funding

irrationality see rationality

Jacob, François I8I, I89

je ne sais quoi $\mathrm{I} 47, \mathrm{I} 70, \mathrm{I} 72$

judgment: aesthetic Ioo; taste 153 , of art IOO, I53

justification $7, \mathrm{I} 8,84, \mathrm{I} 48, \mathrm{I} 58, \mathrm{I} 62$; of beliefs 89, I63, I65-66, I67; political I7; theoretical 59; context of see context

Kant, Immanuel 24, 48, 72, IOO, I34, I5I-53, I57, I7I

Karlsson, Henrik 7, II2, I88nI, 2I8nI

Kessels, Jos 47

Kettering, Emil I29n

Keynes, John M. 99

Kiverstein, Julian I52n9

Kjørup, Søren I52, I55nII, 219

Klatser, Robert 4InI2

Knorr Cetina, Karin I88, I92, I93, 194

knowledge 3I, 47-49; alternative culture of 5, 9, I2; in art see 
artwork; bodily 48, I69; concept of I, I2; conventional 22; embodied I7, 47-49, 68, 90, I22, I48, I68-70, 2IO; embodied in art see artwork; experiential I47, 163, 203, 210, 234; explicit 7I, I22, I53; focal I22, I63; formal 80, I43; implicit 47, 68, 7I, I22, I9I; instrumental I8; intellectual 47-49, I69; know-how, knowing how I8, 47, 49, 71, I22, I24, I62 see also craft, skills; knowthat, knowing that 47, 7I, I22, I24, I62; not-knowing 7I, I24, I62, I64, I73, I8I, I9O, I93-94, 204, 206; material I8, I47, I55, I56; nonconceptual see conceptual; practical 47, 49, I22, I63; prereflective see pre-reflexivity; propositional 122, 162-63, 196; rational I53, 210; scholarly 17,47 ; sensory 48-49, I5I-52; sensuous I52; scientific 22, 52nI9, 90; tacit 47, 49, 68, 7I-72, I22, I63, I7I, I9I, I93, I94, 210; technical I8, I5I, I56; theoretical 47, I22, I63

knowledge production $68,76,80$, 909I, I4O-73, I73 see also Mode 2

Knowles, J. Gary 156

Korthagen, Fred 47

Kristeller, Paul O. 134-35

Kuhn, Thomas 8I, iı

laboratory I8, 23, 5I, 95, I08, I57, I65, I78, I90, I92, 223

language 64, 69, 78-79, 109, I22, 136, I52, I67-68, I69, I97, 237
Latour, Bruno 6, II, I7, I3I, I33, I82, I88, I92, I93, I96, 2IO, 215-I6, 222, $223,232,233,236,24 \mathrm{I}$ law, legal science $25,70,87,95$, I08, I3I learning outcomes 35 , I2I legislation 107, 217 legitimacy 45, 53-55, 70, 78, 82-83, I07, IIO, 204

Levinas, Emmanuel 5 liberalisation 23, 67, 69-70, I20, 232 life science see science linguistic turn 136,152 literature 38,150 Luhmann, Niklas 192 Luntley, Michael I70n26 Lyotard, Jean-François 48, I36, I52n8

Macleod, Katy 36, III Malins, Julian 36, III Manhattan Project 99 market, art see art market Marx, Karl 93 masters 63, I24; degree see degree material 2I, 38, I48, I56, I64 see also artwork, culture, research, knowledge material thinking see thinking McDowell, John I63, I70 media, new 33, 35 media studies see film mediality 92, 135 mediation 156 , 193 medical science, medicine see science Merleau-Ponty, Maurice 48-49, I68-69 Mersch, Dieter II2, I9I, I92n9 metaphysics I24, I30, I36-38, I45, I68-73 
methodological diversity, pluralism 23,

$24,68,69, \mathrm{I} 23, \mathrm{I} 47, \mathrm{I} 57,2 \mathrm{II}$

methodology 7, I7, 22-24, 31, 34, 36,

39, 49-52, 6I, 69, 80, 95, IOI, I08,

I23, I46-48, I55, I56-57, I62, I65-

66, I78, I80-81, I82, I89, 205-07,

218, 226, 236

methods 3I, 42-43; 49-52, 8O, 9I, I45-

49, I65-66, 203, 208, 2II, 236-37 see

also methodology; scientific 88 ,

I59; unconventional 44, 69, 203,

232, 240

mimesis, mimetic 45, 72, I68, I72 see

also imitation

Mittelstraß, Jürgen II2

mobilisation 9, I2, I7, 95, I02, 218

Mode I science 89-96, I78

Mode 2 knowledge production 9, 68,

83, 89-96, II9, I32, I78, I79, 203

modernism 2I, 32, 7I, I34, I36

money 6I, 83, 85, IO5n, IO7

morality 24, 42, 45, 9I, IOI, I32, I33-38,

I49, I53, I79

moving image research see film

multidisciplinarity see research

music education I8, 34, 62-64, 66, I25

musical analysis I9, I50

musicology I9, 38, IOI, I2I, I5O

nanotechnology 79,83

natural law of art see art

naturalisation $136-38,152-53$

navigation 237-39

Nelson, Robin 22n2

Neske, Günther I29n

network 223-25, 240
Nevanlinna, Tuomas 52

Nietzsche, Friedrich 5, I37

Noë, Alva I88

non-cognitive see cognition

non-conceptual(ism) see conceptual

non-discursivity see discursivity

non-propositionality see propositionality normativity 24, I49n7, I65, I68, I88nI,

193

not-knowing see knowledge

Nowotny, Helga 7, 84n3, 89n4, I8I, I88nI, 2I7, 2I8nI

object 3I, 4I, I78, 207-08

objectivity 2, 50, 55, 80, I 88

ontology 7, 31, 34, 44, 45-47, 69, 95, I48, I68, I76, I77, I80-8I, I89, I94,

205-07, 210, 223, 232

open-access 218, 224, 239

open-name review, open-process

collaboration, open-submission

process see peer review

openness 44, 190, 196, 235

ordinary language philosophy see

philosophy

originality 24, 42-43, I6I-62, 208, 209,

233-34

Ott, Michaela II2

outcome, result, finding 24, 3I, 38, IIO, I45-49, I55, I62, I66, I67-68, I82, I97, 203, 218

painting 134,195

Pakes, Anna 42, 46ni6, i62ni6

paradigm 8, 55, I07, I09, IIO-I6, I54, I56, I60nI5, 203 
participant observation 5I, I23, I55

participation 52, I5I, I55, I65, 2 II

Parviainen, Jaana 49, I69n24

Pasteur, Louis 96-IOo

peer review 8, 9, II, 68, 85, 89, I32-33,

I65, 217, 218, 22I, 226-4I; process

I78, 227-28; single-blind 227;

double-blind $\mathrm{I} 33, \mathrm{I} 67,227$;

extended 90, 94, I32, 178-79, 227,

229; open/open-name I33, 227;

open-process collaboration 133,227 ,

239; open-submission process 239 ;

published review 239; pre-

publication review I33, 226

perception 7I, 85, 92, I45, I52, I68, I72

performance: ethnography see

ethnography; practice (in music)

92, II9; studies I23, I57

performative force, power II, I7, 20, 72 ,

93, I00, I48, I67, I72 see also

perspective

performative research see research

performativity 2, IO, 42, 45, 72, 93, I53

perspective (on artistic research) 229, 230

perspective (on theory and practice):

immanent 17, 2O-2I, 38, 203;

instrumental I7-I8, 38, I47, 203;

interpretative $17, \mathrm{I} 9,38, \mathrm{I} 46,203$;

performative $\mathrm{I} 7,20,38,172,203$ see

also performative force, power

Peterson's Guide 99

$\mathrm{PhD}$ see doctorate

phenomenology 2I, 48-49, 68, I23, I45,

I5O, I68-70, I88

philosophy 8, 19, 25, 31, 38, 77; of mind

68, I50, I69n25, I70; ordinary language I37; of science see science

and technology studies; speculative

5, 7I

phronesis $47, \mathrm{I} 63$

Plato I33

pluralism, methodological see

methodological pluralism

poetry, poem I34, I67, I95

poiesis 47

Polanyi, Michael 47, I63, I9I

policy 8, 3I-32 see also science;

education 5, 31, 34, 79, II6-17, I87;

governmental 87

politics, political science 9I, 95, I3I, I47, I66, 236

Popper, Karl 8I, I3I

Porter, James I. I34-35

portfolio 43nis, I67

postgraduate institute $33,58-59$, I33

post-historical art see art

postmodernism 32, 48, 7I, 82, I36-37,

I38, I49

poststructuralism I32, I69n24

power 6I, 85, I07 see also performative

force, degree-awarding power

practice-based $\mathrm{PhD}$ see doctorate;

practice-based research see research

practice-led $\mathrm{PhD}$ see doctorate;

practice-led research see research

practice turn I48, I55, I88, I92-93, 236

pragmatic turn I36, I52

pragmatism I9, 92, I50, I88

praxis 47

pre-publication review see peer review

pre-reflectiveness, pre-reflexivity see

reflexivity 
pre-understanding see understanding process (research) see research

product see outcome

production of knowledge see knowledge production

professional doctorate see doctorate proposition IO-I2, IIn2, I2n3, 43, 2I6, $237,24 \mathrm{I}$

propositionality, non- propositionality I22, I69 see also knowledge

prose 134,167

protection 5, 20, 25, 43, 50, 60, 70, I44n3 pseudoscience see science publication, enhanced 22I, 238 published review see peer review pure research see research Putnam, Hilary I, I2, 23, I37

quadrant model of research see research qualitative research see analysis quality standards see criteria quantitative research see analysis

randomness 8I, I66

rationale: political 7-8; of research 53, II7; theoretical 7-8

rationality 2I, 48-49, I48, I53, I88, I92; irrationality 48

Read, Herbert 37n6

realism IO, II, 20, 70-73, I24, I3O, I37, I68, I7I-72, I94-95, 203, 204, 207 realism, constructivist see constructivist realism

reason 136, 212; artistic reasoning 69, I54nIo, I67, 232, 237; space of II, I63, I67, I70, 234; unity of I34 reception I9, 24, 4I, 68, II7, I22, I44,

I47n6, 207, 208

recognition $8, \mathrm{I} 6,66,68, \mathrm{I07}, \mathrm{I26}, \mathrm{I32}$, 204

reconstruction (of research process) 2I, 6984, I66, I68, 2I2

recursive process see research process reflection 19, 24, 32, 38, 51, 59, 63, 707I, I00, I45, I53, I6I, I72; see also reflexivity

reflection in action 38,155 ; on action 38 reflective practitioners $66,8 \mathrm{I}$ reflexivity, reflexiveness 2I, 39, 7I, 82, 93-94, IOO, IOI, II7, I37, 233, 235; pre-reflexivity, pre-reflectiveness 49 , II7, I37-38, I43, I45, I48, I69-7I, I94, 2IO; unreflective I49, I68; see also reflection

reforms, university, higher education see university reforms

relationship to the world, ourselves, other people 7I, 94, I37, I45, I48, I55, I7I-72, I79

relativism II, 69, I9I, I95

reliability 40, 80, I20, I58, I60

religion $25,78, \mathrm{I} 3 \mathrm{I}$

Renaissance 149

replicability 22, I57

representation IO, 45, 7I, 72, I52, I7I, I88

research: agenda see agenda; community 25; definition see definition; by design see research, design; and development 33, 68, 77, 85 , I09, I44; environment 62, I2425 ; for the arts 37,38 , I08, I46-47; 
hierarchy 3I, 8I-84, 85-86; in and through the arts $24,31,64,70$, IOI, I08, I44, I47, I57, I82, I87, 206, 2II; in the arts $13,17,19,31,38-39$, I4647; infrastructure I07; into the arts 37 , into, for, through design 37 ; I08; method see method; on the arts I3, I7, I9, 37-38, 64, 94, I46-47; process 3I, 4I, 45, 92, 207-08; question 24, 42-43, 80, 9I, I64-65, 208, 2IO-II, 235-36; through the arts 37; training 50, 63, I08, I24-25, I57, I64; university see university research, action I2, 87, 96, I23, I5I, I55; applied I8, 26, 54, 68, 83, 86-87, 9699, I09, IIO, II8, I23, I56-57; arts-based I09; basic 25, 26, 3I, 55, $68,83,86-87,96-99$, IIo, II8-19; the concept, term (artistic) 33, 40, 44, 59, 6In2, 77, 84, IOI, IO8-IO, I43-44, I44n2, I59, I79, I97 see also

terminology; context of see context; design 54, 55, 108, I5I, 157, I57nI2; discovery-led 80, I64; ethnographic see ethnography; field 5I, I55, I65; foundational 3; fundamental see research, basic; historical see history; hypothesis-led 80, I64; interdisciplinary 51, 68, 79, 89, 92, II9, 235; intradisciplinary 92, II9, 235; material 38, 9I; moving image see film; multidisciplinary 9I, I5859, 235; performance-centred I55; performative I08; postdisciplinary I77; practice as 3I, 36, 39, 40, 43, 53, IO8, I44, I59, I87, 207, 212, 224,
225, 230, 23I, 232; practice-based I9, 34, 39, 50, 54, 55, 65-66, 7I, IOI, IO7, I08, I46, I55, I67; practice-led 39, 83, IOI, I08; pure see research, basic; quadrant model of 98-IOO, II9; quantitative, qualitative see analysis; scholarly 6, 3I, 44, 50, 54; scientific 31, 87, 90, 156; standard model of see definition; strategic 87,96 ; studio-based I45, I46; systematic I50; technical 54, I23, I47, I56, I65; text-centred I55; transdisciplinary 9 , 5I, 68, 8I, 89, 92, II9, I32, I49n7, I64-65, I77, I79-80, 235-36; useinspired basic 98-100 researcher see artist-researcher result see outcome revelation 20, 24, 7I, 85, 93-94, I72-73, 195

review process see peer review Rey, Anton II2

Rheinberger, Hans-Jörg 71, I62, I76, I8I-82, I86-98, 204, 206, 232, 233 , 234

Rietveld, Erik I7on26

Riley, Shannon R. II2

Ritterman, Janet II2 robustness, social see accountability Romanticism, early I37, I7I, I95

Roosevelt, Franklin D. 87

Rouse, Joseph I, I2, I93

Rubidge, Sarah 8o, I64 rule, rules 70, 84, I69, 193 see also assessment, criteria Ryle, Gilbert 47 
Säätelä, Simo I7on26

scepticism 4, 20, 53, 69 see also

academia

Schaffer, Simon I88

Schatzki, Theodor I48, I88, I92

Schelling, Friedrich J.W. 48

Schöbi, Stefan II2

scholarship 40, 44, 5I-52

Schön, Donald 38, 8I

Schuijer, Michiel I8

Schwab, Michael 4nI, 176, I78, 219-20, 220n7, 22I, 22In8, 223nio, 224nil

science $5,9,40,44$, I00, I33-34; in action 6, I8I, I93, 2I8; policy 8, 89, I09-IO, 203; system 9, 96, 107, II820

science, agricultural 77, 90; the term, concept I09, I59; fields of see field(s) of science and technology; behavioural 87; biomedical 90 see also biology; cognitive see cognition; exact I8, 23, I54; legal see law; life I58, I88, I89 see also biology; medical 25, 70, 77, 90; natural 23, $25,5 \mathrm{I}-52,55,67,77,90, \mathrm{I} 44, \mathrm{I} 87$, 203; political see politics; pseudoI3I; social 23, 38, 5I, 55, 67, 77, 78, $87,90,96, \mathrm{I} 23, \mathrm{I} 44, \mathrm{I} 46-47, \mathrm{I} 54-56$, I66, I87, 203; sport see sport; subatomic 83; technological 62, 77, 90; theory of see science and technology studies

science and technology 156-59, I64 science and technology studies 3, 7, 9, 50, 84, I82, I86-88, 217-18, 232; history of science 7, 44, 61, 89, 196; theory, sociology, philosophy of science $5,7,8,2 \mathrm{I}, 23,44,63,79,8 \mathrm{I}$, I3I, I46, I77, I86-87, 203 scientific method see method scientific real 195 Scott, Peter 84n3, 89n4, I8I sculpture 134, 195 Sellars, Wilfrid II, I63 semiotics I9, I23, I5O sensory perception 135 serendipity 80, I65, 190, 192 Shapin, Steven I 88 Siegenthaler, Fiona Iı2 single-blind review see peer review situatedness 46, I48, I65, I68-69, I88 skills 47, 72, 162-63, I93 see also craft, artistry, know-how; research I24; writing 63 , I24 social anthropology see anthropology social engineering 96 social science see science sociology 62, 154; of art 146, I50; of science see science and technology studies space of reasons see reason speculative philosophy see philosophy sport, sport science 95, I3I standard model of research and development see definition standards see criteria Stockhausen, Karlheinz I9I Stokes, Donald E. 87, 96-100, II9 Strand, Dennis 54 structuralism I9, I50 studentship I6, II4, I25 studio 92-93, I46n5, I57 
Sullivan, Graeme 36, III

Suoranta, Juha 36, III

supervision 53, 63, I24

system of the arts $134-35$

talent 85,95 , IOO, IOI

taste 45,153

Taylor, Charles I69n25

techne 47

technical objects $189-90$

technological development, progress

87, 89, 96-97; technological science

see science

technology 95, I23-24, I44, 203 see also science; information $18,90,158$;

bio- see biotechnology

terminology 7, 33, 37-4I, 203

theatre 9I, I34

theatre education, school I8, 3I, 35;

studies I9, 38, 49, IOI, I5O, I69n24

theology 25, 70, I3I

theoretical distance 19, 20, 37, 38, I47, I50

theory of science see science and

technology studies

thinking: embodied in art see art;

material 7I, I23-24, I7I, I83;

unfinished 7I, I38, I43, I45, I48, I7I,

173, 18I, 194, 197, 204; the unthought

7I, I73, I96

Thomson, Peter 36

training: professional 19, 60, 84, I56;

research see research; in bachelors

and masters I 24

transcendence 46, 137-38, I62, I9I

transcendentality 70, Ioo; quasi-

transcendentality $7 \mathrm{I}$ transdisciplinarity see research

transformation II, 196, 217, 2I8, 22I,

$223,232,236,238,240$

Tröndle, Martin II3

truth $89,90,133,135$

understanding 7I, I45, I63 see also

knowledge; fundamental 85, 95, 97-

IOO, IIO, II9, I60, 203; pre- I69;

tacit I5I, I64

unexpected, the $40,93,173,196$

unfinished thinking see thinking

unity of reason see reason

university 59, 72, 78, 89, I08, I59;

traditional 22, 3I, I44, I5I; of

applied sciences 9I; research 84;

technical 157

university reforms 3I, 34-35, II6

unknown, the 40, 93, 194

unthought, the see thinking

use, considerations of 98-I00

Vadén, Tere 36, III

validity 40, I48, I57

valorisation $5 \mathrm{I}, 87, \mathrm{I} 32$

values: artistic 160, 230; academic 6 ,

I60, 230

Verstehen I22, I54-55, I63

visual anthropology see anthropology

visual art I8, 35, I66

Wälchli, Tan II2

Warmers, Julia II4

Wellmer, Albrecht I23

Wesseling, Janneke II3

Whitley, Richard 89, 90, 95 
Wilcke, Katharina von II2

Wilson, Stephen I58ni3

wisdom, practical, worldly see phronesis

Wittgenstein, Ludwig I30, I42, I67,

I69n24, I7I, I88

Wolff, Georg I29n

Woolgar, Steven 188

world: constitution see constitution;

disclosure, revelation see revelation

Zijlmans, Kitty 3, 158

Zwijnenberg, Robert 3, 158 
